\title{
Effect of Surface Wettability on the Defrost Process
}

\author{
A Dissertation \\ SUBMITTED TO THE FACULTY OF \\ UNIVERSITY OF MINNESOTA \\ BY \\ Yang Liu \\ IN PARTIAL FULFILLMENT OF THE REQUIREMENTS \\ FOR THE DEGREE OF \\ DOCTOR OF PHILOSOPHY
}

Francis A. Kulacki, Adviser

January 2017 
(C) Yang Liu 2017

ALL RIGHTS RESERVED 


\section{Acknowledgements}

I would like to express my sincere gratitude to Professor Francis A. Kulacki for providing me opportunity to pursue the graduate education, for motivating me to generate new ideas and apply the ideas to application, for discussing with me my research ideas and thesis development, for encouraging me and showing patience when I have difficulties in my research progress.

I want to thank my colleagues William Francis Mohs and Danimae Janssen for sharing their experience on the frost and defrost research. I also want to express my appreciation to Thermo King\Ingersoll Rand for providing partial funding to the research.

I would like to thank Professor Terry Simon and Professor Cari Dutcher from the Mechanical Engineering department and Professor Vaughan Voller from the Civil Engineering department for taking their time to serve on my committee and critically evaluating this work.

Finally, I want to thank my family for their understanding and encouragement. Without the support from my family, I could not have dedicated myself to the long and hard journey exploring the nature of the problem. 


\section{Abstract}

Frost formation and anti-icing methods are studied in a variety of areas for decades. In refrigeration systems, a number of studies are focused on the influence of surface treatment on delaying the time of frost formation. There are far fewer studies on the effect of surface wettability on the defrost process. Some of the literature show experimental results on defrost time for different surfaces, but the results could be different based on individual experimental conditions.

In this study, the influences of surface wettability on the defrost process are investigated analytically. The melting process is divided into three stages based on the behaviors of the meltwater. The water saturation and meltwater draining velocity are formulated for absorption and drainage stages separately. The comparison among the melting rate, the permeation rate, and the draining velocity determines the meltwater behavior, which influences the defrost process and defrost mechanisms. The slumping condition is a special phenomenon in the melting process and can be a potential method for frost removal. Water accumulation at the surface decreases the adherence strength of the frost column to the surface. A slumping criterion is formulated based on the analysis of interfacial forces and the body force on the frost column. The slumping condition of the model depends on the contact angle on hydrophilic surfaces and on the contact angle hysteresis on hydrophobic surfaces.

Experiments of frost and defrost process on vertical surfaces with different wetting conditions are conducted on a lab-build setup. The experimental results show that defrost time and efficiency are determined by the system design, the heating methods, the heat flux applied at the surface and the surface wettability. Defrost mechanisms vary with surface wettability. During the defrost process, a frost column detaches from a superhydrophobic surface and falls off as a whole piece. While on the superhydrophilic and plain surfaces, frost melts, and water film or retention evaporates. Defrost time and efficiency are not significantly different on the tested surfaces at the point that frost melts and water film/retention droplets remain on the surfaces. However, defrost time and 
efficiency are improved noticeably on the superhyrophobic surface for a complete defrost process in which the water evaporation time is included.

This research serves as a supplement to current studies on the effect of surface wettability in refrigeration systems. In application, the preference to the different surface wettability depends on the practical operation requirements and the actual system design. 


\section{Table of Contents}

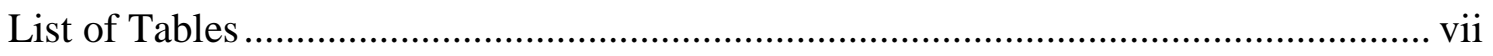

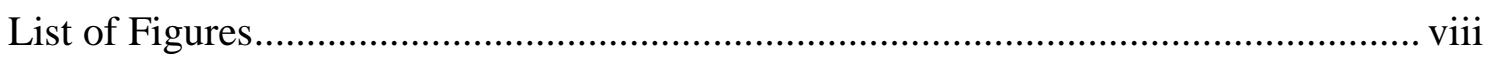

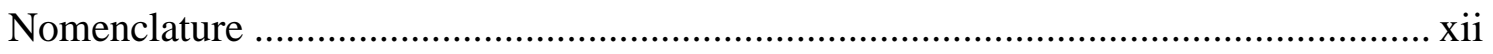

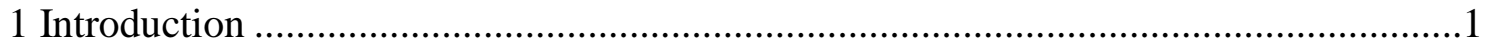

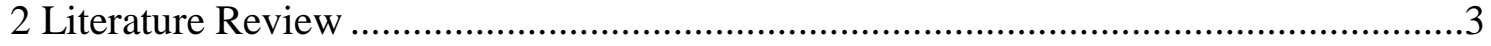

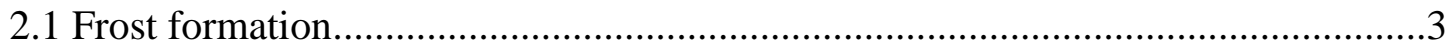

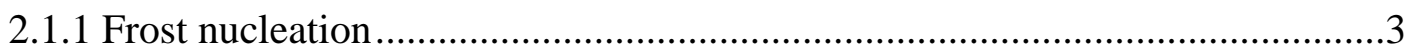

2.1.2 Experiments and correlations .............................................................

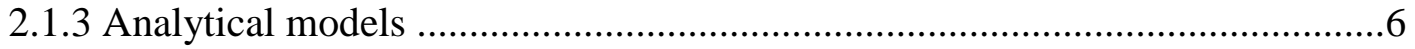

2.2 Frost growth on wetted surface .......................................................................

2.2.1 Frost properties on wetted surface ....................................................

2.2.2 Effect of surface wettability on frost formation .......................................

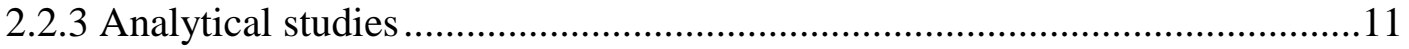

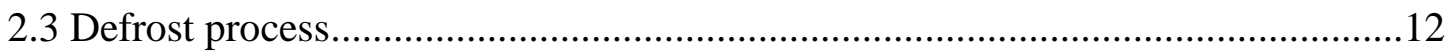

2.3.1 Effect of surface wettability on defrost process ........................................12

2.3.2 Frost release and condensation retention ................................................. 16

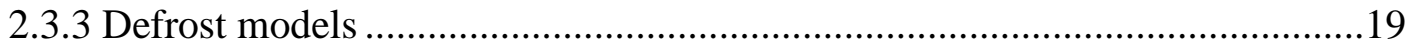

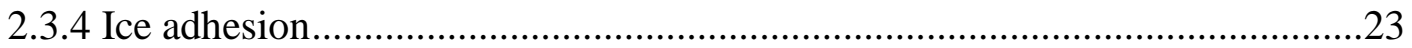

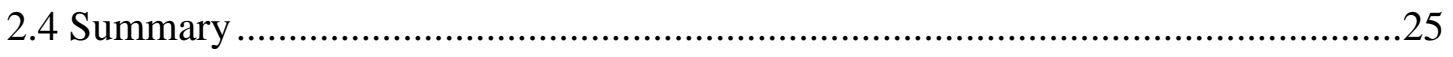

3 Model Development and Mathematical Formulation............................................27

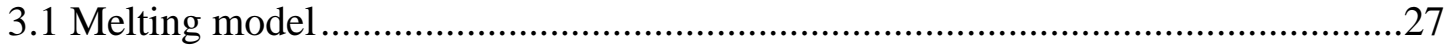

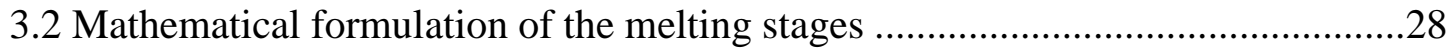

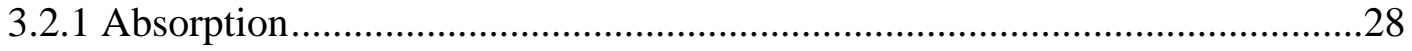

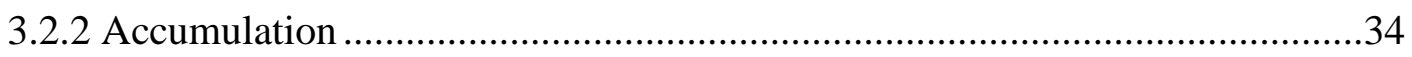

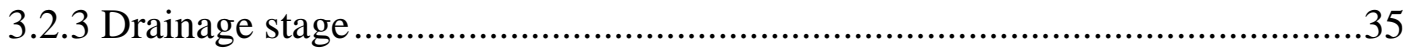

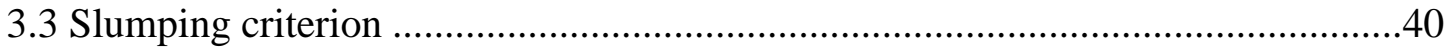

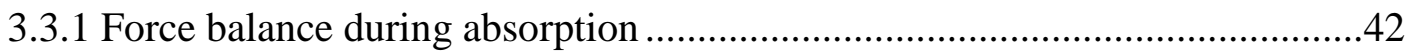

3.3.2 Force balance during accumulation ........................................................ 43

3.3.3 Force balance during draining ......................................................... 45 


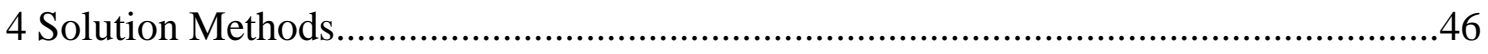

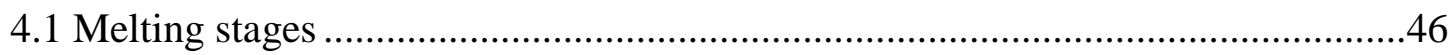

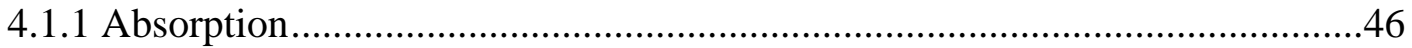

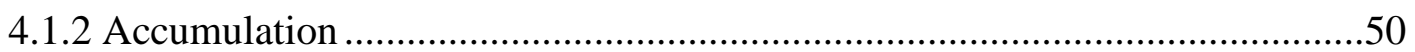

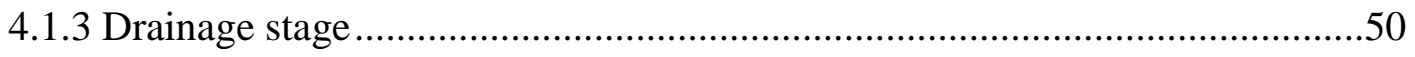

4.2 Slumping criterion .......................................................................................

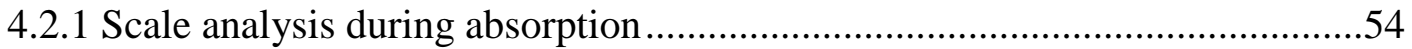

4.2.2 Scale analysis during accumulation ............................................................54

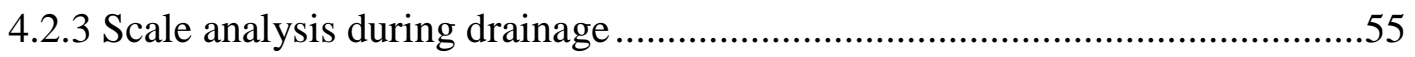

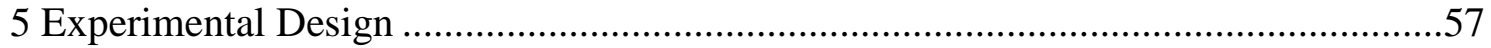

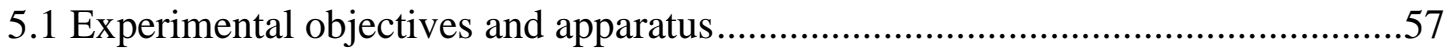

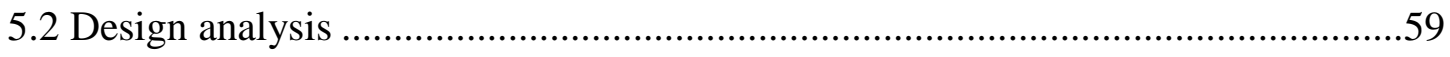

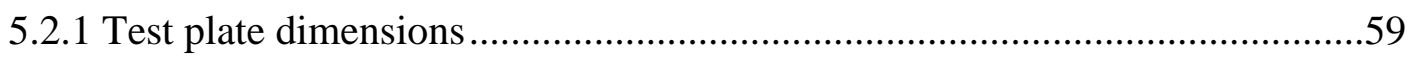

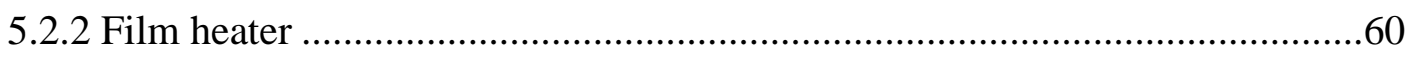

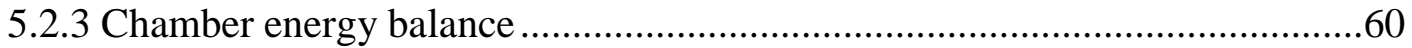

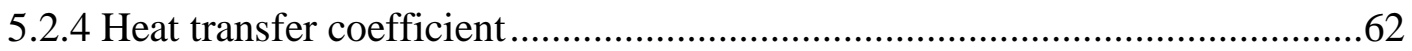

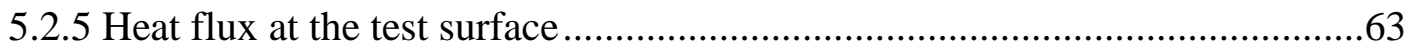

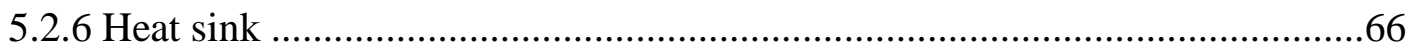

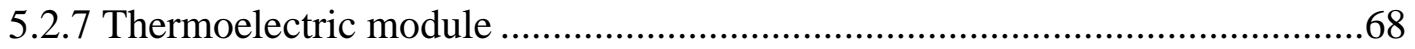

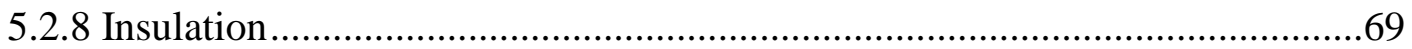

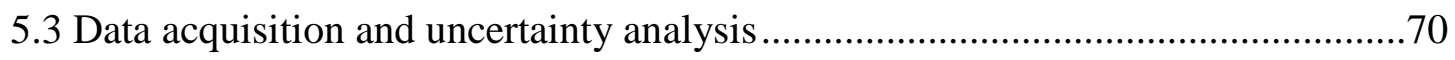

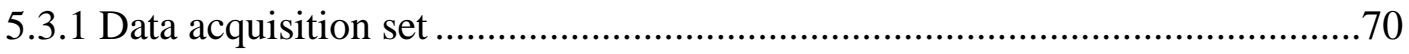

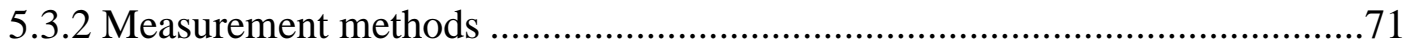

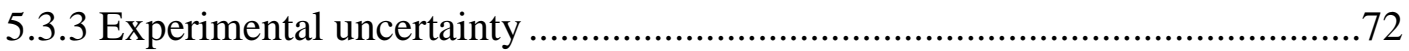

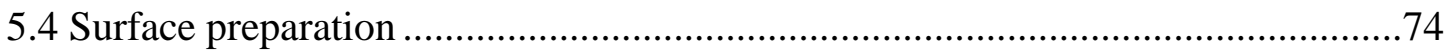

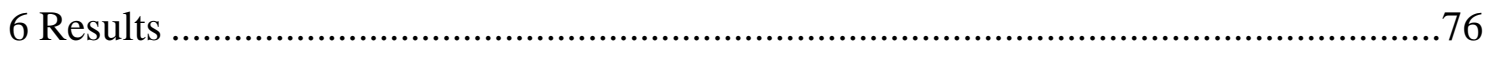

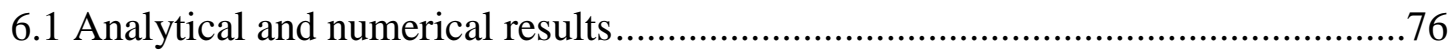

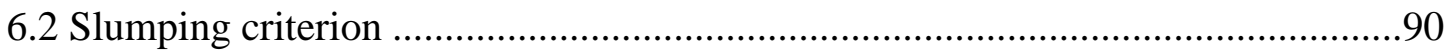

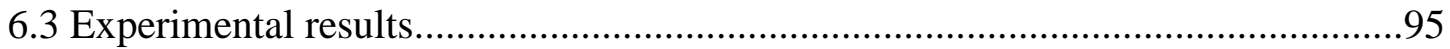

6.4 Comparison between physical model and experiments .......................................118 


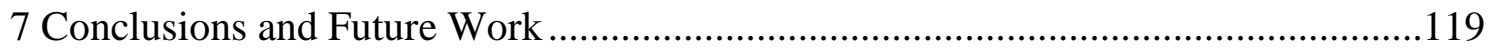

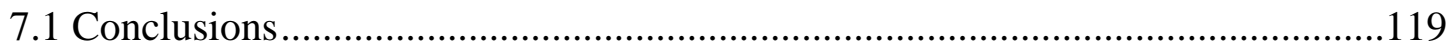

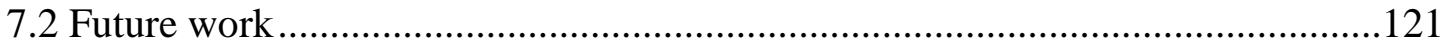

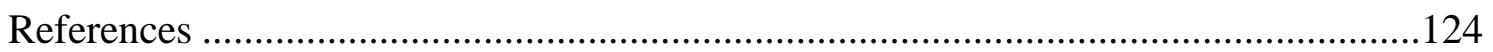

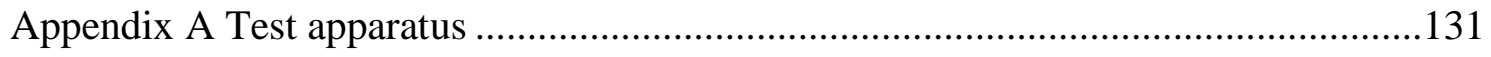

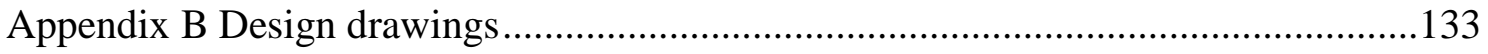

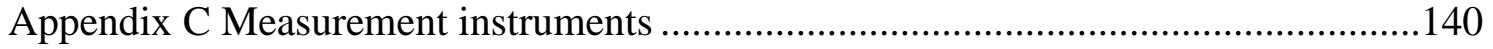

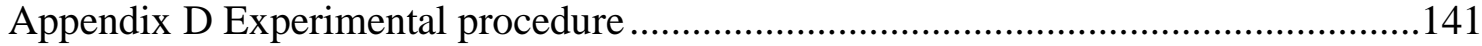

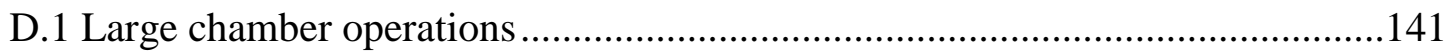

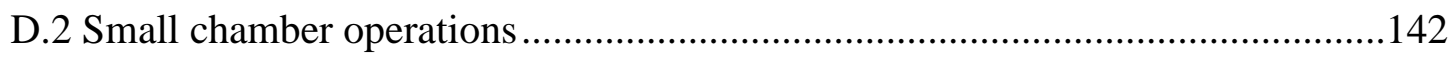

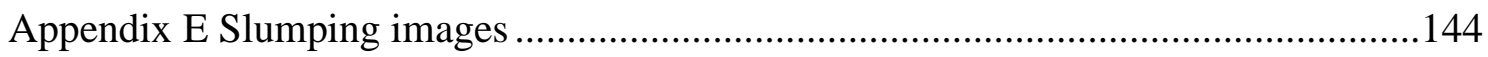




\section{List of Tables}

Table 2.1. Wettability effect on the frost/defrost process. ..................................... 15

Table 3.1. Mass composition during melting process........................................... 28

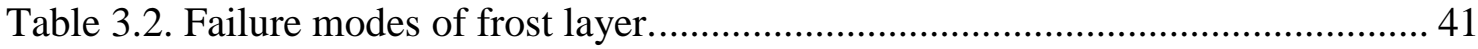

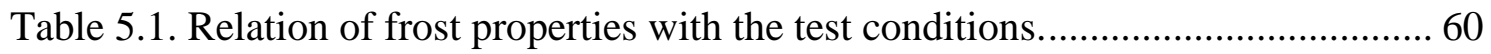

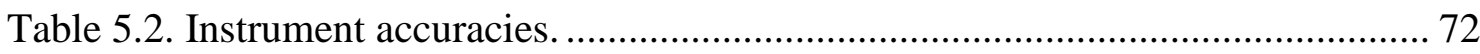

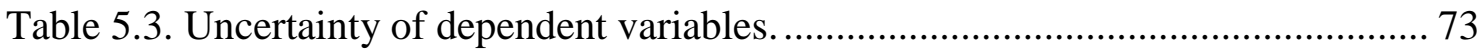

Table 5.4. Characterization of the sample surfaces. .............................................. 74

Table 6.1. Comparison of drainage velocity and average drainage rate. ..................... 81

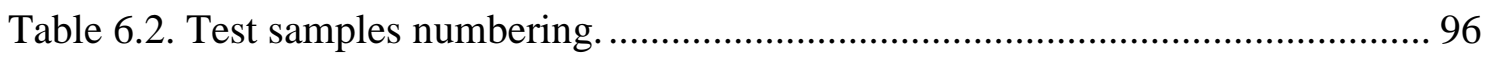

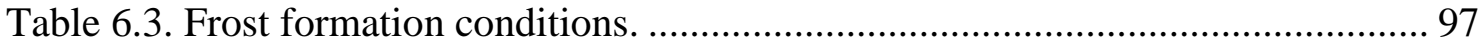

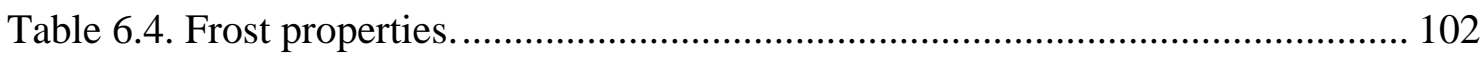

Table 6.5. Defrost properties for test surfaces $38 \mathrm{~mm}$ x $38 \mathrm{~mm}$............................ 107

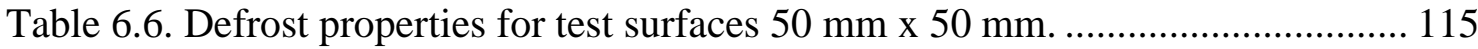

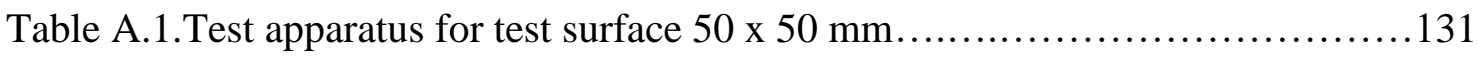

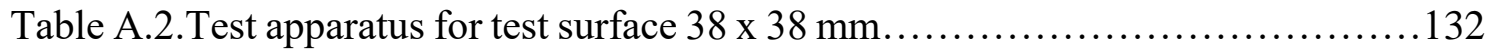

Table C.1. Measurement instruments.......................................... 140 


\section{List of Figures}

Figure 2.1. Comparison of frost deposition on the coated and uncoated surfaces [29]. .. 9

Figure 2.2. Effect of surface contact angle: (a) frosting and (b) defrosting behavior [41].

Figure 3.1. A general illustration of the initial frost column........................................ 29

Figure 3.2. $\mathrm{CV}$ in the permeation layer during absorption............................................ 30

Figure 3.3. CV in frost layer during the absorption. ................................................ 33

Figure 3.4. Heat and mass transfer during accumulation.............................................. 35

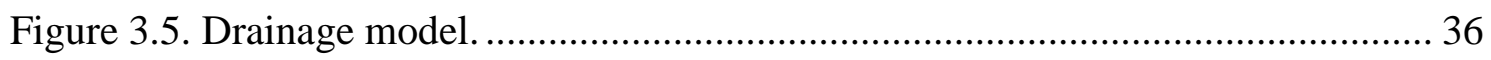

Figure 3.6. Heat and mass transfer during drainage for a vertical frost surface.............. 37

Figure 3.7. Definition of the slip length for a simple shear flow [98]........................... 39

Figure 3.8. The scheme and mechanisms of frost slumping. ......................................... 41

Figure 3.9. Force balance during absorption............................................................. 42

Figure 3.10. Force balance during accumulation. ......................................................... 43

Figure 3.11. Surface tension on hydrophobic surfaces.................................................. 44

Figure 3.12. Force balance during drainage ........................................................... 45

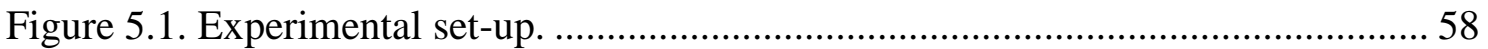

Figure 5.2. Chamber volume versus chamber temperature …………………………... 61

Figure 5.3. Local Nusselt number at constant heat flux .............................................. 64

Figure 5.4. Local heat transfer coefficient at constant heat flux ................................... 64

Figure 5.5. Heat transfer coefficient versus temperature difference between the test plate and surrounding under free convection where $\operatorname{Pr}=0.7, \mathrm{~L}=5.5 \mathrm{~cm}$......................... 65

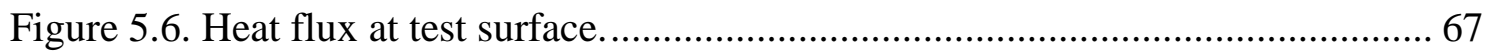

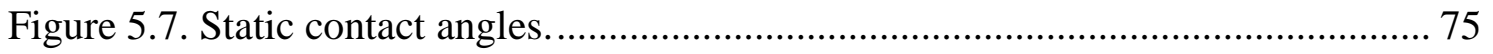

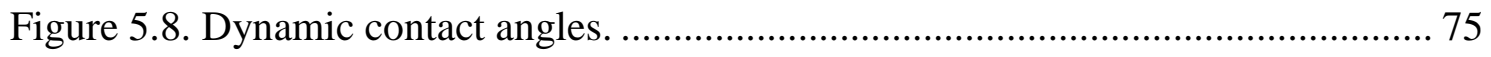

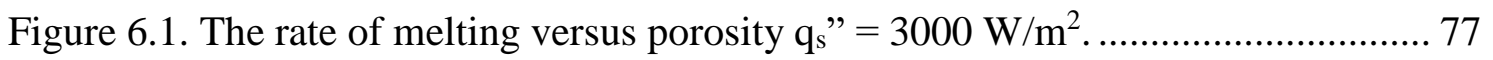

Figure 6.2. The rate of melting versus heat flux applied at the test surface $\varepsilon=0.4 \ldots \ldots . .77$

Figure 6.3. Water saturation versus time $\mathrm{q}_{\mathrm{s}}{ }^{\prime}=3000 \mathrm{~W} / \mathrm{m}^{2}, \varepsilon=0.6, \delta_{\mathrm{f}}=5 \mathrm{~mm}, \mathrm{p}=3, \mathrm{q}=$

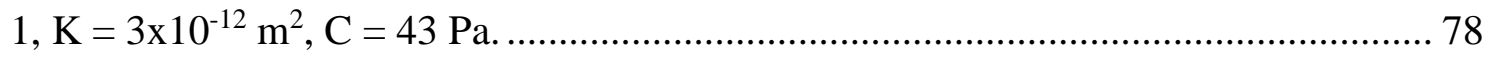


Figure 6.4. Water saturation versus location $\mathrm{q}_{\mathrm{s}} "=3000 \mathrm{~W} / \mathrm{m}^{2}, \varepsilon=0.6, \delta_{\mathrm{f}}=5 \mathrm{~mm}, \mathrm{p}=3$, $\mathrm{q}=1, \mathrm{~K}=3 \times 10^{-12} \mathrm{~m}^{2}, \mathrm{C}=43 \mathrm{~Pa}$. 78

Figure 6.5. Dimensionless temperature of frost layer versus time $\mathrm{q}_{\mathrm{s}} "=3000 \mathrm{~W} / \mathrm{m}^{2}, \varepsilon=$ $0.7, \delta_{\mathrm{f}}=5 \mathrm{~mm}, \mathrm{~h}_{\mathrm{a}}=5 \mathrm{~W} / \mathrm{m}^{2}-\mathrm{K}$ 79

Figure 6.6. Dimensionless temperature distribution in frost layer qs" $=3000 \mathrm{~W} / \mathrm{m}^{2}, \varepsilon=$ $0.7, \delta_{\mathrm{f}}=5 \mathrm{~mm}, \mathrm{~h}_{\mathrm{a}}=5 \mathrm{~W} / \mathrm{m}^{2}-\mathrm{K}$ 79

Figure 6.7. Comparison of draining velocities with different boundary conditions $\alpha=1.2$, $\mathrm{K}=10^{-9} \mathrm{~m}^{2}, \mathrm{~b}=20 \mu \mathrm{m}$. 80

Figure 6.8. The effect of slip length on the draining velocity. 82

Figure 6.9. Melting time versus the initial frost thickness $\mathrm{q}_{\mathrm{s}} "=3000 \mathrm{~W} / \mathrm{m}^{2}, \mathrm{~T}_{\mathrm{a}}=-5 \mathrm{C} . .83$ Figure 6.10. Melting time versus ambient temperature $\mathrm{q}_{\mathrm{s}} "=3000 \mathrm{~W} / \mathrm{m}^{2}, \delta_{\mathrm{f} 0}=3 \mathrm{~mm} .83$ Figure 6.11. The relation of draining time with porosity $\mathrm{H}=38 \mathrm{~mm}$. 84

Figure 6.12. The relation of draining time with the initial frost thickness $\mathrm{H}=38 \mathrm{~mm} . .84$ Figure 6.13 . The relation of draining time with the height of test plate $\delta_{\mathrm{f} 0}=3 \mathrm{~mm}$..... 85

Figure 6.14. The relation of draining time with the water film thickness $\mathrm{H}=38 \mathrm{~mm} \ldots 85$ Figure 6.15 . The relation of defrost time with the porosity q" $=8000 \mathrm{~W} / \mathrm{m}^{2} . \mathrm{H}=380 \mathrm{~mm}$. $\delta_{\mathrm{w}}=0.3 \mathrm{~mm}$.

Figure 6.16. The relation of defrost time with the porosity q " $=8000 \mathrm{~W} / \mathrm{m}^{2} . \mathrm{H}=380 \mathrm{~mm}$. $\delta_{\mathrm{w}}=0.6 \mathrm{~mm}$. 87

Figure 6.17. The relation of defrost time with the porosity $\mathrm{q}_{\mathrm{s}} "=3000 \mathrm{~W} / \mathrm{m}^{2} . \mathrm{H}=38 \mathrm{~mm}$. $\delta_{\mathrm{w}}=0.3 \mathrm{~mm}$. 88 Figure 6.18. The relation of defrost time with the porosity qs" $=3000 \mathrm{~W} / \mathrm{m}^{2} . \mathrm{H}=380 \mathrm{~mm}$. $\delta_{\mathrm{w}}=0.3 \mathrm{~mm}$. 88

Figure 6.19. Comparison of the draining time with different boundary conditions $\mathrm{H}=380$ $\mathrm{mm} . \delta_{\mathrm{w}}=0.3 \mathrm{~mm}$.

Figure 6.20. Comparison of defrost time with different boundary conditions q $"=3000$ $\mathrm{W} / \mathrm{m}^{2} . \mathrm{H}=380 \mathrm{~mm} . \delta_{\mathrm{w}}=0.3 \mathrm{~mm}$. 89

Figure 6.21 . Force ratio versus porosity $\mathrm{W}=38 \mathrm{~mm} . \delta_{\mathrm{f} 0}=3 \mathrm{~mm} . \mathrm{r}=1 . \mathrm{CA}=20^{\circ}$ 91 Figure 6.22 . Force ratio versus aspect ratio of the test plate $\mathrm{W}=38 \mathrm{~mm}$. $\delta_{\mathrm{f} 0}=3 \mathrm{~mm}$. $\varepsilon=$ 0.6. $\mathrm{CA}=20^{\circ}$ 91 
Figure 6.23. Force ratio versus temperature at the surface $\mathrm{W}=38 \mathrm{~mm} . \delta_{\mathrm{f} 0}=3 \mathrm{~mm} . \mathrm{r}=$

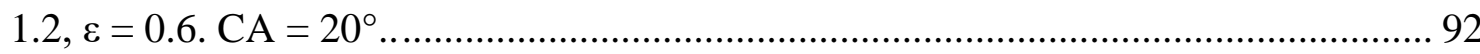

Figure 6.24. Force ratio versus contact angle on hydrophilic surfaces $\mathrm{W}=38 \mathrm{~mm}$. $\delta_{\mathrm{f} 0}=3$

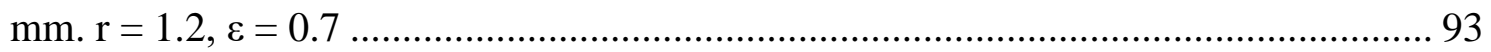
Figure 6.25. Force ratio versus receding contact angle on hydrophobic surfaces $\mathrm{W}=38$

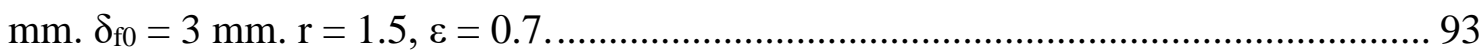
Figure 6.26 . Force ratio versus porosity and contact angle $\mathrm{W}=38 \mathrm{~mm}$. $\delta_{\mathrm{f} 0}=3 \mathrm{~mm} . \mathrm{r}=$ 1.2 . 94

Figure 6.27. Force ratio versus aspect ratio and contact angle $\mathrm{W}=38 \mathrm{~mm}$. $\delta_{\mathrm{f} 0}=3 \mathrm{~mm}$., $\varepsilon$ $=0.7$. 94

Figure 6.28. Front view of the frost formation at test surface (TestID-1) ................... 96 Figure 6.29. Side view of the frost formation at test surface (TestID-1) ..................... 97

Figure 6.30. Front view of the frost formation at test surface (TestID-2) ................... 98

Figure 6.31. Side view of the frost formation at test surface (TestID-2) .................... 99

Figure 6.32. Front view of the frost formation at test surface (TestID-3) .................. 100

Figure 6.33. Side view of the frost formation at test surface (TestID-3) .................. 101

Figure 6.34. Frost mass versus frost growth period. ........................................... 102

Figure 6.35. Defrost process after frost grows for $4 \mathrm{~h}$ (TestID-1). ............................ 104

Figure 6.36. Defrost process after frost grows for $4 \mathrm{~h}$ (TestID-2) . .......................... 105

Figure 6.37. Frost slumping process after frost grows for $6 \mathrm{~h}$ (TestID-3). ................. 106

Figure 6.38. Heat flux applied at the test plate (TestID-3) where direct current (DC) sets at $12 \mathrm{~V} / 5 \mathrm{~A}$. 107

Figure 6.39. Temperature difference between the heat flux sensor and the test plate (TestID-3) where DC sets at 12V/5A. 108

Figure 6.40. Temperature at the test plate (TestID-2) during the defrost period where DC sets at $12 \mathrm{~V} / 5 \mathrm{~A}$. 108

Figure 6.41. Temperature at the test plate (TestID-3) during the defrost period where DC sets at $12 \mathrm{~V} / 5 \mathrm{~A}$. 109

Figure 6.42. Temperature inside the chamber during the defrost period where DC sets at $12 \mathrm{~V} / 5 \mathrm{~A}$. 110 
Figure 6.43. Defrost time versus average heat flux at TestID-3 where frost grows for $4 \mathrm{~h}$.

Figure 6.44. Defrost efficiency versus average heat flux at TestID-3 where frost grows for $4 h$. 111

Figure 6.45. Defrost time versus mass on wet surface where heating power sets at $60 \mathrm{~W}$.

Figure 6.46. Defrost time versus mass on dry surface where heating power sets at $60 \mathrm{~W}$.

Figure 6.47. Defrost efficiency versus mass on wet surface where heating power sets at $60 \mathrm{~W}$.

Figure 6.48. Defrost efficiency versus mass on dry surface where heating power sets at $60 \mathrm{~W}$.

Figure 6.49. Defrost time versus mass on wet surface where actual heating power is 7.7 W. 116

Figure 6.50. Defrost time versus mass on dry surface where actual heating power is 7.7 W. 116

Figure 6.51. Defrost efficiency versus mass on wet surface where actual heating power is $7.7 \mathrm{~W}$. 117

Figure 6.52. Defrost efficiency versus mass on dry surface where actual heating power is $7.7 \mathrm{~W}$ 117

Figure E.1. Frost slumping process after frost grows for $4 \mathrm{~h}$ (TestID-3) 140 


\section{Nomenclature}

b slip length [m]

bl gap between fins [m]

$c_{p}$ specific heat at constant pressure $\left[\mathrm{J} \mathrm{kg}^{-1} \mathrm{~K}^{-1}\right]$

g gravitational acceleration $\left[\mathrm{m} \mathrm{s}^{-2}\right]$

$\mathrm{h}$ heat transfer coefficient $\left[\mathrm{W} \mathrm{m} \mathrm{m}^{-2} \mathrm{~K}^{-1}\right.$ ]

$\mathrm{k}$ thermal conductivity $\left[\mathrm{W} \mathrm{m} \mathrm{m}^{-1} \mathrm{~K}^{-1}\right.$ ]

$\mathrm{m}$ mass [kg]

m" mass flux $\left[\mathrm{kg} \mathrm{s}^{-1} \mathrm{~m}^{-2}\right]$

p permeability power law constant

q capillary pressure power law constant

q" heat flux $\left[\mathrm{W} \mathrm{m}^{-2}\right]$

$r$ aspect ratio of the width to the length

$\mathrm{t}$ time [s]

$\mathrm{t}^{+}$dimensionless time

$\mathrm{u}$ velocity in $\mathrm{x}$-direction $\left[\mathrm{m} \mathrm{s}^{-1}\right]$

$\mathrm{u}^{+}$dimensionless velocity

$\mathrm{u}_{\mathrm{s}} \quad$ slip velocity $\left[\mathrm{m} \mathrm{s}^{-1}\right]$

$\mathrm{u}_{\mathrm{B}}$ velocity at the water/permeation interface $\left[\mathrm{m} \mathrm{s}^{-1}\right]$

$\mathrm{v}$ velocity in y-direction [ $\mathrm{m} \mathrm{s}^{-1}$ ]

$\mathrm{x}$ direction parallel to gravity [m]

$\mathrm{x}^{+}$dimensionless location

$\mathrm{y}$ direction normal to the test surface [m]

$\mathrm{v}_{\mathrm{b}}$ bulk flow rate $\left[\mathrm{m} \mathrm{s}^{-1}\right]$

$\mathrm{v}_{\mathrm{s}} \quad$ slip velocity $\left[\mathrm{m} \mathrm{s}^{-1}\right]$

A area $\left[\mathrm{m}^{2}\right]$

Bi Biot number, $\mathrm{hL}_{\mathrm{c}} / \mathrm{k}$

$\mathrm{C}$ entry capillary pressure $\left[\mathrm{N} \mathrm{m}^{-2}\right]$

$\mathrm{CAH}$ contact angle hysteresis $\left[{ }^{\circ}\right]$ 
CFM cubic feet per minute

$\mathrm{D}$ diameter $[\mathrm{m}]$

$\mathrm{F}$ force $[\mathrm{N}]$

FR force ratio of gravity to surface tension

Fr Froude number, $\mathrm{u} /(\mathrm{gl})^{1 / 2}$

$\mathrm{G}$ gravity [N]

Gr Grashof number

$\mathrm{H}$ height $[\mathrm{m}]$

$\mathrm{K}$ permeability or intrinsic permeability $\left[\mathrm{m}^{2}\right]$

$\mathrm{L}$ length $[\mathrm{m}]$

$\mathrm{L}_{\mathrm{f}}$ latent heat of fusion $\left[\mathrm{kJ} \mathrm{kg}^{-1}\right]$

$\mathrm{Nu}$ Nusselt number

$\mathrm{P}$ pressure $[\mathrm{Pa}]$

$\mathrm{P}^{+}$dimensionless pressure

$\mathrm{P}_{\text {ca }}$ capillary pressure

Pr Prandtl number

Pwr power [W]

$\mathrm{Q}$ heat transfer $[\mathrm{J}]$

$\mathrm{T}$ temperature $[\mathrm{K}]$

$\mathrm{U}$ Characteristic velocity $\left[\mathrm{m} \mathrm{s}^{-1}\right]$

$\mathrm{V}$ volume $\left[\mathrm{m}^{3}\right]$

W width [m]

Re Reynolds number

$\mathrm{R}_{\mathrm{th}}$ thermal resistance $\left[\mathrm{W} \mathrm{K}^{-1}\right.$ ]

S water saturation, the volume fraction of water to the pore volume

\section{Greek symbols}

$\alpha$ thermal diffusivity $\left[\mathrm{m}^{2} \mathrm{~s}^{-1}\right]$

$\beta \quad$ dimensionless parameter depending on the material

$\delta \quad$ thickness [m] 


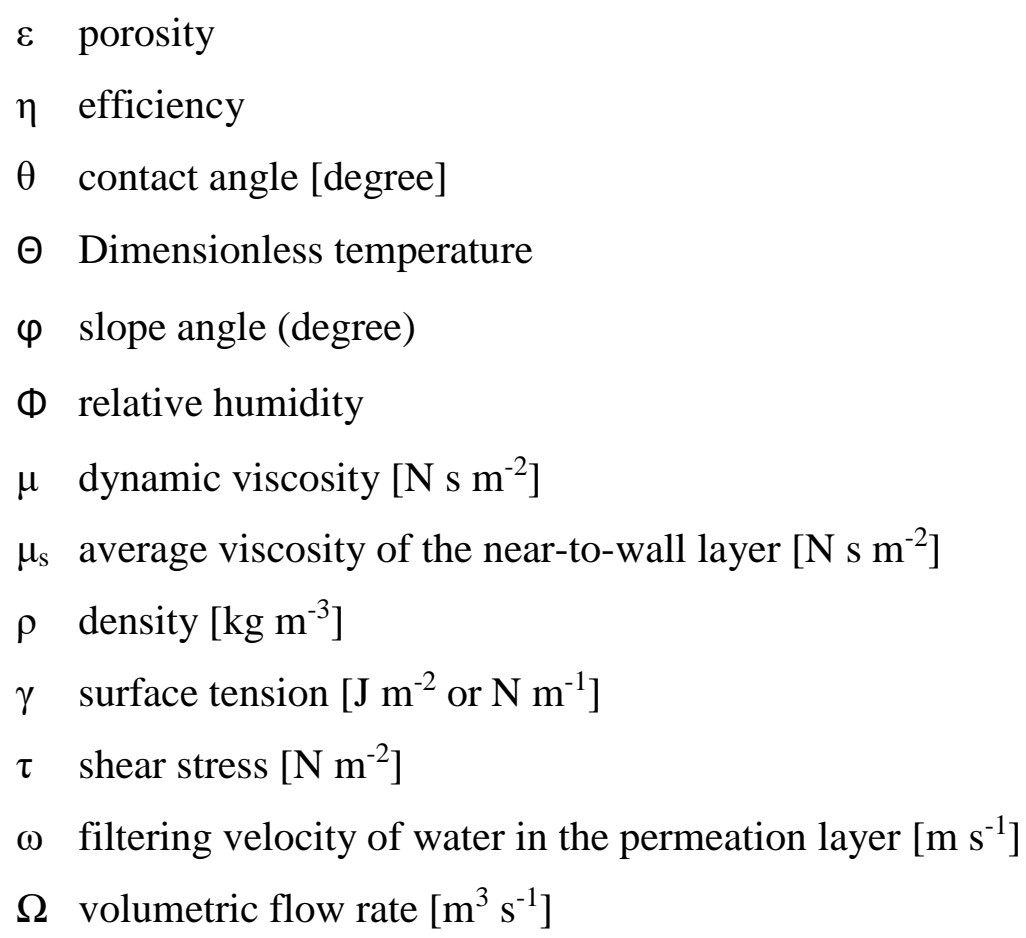

\section{Subscripts \\ 0 initial \\ a air adv advancing}

Al aluminum

avg average

b bulk

c cold

ca capillary

ch chamber

cond conduction

conv convection

d drain

df defrost

eff effective

f frost 


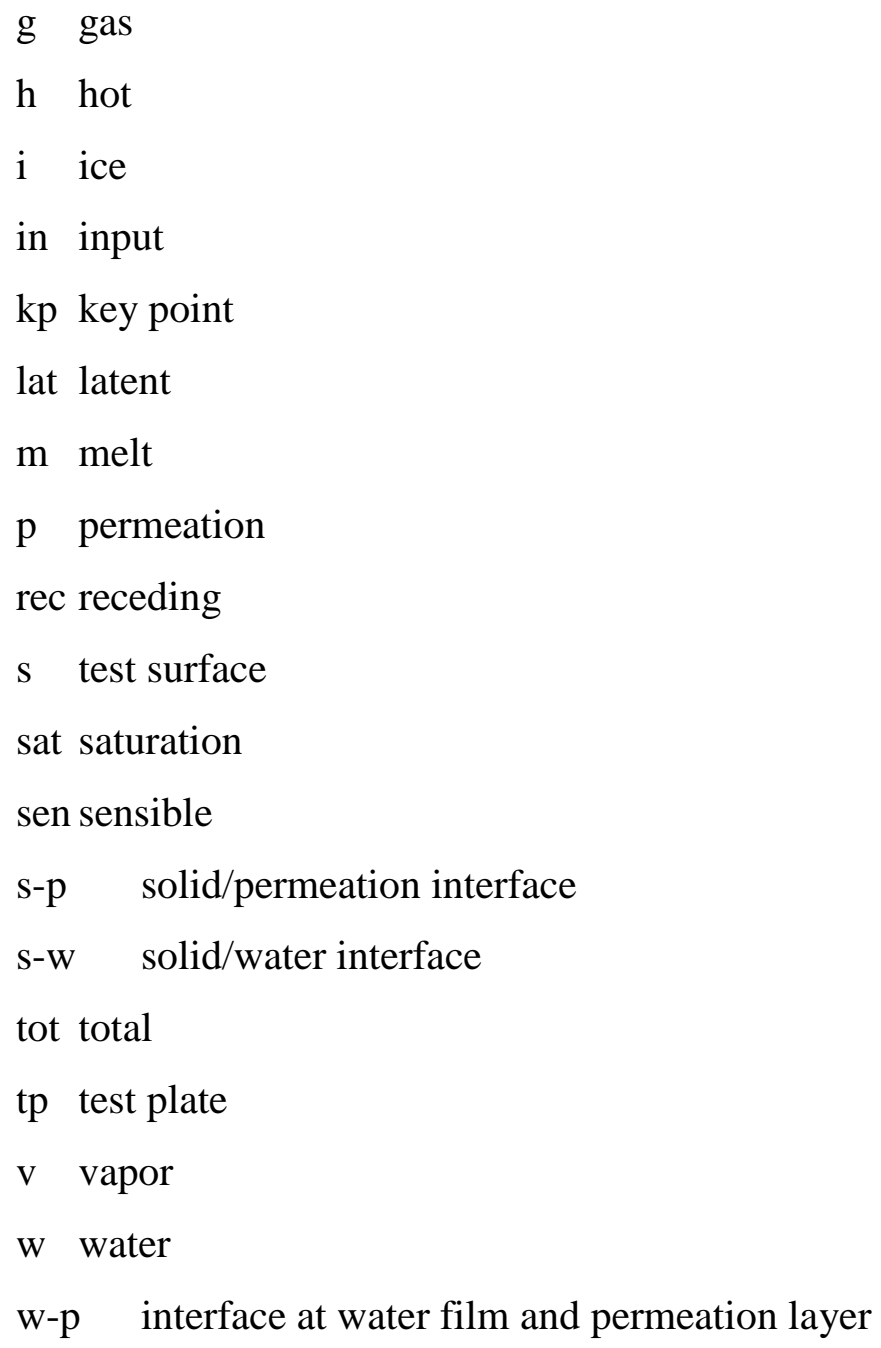




\section{Introduction}

Frost formation is a common problem across a wide range of areas. It can prevent equipment from normal operation in refrigeration system, power lines, wind turbines, and aircraft. In refrigeration systems, frost formation on evaporator surfaces can block airflow, increase thermal resistance and pressure drop, and decrease system performance. Consequently, a defrost process is necessary to maintain normal operation.

In current literature, a general defrost process consists of preheating the frost column, frost melting and water vaporizing. Frost melting is accompanied by water draining. The physical mechanisms of the melting process are not thoroughly investigated to cover the different meltwater behaviors. Recently, passive de-icing methods have attracted interest as a way to speed the defrost process and thus reduce down time for the refrigeration system. Among them, the use of hydrophilic and hydrophobic surfaces is thought to influence frost growth and the defrost process. Many researchers have investigated via experiment the effects of hydrophilic and hydrophobic surfaces on the properties of frost growth. Experimental results show that a hydrophobic surface can retard the frost process during nucleation and at the beginning period of frost growth. After the surface is covered with frost, however, the effect of surface wettability shows no significant difference in the frost growth period.

The current study of the effect of surface wettability on the defrost process is limited. Compared to hydrophobic surfaces, a hydrophilic surface shows much lower percent of water retention after melting. Film condensate is easier to drain away from the

surface. The conditions under which the experiments have been performed differ with a range of surface temperatures, air temperatures and humidity values. Also, only few experimental results are available on the effect of surface wettability on the defrost process. It is difficult to conclude whether hydrophilic surfaces are superior to hydrophobic surfaces or vice versa.

The theoretical study of the defrost process is focused on defrost models. Many researchers have investigated defrost models for electrical defrosting and hot gas defrosting. However, the effect of surface wettability has not been fully discussed in the current models. Another observation from the current literature is that frost slumping, 
which is the behavior of bulk mass peeling off the surface, is not analyzed theoretically and experimentally. Slumping is a favorable phenomenon during the melting process. If bulk mass peels off the surface during the defrost period, defrost time can be reduced significantly, and the defrost efficiency would be improved greatly with less energy consumption.

Motivated by these observations, the goal of this thesis is to develop an analytical model of the defrost process with an emphasis on the effect of surface wettability. The effect of surface wettability is expected to be significant during the melting period and to have an effect on the initiation of slumping. The defrost model is governed by heat and mass transfer within the frost layer, and the slumping model is dominated by the balance of surface tension, adhesion and gravity. However, the two models are connected in nature. Surface tension and ice adhesion are functions of temperature which can be obtained from the defrost model.

The objectives of this research are to (a) formulate the analytical model to describe the melting process with a good understanding of the physical mechanisms, (b) study the effect of surface wettability on the defrost process, (c) investigate the criterion when slumping might happen, and (d) test the defrost process on the different surface wettability.

The effect of surface wettability on the defrost model is a new feature of this research and has theoretical and practical importance. This study provides a mathematical model with different meltwater behavior discussed and relates defrost time and efficiency with the surface wettability. The slumping model is expected to provide a new prospect on frost removal methods and might be applied to design and optimization of refrigeration systems. 


\section{Literature Review}

The defrost process initiates with a frost layer of a certain thickness and porosity. A comprehensive review [1-26] of frost formation aids in formulating the physical and thermal properties in the frost layer.

\subsection{Frost formation}

Frost formation involves nucleation, crystal growth and frost layer growth. The present investigation of frost formation is focused on nucleation, empirical models and correlations, and analytical models to predict frost growth.

\subsubsection{Frost nucleation}

Frost may form by either condensation of water vapor or by the freezing of liquid water. The initiation of frost formation involves a nucleation process, which is divided into two types, homogeneous nucleation and heterogeneous nucleation. Homogeneous nucleation is also called spontaneous nucleation with water molecules combining together to form a frost embryo. Heterogeneous nucleation occurs on foreign particles and is more common in nature. The discussion herein refers to heterogeneous nucleation.

Frost nucleation may be affected by water vapor pressure, surface temperature and surface energy. Na and Webb [1] analyze the thermodynamic process of nucleation and conclude that super-saturation of water vapor is a requirement for frost nucleation. They also point out that the degree of super-saturation ${ }^{1}$ depends on the surface energy ${ }^{2}$. Lower energy surfaces require higher super-saturation for nucleation than higher energy surfaces do. This analysis agrees with the experimental results. They test five kinds of surfaces with different surface energy, or contact angle: hot water treated aluminum surface, bare aluminum surface, transparent polymer packaging tape on the aluminum surface, silicone wax coated aluminum surface, and Teflon coated aluminum surface. Experiments show that frost formation starts at discrete points, and some regions are not covered by frost at a certain temperature drop. This inhomogeneity results from different local surface energy. They observe that surface roughness reduces the required supersaturation for nucleation as the contact area between the nucleation embryo and the

\footnotetext{
${ }^{1}$ Degree of super-saturation is the humidity ratio difference of the air stream and the surface.

${ }^{2}$ Surface energy is the sum of all the excess energies of atoms at the surface.
} 
substrate increases. The results imply the possibility to develop surfaces that may delay frost formation.

The influence of contact angle on super-cooling degree ${ }^{3}$ is also reported by Piucco et al. [2]. They put forward a nucleation model based on classical nucleation theory, in which the minimum energy barrier of nucleation is expressed as a function of supersaturation degree and contact angle. The model applies to smooth surfaces ${ }^{4}$. They also show that nucleation limits are a function of the super-cooling and contact angle and are independent of surface temperature. Their experimental work was carried out in an open loop tunnel. Five plates, each with a different surface treatment, were tested under a fixed environmental condition. Results show that greater surface roughness favors the occurrence of nucleation. The experimental results show agreement with the theoretical prediction.

\subsubsection{Experiments and correlations}

A number of experimental studies [3-10] have been done to investigate thermophysical properties and empirical correlations during frost growth. Quantities of interest include density, thermal conductivity, thickness and mass, growth rate, and heat and mass transfer coefficients. Both environmental and surface conditions affect the properties. Environmental conditions include air temperature, velocity and humidity. Surface conditions include surface temperature and treatment.

Brian et al. [3] investigate frost densities, thermal conductivities and heat and mass fluxes as a function of time under the conditions of gas temperature from 1.1 to $33.9{ }^{\circ} \mathrm{C}$, dew point from -10 to $14.4^{\circ} \mathrm{C}$ and Reynolds number from 3770 to 15,800 . The data agree with the theoretical predictions of a simple analytical model emphasizing the internal diffusion process within the frost. The experimental results show no significant density gradients in the frost, which is not thoroughly explained. It is postulated that very small ice particles are nucleated in the frost and the nuclei are transported by thermal diffusion forces.

\footnotetext{
${ }^{3}$ Super-cooling degree is defined as the temperature difference when subtracting plate temperature from the air saturation temperature.

${ }^{4}$ Smooth surfaces are surfaces that the deviations in the direction of the normal vector of a real surface from its ideal form are small.
} 
Hayashi et al. [5] relate frost properties with frost formation types. The experiments are set under forced convection with ambient temperature from 15 to $30{ }^{\circ} \mathrm{C}$. The frost formation process is divided into three periods: crystal growth, frost layer growth and frost layer full growth. The crystal growth period is characterized by crystal growth in vertical direction at about the same rate, and the frost shape is like a forest of trees. During the frost layer growth period, frost grows into a meshed and uniform frost layer. The frost layer full growth period is characterized by melting, freezing and deposition, and the frost shape does not change. The frost layer becomes denser in this period. Frost formation types are classified into four groups based on structure which is determined by humidity and the cold surface temperature. Experiments show that frost density increases rapidly at the early stage. A higher ambient velocity produces a denser frost, but frost formation types are almost not affected by the ambient velocity. Thermal conductivity is shown to be not only a function of density, but also a function of the other factors. The structure of the frost layer, internal diffusion of water vapor and surface roughness may also affect thermal conductivity.

An experimental study of frost properties under free convection is described by Fossa and Tanda [7]. Frost thickness, frost surface temperature, deposited mass and heat flux are investigated on a vertical plate. The plate is placed in a vertical channel with air temperature from 26 to $28{ }^{\circ} \mathrm{C}$ and ambient humidity controlled from 31 to $58 \%$. The test surface temperature varies from -13 to $-4{ }^{\circ} \mathrm{C}$. Data show that frost thickness increases with time. The frost layer is not uniform during the early time period, and thickest frost occurs on the coldest plate and at the highest relative humidity. Frost surface temperature is close to the triple-point value at relative high humidity. The deposited mass increases linearly with time and is more affected by the relative humidity than by the surface temperature. Heat flux at the plate/frost interface is measured and is shown to be a function of relative humidity and plate temperature. Local heat flux decreases markedly on the coldest plate. The total heat flux is higher at the higher relative humidity, which is explained by the increased rate of latent heat transfer.

Janssen et al. [10] present a new correlation and model based on digital reduction of in-plane observations of frost thickness. Visual and digital methods are employed to determine frost thickness, porosity and droplet statistics. Experiments show frost 
thickness increases with time exponentially, and a fast and slow growth period are identified. Frost thickness is expressed as a function of system state and growth resistance. The key physical and correlating parameter within this model is the ratio of sensible heat transfer to total heat transfer, and the growth rate varies inversely with this ratio. The resulting correlation faithfully captures measured growth rates and gives better predictive capability than that of existing correlations across a wide spectrum of frosting conditions. Experimental uncertainty on frost thickness is reduced of $0.1 \mathrm{~mm}$, and the need is eliminated for measurement of the frost-air interface temperature. Janssen et al. also present a comprehensive review of experimental studies of frost growth illustrating the wide variety of techniques and frosting conditions employed over the past 30 years.

\subsubsection{Analytical models}

Analytical study of frost formation is focused on models to predict frost densification and thickness, thermal conductivity, and growth rate [11-24].

Tao et al. [14] present a one-dimensional theoretical model to predict temperature distribution, frost density and thickness. The model involves two stages: ice column growth and fully developed frost layer growth. The frost layer is treated as a porous medium during the frost growth period. Both temporal and spatial variations of frost properties are analyzed using the local volume averaging technique. Calculations show that ice column diameter at the frost surface is smaller than that at the cold plate surface during the ice column growth period. During the frost layer growth period, temperature and vapor density show non-linear distribution within the frost layer. The rate of densification has a maximum absolute value near the frost-air interface, the warm side of the frost layer. The experimental study shows good agreement with the theoretical calculations. A two-dimensional model is analyzed by Tao and Besant [15]. The initial stage is modeled with convective heat and mass transfer over the ice columns rather than diffusion within the frost. After a transition time, a homogeneous porous medium model applies to the frost layer. Vapor diffusion is considered to be the mechanism for water vapor transport within the frost layer, and phase change is due to sublimation. Calculations show good agreement with the reported experimental data.

Lee et al. [19] present a model to predict the thickness, density and surface temperature within an error band of $10 \%$ during the frost growth period. Assumptions 
include that all the processes are quasi-steady state and the variation of frost density in the normal direction is negligible. Governing equations on the air side and in the frost layer are solved numerically. Experiments are set up to validate the analytical predictions. Results show that the frost layer thickness grows rapidly at the early stage and then slows down. Frost density increases rapidly at the beginning then slows down. The model predicts the results accurately within an error of $10 \%$ except the early stage of the frost formation, which may be attributed to the uncertainties of the weight measurement. The surface temperature increases rapidly at beginning but the increase rate slows down with the decrease of the growth rate. Heat and mass transfer are also estimated by the present model. The heat transfer rate decreases rapidly at the early stage but the rate of decrement is then reduced with time. The trend of mass transfer rate is similar to that of the heat transfer rate.

Compared to research on frost growth, theoretical studies of the crystal growth periods are limited. Sahin $[25,26]$ investigates frost properties and presents an analytical study of the crystal growth period. The frost layer is assumed to consist of several frost columns. The crystal structure varies with temperature. The temperature distribution shows that more sublimation of water vapor occurs in the upper half of the frost layer. The temperature distribution in the frost layer is mostly affected by the ambient humidity, ambient temperature, and surface temperature. The Reynolds number has less effect on the temperature distribution. The effective thermal conductivity is found to be not only a function of density, but also depends on the vapor diffusion and sublimation. The effective thermal conductivity increases rapidly with time as densification occurs and levels off as the frost layer thickens. Higher surface temperature and higher air temperature yield larger effective thermal conductivity. Low humidity results in nearly constant thermal conductivity, which is explained by the negligible vapor diffusion in the frost layer. Reynolds numbers have less effect on the frost thermal conductivity.

\subsection{Frost growth on wetted surfaces}

The effect of surface wettability on frost formation has attracted many researchers in the last decade. The studies are mainly focused on the experimental observations of frost properties corresponding to surface wettability and frost formation with respect to 
surface wettability. Some analytical models are proposed with the effect of surface wettability included during frost formation.

\subsubsection{Frost properties on wetted surfaces}

Shin et al. [27] investigate the effects of surface energy on frost formation and provide correlations for frost layer properties as a function of time and surface energy. The tests are performed on three different surfaces with dynamic contact angle ${ }^{5}$ (DCA) of $23^{\circ}, 55^{\circ}$, and $88^{\circ}$. Experimental conditions are maintained at a Reynolds number of 9000 , relative humidity $48.1 \%$, air temperature $12{ }^{\circ} \mathrm{C}$ and cold plate temperature $-22{ }^{\circ} \mathrm{C}$. The experimental results show frost thickness increases rapidly with time at the beginning of frost growth and then approaches a constant rate of growth. Frost thickness on the surface of $23^{\circ} \mathrm{DCA}$ is $76 \%$ of that with $88^{\circ} \mathrm{DCA}$ after $30 \mathrm{~min}$, but the difference is not significant after $120 \mathrm{~min}$. Filmwise condensation and dense droplets form on lower dynamic contact angle surfaces. Dropwise and less dense condensate are generated on higher DCA surfaces. Frost mass increases linearly with time, and the differences on tested surfaces are minor. Frost density is larger on lower DCA surfaces at the initial stage, and the difference becomes less significant after $120 \mathrm{~min}$. Thermal conductivity on surfaces with different DCAs shows smaller variation than density. Local thermal conductivity varies significantly along the frost layer. Conductivity close to the surface and frost-air interface is two to three times larger than that inside the frost layer.

\subsubsection{Effect of surface wettability on frost formation}

The effects of surface wettability on frost formation have been investigated extensively. A number of investigations [28-38] address anti-icing performance of the superhydrophobic surfaces.

Zhong et al. [28] present a method of producing superhydrophobic surfaces with micro-posts and micro-grooves. Water droplets form on the surface with static contact angle $(\mathrm{SCA})^{6}$ of $148^{\circ}$. Experiments demonstrate that condensate appears everywhere when droplets are smaller than the dimension of micro-structures. As condensate

\footnotetext{
${ }^{5}$ Dynamic contact angle is measured when the three phase boundary is moving. Dynamic contact angle is referred as advancing angle and receding angle.

${ }^{6}$ Static contact angles are measured when droplet is standing on the surface and the three phase boundary is not moving. Contact angle in this thesis is referred as static contact angle.
} 

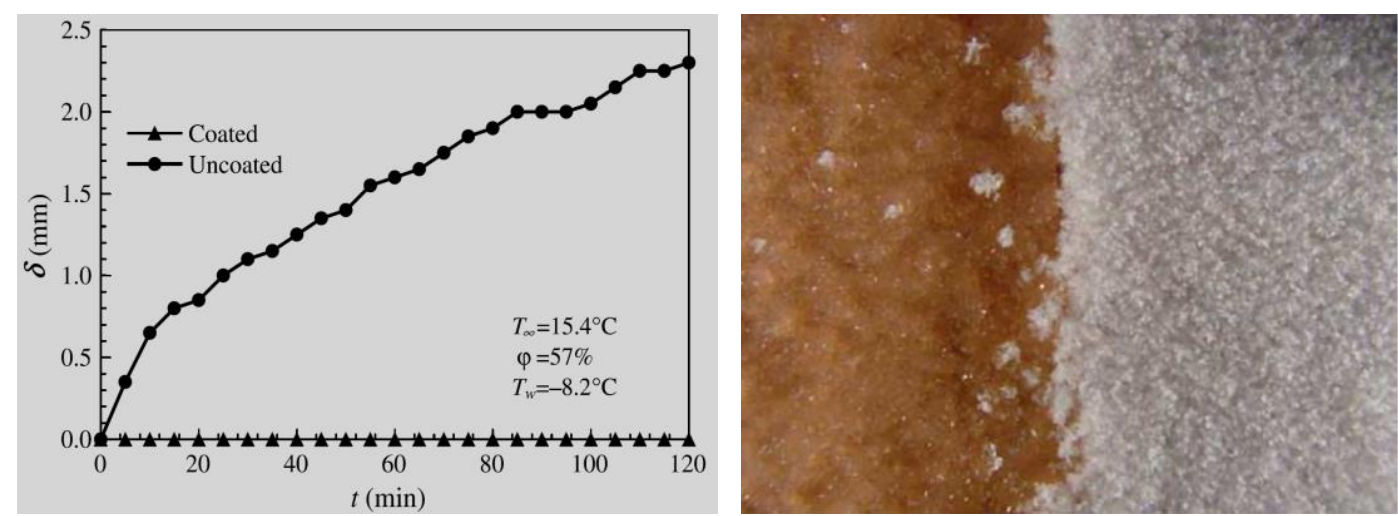

Figure 2.1. Comparison of frost deposition on the coated and uncoated surfaces [29].

accumulates, droplets either group around the posts or condense and form a thin film depending on the micro-structure. This phenomenon influences condensate drainage and frost formation. The density and thermal conductivity of the frost layer varies significantly for the frost growing from dropwise condensate and for the frost growing from film wise condensate.

A long delay time of frost formation up to $3 \mathrm{~h}$ is reported by Liu et al. [29]. An anti-frosting paint is coated on the surface of the cold plate. Liu and his colleague show cold plate temperature and ambient humidity have a strong influence on the performance of the anti-frosting paint. Experimental results show that the cold plate surface maintains no frost condition for up to $3 \mathrm{~h}$ (Fig. 2.1.) under the condition of relative humidity less than $60 \%$ and a cold plate temperature greater than $-10{ }^{\circ} \mathrm{C}$. The influence of hydrophobicity on frost formation on a vertical plate under natural convection conditions is also studied by Liu et al. [30]. A hydrophobic surface with an SCA of $133^{\circ}$ and plain copper surface with an SCA of $63^{\circ}$ are tested, and experiments suggest that smaller droplets are formed on hydrophobic surfaces. The explanation is that the contact area on a hydrophobic surface is smaller than that on a hydrophilic surface if the volumes are equal. It is also observed that frost crystal growth on a hydrophobic surface has a stronger dendrite pattern resulting into looser and weaker frost layer at the initial stage. Frost thickness on the hydrophobic surface is smaller than that for a hydrophilic surface at the beginning of frost growth but approaches that for the hydrophilic surface when frost fully 
covers the surface. The potential barrier ${ }^{7}$ equation shows that increasing contact angle increases the potential barrier and thus retards the frost crystal nucleation in early stage frost formation. After the surface is covered by frost, frost thickness growth on hydrophobic and hydrophilic surfaces is almost the same. Liu et al. [31] further examine frost formation on a super hydrophobic surface under natural convection. Their experiments are performed on a horizontal surface with droplet SCA of $162^{\circ}$, relative humidity of $40 \%$, surface temperature of $-10.1{ }^{\circ} \mathrm{C}$, and ambient temperature of $18.4{ }^{\circ} \mathrm{C}$. Results show that frost formation delays for 55 min compared to the plain copper surface, and the frost layer structure on the superhydrophobic surface is looser and easily removed. A frost layer pattern similar to a cluster of chrysanthemum petals is firstly reported in this article. Water droplets on the superhydrophobic surface grow in a similar way as on the normal copper surface, but frost crystals grow in a different way. Frost crystals grow in horizontal direction compared to the vertical direction on normal copper surface.

More studies show the retarding effect of the superhydrophobic surface on the frost formation at the early stage. Wang et al. [33] generate superhydrophobic surfaces with contact angles of $120^{\circ}$ and $150^{\circ}$. Samples with different hydrophobicity are tested under the relative humidity of $55 \%$ and surface temperature of $-7.2^{\circ} \mathrm{C}$. Experiments show that condensed water droplets are larger with bigger contact angles. No frost appears after $600 \mathrm{~s}$ on vertical plate and $140 \mathrm{~s}$ on horizontal surface compared with $50 \mathrm{~s}$ on normal copper surfaces. Stability is tested, and the surface maintains the superhydrophobicity after 10 frosting and defrosting cycles.

One of the advantages of the superhydrophobic surface is that water droplets are easily removed. Wang et al. [34] show that the water droplets fall down easily with contact angle greater than $150^{\circ}$. They propose a technique to construct an aluminum superhydrophobic surface using chemical etching and test the wettability effect on frost formation when spraying on vertical plates. Less surface area is covered by frost on the superhydrophobic aluminum surface. Frost begins to form at some points and increases at these sites, and no new area shows ice formation. The contact angle is measured and shows no significant variation with climatic temperature.

\footnotetext{
${ }^{7}$ The potential barrier is the Gibbs free energy difference when supersaturated vapor changes from its metastable phase into the stable phase (frost crystal).
} 
He et al. [37] find that superhydrophobic surfaces retard frost formation at temperatures below the freezing point. Nano-rod arrays of $\mathrm{ZnO}$ are fabricated on the test surface. Experiments show that average water SCAs are $170.9^{\circ}, 166.1^{\circ}$ and $165.8^{\circ}$ on the surface with the growth time $\left(\mathrm{t}_{\mathrm{ZnO}}\right)$ of $\mathrm{ZnO}$ nano-rod of $1 \mathrm{~h}, 2 \mathrm{~h}$ and $3 \mathrm{~h}$ at room temperature. Wettability of the modified surface to condensed micro-droplets is investigated at surface temperatures of $-5{ }^{\circ} \mathrm{C}$ and $-10^{\circ} \mathrm{C}$. With tZno equals 1,2 and $3 \mathrm{~h}$, water SCAs are $167.9^{\circ}, 160.3^{\circ}$, and $154.6^{\circ}$ at surface temperature of $-5{ }^{\circ} \mathrm{C}$ and $163.4^{\circ}$, $158.2^{\circ}$ and $155.4^{\circ}$ at $-10{ }^{\circ} \mathrm{C}$. Solidification time of condensed droplets is longer on superhydrophobic $\mathrm{ZnO}$ nano-rod array surfaces than that on the hydrophobic surface and increases with $\mathrm{t}_{\mathrm{ZnO}}=3,2$ and $1 \mathrm{~h}$. The time is shorter at $-10^{\circ} \mathrm{C}$ than that at $-5^{\circ} \mathrm{C}$, which is explained by the decrease of nucleation free energy barrier ${ }^{8}$. These results provide the possibility of fabrication of anti-frost materials at low surface temperature conditions.

The durability of a superhydrophobic surface is a challenge to the anti-icing properties of the surface. Farhadi et al. [38] study the anti-icing capability with different superhydrophobic surfaces. Experiments are performed in a wind tunnel by spraying super cooled water micro-droplets at $-10{ }^{\circ} \mathrm{C}$. Results show that ice adherence increases, and the anti-icing performance of the tested surfaces decreases during icing/deicing cycles. The contact angle decreases and contact angle hysteresis ${ }^{9}$ increases on the wet surface caused by water condensation from air.

\subsubsection{Analytical studies}

The theoretical study of the effect of surface wettability on frost formation is limited. Bahadur et al. [39] present a model to predict ice formation on superhydrophobic surfaces resulting from super cooled water droplets. The model is composed of three submodels: droplet impact dynamics, heat transfer, and heterogeneous ice nucleation. The droplet impact dynamics sub-model predicts the spreading and retraction dynamics of a droplet impacting a superhydrophobic surface. The heat transfer sub-model predicts the transient temperature distribution inside the droplet during spreading and retraction. The heterogeneous ice nucleation sub-model predicts the kinetics of nucleation of ice clusters.

\footnotetext{
${ }^{8}$ Nucleation free energy barrier is the change in free energy per unit volume and is balanced by the energy gain of creating a new volume and the energy cost due to creation of a new interface.

${ }^{9}$ Contact angle hysteresis is the difference between the advancing and receding contact angles.
} 
The integrated model estimates the droplet radius and retraction force ${ }^{10}$ with regard to the retraction time ${ }^{11}$. The model includes the effect of interface temperature on the droplet dynamics and the freezing process. It is validated by experiments with relative humidity of $<5 \%$, and the results are in good agreement with the model.

\subsection{Defrost process}

Industrial defrost processes are initiated at intervals to remove the frost layer from working equipment so as to maintain normal operating conditions. Some studies show that surface wettability has an influence on defrosting, and a number of models have been developed to simulate the defrost process. The goal of past investigations of the defrost process has been to improve overall defrost efficiency and thus reduce defrost time and energy cost.

\subsubsection{Effect of surface wettability on the defrost process}

Studies of the effect of surface wettability on the defrost process are limited [4042]. Jhee and Lee [41] report the effect of the surface treatment on the performance of the heat exchanger during the frosting and defrosting process. The contact angles of the surfaces tested in the experiments are $12^{\circ}, 72^{\circ}$, and $124^{\circ}$. During the defrosting stage, the average water drain rates increase $3.7 \%$ for hydrophilic heat exchanger and $11.1 \%$ for hydrophobic heat exchanger (Fig. 2.2). On the hydrophilic heat exchanger, frost density is higher, and the meltwater absorbed into frost layer is small. The water drain rate increases accordingly. The water drain rate on the hydrophobic surface has a larger value because frost that is not fully saturated with meltwater drains by gravity. The draining water ratio during the frost melting period is $20.9 \%$ for the hydrophilic heat exchanger, $21.5 \%$ for the bare one, and $36.2 \%$ for the hydrophobic one. The draining rate on the hydrophobic surface is higher as frost drains with meltwater. The average heater temperature on the hydrophilic surface is $4.8^{\circ} \mathrm{C}$ lower than the bare one because heat is conducted to melt the frost. The average heater temperature on the hydrophobic surface is higher as only parts of the surface are covered by frost. An interesting observation is that frost accumulation increases by $4.9 \%$ for a hydrophilic surface and by $0.4 \%$ for a hydrophobic surface. On the hydrophilic surface, the water film increases the coverage

\footnotetext{
${ }^{10}$ Retraction force is the difference in the surface tension forces on the two sides of the droplet.

${ }^{11}$ Retraction time is the time of retraction stage of droplet impact.
} 


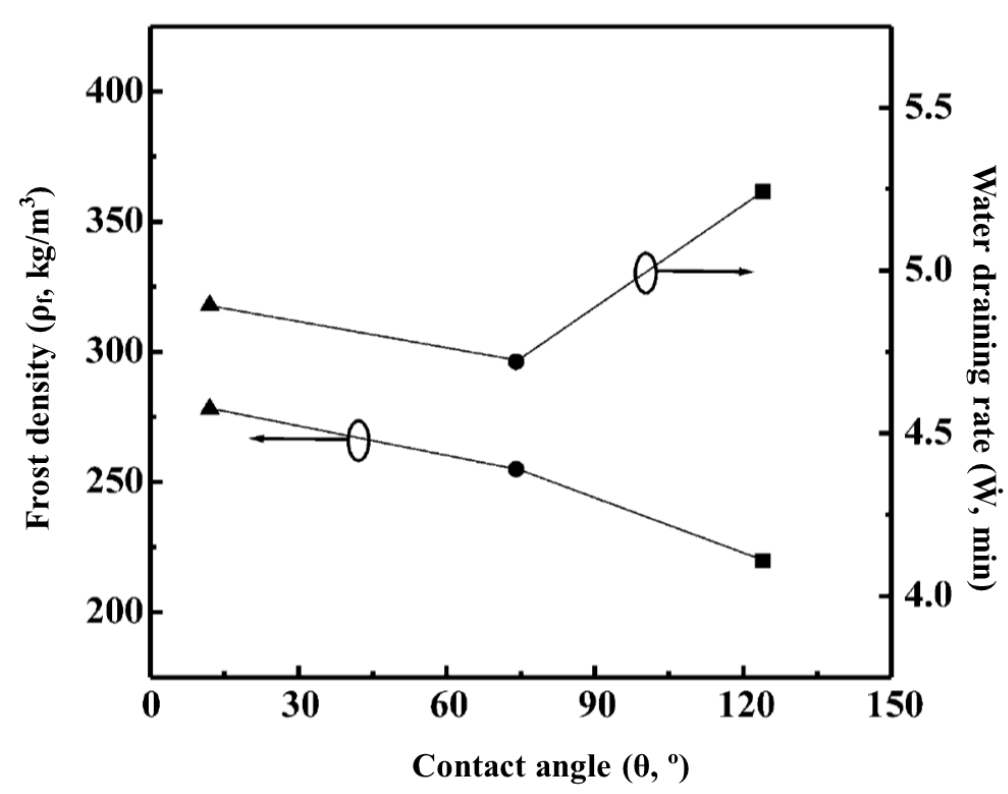

(a)

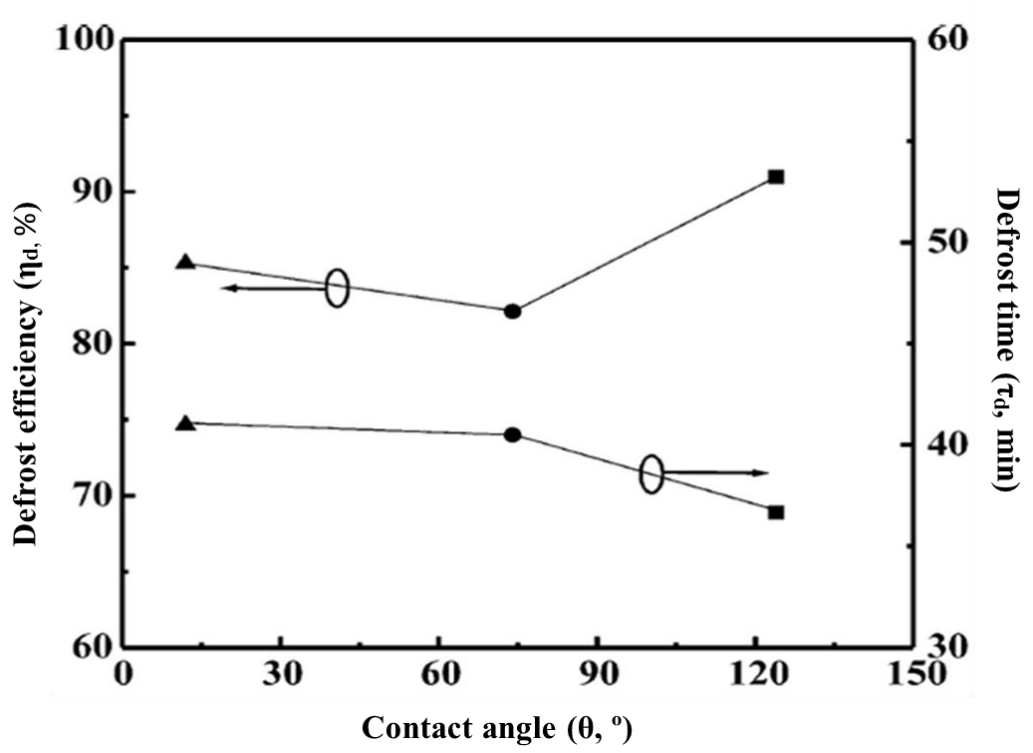

(b)

Figure 2.2. Effect of surface contact angle: (a) frosting and (b) defrosting behavior [41].

area, which promotes frost formation. On the hydrophobic surface, a large blocking ratio $^{12}$ increases local air velocity and promotes frost formation. The defrost efficiency is defined as the ratio of the latent heat to the total heat consumption. The defrost

12 Blocking ratio is a parameter indicating the extent of the blockage of the flow passage between the fins of a heat exchanger by frost layer. 
efficiency increases by $3.5 \%$ for the hydrophilic heat exchanger and by $10.8 \%$ for the hydrophobic surface. The enhancement of the efficiency is due to the increment of the water draining rate. It is concluded that the hydrophobic surface has the most significant effect on the defrost process.

Kim and Lee [42] investigate the effect of surface conditions on frosting and defrosting characteristics on an extended surface. Test conditions are set with the ambient air temperature of $2-6{ }^{\circ} \mathrm{C}$, air velocity $1-2 \mathrm{~m} / \mathrm{s}$, surface temperature $-10{ }^{\circ} \mathrm{C}$ to $-18{ }^{\circ} \mathrm{C}$, absolute humidity of $0.00254-0.00418 \mathrm{~kg} / \mathrm{kg}_{\mathrm{a}}$, and surfaces with a static contact angle of $2.5^{\circ}, 75^{\circ}$ and $142^{\circ}$ for hydrophilic, bare, and hydrophobic surfaces. Experiments show that a thin frost film forms on a hydrophilic surface; water droplets and frost crystals appear on the bare surface; and only water droplets form on the hydrophobic surface after $10 \mathrm{~min}$. After $20 \mathrm{~min}$, the three samples have frost on the surface. Frost structures are in different patterns. Pillar like structures form on the hydrophilic surface, and a hexagonal structure is on hydrophobic surface. Frost thickness is different on the surfaces only during the early stages of frosting. The lowest thickness is on the hydrophilic surface, and the other two are similar. Frost density is highest on the hydrophilic surface, and lowest on hydrophobic surface. Frost surface temperature on the hydrophilic surface is lower than those on the others, but the temperature difference is insignificant. On the hydrophilic surface, the average density is the highest, thus, the thermal resistance is the lowest. As the frost mass is higher, the heat capacity for defrosting is larger on the hydrophilic surface. On the other hand, the frost density is the lowest on hydrophobic surface, and frost mass is the smallest. The difference in defrosting time is not significant because of the combined influence of frost thermal conductivity and mass of frost layer on the fin. The ratio of residual water on hydrophilic surface has significant difference, which is only $1 / 6$ to $1 / 10$ of that on other fin surfaces. The water on a hydrophilic surface forms a thin film and flows away easily, while water on a hydrophobic surface falls only after forming larger water droplets. Residual water on a hydrophobic surface speeds up frost growth, the frost layer grows faster around the residual water, and frost mass is about $5 \%$ greater. Overall the hydrophilic surface exhibits the best thermal performance during testing. A summary of the effects of the surface wettability on the frost formation and the defrost process is listed in Table 2.1. 
Table 2.1. Wettability effect on the frost/defrost process.

\begin{tabular}{|c|c|c|c|c|}
\hline & $\begin{array}{l}\text { Test sample } \\
(\mathbf{L} \times \mathbf{W} \times \mathbf{T})\end{array}$ & $\begin{array}{l}\text { Environmental } \\
\text { conditions }\end{array}$ & $\begin{array}{c}\text { Frost/condensate } \\
\text { pattern }\end{array}$ & $\begin{array}{l}\text { Frost layer } \\
\text { properties }\end{array}$ \\
\hline $\begin{array}{l}\text { Shin et } \\
\text { al. [27] }\end{array}$ & $\begin{array}{l}\text { 100x300x } 20 \mathrm{~mm} \\
\text { Al } \\
\text { Advancing } \\
\text { DCA: } \\
23^{\circ}, 55^{\circ}, 88^{\circ}\end{array}$ & $\begin{array}{l}\text { Air: } \\
+5^{\circ} \mathrm{C} \text { to }+20{ }^{\circ} \mathrm{C} \\
\text { RH: } 40 \% \text { to } 80 \% \\
\text { Surface: }-25^{\circ} \mathrm{C} \text { to } \\
-5{ }^{\circ} \mathrm{C} \\
\text { Limitation: } \\
\text { Fixed test conditions }\end{array}$ & $\begin{array}{l}\text { Higher DCA: } \\
\text { Irregular, dropwise } \\
\text { condensate } \\
\text { Lower DCA: } \\
\text { Uniform, filmwise } \\
\text { droplets }\end{array}$ & $\begin{array}{l}\text { Higher DCA: } \\
\text { Less dense, larger } \\
\text { thickness } \\
\text { Lower DCA: } \\
\text { Denser, smaller } \\
\text { thickness }\end{array}$ \\
\hline $\begin{array}{l}\text { Liu et } \\
\text { al. [30] }\end{array}$ & $\begin{array}{l}\text { 150x52x6 mm } \\
\text { Copper } \\
\text { Vertical } \\
\text { CA: } 133^{\circ}, 63^{\circ}\end{array}$ & $\begin{array}{l}\text { Air : }+24{ }^{\circ} \mathrm{C} \\
\text { RH : } 62 \% \\
\text { Surface : }-8{ }^{\circ} \mathrm{C}\end{array}$ & $\begin{array}{l}\text { Hydrophobic surface: } \\
\text { Smaller and fewer water } \\
\text { droplets } \\
\text { Looser and weaker } \\
\text { Plain/Hydrophilic surface: } \\
\text { Freezing quicker }\end{array}$ & $\begin{array}{l}\text { The thickness on } \\
\text { hydrophobic surface } \\
\text { is smaller at the initial } \\
\text { stage and is almost } \\
\text { the same with that on } \\
\text { plain surface after } \\
\text { long test. }\end{array}$ \\
\hline $\begin{array}{l}\text { Liu et } \\
\text { al. [31] }\end{array}$ & $\begin{array}{l}\text { Copper } \\
\text { Horizontal } \\
\text { CA: } 162^{\circ}, 72^{\circ}\end{array}$ & $\begin{array}{l}\text { Air : } 18.4{ }^{\circ} \mathrm{C} \\
\text { RH : } 40 \% \\
\text { Surface : }-10.1{ }^{\circ} \mathrm{C}\end{array}$ & & $\begin{array}{l}\text { Hydrophobic surface } \\
\text { delays frost formation } \\
\text { for } 55 \text { min and } \\
\text { reduces the thickness } \\
\text { by } 52 \% \text { at the end. }\end{array}$ \\
\hline $\begin{array}{l}\text { Wang } \\
\text { et al. } \\
{[33]}\end{array}$ & $\begin{array}{l}\text { Copper } \\
\text { Horizontal \& } \\
\text { Vertical } \\
\text { CA: } 120^{\circ}, 150^{\circ}\end{array}$ & $\begin{array}{l}\text { Temperature: } \\
-7.2^{\circ} \mathrm{C} \\
\text { Humidity: } \\
55 \%\end{array}$ & $\begin{array}{l}\text { Hydrophobic surface: } \\
\text { Condensed droplets } \\
\text { become larger when } \\
\text { contact angle changes } \\
\text { from } 120^{\circ} \text { to } 155^{\circ} \text {. } \\
\text { Bare surface: } \\
\text { Irregular small droplets }\end{array}$ & \\
\hline $\begin{array}{l}\text { Wang } \\
\text { et al. } \\
\text { [34] }\end{array}$ & $\begin{array}{l}20 \times 15 \times 3 \mathrm{~mm} \\
\mathrm{Al} \\
\text { Vertical } \\
\text { CA: } 150^{\circ}\end{array}$ & $\begin{array}{l}\text { Climatic temperature: } \\
-6^{\circ} \mathrm{C} \\
\text { Water temperature: } \\
0{ }^{\circ} \mathrm{C} \text { (Spraying) } \\
\end{array}$ & $\begin{array}{l}\text { Hydrophobic surface: } \\
\text { Icing at partial area } \\
\text { Smooth surface: } \\
\text { Ice covering the surface }\end{array}$ & $\begin{array}{l}\text { Ice layer thickness } \\
\text { increases with } \\
\text { spraying time. }\end{array}$ \\
\hline $\begin{array}{c}\text { Kim \& } \\
\text { Lee } \\
{[42]}\end{array}$ & $\begin{array}{l}60 \times 52.5 \times 0.8 \mathrm{~mm} \\
\text { Al } \\
\text { Fin } \\
\text { CA: } 2.5^{\circ}, 75^{\circ} \text {, } \\
142^{\circ}\end{array}$ & $\begin{array}{l}\text { Air: } \\
+2{ }^{\circ} \mathrm{C} \text { to }+6{ }^{\circ} \mathrm{C} \\
\text { Absolute humidity } \\
\left(\mathrm{kg} / \mathrm{kg}_{\mathrm{a}}\right): \\
0.00254-0.00418 \\
\text { Air velocity }(\mathrm{m} / \mathrm{s}) \text { : } \\
1.0-2.0 \\
\text { Fin base temperature: } \\
-10{ }^{\circ} \mathrm{C} \text { to }-18^{\circ} \mathrm{C}\end{array}$ & $\begin{array}{l}\text { Hydrophobic \& Bare } \\
\text { surface: } \\
\text { Water droplets } \\
\text { Hydrophilic Surface: } \\
\text { A thin water film }\end{array}$ & $\begin{array}{l}\text { Thickness at early } \\
\text { stage: } \\
\text { Bare > } \\
\text { Hydrophobic > } \\
\text { Hydrophilic } \\
\text { Frost density: } \\
\text { Hydrophilic > Bare > } \\
\text { Hydrophobic } \\
\text { Defrosting time } \\
\text { differs insignificantly. }\end{array}$ \\
\hline $\begin{array}{c}\text { Wu \& } \\
\text { Webb } \\
{[43]}\end{array}$ & $\begin{array}{l}40 \times 40 \times 0.25 \mathrm{~mm} \\
\text { Al } \\
\text { Vertical } \\
\text { Advancing/Rece- } \\
\text { ding CA: } \\
98^{\circ} / 73^{\circ} \\
\text { (hydrophobic) } \\
12^{\circ} / 0^{\circ} \\
\text { (hydrophilic) } \\
\end{array}$ & $\begin{array}{l}\text { Inlet air temperature: } \\
24{ }^{\circ} \mathrm{C} \\
\text { RH : } 55 \% \\
\text { Surface temperature: } \\
-18{ }^{\circ} \mathrm{C} \text { to }-6^{\circ} \mathrm{C}\end{array}$ & $\begin{array}{l}\text { Hydrophobic surface: } \\
\text { Non-uniform frost } \\
\text { Larger structure } \\
\text { Water droplets stay on } \\
\text { surface } \\
\text { Hydrophilic surface: } \\
\text { Uniform frost } \\
\text { Fully melted surface } \\
\text { during melting } \\
\end{array}$ & \\
\hline
\end{tabular}




\subsubsection{Frost release and condensate retention}

Surface wettability influences frost release [43-48]. A possibility to release frost from the cold surface is investigated by $\mathrm{Wu}$ and Webb [43] with mechanical vibration. They study the effect of surface wettability on frost pattern and melted water and the possibility of frost release on hydrophobic and hydrophilic surfaces. Experiments are set up on a vertical plate with the air temperature of $24^{\circ} \mathrm{C}$, relative humidity of $55 \%$, and surface temperature of $-18{ }^{\circ} \mathrm{C}$ and $-6^{\circ} \mathrm{C}$. A thermoelectric cooler is used to cool the frost surface. Frost formed on a hydrophilic surface is uniform in thickness, but that on a hydrophobic surface is not uniform. Condensate droplets are larger on hydrophobic surfaces. Further, frost on hydrophobic surfaces cannot be released by surface vibration. During melting, the hydrophilic surface is fully wetted, while the droplets on the hydrophobic surface do not run away, i.e., they tend to stand up on the surface. Surface tension retains some of the condensate and is balanced by gravity and air shear. Melted condensate retention is influenced by the contact angle of water. It suggests that retained water on the surface should be dried out, otherwise it will refreeze quickly. However, it is very difficult to dry the moisture absorbed into a hydrophilic surface.

Recent literature shows that fabricated superhydrophobic surfaces favors the frost release and the defrost process. Jing et al. [46] present an experimental result showing that frost layer detaches from a rigid super hydrophobic surface during the melting. After defrosting, the rigid super hydrophobic surface recovers its super hydrophobic property. Boreyko et al. [47] report a nanostructured superhydrophobic surfaces that promote frost growth in Cassie state ${ }^{13}$. The frost layer is removed by dynamic defrosting which is driven by a low contact angle hysteresis of the meltwater. Chen et al. report on a hierarchical surface that shows influential effect on the frost formation and the defrost stage [48]. The influence rests on suppressing freezing wave propagation during the frost formation and increasing lubrication and mobility of frost during the defrost stage. Frost formation is carried out under ambient temperature of $22{ }^{\circ} \mathrm{C}$ and relative humidity of $60 \%$. The sample plate is placed horizontally onto a cooling state with present temperature of $10{ }^{\circ} \mathrm{C}$. The study of the condensation evolution shows that droplets freeze beginning

\footnotetext{
${ }^{13}$ Cassie state is the wetting state that air trapped in the grooves between surface features forms a composite (solid/air) hydrophobic surface.
} 
from the outer edge corners of the substrate owing to its geometric singularity and low free energy barrier for heterogeneous nucleation. Droplet freezing and the inter-droplet freezing wave vary on hierarchical surface and nano-grassed ${ }^{14}$ super hydrophobic surface. On the hierarchical surface with contact angle of $\sim 160^{\circ}$ and contact angle hysteresis of $1^{\circ}$, consistent droplets departure causes rare direct freezing of droplets during the condensation stage. The condensate droplets maintain the liquid state until a freezing wave invades from the edge corners at $1410 \mathrm{~s}$. The frozen droplet then sprouts dendritic ice crystal, which is the freezing front, towards the surrounding unfrozen liquid droplets. The newly freezing droplet triggers new ice crystals as well as an inter-droplet freezing wave which eventually propagates over the entire surface. The freezing duration is 395 s. The average propagation velocity of the freezing wave is $\sim 0.9 \mu \mathrm{m} / \mathrm{s}$. On a nanograssed superhydrophobic surface with contact angle of $\sim 160^{\circ}$ and contact angle hysteresis of $1 \sim 2^{\circ}$, the condensate droplets maintain the liquid state for $1090 \mathrm{~s}$. The interdroplet freezing wave propagates at $\sim 1.4 \mu \mathrm{m} / \mathrm{s}$, which is $\sim 1.5$ times that on the hierarchical surface. On the hierarchical superhydrophobic surface, liquid droplets gradually decrease their size by evaporation during the freezing processes. The evaporation of the liquid separates the freezing front from the droplets. All the liquid droplets evaporate without the connection to the freezing front. The success of ice bridging is associated with a length competition between the liquid droplet diameter and frozen ice-to-liquid droplet separation. The ratio of the separation length to the droplet diameter is defined as the bridging parameter. Smaller separation length relative to droplet diameter might cause successful ice bridging. About $85 \%$ of liquid droplets on the hierarchical superhydrophobic surface correspond to ice bridging greater than one as opposed to $\sim 67 \%$ on the nano-grassed surface. During the defrost stage, bulk frost fracture is observed on a hydrophobic surface. The frost fractures avalanche and create a crack. On the nano-grassed surface, the density of the fracture is low. The frost melts away and leaves a spherical water droplet on the sample surface. In contrast, no visible fracture is found on the hierarchical surface. The frost is detached as a whole from the

\footnotetext{
${ }^{14}$ The hierarchical surface with nano-grassed micro-truncated cone architecture was fabricated using a combined anisotropic wet-etching and deep reactive ion etching process.
} 
sample plate during the defrost stage. The properties of frost on hierarchical surfaces show repeatability during many frost and defrost cycles.

Condensate water is retained on the plate surface under defrost conditions. The number of drops and their distribution varies with surface wettability [49-55]. Min and Webb [50] investigate the condensate formation and drainage on the vertical surfaces with different wettability. Substrates are aluminum fin stock, copper fin stock, a coated hydrophilic surface on aluminum, and a coated organic polymer surface on aluminum. Aluminum and copper substrates are treated by acetone cleaning, grinding, and oil contamination separately. The experiments are performed under the air relative humidity of $80 \%$ to $90 \%$ and ambient air velocity of $3 \mathrm{~m} / \mathrm{s}$. Surface grinding increases the advancing angle and decreases the receding contact angle. The hysteresis is caused by surface heterogeneity, surface roughness and impurities on surface. On the aluminum surface, condensate droplets nucleate at the pits and other imperfections and grow rapidly by vapor condensation and coalescence. After $20 \mathrm{~min}$, an aluminum surface treated by grinding shows no condensate droplets because condensate forms a sheet film. Droplets stand up on a large area of both the aluminum surface and the surface with acetone cleaning. Condensate retention is related to the receding contact angle. Results show that condensate retention increases with the increase of the receding contact angle within $40^{\circ}$ because the droplets stand up more. However, as the receding contact angle ranges from $40^{\circ}$ to $90^{\circ}$, condensate retention decreases with the increase of the receding contact angle because the surface tension retaining force in vertical direction decreases sharply and size of the droplets decreases. Filmwise condensate forms on the surface with low receding contact angle while dropwise condensate forms on the surface with high receding contact angle regardless of the advancing contact angle. The height-to-base diameter ratio of the droplets increases with the increasing receding contact angle. When the receding contact angle is very small, condensate fully wets the surface.

EI Sherbini and Jacobi [52] propose a model to predict the amount of condensate retained on plain-fin heat exchangers. The maximum diameter of a retained drop is obtained from the balance between gravitational force and surface tension. The total volume of the drops is obtained by integrating all drop diameters. The prediction of the model agrees well with the measurements by other researchers of the mass of the 
condensate retained on heat exchangers. Application of the model is restricted to advancing contact angles from $45^{\circ}$ to $120^{\circ}$. Microgrooves and surface roughness are found to affect the meltwater retention. Rahman and Jacobi [55] reveal that microgrooved surfaces drain up to $70 \%$ more condensate than a flat surface. During the defrost process, the shape and distribution of the water droplets appear to be random on the plain surface and form parallel streams on the micro-grooved surfaces. Effects of defrost heating rate on the frost surface temperature are investigated. Mass concentration is lower on the micro-grooved surfaces than on the plain surface.

\subsubsection{Defrost models}

Defrost can be accomplished using electric resistance heating, hot gas or warm water. Many researchers have investigated defrost models to predict performance during the defrost process [56-66]. Defrost on plain surfaces is modeled in the current literature. None of the defrost models includes the effect of surface wettability on the defrost process.

Sanders [56] presents two models of defrosting process. The first model simulates the hot gas defrosting with constant heat flux, while the second model uses constant defrosting medium temperature to model an electrical defrosting process. Experimental results show that defrosting time for the model with constant heat flux is larger than that with constant defrosting medium temperature, so the defrosting efficiency is lower. The model suggests that thick frost layers have enhanced the possibility of occurrence of air gaps. A longer period of defrosting time would be expected while the defrost efficiency might be improved.

Krakow et al. [57,58] build an idealized model of reversed-cycle hot gas defrosting. The transient defrost cycle in reality is simplified using a quasi-steady-state cycle. When operating at defrost mode, a cold side heat exchanger works as a condenser, and a hot side heat exchanger works as an evaporator. In the defrost model, superheated refrigerant passes through the coil. Experiments show that the surface is not at a uniform condition at a given time. They divide the defrost process into four stages: preheating, melting, vaporizing, and dry heating. The observations show that the frost begins to melt at the refrigerant inlet. The surface conditions are not uniform and might be frosted, slushy, wet or dry at a given time. Part of the resulting water is drained from the surface while the remaining stays as surface water. A glycol-cooled, electrically defrosted coil 
is used to obtain a uniform condition. In the model, the frost layer is assumed to be a porous medium composed of ice crystals and air. A film of water and entrapped air will form between coil surface and frost layer, and the thickness will increase as defrosting process proceeds. Part of the water will remain due to viscosity, and part will drain due to gravity. During the defrost process, some factors could be indeterminable, such as the initial distribution of the frost, the effect on heat transfer of drained water, and the freeconvection heat transfer. This complexity requires an idealized model. The defrost process is modeled by a number of continuous steady state where the time variation is modeled by a large number of successive time intervals. The defrost process is considered as a time-independent steady flow for each time interval. Heat and mass transfer are analyzed for the air-side and refrigerant-side. The refrigerant film conductance is evaluated from correlations. Other heat and mass transfer parameters, including maximum surface water, free-convection air film conductance, air/water film conductance, and surface water vaporization are obtained experimentally.

Sherif et al. [59] present a defrost model for a cylindrical coil cooler using electric defrosting method. In the model, total energy released from the electrical heat equals the heat conducted into the melted frost layer and the heat entering into refrigerant vapor. The melt is assumed to continuously drain away from the coil surface. A lumped system analysis for the refrigerant is adopted. Frost-air interface temperature and frost thickness are computed as function of time. The point marking the end of defrosting process is $0{ }^{\circ} \mathrm{C}$ corresponding closely to zero-frost thickness. The model has limited application due to the restrictions by the assumptions. It assumes that thermal energy transferred into frost is an arbitrary value. Thermal resistance of refrigerant-coil surface boundary layer and coil thermal resistance are negligible.

Parasitic energy loads are generated during the defrost process. Hoffenbecker et al. [62] develop a transient model to predict defrost time and efficiency. A unique contribution of the model is to estimate the parasitic energy associated with thermal convection, moisture re-evaporation, and extraction of the stored energy in the coil. Heat and mass transfer mechanisms during the defrost process include condensation of highpressure high temperature gaseous refrigerant inside tubes, heat conduction through coil tubes and fins, sensible heating of accumulated frost, latent melting of accumulated frost, 
and re-evaporation of moisture from coil surface to surrounding. A finite difference approach is implemented, and an implicit time integration scheme is applied. One difficulty is the effect of phase change on the continuity of the computational domain. Instead of solving a moving boundary domain, the model approximates the effects of frost melting by assuming mass and volume at each node are constant. When ice melts, water drains, and the volume formally occupied by water is replaced by air. The model overestimates the mass-specific heat product, but the simulation is supported by comparisons with experimental results and the results of other studies. Experimental information is obtained from a fruit product storage freezer. The defrost time agrees with the predicted value. Only $43.7 \%$ of total energy input is used for melting the frost. Results show that the initial rate of energy input is high and decreases with time. The model predicts that the mass of moisture re-evaporated back to the refrigerated space increases with decreasing hot gas temperature due to prolonged defrost dwell time. Parasitic energy impacts could be minimized by limiting defrost dwell time. The model suggests that an optimum hot gas temperature is a function of both accumulated mass and density of frost.

Dopazo et al. [63] model the defrost process with six stages: preheating, tube frost melting start, fin frost melting start, air presence, tube-fin water film and dry-heating. Assumptions include: refrigerant liquid and vapor phase are in thermodynamic equilibrium, constant thermal properties of the refrigerant and the tube wall, and insignificant heat transfer in axial direction. Heat and mass transfer and energy equation were analyzed. Convective heat transfer coefficients, condensation heat transfer coefficient, free convection coefficient, convective mass transfer coefficient are obtained from current correlations. A finite difference method is used to find the defrost time and energy distribution during defrost process as well as temperature distribution on tube, fin and frost. The simulation results agree with the experimental results regarding to the defrost time and the energy used to melt the frost. The influence of mass flow rate and inlet temperature on defrost time, and energy delivered by the refrigerant is also studied in the model. Experiments show that defrost time and energy supplied by the refrigerant increases with the decreasing mass flow rate. 
An experimental study of the reverse cycle defrosting performance of a multicircuit outdoor coil ${ }^{15}$ on a $6.5 \mathrm{~kW}$ air source heat pump is reported by Qu et al. [64]. The outdoor coil includes four refrigerant circuits on a single tube. An environmental chamber with separate air conditioning system is provided to control the temperature and humidity. The experimental temperature of outdoor ambient is $0.5{ }^{\circ} \mathrm{C}$, and the relative humidity is $90 \%$. After $2 \mathrm{~h}$ of frosting, reverse cycle defrosting starts. Results show that no solid frost left after $7.5 \mathrm{~min}$ into defrosting. Frost melting on the upper level coil is quicker than that on the lower surface of outdoor coil. Surface temperature on the upper level circuit is larger than that on the lower level. A noticeable phenomenon is that melted frost flows downwards by gravity from high level along coil surface of lower circuit. The moving frost column causes a negative effect on the defrosting efficiency. As melted frost temperature is significantly lower than coil surface temperature, part of the heat is taken away by the moving frost column, which results in the increase of water temperature in the collecting pan. The moving frost column also brings greater thermal load to the lower level circuits. Total heat input increases with the delayed termination time, which is determined by the surface temperature of the lowest level circuit. Thus defrosting efficiency is reduced due to the effect of the melted frost flowing. Qu et al. [65] also propose an analytical model to compare with the experimental results. The defrosting process is divided into three stages: frost melting without water flow, frost melting with water flow and water layer vaporization. The melted frost is held to the surface at first due to surface tension until the mass of the melted frost held reaches the maximum point and then flows downwards due to gravity. The four-circuit outdoor coil surface is divided into four control volumes, and the lumped parameter modeling is applied. The mass flow rate of refrigerant is assumed to be evenly distributed into the four refrigerant circuits. The water layer is considered to be in the laminar regime due to the very small velocity observed from the experiments. The contact area between the melted frost and the frost layer increases with flowing water. The flow resistance increases downwards, and the velocity of water layer decreases from the top circuit to the bottom one. Prediction of the defrost duration and temperature variation of the collected

\footnotetext{
${ }^{15}$ Coil refers to low temperature heat exchanger surfaces.
} 
melted frost agrees well with the experimental results. Mass flow of the melted frost increases while the frost melting rate decreases from the top circuit to the bottom circuit.

Mohs [66] proposes a defrosting model including vapor diffusion. The defrost process is divided into the vapor diffusion sub-model, permeation sub-model and dry out sub-model. The initial frost is composed of ice crystals and air pockets. The porosity could be constant or variable. The water vapor pressure within air pockets is assumed to be at the saturation pressure of the local frost temperature. During first stage, water molecules diffuse from the ice surface, through the frost layer, and escape into the surrounding air due to the increasing vapor pressure. Thus, latent heat and sensible heat is lost to the surrounding air. In the second stage, permeation, the composite of a layer of meltwater and ice is formed. Meltwater is absorbed into frost layer by capillary forces. Within the permeation layer, the water content varies from completely water near the surface to no water further into the frost layer. Two fronts may be expected. The permeation layer is moving from the surface, while the air/frost front is moving toward the surface. After the second stage, a small portion of liquid will adhere to the surface through surface tension. Defrost efficiency during the evaporation process is very low because most of the supplied heat are lost into the ambient air. The amount of retained liquid mass on the surface will be a function of inclination angle and surface wettability. The model includes a vaporization phase at the beginning of the defrost process and can be used to estimate defrost rate and efficiency.

\subsubsection{Ice adhesion}

Ice adhesion attaches the frost column to the solid surface, varying with temperature and surface wettability. However, bulk movement of the frost column is possible during the defrost process. Movement is determined by a force balance analysis.

Raraty and Tabor [67] investigated the adhesion of ice to various solids. The interfacial strength of ice to metals is higher than the strength of ice. Adhesion experiments show that the primary factor causing failure is the rate of strain at the interface instead of the amount of strain. When tensile stress is high, the failure is brittle, and the breaking stress is temperature independent. If the tensile stress is below a critical limit, the failure is ductile, and the breaking stress increases linearly as the temperature is reduced below $0{ }^{\circ} \mathrm{C}$. Ductile failure appears to be determined by the onset of a critical 
creep rate. Ice adhesion is reduced by a large factor with surface contaminants on metals. This is caused by the reduction of contact area over which strong metal/ice adhesion occurs. The interfacial strength of ice on polymeric materials is lower than the strength of ice, thus failure occurs at the interface. Shear strength of the solid/ice interface is studied with polymers sliding on ice. The study shows that ice layers may be removed more easily if brittle fracture can be achieved. Constraints of ice inhibit brittle fracture. Hydrophobic materials show a very low adhesion.

Jellinek [68] studies the adhesive strength of ice by shear experiments. Experiments show that snow-ice/stainless steel yields adhesive breaks to a temperature of about $-13^{\circ} \mathrm{C}$, where a sharp transition to cohesive breaks take place. Ice on polystyrene yields pure adhesive breaks on shear. The adhesive strength is found to be a function of temperature. Marked difference is found in the behavior of the ice disks in tension and in shear. The experimental results are explained by a liquid-like layer assumption between ice and the solid surface. The thickness and consistency of the liquid-like layer are functions of temperature and the nature of the solid surface.

Ryzhkin and Petrenko [69] present an electrostatic model of ice adhesion. When distances are greater than one intermolecular distance, the model gives an order of magnitude for the adhesive energy, which is significantly greater than both chemical bonding energy and van der Waals forces.

Makkonen [70] presents concepts and models to estimate ice adhesion. The material deformations affect adhesion strength, which is explained by an indirect effect arising from the brittle-ductile nature of ice. The ice interface behaves as a ductile material with little tendency to fracture even at high strain rates when the substrate material is either highly elastic or the ice is close to its melting temperature. On a rigid substrate or cold surface, however, mechanical removal of ice occurs in a brittle manner. Interface morphology and crystal structure of ice have effects on adhesion strength. When the interface includes micropores that are filled with water, the true interface area is large. In such case, a pure adhesion-failure might not be possible, and fracture occurs partly due to cohesion-failure within the ice. The effects of temperature and substrate materials on ice adhesion are discussed. A liquid film at the solid-ice interface is expected to reduce adhesive strength. The thicker the liquid film, the lower the adhesion is 
expected. Qualitatively, the adhesion strength of ice increases with decreasing temperature down to the temperature at which the liquid film disappears.

Chen et al. [71] present a study on ice adhesion on surfaces with different wettability. Experimental results show that a superhydrophobic surface cannot reduce the ice adhesion, and ice adhesion strength on the superhydrophilic surface is almost the same as that on the superhydrophobic surface. This phenomenon is explained by the mechanical interlocking between ice and the surface texture. Meuler et al. [72] present a relationship between water wettability and ice adhesion. Twenty-two surfaces with different advancing/receding contact angles are tested. The strengths of ice adhesion are measured on bare steel discs. A liquid-like interface between ice and a substrate could facilitate lateral sliding prior to detachment of the ice column. The interactions of the substrate with liquid water are scaled with respect to liquid drop roll-off angle, equilibrium work of adhesion and practical work of adhesion. A strong correlation is found between the ice adhesion and the practical work of adhesion.

The instability of an ultra-thin water film on a hydrophilic surface is investigated by Majumdar and Mezic, who propose a new theory of droplet formation during condensation [73]. The theory uses hydration, electrostatic force and van der Waals force between a hydrophilic solid surface and a water film. Hydration force dominates for films thinner than $\sim 3 \mathrm{~nm}$. At $300 \mathrm{~K}$, the equilibrium film thickness is found to be almost constant at $0.5 \mathrm{~nm}$ for a wide range of relative humidity and increases sharply when the relative humidity approaches to unity. The theory shows that the competition of strain energy with hydration, van der Waals force, and liquid-vapor surface tension induces the instability for films thicker than a critical value.

\subsection{Summary}

A wide range of studies have been conducted on frost formation and the defrost process. The effect of surface wettability has attracted a lot of interests for decades. The study on the effect of surface wettability has been focused mainly on frost formation. For the defrost process, the study is focused on the relationship between retention droplets and water contact angles of substrates. There are a few papers in the literature that present the influence of contact angle on defrost time and efficiency. The study on frost removal attracts the interests of researchers with the findings of surface characteristics. The rigid 
superhydrophobic surface might be able to facilitate the defrost process by reducing the evaporation time of water retention, and defrost efficiency could improve accordingly. 


\section{Model Development and Mathematical Formulation}

\subsection{Melting model}

The defrost process includes the preheating of the test surface, the melting of the frost layer, and the vaporization of the retention water. The melting behavior has been widely studied in cold region science and water resources research. The complexity lies in that the permeation process of the meltwater is not easy to define. The permeation rate depends on the structure of the porous medium (i.e., frost), surface tension, capillary pressure, and water saturation ${ }^{16}$.

When the frost column is heated, the meltwater is either absorbed into the frost layer or drains. To fully investigate the process, a melting model is developed to formulate the physical behaviors of the meltwater. The melting model includes three stages: absorption, accumulation, and drainage. Melting begins with the absorption where meltwater is absorbed into the frost layer by capillary pressure. Mass transfer of the meltwater into the frost layer depends on surface tension, fluid viscosity, grain size, porosity and capillary pressure. When the frost layer becomes saturated with meltwater, accumulation occurs wherein a thin water film accumulates between the solid surface and the permeation layer. The water film is balanced by gravity, surface tension and shear force. With the growth of water film, meltwater drains by gravity.

The composition of the frost layer varies with the stages of the melting process. When the permeation rate of meltwater is greater than the melting rate, all the meltwater is absorbed into the frost layer during the absorption stage. The mass composition consists of a permeation and frost layer. The meltwater accumulates between the surface and the permeation layer when the frost layer is saturated. The mass composition includes a thin water film and the permeation layer. A summary of the mass composition is listed in Table 3.1.

The melting process is closely related to surface wettability. In the absorption stage, the permeation rate is determined by the structure of the porous medium, which is

\footnotetext{
${ }^{16}$ Water saturation is the volume fraction of water to the pore volume.
} 
Table 3.1. Mass composition during melting process.

\begin{tabular}{|c|c|c|c|c|}
\hline Melting process & $\begin{array}{c}\text { Water film } \\
\text { without } \\
\text { draining }\end{array}$ & $\begin{array}{c}\text { Water film } \\
\text { with } \\
\text { draining }\end{array}$ & $\begin{array}{c}\text { Permeation } \\
\text { layer }\end{array}$ & Frost layer \\
\hline I Absorption & & & & \\
\hline II Accumulation & & & & \\
\hline III Drainage & & & & \\
\hline
\end{tabular}

a function of surface wettability in the frost formation period. The effect of surface wettability in the accumulation stage lies in that the maximum thickness of the thin water film depends on the surface tension acting on the perimeter of the frost column, and the surface tension is related to surface wettability. When the meltwater drains by gravity, the average volumetric flow rate depends on the velocity boundary conditions at the solid/water interface and the water/permeation interface. A slip boundary condition for velocity applies at the solid/water interface for hydrophobic surface.

\subsection{Mathematical formulation of the melting stages}

The melting process is formulated to find the key variables in each stage. In the absorption stage, the permeation layer is a mixture of ice crystals, water and air. The rate of meltwater permeation is expressed in the mass continuity of the water saturation. In the accumulation stage, the maximum water thickness is expressed by a static force analysis on the water film. The growth of the water film depends on the energy transferred into the permeation layer. In the drainage stage, the draining velocity is expressed by the momentum equation of the draining water.

The initial mass of the frost layer comprises ice crystals and air. At the beginning of the melting process, the temperature across the frost layer is assumed to be uniform. Heat transfer is assumed to be one-dimensional and normal to the test surface. A general diagram of the frost layer structure is shown in Fig. 3.1. The initial frost thickness is $\delta_{\mathrm{f}}$. The direction along the surface is $\mathrm{x}$, and the direction normal to the surface is $\mathrm{y}$. A special condition considered here is where the slope angle $\varphi$ is $90^{\circ}$, and the surface is placed vertically.

\subsubsection{Absorption}

Absorption of meltwater occurs at the beginning of the melting process. The assumptions for the absorption process include: (1) The permeation rate is greater than the melting rate of the frost layer, and all meltwater is absorbed into the frost layer. (2) 


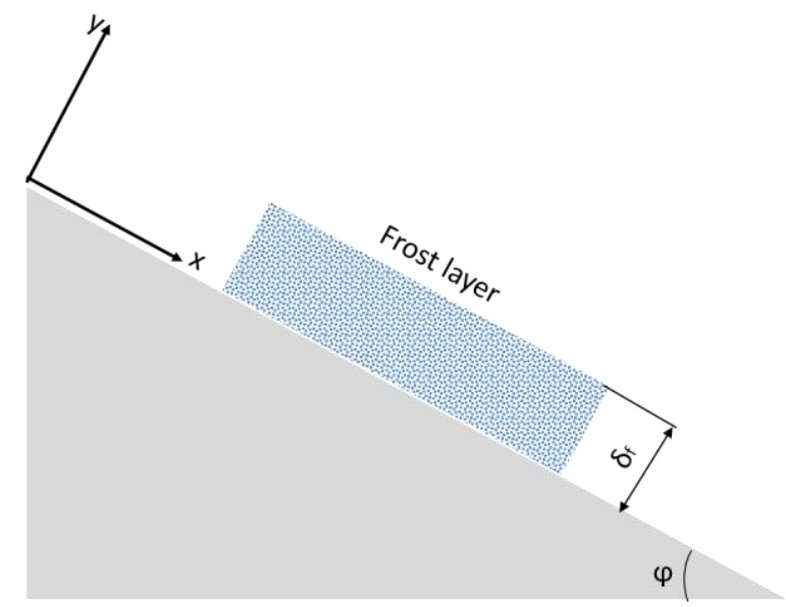

Figure 3.1. A general illustration of the initial frost column.

The frost layer is treated as rigid porous medium. (3) Temperature in the permeation layer maintains the melting temperature. (4) Capillary pressure varies with the water saturation. (5) The water saturation equals unity at the solid/permeation interface and zero at the permeation/frost interface.

In the absorption stage, the bulk mass consists of the permeation layer and the frost layer. A control volume (CV) analysis is applied to formulate the mass and heat transfer equations in the permeation and frost layers. A CV is selected in the permeation layer for the mass balance analysis as shown in Fig. 3.2.

The mass of water in the $\mathrm{CV}$ is written as a function of the water saturation $\mathrm{S}$,

$$
\mathrm{m}_{\mathrm{w}}=\varepsilon \rho_{\mathrm{w}} \mathrm{SA} \mathrm{t}_{\mathrm{ts}} \mathrm{dy} .
$$

The mass balance of water in the permeation layer is,

$$
\varepsilon \rho_{\mathrm{w}} \frac{\partial \mathrm{S}}{\partial \mathrm{t}}=-\frac{\partial \mathrm{m}_{\mathrm{w}, \mathrm{p}}^{\prime \prime}}{\partial \mathrm{y}}-\varepsilon \rho_{\mathrm{w}} \mathrm{v}_{\mathrm{f}} \frac{\partial \mathrm{S}}{\partial \mathrm{y}},
$$

where the 1.h.s. represents the rate of change of water mass in the $\mathrm{CV}$, the first term on the r.h.s. represents the net mass transfer into the $\mathrm{CV}$ by water permeation, and the second term represents mass transport due to the motion of the bulk mass. 


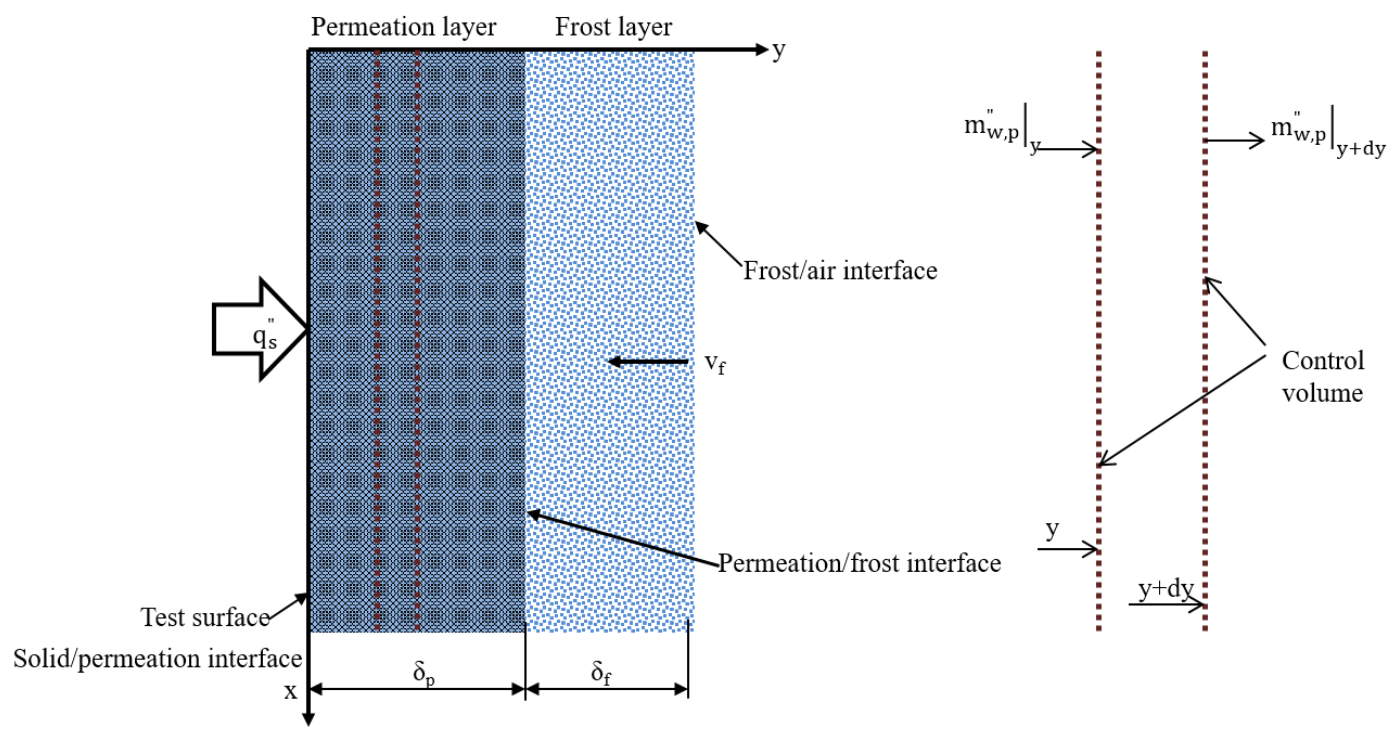

Figure 3.2. $\mathrm{CV}$ in the permeation layer during absorption.

The melting velocity depends on the heat flux applied at the test surface, the density of the frost layer and the latent heat of fusion $\mathrm{L}_{\mathrm{f}}$,

$$
v_{f}=-\frac{q_{s}^{\prime \prime}}{L_{f} \rho_{f}}
$$

where

$$
\rho_{\mathrm{f}} \approx(1-\varepsilon) \rho_{\mathrm{i}}
$$

The minus sign indicates that the direction of the movement is toward the test surface. The permeation layer is a mixture of air, water and ice crystals. At the test plate surface, the permeation layer is composed of meltwater and ice crystals and is maintained at the melting temperature, thus only the latent heat is considered.

The water permeation flux, $\mathrm{m}_{\mathrm{w}, \mathrm{p}}$, equals $\rho_{\mathrm{w}} \mathrm{V}_{\mathrm{w}}$, where $\mathrm{v}_{\mathrm{w}}$ is the volume flux of water. Eqn. (3.2) becomes,

$$
\varepsilon \frac{\partial S}{\partial t}=-\frac{\partial v_{w}}{\partial y}-\varepsilon v_{f} \frac{\partial S}{\partial y}
$$


The volume flux of water is given by Darcy's law,

$$
\mathrm{v}_{\mathrm{w}}=\frac{\mathrm{K}_{\mathrm{w}}}{\mu_{\mathrm{w}}} \frac{\partial \mathrm{P}_{\mathrm{ca}}}{\partial \mathrm{y}}
$$

The water flow is driven by the gradient of the capillary pressure. Literature [74-89] is reviewed to understand the water permeation in a porous medium. The review covers the capillary pressure of water transport, water percolation in snowpack and flow in porous media in the areas of water resource and cold region science. In a porous medium, the water volume flux depends on the capillary pressure, fluid viscosity, surface tension, and structure of the medium. Capillary pressure is a function of the water saturation. The structural description of the porous medium includes grain size, tortuosity and the porosity. The rate of liquid penetration in a porous body may be modeled as a number of cylindrical capillary tubes with varying radii. The rate of liquid penetration is proportional to the square root of time and to the square root of the ratio of the surface tension to gravity. Aoki et al. [74] present a model describing the melting process of a snow layer when heat is supplied at the bottom. The study shows that the melt time and the melting efficiency are affected by water permeation. The calculated melting efficiency is higher when neglecting water permeation. An empirical correlation is applied to represent the water permeation rate, which relates to the capillary suction pressure and the porous structure. An empirical correlation for the dimensionless capillary pressure is given as,

$$
\mathrm{P}^{+}(\mathrm{S})=\frac{\mathrm{P}}{\gamma} \frac{\varepsilon}{(1-\varepsilon)} \frac{\mathrm{D}}{6}=1.6 \mathrm{e}^{-0.46 \mathrm{~S}}-\mathrm{e}^{20(\mathrm{~S}-1)} .
$$

In water resources research, the theory of water transport in melting snow attracts many interests. Colbeck [75-78] presents the capillary effects on water percolation and investigates the relation of capillary pressure to the water saturation. In Colbeck's model, gravity is the driving force for water flow. Capillarity accounts for less than $10 \%$ of the total forces when the water volume flux is $10^{-8} \mathrm{~m} / \mathrm{s}$. The relationship between capillary 
pressure and water saturation depends on a number of parameters including contact angle, interfacial tension, particle shape and pore-size distribution.

A typical expression relating effective permeability and the capillary pressure is by a power law, where the permeability $\mathrm{K}_{\mathrm{w}}$ and capillary pressure $\mathrm{P}_{\mathrm{ca}}$ are assumed to be functions of the water saturation, $\mathrm{S}$, and are given as [81],

$$
\mathrm{K}_{\mathrm{w}}=\mathrm{K}_{\mathrm{w}}(\mathrm{S})=\mathrm{KS}^{\mathrm{p}}, \quad \mathrm{P}_{\mathrm{ca}}=\mathrm{P}_{\mathrm{ca}}(\mathrm{S})=\mathrm{CS}^{-\mathrm{q}},
$$

where $\mathrm{K}, \mathrm{C}, \mathrm{p}, \mathrm{q}$ are constants, $\mathrm{S}$ is water saturation, $\mathrm{K}$ is the intrinsic permeability (a function of the geometry of the porous medium), and $\mathrm{C}$ is the entry capillary pressure. The exponent $\mathrm{q}$ is related to the pore-size distribution.

The volume flux of water thus becomes,

$$
\mathrm{v}_{\mathrm{w}}=-\frac{\mathrm{KCq}}{\mu_{\mathrm{w}}} \mathrm{S}^{\mathrm{p}-\mathrm{q}-1} \frac{\partial \mathrm{S}}{\partial \mathrm{y}}
$$

Substituting Eqn. (3.9) into Eqn. (3.5), the mass balance of water becomes,

$$
\varepsilon \frac{\partial S}{\partial t}=\frac{K C q}{\mu_{w}}\left[(p-q-1) S^{p-q-2}\left(\frac{\partial S}{\partial y}\right)^{2}+S^{p-q-1} \frac{\partial^{2} S}{\partial y^{2}}\right]-\varepsilon v_{f} \frac{\partial S}{\partial y}
$$

Within the permeation layer, water saturation decreases from the solid/water interface to the permeation front. Water content at the solid/permeation interface and at the permeation/frost interface are assumed as,

$$
\begin{array}{ll}
\mathrm{y}=0, & \mathrm{~S}=1 . \\
\mathrm{y}=\delta_{\mathrm{p}}, & \mathrm{S}=0 .
\end{array}
$$

The initial condition is, 


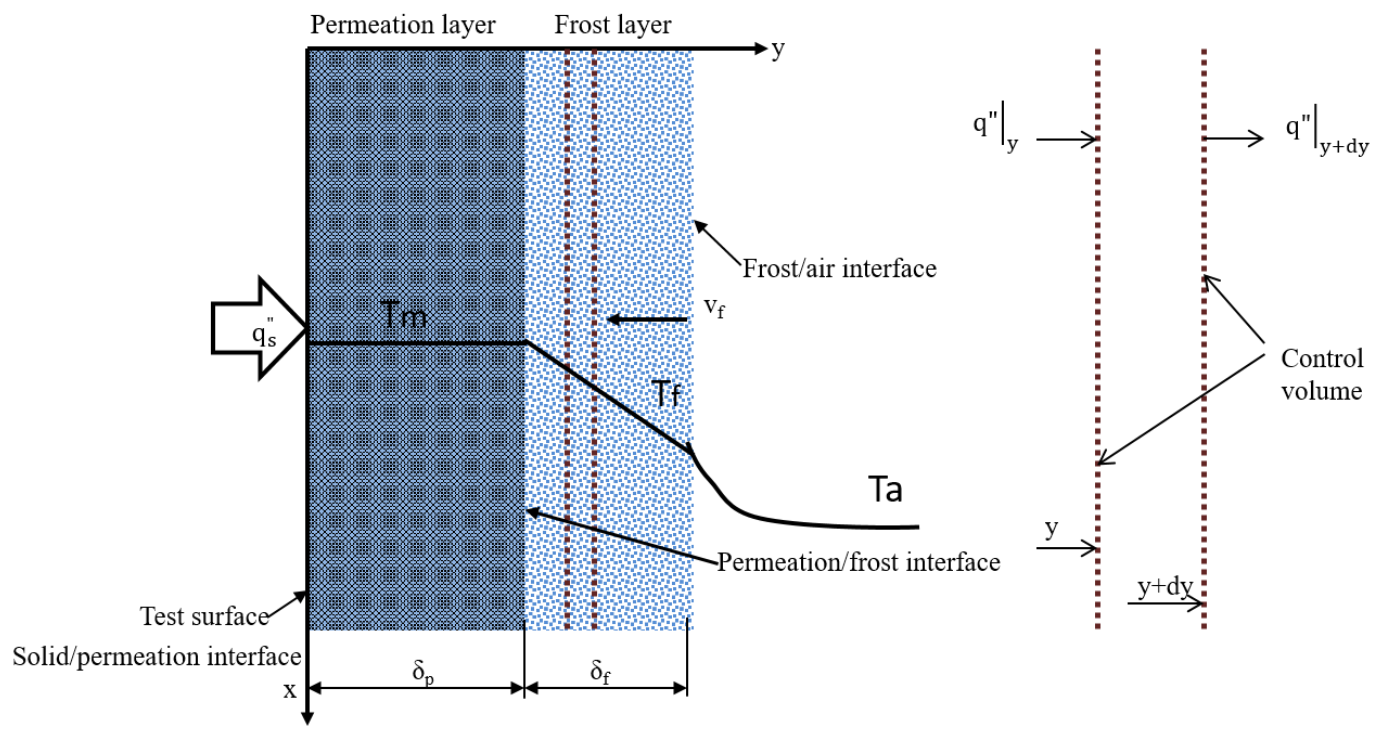

Figure 3.3. CV in frost layer during the absorption.

$$
\mathrm{t}=0, \quad \mathrm{~S}=0 .
$$

The temperature of the permeation layer is assumed to be constant at the melting temperature. A CV is selected in the frost layer for the energy analysis, as shown in Fig. 3.3. The energy balance for the frost layer is assumed to be one-dimensional,

$$
\left(\rho c_{p}\right)_{f} \frac{\partial T_{f}}{\partial t}=\frac{\partial}{\partial y}\left(k_{f} \frac{\partial T_{f}}{\partial y}\right)-\left(\rho c_{p}\right)_{f} v_{f} \frac{\partial T_{f}}{\partial y}
$$

The 1.h.s. represents the time rate of change of energy in the CV. The first term on the r.h.s. represents heat transfer by conduction, and the second term on the r.h.s. represents the energy transport due to bulk motion. The boundary conditions at the solid-permeation interface, permeation-frost interface, and frost-air interface are,

$$
\begin{array}{ll}
\mathrm{y}=0, & \mathrm{q}^{\prime \prime}=\mathrm{q}_{\mathrm{s}}^{\prime \prime}, \\
\mathrm{y}=\delta_{\mathrm{p}}, & \mathrm{T}_{\mathrm{f}}=\mathrm{T}_{\mathrm{m}},
\end{array}
$$




$$
\begin{aligned}
& \mathrm{y}=\delta_{\mathrm{p}+\mathrm{f}}, \quad-\mathrm{k}_{\mathrm{f}} \frac{\partial \mathrm{T}_{\mathrm{f}}}{\partial \mathrm{y}}=\mathrm{h}_{\mathrm{a}}\left(\mathrm{T}_{\mathrm{f}}-\mathrm{T}_{\mathrm{a}}\right), \\
& \mathrm{t}=0, \quad \mathrm{~T}_{\mathrm{f}}=\mathrm{T}_{\mathrm{m}} .
\end{aligned}
$$

\subsubsection{Accumulation}

When the frost layer is saturated with meltwater, a water film accumulates between the solid surface and the permeation layer. The frost column then comprises a water film and permeation layer, as shown in Fig. 3.4. The growth of the water film is formulated from the energy balance analysis at the water/permeation interface.

$$
-\left.\mathrm{k}_{\mathrm{w}} \frac{\partial \mathrm{T}_{\mathrm{w}}}{\partial \mathrm{y}}\right|_{\delta_{\mathrm{w}}}=(1-\varepsilon) \rho_{\mathrm{i}} \mathrm{L}_{\mathrm{f}} \mathrm{V}_{\mathrm{y}}
$$

where $\mathrm{v}_{\mathrm{y}}$ is the velocity of the interface. The interface velocity of the permeation layer is,

$$
\mathrm{v}_{\mathrm{y}}=\frac{\mathrm{d} \delta_{\mathrm{w}}}{\mathrm{dt}}
$$

Substituting Eqn. (3.15) into Eqn. (3.14), the energy equation at the water/permeation interface becomes,

$$
-\left.\mathrm{k}_{\mathrm{w}} \frac{\partial \mathrm{T}_{\mathrm{w}}}{\partial \mathrm{y}}\right|_{\delta_{\mathrm{w}}}=(1-\varepsilon) \rho_{\mathrm{i}} \mathrm{L}_{\mathrm{f}} \frac{\mathrm{d} \delta_{\mathrm{w}}}{\mathrm{dt}}
$$

The energy balance in the water film is,

$$
\left(\rho c_{p}\right)_{w} \frac{\partial \mathrm{T}_{\mathrm{w}}}{\partial \mathrm{t}}=\frac{\partial}{\partial \mathrm{y}}\left(\mathrm{k}_{\mathrm{w}} \frac{\partial \mathrm{T}_{\mathrm{w}}}{\partial \mathrm{y}}\right)
$$




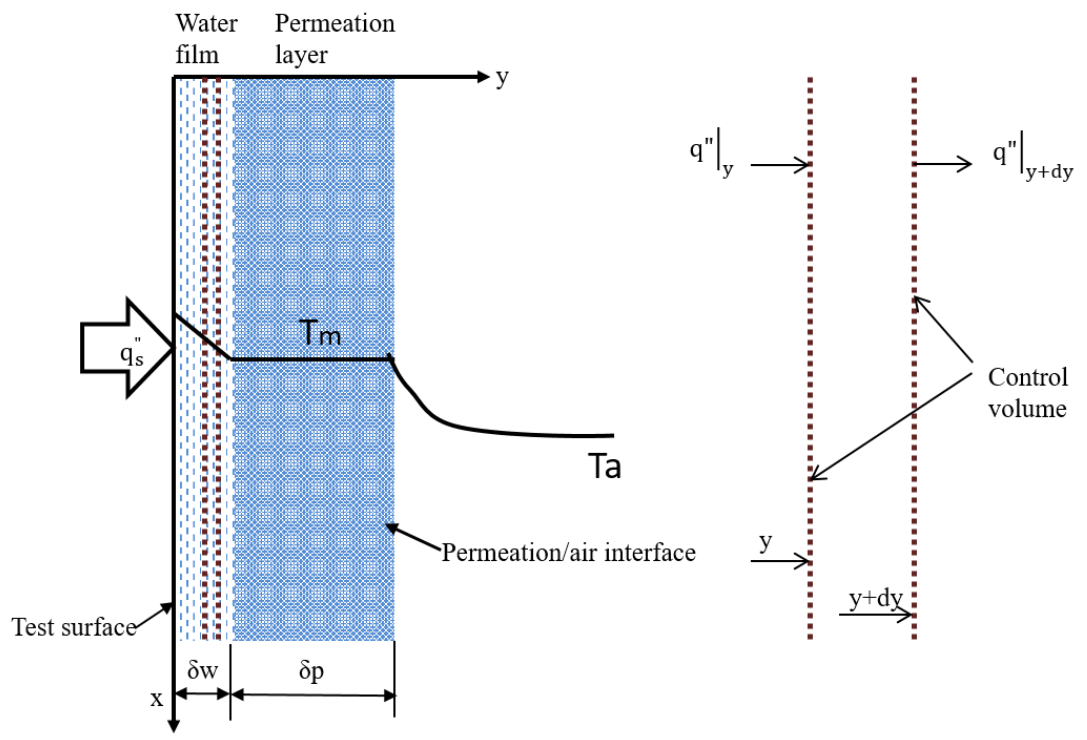

Figure 3.4. Heat and mass transfer during accumulation.

The boundary and initial conditions at the solid-water interface and the water-permeation interface are,

$$
\begin{array}{ll}
\mathrm{y}=0, & \mathrm{q}^{\prime \prime}=\mathrm{q}_{\mathrm{s}}^{\prime \prime} \\
\mathrm{y}=\delta_{\mathrm{w}}, & \mathrm{T}_{\mathrm{w}}=\mathrm{T}_{\mathrm{p}}=\mathrm{T}_{\mathrm{m}}, \\
\mathrm{t}=0, & \mathrm{~T}_{\mathrm{w}}=\mathrm{T}_{\mathrm{m}} .
\end{array}
$$

\subsubsection{Drainage}

Meltwater drains away when the frost layer is saturated and when the gravity outweighs the adhesive force at the solid/water interface. A drainage model is shown in Fig. 3.5. Assuming that the meltwater drains between the test plate and frost column, the draining velocity is determined by the boundary conditions at the interfaces.

The momentum balance in the $\mathrm{x}$-direction is,

$$
\rho_{\mathrm{w}}\left(\frac{\partial \mathrm{u}_{\mathrm{w}}}{\partial \mathrm{t}}+\mathrm{u}_{\mathrm{w}} \frac{\partial \mathrm{u}_{\mathrm{w}}}{\partial \mathrm{x}}+\mathrm{v}_{\mathrm{w}} \frac{\partial \mathrm{u}_{\mathrm{w}}}{\partial \mathrm{y}}\right)=\rho_{\mathrm{w}} \mathrm{g}_{\mathrm{x}}+\mu_{\mathrm{w}}\left(\frac{\partial^{2} \mathrm{u}_{\mathrm{w}}}{\partial \mathrm{x}^{2}}+\frac{\partial^{2} \mathrm{u}_{\mathrm{w}}}{\partial \mathrm{y}^{2}}\right)-\frac{\partial \mathrm{P}}{\partial \mathrm{x}}
$$




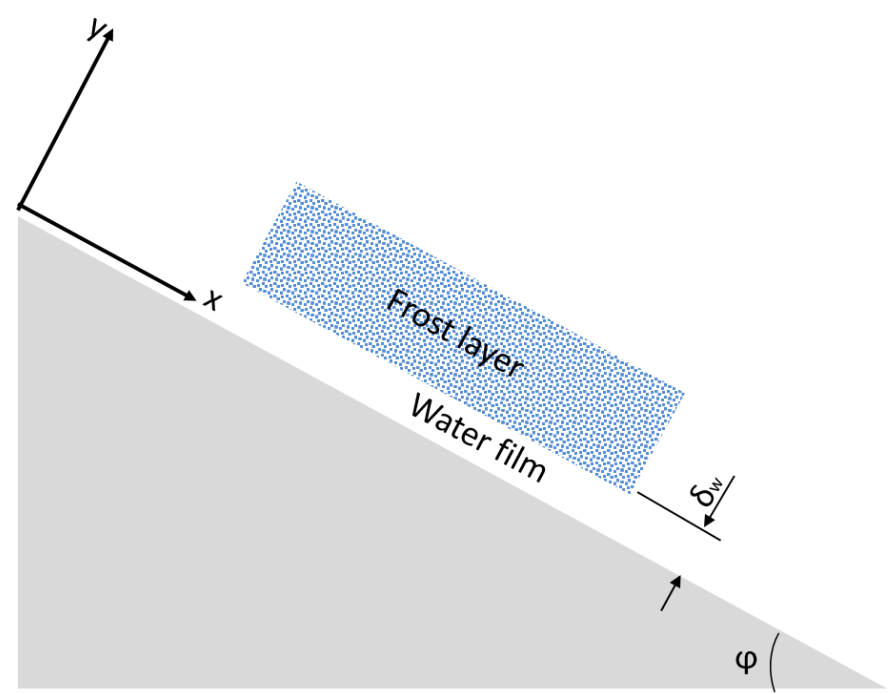

Figure 3.5. Drainage model.

The momentum balance in y-direction is,

$$
\begin{gathered}
\rho_{\mathrm{w}}\left(\frac{\partial \mathrm{v}_{\mathrm{w}}}{\partial \mathrm{t}}+\mathrm{u}_{\mathrm{w}} \frac{\partial \mathrm{v}_{\mathrm{w}}}{\partial \mathrm{x}}+\mathrm{v}_{\mathrm{w}} \frac{\partial \mathrm{v}_{\mathrm{w}}}{\partial \mathrm{y}}\right)=\rho_{\mathrm{w}} \mathrm{g}_{\mathrm{y}}+\mu_{\mathrm{w}}\left(\frac{\partial^{2} \mathrm{v}_{\mathrm{w}}}{\partial \mathrm{x}^{2}}+\frac{\partial^{2} \mathrm{v}_{\mathrm{w}}}{\partial \mathrm{y}^{2}}\right)-\frac{\partial \mathrm{P}}{\partial \mathrm{y}} \\
\mathrm{g}_{\mathrm{x}}=\operatorname{gsin} \varphi, \quad \mathrm{g}_{\mathrm{y}}=-\operatorname{gcos} \varphi
\end{gathered}
$$

Meltwater is assumed to drain along the x-direction and is only a function of $\mathrm{y}$. Eqns. (3.19), (3.20) are simplified as,

$$
\begin{aligned}
\frac{\partial \mathrm{u}_{\mathrm{w}}}{\partial \mathrm{t}}+\mathrm{v}_{\mathrm{w}} \frac{\partial \mathrm{u}_{\mathrm{w}}}{\partial \mathrm{y}} & =\mu_{\mathrm{w}} \frac{\partial^{2} \mathrm{u}_{\mathrm{w}}}{\partial \mathrm{y}^{2}}+\mathrm{g} \sin \varphi \\
\frac{\partial \mathrm{P}}{\partial \mathrm{y}} & =-\rho_{\mathrm{w}} \mathrm{g} \cos \varphi .
\end{aligned}
$$

When $\varphi=90^{\circ}$, the frost surface is vertical, and the drainage model is shown in Fig. 3.6. The energy equation is similar to that in the accumulation stage. The draining velocity varies in the y-direction and is perpendicular to the solid plate. 

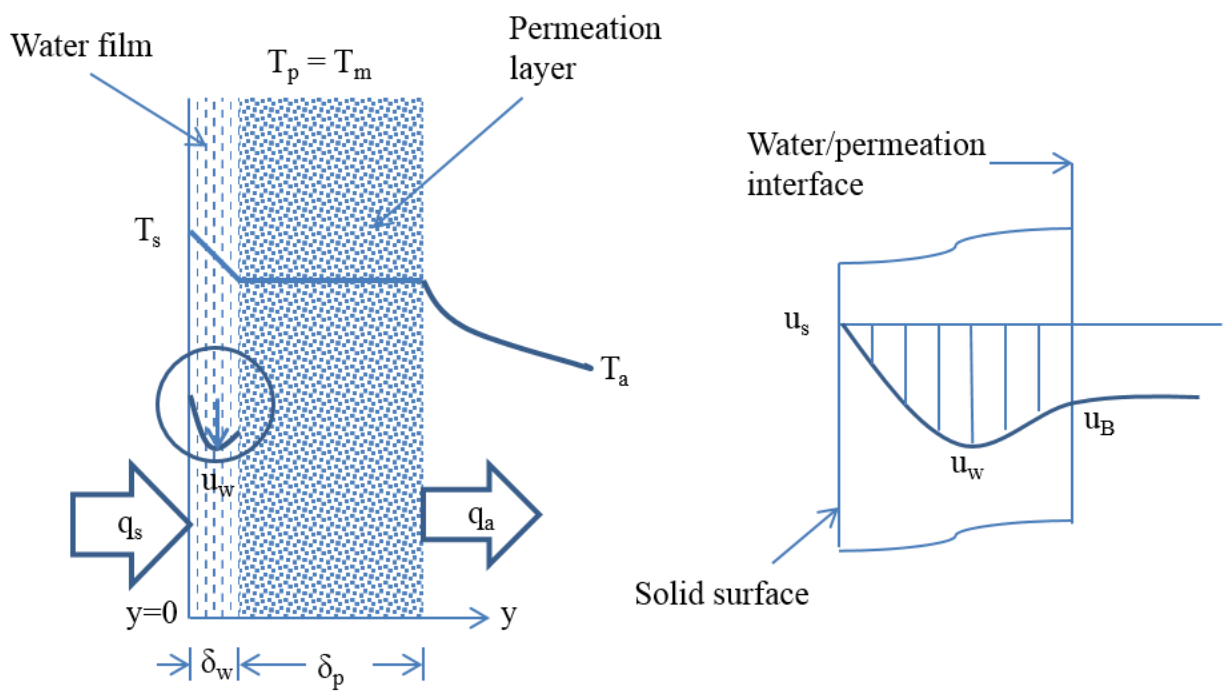

Figure 3.6. Heat and mass transfer during drainage for a vertical frost surface.

At the water/permeation interface, a slip boundary condition is applied owning to the effects of viscous shear [90-93]. Beavers and Joseph [90] present a slip velocity proportional to the shear rate at the permeable boundary for free fluid over a porous medium,

$$
y=\delta_{w}, \quad \frac{d u_{w}}{d y}=\frac{\beta}{\sqrt{K}}\left(u_{B}-\omega\right),
$$

where $\mathrm{K}$ is the permeability of the permeation layer, $\beta$ is a dimensionless parameter depending on the material which characterizes the structure of permeable material within the boundary region, $\omega$ is the filtering velocity of water in the permeation layer with a unit of $\mathrm{m} / \mathrm{s}$, and $\mathrm{u}_{\mathrm{B}}$ is the velocity at the water/permeation interface.

For viscous liquids at low Reynolds number, flow in permeable material is governed by Darcy's law. When gravity dominates the flow, $\omega$ is,

$$
\omega=\frac{\mathrm{K}}{\mu_{\mathrm{w}}} \rho_{\mathrm{w}} \mathrm{g}
$$


At the solid/water interface, boundary conditions depend on the surface wettability. For the hydrophilic surface, a no-slip boundary condition is assumed at the solid/water interface,

$$
\mathrm{y}=0, \quad \mathrm{u}_{\mathrm{w}}=0
$$

For a thin liquid film, velocity slip is present for liquid flowing over hydrophobic surfaces [94-100]. A slip velocity condition is applied to the hydrophobic surface. The slip velocity $\mathrm{u}_{\mathrm{s}}$, on the wall can be expressed as [98],

$$
\mathrm{u}_{\mathrm{s}}=\mathrm{b} \frac{\partial \mathrm{u}_{\mathrm{w}}}{\partial \mathrm{y}}
$$

where $b$ is the slip length and can be estimated as,

$$
\mathrm{b}=\delta\left(\frac{\mu_{\mathrm{b}}}{\mu_{\mathrm{s}}}-1\right)
$$

where $\delta$ is the thickness of the thin layer at the boundary, $\mu_{\mathrm{b}}$ is the bulk viscosity, and $\mu_{\mathrm{s}}$ is the average viscosity of the near-to-wall layer. Slip length is defined as an extrapolated distance relative to the wall where the tangential velocity vanishes as shown in Fig. 3.7.

The average draining velocity across the water film thickness is,

$$
\mathrm{u}_{\mathrm{avg}}=\frac{\int_{0}^{\delta_{\mathrm{w}}} \mathrm{u}_{\mathrm{w}} \mathrm{dy}}{\delta_{\mathrm{w}}}
$$

The average volumetric flow rate across the water film thickness is,

$$
\Omega=\mathrm{u}_{\mathrm{avg}} \mathrm{W} \delta_{\mathrm{w}}
$$

where $\mathrm{W}$ is the width of the test plate. 


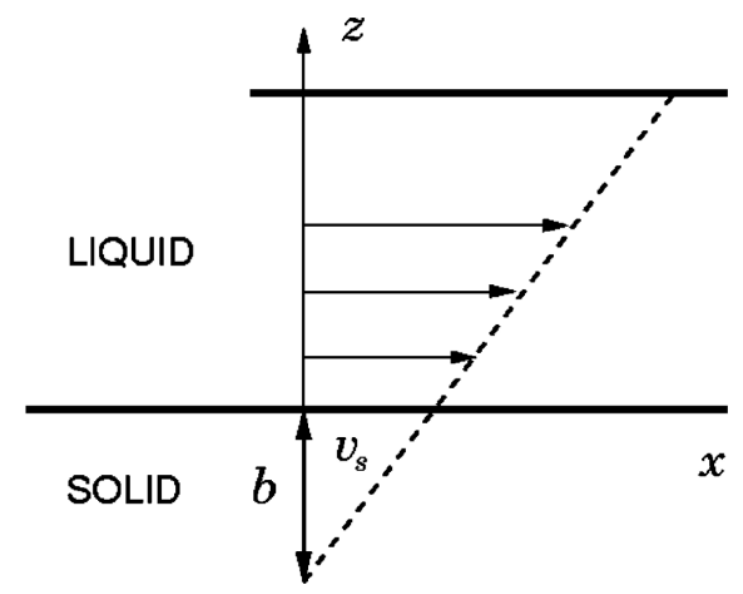

Figure 3.7. Definition of the slip length for a simple shear flow [98].

During the defrost process, defrost time and efficiency are properties used to evaluate the system effectiveness. Defrost time and efficiency depend on the system design, ambient temperature and heating methods. Defrost time includes the preheating time of the plate, the melting time of the frost column, the draining time of the meltwater and the evaporation time of the retention water. Defrost time for a lumped frost layer can be defined as,

$$
\mathrm{t}_{\mathrm{df}}=\frac{(1-\varepsilon) \rho_{\mathrm{i}} \delta_{\mathrm{f}} \mathrm{L}_{\mathrm{f}}}{\mathrm{q}_{\mathrm{s}}^{\prime \prime}-\mathrm{h}_{\mathrm{a}}\left(\mathrm{T}_{\mathrm{m}}-\mathrm{T}_{\mathrm{a}}\right)}+\frac{(1-\varepsilon) \rho_{\mathrm{i}} \delta_{\mathrm{f}} \mathrm{H}}{\rho_{\mathrm{w}} \mathrm{u}_{\mathrm{avg}} \delta_{\mathrm{w}}},
$$

where $\mathrm{H}$ is the height of the test plate. Defrost time in the definition consists of melting time of the frost column and the draining time of the meltwater.

In theoretical study, defrost efficiency can be defined as the ratio of the energy required to melt the frost to the total heat applied at the surface,

$$
\eta_{d f}=\frac{(1-\varepsilon) \rho_{i} \delta_{f}\left[L_{f}+c_{p, i} \Delta T_{f}\right]}{q_{s}^{\prime \prime} t_{d f}}
$$

From the definition, defrost efficiency is a function of the frost mass, the initial temperature of the frost layer, the heat flux applied at the test surface, and the defrost time. Defrost efficiency also varies with different melting stages. 


\subsection{Slumping criterion}

Frost slumping is a method of frost removal and is different from the traditional defrost process. During the melting period, frost might be able to peel away from the surface in a bulk movement or slump. In this case, frost falls off as a whole rigid piece. Time for water draining and evaporation could be saved, thus defrost efficiency improves. The possible criteria of frost failure are attributed to the categories as shown in Table 3.2. Unbalanced forces might cause the frost to break up into pieces or fall off from the surface during the defrost process. When subject to axial compression, the frost column on the coils might buckle and fail. At low temperature, thermal contraction or expansion might cause failure of the solid-frost interface, which is due to the different thermal expansion coefficients of the solid and the ice crystals. The frost column and the solid material may also cool at different rates when their heat capacities and thermal conductivities differ. Additional stress at the interface results from this. The significance of the added stress depends on the cooling rate. When a thin liquid film exists, the interface might be ductile, and it adjusts to the thermal expansion without fracturing.

Static force balance is applied to formulate the slumping criterion and is discussed for each of the melting stages. Frost slumping is likely to occur when the adhesive force and surface tension get weak. Water accumulation between the test surface and the frost column is a favorable condition that weakens the adhesive force. When gravity outweighs adhesive force or surface tension, the frost layer peels off from the solid surface during the melting process. The different failure mechanisms are illustrated in Fig. 3.8. with respect to hydrophilic and hydrophobic surfaces. At the beginning of melting, the force balance is determined by the competition between the gravity and adhesion force. When the frost layer is saturated with the meltwater, a thin water film develops and is subjected to gravity and shear at the interfaces. On hydrophilic surfaces, meltwater is assumed in the form of thin water film. When the water film becomes unstable, it breaks up and causes fracture in the frost column. On hydrophobic surfaces, meltwater is assumed in the form of water droplets. During melting, the adhesive force at the solid/frost interface and the cohesive force inside the frost layer might become unbalanced, which causes fracture and crack of the frost column. 
Table 3.2. Failure modes of frost layer.

\begin{tabular}{|c|c|c|c|c|}
\hline Melting periods & $\begin{array}{l}\text { Static force } \\
\text { balance }\end{array}$ & $\begin{array}{l}\text { Instability of } \\
\text { water film }\end{array}$ & $\begin{array}{l}\text { Buckling due } \\
\text { to axial } \\
\text { compression }\end{array}$ & $\begin{array}{c}\text { Thermal expansion/ } \\
\text { contraction }\end{array}$ \\
\hline Pre-melting & & $\begin{array}{l}\text { Water thickness is } \\
\text { less than } 100 \mathrm{~nm} \text {. } \\
\text { Frost column } \\
\text { might break up } \\
\text { into pieces. }\end{array}$ & & \\
\hline Absorption & $\begin{array}{l}\text { Frost column falls } \\
\text { off from the solid } \\
\text { surface. }\end{array}$ & & & \\
\hline Accumulation & $\begin{array}{l}\text { Frost column falls } \\
\text { off from the solid } \\
\text { surface. }\end{array}$ & & & \\
\hline Drainage & $\begin{array}{l}\text { Frost column falls } \\
\text { off from the solid } \\
\text { surface. }\end{array}$ & & & \\
\hline $\begin{array}{l}\text { On site coils with } \\
\text { complex geometry }\end{array}$ & & & $\begin{array}{l}\text { Frost column } \\
\text { buckles when } \\
\text { subjected to } \\
\text { compression }\end{array}$ & \\
\hline Sudden cooling & & & & $\begin{array}{l}\text { Failure at the } \\
\text { interface due to } \\
\text { different thermal } \\
\text { expansion coefficients } \\
\text { of solid and ice }\end{array}$ \\
\hline
\end{tabular}

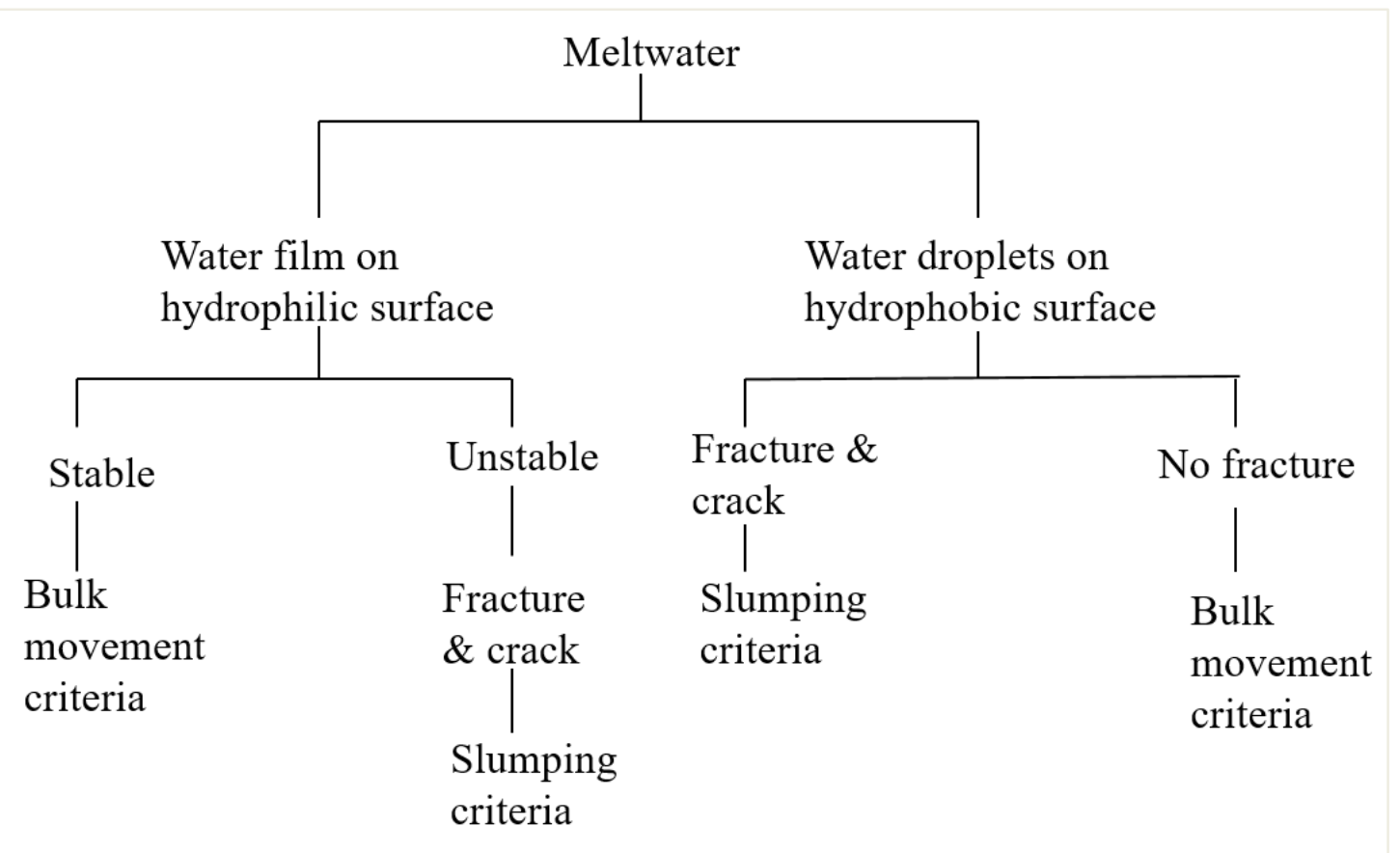

Figure 3.8. The scheme and mechanisms of frost slumping. 


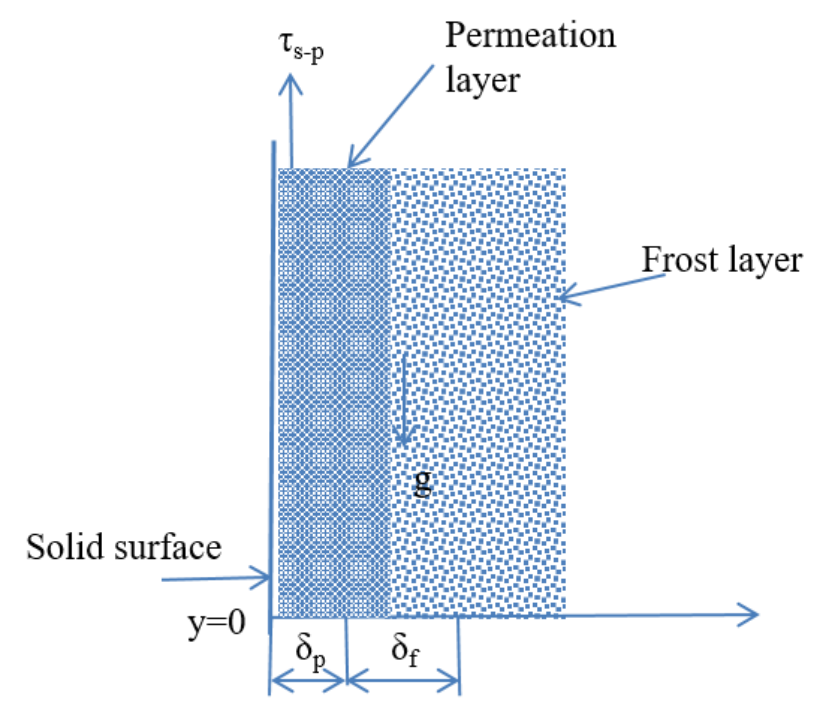

Figure 3.9. Force balance during absorption.

\subsubsection{Force balance during absorption}

During absorption, when the permeation rate of the meltwater is greater than the melting rate of the frost layer, all the meltwater is absorbed into the frost layer. A permeation layer is formed between the solid surface and the frost layer as shown in Fig. 3.9. The bulk column is subjected to gravity and adhesion force at the solid/permeation interface. When gravity exceeds adhesion in shear, the frost column might pull away from the solid surface. The body force on the frost column varies with the porosity and thickness of the frost layer. The adhesion force in shear is determined by surface wettability and is also associated with the surface temperature.

The force balance on the bulk column is described as,

$$
\mathrm{m}_{\mathrm{f} 0} \mathrm{~g}-\tau_{\mathrm{i}} \mathrm{A}_{\mathrm{s}}=0 \text {, }
$$

where $\mathrm{m}$ is the mass of the bulk column and,

$$
\mathrm{m}_{\mathrm{f} 0} \approx \mathrm{A}_{\mathrm{s}}(1-\varepsilon) \delta_{\mathrm{f} 0} \rho_{\mathrm{i}}
$$

Adhesion under shear is much smaller than that under tension because a liquidlike layer is assumed to exist between ice crystals and the solid surface. The shear 


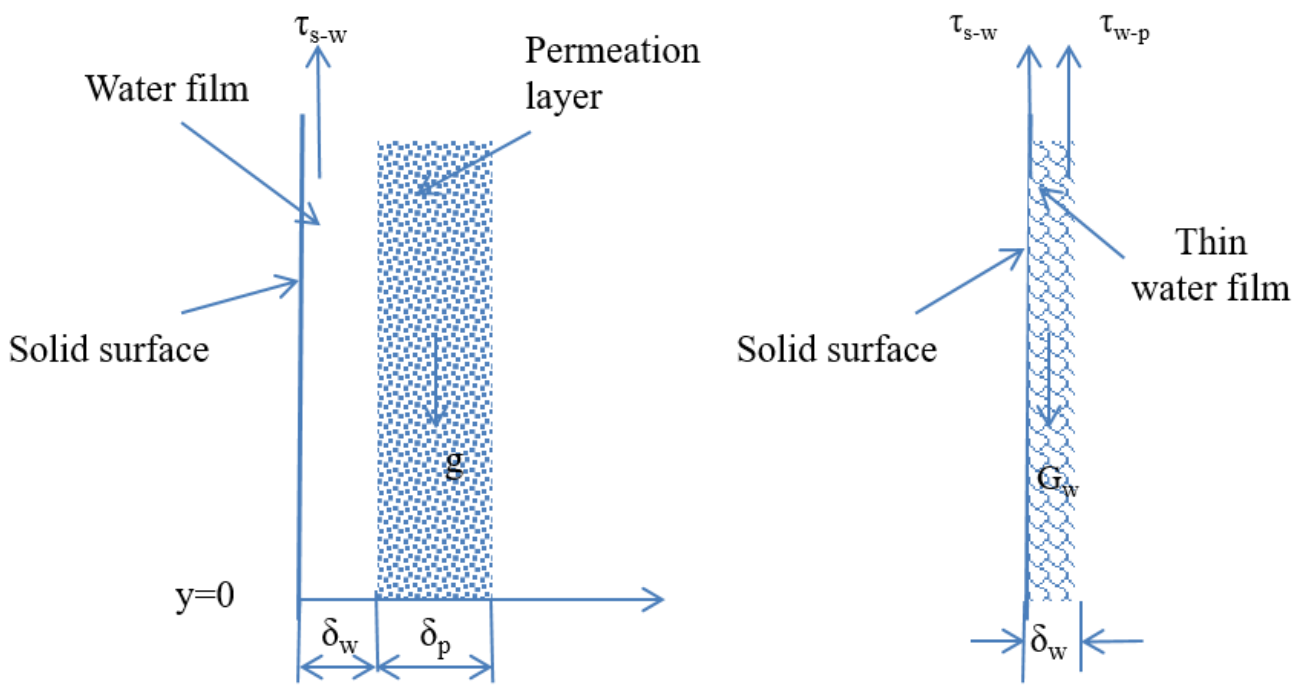

Figure 3.10. Force balance during accumulation.

strength of ice adhesion is related to the advancing/receding contact angle. The correlation between ice adhesion, $\tau_{\mathrm{i}}$, and the contact angle is described as [72],

$$
\tau_{\mathrm{i}}=(340 \pm 40)\left(1+\cos \theta_{\mathrm{rec}}\right)[\mathrm{kPa}], \quad \text { Residual }=0.92
$$

where the ice adhesion is measured at $-10{ }^{\circ} \mathrm{C}$.

The adhesion force also decreases with the increase of the temperature. When the surface temperature increases, the adhesion force might get weaker. The gravity then dominates and leads to frost slumping. The strength of solid/liquid interaction is greater on hydrophilic surfaces than on hydrophobic surfaces. It might be easier for frost column to slump on hydrophobic surfaces.

\subsubsection{Force balance during accumulation}

During the accumulation stage, when the frost layer is either saturated with meltwater or under the condition that the melting rate is greater than the permeation rate, meltwater can accumulate at the solid surface. A thin water film stands between the solid surface and the frost layer, as shown in Fig. 3.10. The maximum thickness of the water film is determined by a force balance acting on it. The water film is subject to gravity, shear force at the solid/water interface, and at the water/frost interface. The frost column is subject to gravity and shear forces at the water/frost interface. The bulk mass is 


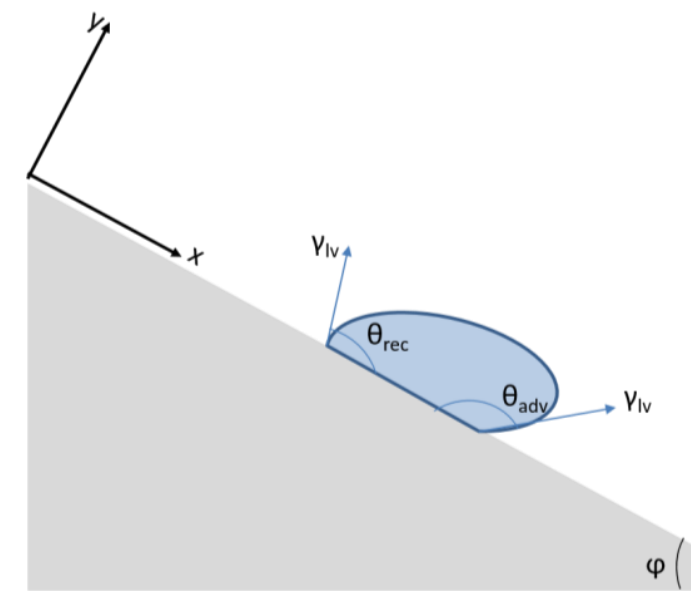

Figure 3.11. Surface tension on hydrophobic surfaces.

attached to the solid surface by surface tension. The shear force at the solid surface is associated with the surface wettability and surface temperature. The force balance for water film is,

$$
\mathrm{G}_{\mathrm{w}}-\mathrm{F}_{\mathrm{s}-\mathrm{w}}-\mathrm{F}_{\mathrm{w}-\mathrm{p}}=0 .
$$

The force balance for frost column is,

$$
\mathrm{G}_{\mathrm{f}}+\mathrm{F}_{\mathrm{w}-\mathrm{p}}=0
$$

On hydrophilic surfaces, force balance on the bulk mass becomes,

$$
\mathrm{m}_{\mathrm{f} 0} \mathrm{~g}=\gamma \cdot 2(\mathrm{~L}+\mathrm{W}) \cdot \cos \theta
$$

where $\gamma$ is surface tension of water, $\mathrm{L}$ is the length, $\mathrm{W}$ is the width of the test surface, and $\theta$ is the water contact angle at the solid surface.

On hydrophobic surfaces, surface tension is related to the advancing contact angle $\theta_{\text {adv }}$ and the receding contact angle $\theta_{\text {rec }}{ }^{17}$ as shown in Fig. 3.11. The force balance on the hydrophobic surface is,

\footnotetext{
${ }^{17}$ The contact angles formed by expanding and contracting the liquids are referred to as the advancing contact angle and the receding contact angle respectively.
} 


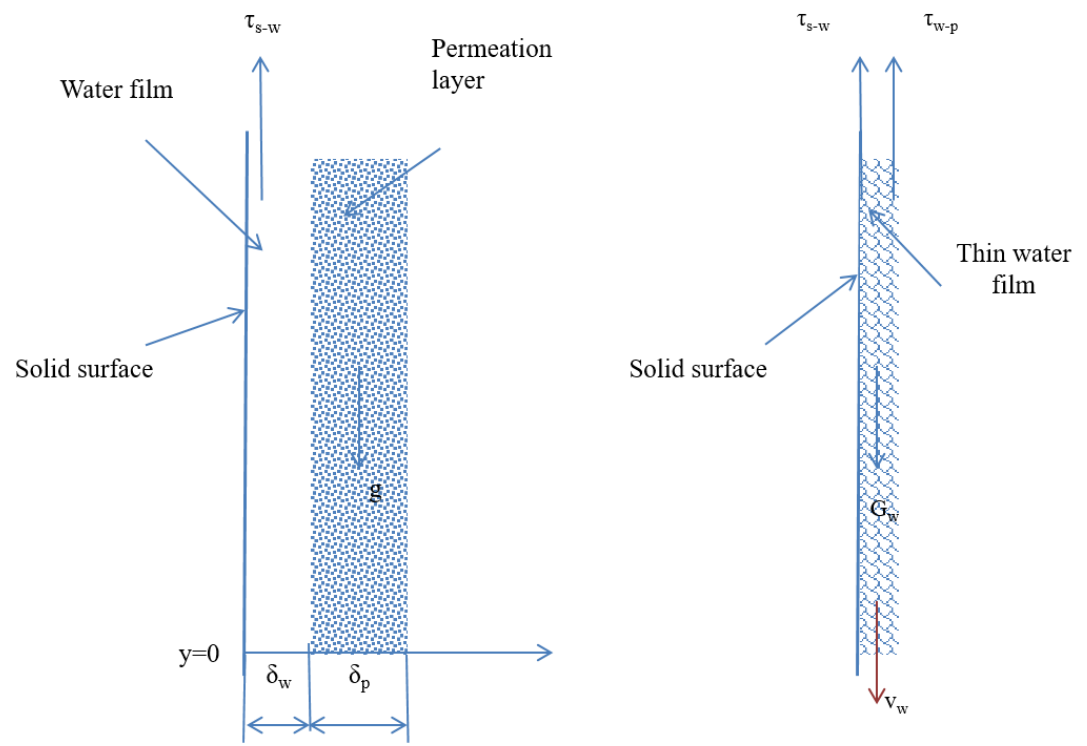

Figure 3.12. Force balance during drainage.

$$
\mathrm{m}_{\mathrm{f} 0} \mathrm{~g}=\gamma \cdot 2(\mathrm{~L}+\mathrm{W}) \cdot\left(\cos \theta_{\mathrm{rec}}-\cos \theta_{\mathrm{adv}}\right)
$$

The difference between the advancing contact angle and the receding contact angle is called contact angle hysteresis. Hysteresis is caused by surface roughness, heterogeneity and impurities on surface. Surface tension is a function of contact angle hysteresis.

\subsubsection{Force balance during drainage}

During drainage, meltwater drains by gravity, as shown in Fig. 3.12. A force balance is similar to that used in the accumulation stage. Forces compete between gravity and shear force at the solid/water interface. Gravity decreases with draining of the water, and shear force also decreases with the rising surface temperature. Slumping would be possible, where the decrease of the shear stress is much larger than the decrease of the gravity. At a point, the bulk mass falls off with the draining water. 


\section{Solution Methods}

\subsection{Melting stages}

Melting stages cover the behavior of the meltwater at different time period during the defrost process. Water permeation rate describes the rate of meltwater transporting into the frost layer in absorption. Water accumulation reduces the strength of ice adhesion and promotes the slumping possibility in accumulation. Water drainage rate depends on the boundary conditions at the interfaces in drainage. Large drainage rate helps reduce defrost time and improve defrost efficiency.

\subsubsection{Absorption}

During the absorption stage, the permeation rate of the meltwater depends on the water saturation distribution through the permeation layer. The water saturation in the permeation layer is governed by Eqn. (3.10). Front fixing methods are applied to track the phase front as the phase boundary moves [101].

When letting $\mathrm{y}^{+}=\frac{\mathrm{y}}{\delta_{\mathrm{p}}(\mathrm{t})}$, the dimensionless equation of the water saturation becomes,

$$
\begin{aligned}
& \frac{\partial \mathrm{S}(\mathrm{t}, \mathrm{y})}{\partial \mathrm{y}}=\frac{\partial \mathrm{S}}{\partial \mathrm{y}^{+}} \frac{\partial \mathrm{y}^{+}}{\partial \mathrm{y}}=\frac{1}{\delta_{\mathrm{p}}(\mathrm{t})} \frac{\partial \mathrm{S}\left(\mathrm{t}, \mathrm{y}^{+}\right)}{\partial \mathrm{y}^{+}} \\
& \frac{\partial^{2} \mathrm{~S}(\mathrm{t}, \mathrm{y})}{\partial \mathrm{y}^{2}}=\frac{\partial \mathrm{S}}{\partial \mathrm{y}}\left(\frac{\partial \mathrm{S}}{\partial \mathrm{y}}\right)=\frac{1}{\delta_{\mathrm{p}}(\mathrm{t})^{2}} \frac{\partial^{2} \mathrm{~S}\left(\mathrm{t}, \mathrm{y}^{+}\right)}{\partial \mathrm{y}^{+2}} \\
& \frac{\partial \mathrm{S}(\mathrm{t}, \mathrm{y})}{\partial \mathrm{t}}=\frac{\partial \mathrm{S}\left(\mathrm{t}, \mathrm{y}^{+}\right)}{\partial \mathrm{t}}-\frac{\mathrm{y}^{+}}{\delta_{\mathrm{p}}(\mathrm{t})} \frac{\mathrm{d} \delta_{\mathrm{p}}(\mathrm{t})}{\mathrm{dt}} \frac{\partial \mathrm{S}\left(\mathrm{t}, \mathrm{y}^{+}\right)}{\partial \mathrm{y}^{+}}
\end{aligned}
$$

The non-dimensional mass continuity of water Eqn. (3.10) becomes, 


$$
\begin{aligned}
\frac{\partial \mathrm{S}\left(\mathrm{t}, \mathrm{y}^{+}\right)}{\partial \mathrm{t}}= & \frac{\mathrm{KCq}}{\varepsilon \mu_{\mathrm{w}}} \frac{1}{\delta_{\mathrm{p}}{ }^{2}}\left[(\mathrm{p}-\mathrm{q}-1) \mathrm{S}^{\mathrm{p}-\mathrm{q}-2}\left(\frac{\partial \mathrm{S}\left(\mathrm{t}, \mathrm{y}^{+}\right)}{\partial \mathrm{y}^{+}}\right)^{2}+\mathrm{S}^{\mathrm{p}-\mathrm{q}-1} \frac{\partial^{2} \mathrm{~S}\left(\mathrm{t}, \mathrm{y}^{+}\right)}{\partial \mathrm{y}^{+2}}\right] \\
& -\mathrm{v}_{\mathrm{f}}\left(1-\mathrm{y}^{+}\right) \frac{1}{\delta_{\mathrm{p}}} \frac{\partial \mathrm{S}\left(\mathrm{t}, \mathrm{y}^{+}\right)}{\partial \mathrm{y}^{+}}
\end{aligned}
$$

When letting $\mathrm{t}^{+}=\frac{\mathrm{t} *\left|\mathrm{v}_{\mathrm{f}}\right|}{\delta_{\mathrm{fo}}}$, the dimensionless equation of the water saturation becomes,

$$
\begin{aligned}
\frac{\partial \mathrm{S}\left(\mathrm{t}^{+}, \mathrm{y}^{+}\right)}{\partial \mathrm{t}^{+}}= & \frac{\delta_{\mathrm{f} 0}}{\left|\mathrm{v}_{\mathrm{f}}\right|} \frac{\mathrm{KCq}}{\varepsilon \mu_{\mathrm{w}}} \frac{1}{\delta_{\mathrm{p}}{ }^{2}}\left[(\mathrm{p}-\mathrm{q}-1) \mathrm{S}^{\mathrm{p}-\mathrm{q}-2}\left(\frac{\partial \mathrm{S}\left(\mathrm{t}^{+}, \mathrm{y}^{+}\right)}{\partial \mathrm{y}^{+}}\right)^{2}+\mathrm{S}^{\mathrm{p}-\mathrm{q}-1} \frac{\partial^{2} \mathrm{~S}\left(\mathrm{t}^{+}, \mathrm{y}^{+}\right)}{\partial \mathrm{y}^{+2}}\right] \\
& -\frac{\delta_{\mathrm{f} 0}}{\left|\mathrm{v}_{\mathrm{f}}\right|} \mathrm{v}_{\mathrm{f}}\left(1-\mathrm{y}^{+}\right) \frac{1}{\delta_{\mathrm{p}}} \frac{\partial \mathrm{S}\left(\mathrm{t}^{+}, \mathrm{y}^{+}\right)}{\partial \mathrm{y}^{+}}
\end{aligned}
$$

The boundary conditions are,

$$
\begin{array}{ll}
\mathrm{y}^{+}=0, & \mathrm{~S}=1, \\
\mathrm{y}^{+}=1, & \mathrm{~S}=0 .
\end{array}
$$

The initial condition is,

$$
\mathrm{t}^{+}=0, \quad \mathrm{~S}=0 .
$$

The governing equation of water saturation is thus a second order, nonlinear partial differential equation that can be solved by finite difference methods. Finite difference schemes are used to solve the governing equations [102-106]. Forward-time central-space discretization scheme applies to the nodes.

$$
\frac{\partial S}{\partial t}=\frac{S_{i}^{j+1}-S_{i}^{j}}{\Delta t} .
$$




$$
\begin{gathered}
\frac{\partial S}{\partial y}=\frac{S_{i+1}^{j}-S_{i-1}^{j}}{2 \Delta y} . \\
\frac{\partial^{2} S}{\partial y^{2}}=\frac{S_{i+1}^{j}-2 S_{i}^{j}+S_{i-1}^{j}}{\Delta y^{2}} .
\end{gathered}
$$

When $\mathrm{p}-\mathrm{q}-1=1$, the discretization of the water permeation equation becomes,

$$
\frac{S_{i}^{j+1}-S_{i}^{j}}{\Delta t}=\frac{K C q}{\varepsilon \mu_{w}}\left[\left(\frac{S_{i+1}^{j}-S_{i-1}^{j}}{2 \Delta y}\right)^{2}+S_{i}^{j} \frac{S_{i+1}^{j}-2 S_{i}^{j}+S_{i-1}^{j}}{\Delta y^{2}}\right]-v_{f} \frac{S_{i+1}^{j}-S_{i-1}^{j}}{2 \Delta y}
$$

The discretization of the non-dimensional water permeation equation becomes,

$$
\begin{gathered}
\frac{S_{i}^{j+1}-S_{i}^{j}}{\Delta t}=\frac{K C q}{\varepsilon \mu_{w}} \frac{1}{\delta_{p}^{2}}\left[\left(\frac{S_{i+1}^{j}-S_{i-1}^{j}}{2 \Delta y}\right)^{2}+S_{i}^{j} \frac{S_{i+1}^{j}-2 S_{i}^{j}+S_{i-1}^{j}}{\Delta y^{2}}\right] \\
-v_{f} \frac{1}{\delta_{p}}[1-(i-1) \Delta y] \frac{S_{i+1}^{j}-S_{i-1}^{j}}{2 \Delta y} .
\end{gathered}
$$

Heat diffusion in the frost layer is governed by Eqn. (3.14). Let $\Theta=\frac{T_{f}-T_{a}}{T_{i}-T_{a}}, y^{+}=$ $\frac{\mathrm{y}-\delta_{\mathrm{p}}}{\delta_{\mathrm{f}}}, \mathrm{U}=\frac{\delta_{\mathrm{f}}}{\alpha_{\mathrm{f}}} \mathrm{v}_{\mathrm{f}}$, and $\mathrm{t}^{+}=\frac{\alpha_{\mathrm{f}} \mathrm{t}}{\delta_{\mathrm{f}}{ }^{2}}$. The thickness of frost layer and permeation layer varies with time. At a specified time, the energy equation can be simplified as,

$$
\frac{\partial \Theta}{\partial \mathrm{t}^{+}}=\frac{\partial^{2} \Theta}{\partial \mathrm{y}^{+2}}-\mathrm{U} \frac{\partial \Theta}{\partial \mathrm{y}^{+}}
$$

The boundary and initial conditions become,

$$
y^{+}=0, \quad \Theta=1,
$$




$$
\begin{gathered}
\mathrm{y}^{+}=1, \quad-\frac{\partial \Theta}{\partial \mathrm{y}^{+}}=\mathrm{Bi} \Theta, \quad \mathrm{Bi}=\frac{\mathrm{h}_{\mathrm{a}} \delta_{\mathrm{f}}}{\mathrm{k}_{\mathrm{f}}}, \\
\mathrm{t}^{+}=0, \quad \Theta=1 .
\end{gathered}
$$

The dimensionless heat diffusion equation is homogeneous with one nonhomogeneous boundary condition at the permeation-frost interface and one homogeneous boundary condition at the frost-air interface. Thus, the problem comprises two sub-problems: a steady state problem with nonhomogeneous boundary conditions, and a transient problem with homogeneous boundary conditions. Forward-time centralspace discretization scheme applies to the internal nodes.

$$
\begin{aligned}
& \frac{\partial \Theta}{\partial \mathrm{t}^{+}}=\frac{\Theta_{\mathrm{i}}^{\mathrm{j}+1}-\Theta_{\mathrm{i}}^{\mathrm{j}}}{\Delta \mathrm{t}^{+}} . \\
& \frac{\partial \Theta}{\partial \mathrm{y}^{+}}=\frac{\Theta_{\mathrm{i}+1}^{\mathrm{j}}-\Theta_{\mathrm{i}-1}^{\mathrm{j}}}{2 \Delta \mathrm{y}^{+}} . \\
& \frac{\partial^{2} \Theta}{\partial \mathrm{y}^{+2}}=\frac{\Theta_{\mathrm{i}+1}^{\mathrm{j}}-2 \Theta_{\mathrm{i}}^{\mathrm{j}}+\Theta_{\mathrm{i}-1}^{\mathrm{j}}}{\Delta \mathrm{y}^{+^{2}}} .
\end{aligned}
$$

The discretization of the non-dimensional energy equation becomes,

$$
\Theta_{i}^{j+1}=\Theta_{i}^{j}+\frac{\Delta t^{+}}{\Delta y^{+^{2}}}\left(\Theta_{i+1}^{j}-2 \Theta_{i}^{j}+\Theta_{i-1}^{j}\right)-\frac{U \Delta t^{+}}{2 \Delta y^{+}}\left(\Theta_{i+1}^{j}-\Theta_{i-1}^{j}\right) .
$$

The backward difference applies to the node at the upper bound.

$$
\frac{\partial \Theta}{\partial y^{+}}=\frac{\Theta_{i}^{j}-\Theta_{i-1}^{j}}{\Delta y^{+}}
$$

The discretization of the boundary condition is, 


$$
\Theta_{i}^{j}=\frac{\Theta_{i-1}^{j}}{\left(1+B i \Delta y^{+}\right)}
$$

\subsubsection{Accumulation}

The water film expands when the permeation layer melts. The temperature in the permeation layer maintains the melting temperature. The water film is expected to be very thin where the Biot number is less than 0.1. A uniform temperature is assumed as,

$$
\mathrm{T}_{\mathrm{w}}=\mathrm{T}_{\mathrm{s}} .
$$

The thickness of the water film approximates as,

$$
\delta_{w(t)}=\frac{q_{s}^{\prime \prime}}{\rho_{p} L_{f}} t .
$$

\subsubsection{Drainage}

Conservation of momentum in the water film is described by Eqn. (3.22). When the slope angle is $90^{\circ}$, the equation becomes,

$$
\frac{\partial \mathrm{u}_{\mathrm{w}}}{\partial \mathrm{t}}+\mathrm{v}_{\mathrm{w}} \frac{\partial \mathrm{u}_{\mathrm{w}}}{\partial \mathrm{y}}=\frac{\mu_{\mathrm{w}}}{\rho_{\mathrm{w}}} \frac{\partial^{2} \mathrm{u}_{\mathrm{w}}}{\partial \mathrm{y}^{2}}+\mathrm{g}
$$

Let $u_{\mathrm{w}}^{*}=\frac{\mathrm{u}_{\mathrm{w}}}{\mathrm{u}}, \mathrm{v}_{\mathrm{w}}^{*}=\frac{\mathrm{v}_{\mathrm{w}}}{\mathrm{u}}, \mathrm{t}^{*}=\mathrm{t} \frac{\mathrm{U}}{\delta_{\mathrm{w}}}, \mathrm{y}^{*}=\frac{\mathrm{y}}{\delta_{\mathrm{w}}}$, the dimensionless form of the momentum equation becomes,

$$
\frac{\partial \mathrm{u}_{\mathrm{w}}^{*}}{\partial \mathrm{t}^{*}}+\mathrm{v}_{\mathrm{w}}^{*} \frac{\partial \mathrm{u}_{\mathrm{w}}^{*}}{\partial \mathrm{y}^{*}}=\frac{1}{\operatorname{Re}} \frac{\partial^{2} \mathrm{u}_{\mathrm{w}}^{*}}{\partial\left(\mathrm{y}^{*}\right)^{2}}+\frac{1}{\mathrm{Fr}^{2}}
$$


where the characteristic velocity $U=\left|v_{f}\right|=\frac{q_{s}^{\prime \prime}}{(1-\varepsilon) \rho_{i} L_{f}}$, the Reynolds number $R e=$ $\frac{\rho_{\mathrm{w}} \mathrm{U} \delta_{\mathrm{w}}}{\mu_{\mathrm{w}}}$, the Froude number $\mathrm{Fr}=\frac{\mathrm{U}}{\sqrt{\mathrm{g} \delta_{\mathrm{w}}}}$. The Reynolds number is relatively small because the scales of melting velocity and thickness of water film are small. Thus the inertia force is neglected. The momentum equation becomes,

$$
\frac{1}{\operatorname{Re}} \frac{\mathrm{d}^{2} \mathrm{u}_{\mathrm{w}}^{*}}{\mathrm{~d}\left(\mathrm{y}^{*}\right)^{2}}+\frac{1}{\mathrm{Fr}^{2}}=0
$$

A parabolic draining velocity profile is assumed.

$$
\begin{gathered}
\frac{\mathrm{du}_{\mathrm{w}}^{*}}{\mathrm{dy}^{*}}=-\frac{\mathrm{Re}}{\mathrm{Fr}^{2}} \mathrm{y}^{*}+\mathrm{C}_{1}, \\
\mathrm{u}_{\mathrm{w}}^{*}=-\frac{\mathrm{Re}}{2 \mathrm{Fr}^{2}}\left(\mathrm{y}^{*}\right)^{2}+\mathrm{C}_{1} \mathrm{y}^{*}+\mathrm{C}_{2},
\end{gathered}
$$

where $\mathrm{C}_{1}$ and $\mathrm{C}_{2}$ are constants that can be obtained from the boundary conditions.

Boundary conditions are formulated with regard to surface wettability. For hydrophilic surfaces, the no slip boundary condition is assumed at the solid/water interface. Due to the effect of the boundary layer in the porous medium, a slip velocity is expected at the water/permeation interface.

$$
\begin{aligned}
& \mathrm{y}^{*}=0, \\
& \mathrm{u}_{\mathrm{w}}^{*}=0 . \\
& \mathrm{y}^{*}=1, \quad \frac{\mathrm{du}_{\mathrm{w}}^{*}}{\mathrm{dy}^{*}}=\frac{\beta}{\sqrt{\mathrm{K}^{*}}}\left(\mathrm{u}_{\mathrm{B}}^{*}-\omega^{*}\right),
\end{aligned}
$$

where $\mathrm{K}^{*}=\frac{\mathrm{K}}{\delta_{\mathrm{w}}{ }^{2}}$, and $\omega^{*}=\frac{\omega}{\mathrm{U}}$. Solving $\mathrm{C}_{1}$ and $\mathrm{C}_{2}$ where,

$$
\mathrm{C}_{1}=\frac{\mathrm{Re}}{\mathrm{Fr}^{2}}+\frac{\beta}{\sqrt{\mathrm{K}^{*}}}\left(\mathrm{u}_{\mathrm{B}}^{*}-\omega^{*}\right)
$$




$$
\mathrm{C}_{2}=0
$$

The momentum equation for hydrophilic surface is solved with,

$$
\mathrm{u}_{\mathrm{w}}^{*}=-\frac{\mathrm{Re}}{2 \mathrm{Fr}^{2}}\left(\mathrm{y}^{*}\right)^{2}+\left[\frac{\mathrm{Re}}{\mathrm{Fr}^{2}}+\frac{\beta}{\sqrt{\mathrm{K}^{*}}}\left(\mathrm{u}_{\mathrm{B}}^{*}-\omega^{*}\right)\right] \mathrm{y}^{*}
$$

The velocity at water/permeation interface is obtained where $y^{*}=1$,

$$
\mathrm{u}_{\mathrm{B}}^{*}=\frac{\frac{\mathrm{Re}}{2 \mathrm{Fr}^{2}}-\frac{\beta}{\sqrt{\mathrm{K}^{*}}} \omega^{*}}{\left(1-\frac{\beta}{\sqrt{\mathrm{K}^{*}}}\right)} .
$$

For the hydrophobic surface, a slip boundary condition is assumed at solid/water interface by Eqn. (3.27). Letting $\mathrm{u}_{\mathrm{s}}^{*}=\frac{\mathrm{u}_{\mathrm{s}}}{\mathrm{U}}, \mathrm{b}^{*}=\frac{\mathrm{b}}{\delta_{\mathrm{w}}}$, a dimensionless slip boundary condition is,

$$
y^{*}=0, \quad u_{s}^{*}=b^{*} \frac{d u_{w}^{*}}{d y^{*}}
$$

The boundary condition at water/permeation interface is described as,

$$
\mathrm{y}^{*}=1, \quad \frac{\mathrm{du}_{\mathrm{w}}^{*}}{\mathrm{dy}^{*}}=\frac{\beta}{\sqrt{\mathrm{K}^{*}}}\left(\mathrm{u}_{\mathrm{B}}^{*}-\omega^{*}\right)
$$

Solving for the constants $\mathrm{C}_{1}$ and $\mathrm{C}_{2}$,

$$
\begin{aligned}
& \mathrm{C}_{1}=\frac{\mathrm{Re}}{\mathrm{Fr}^{2}}+\frac{\beta}{\sqrt{\mathrm{K}^{*}}}\left(\mathrm{u}_{\mathrm{B}}^{*}-\omega^{*}\right), \\
& \mathrm{C}_{2}=\mathrm{b}^{*} \mathrm{C}_{1}=\mathrm{b}^{*}\left[\frac{\mathrm{Re}}{\mathrm{Fr}^{2}}+\frac{\beta}{\sqrt{\mathrm{K}^{*}}}\left(\mathrm{u}_{\mathrm{B}}^{*}-\omega^{*}\right)\right] .
\end{aligned}
$$


Momentum equation for hydrophobic surface is solved with,

$$
\begin{gathered}
\mathrm{u}_{\mathrm{w}}^{*}=-\frac{\operatorname{Re}}{2 \mathrm{Fr}^{2}}\left(\mathrm{y}^{*}\right)^{2}+\left[\frac{\operatorname{Re}}{\mathrm{Fr}^{2}}+\frac{\beta}{\sqrt{\mathrm{K}^{*}}}\left(\mathrm{u}_{\mathrm{B}}^{*}-\omega^{*}\right)\right] \mathrm{y}^{*}+\mathrm{b}^{*}\left[\frac{\operatorname{Re}}{\mathrm{Fr}^{2}}+\frac{\beta}{\sqrt{\mathrm{K}^{*}}}\left(\mathrm{u}_{\mathrm{B}}^{*}-\omega^{*}\right)\right] . \\
\mathrm{u}_{\mathrm{B}}^{*}=\frac{\left(\frac{1+2 \mathrm{~b}^{*}}{2}\right) \frac{\mathrm{Re}}{\mathrm{Fr}^{2}}-\frac{\beta}{\sqrt{\mathrm{K}^{*}}}\left(1+\mathrm{b}^{*}\right) \omega^{*}}{1-\frac{\beta}{\sqrt{\mathrm{K}^{*}}}\left(1+\mathrm{b}^{*}\right)} .
\end{gathered}
$$

The average draining velocity and the average draining rate across the water film is,

$$
u_{\mathrm{avg}}^{*}=\int_{0}^{1} u_{\mathrm{w}}^{*} d y^{*},
$$

and the average draining rate is,

$$
\Omega^{*}=u_{\mathrm{avg}}^{*} \frac{\mathrm{W}}{\delta_{\mathrm{w}}},
$$

where $\mathrm{W}$ is the width of the test plate.

The average draining velocity for the hydrophilic surface is,

$$
\mathrm{u}_{\mathrm{avg}}^{*}=\frac{\mathrm{Re}}{3 \mathrm{Fr}^{2}}+\frac{\beta}{2 \sqrt{\mathrm{K}^{*}}}\left(\mathrm{u}_{\mathrm{B}}^{*}-\omega^{*}\right)
$$

The average draining velocity for hydrophobic surface is,

$$
\mathrm{u}_{\mathrm{avg}}^{*}=\left(\frac{1}{3}+\mathrm{b}^{*}\right) \frac{\mathrm{Re}}{\mathrm{Fr}^{2}}+\left(\frac{1}{2}+\mathrm{b}^{*}\right) \frac{\beta}{\sqrt{\mathrm{K}^{*}}}\left(\mathrm{u}_{\mathrm{B}}^{*}-\omega^{*}\right)
$$




\subsection{Slumping criterion}

\subsubsection{Scale analysis during absorption}

The bulk frost is balanced by adhesion force in shear and gravity as described by Eqn. (3.33). A ratio is defined corresponding to the competition between these two forces.

$$
\mathrm{FR}_{1}=\frac{\mathrm{G}_{\mathrm{f} 0}}{\mathrm{~A}_{\mathrm{s}} \tau_{\mathrm{i}}}=\frac{\rho_{\mathrm{f}} \mathrm{g} \delta_{\mathrm{f} 0}}{\tau_{\mathrm{i}}}
$$

where density is approximated as $\rho_{\mathrm{f}}=(1-\varepsilon) \rho_{\mathrm{i}}$.

The tension force in shear of ice decreases with the increase of the surface temperature during the defrost process. To quantify the $\mathrm{FR}_{1}$, the tension force in shear is assumed to be $100 \mathrm{kPa}$ [67]. Substituting $\varepsilon=0.5, \rho_{\mathrm{i}}=\frac{900 \mathrm{~kg}}{\mathrm{~m}^{3}}, \delta_{\mathrm{f}}=3 \mathrm{~mm}, \mathrm{FR}_{1}$ is,

$$
\mathrm{FR}_{1}=\frac{450 \frac{\mathrm{kg}}{\mathrm{m}^{3}} \times 0.003 \mathrm{~m} \times 9.81 \frac{\mathrm{m}}{\mathrm{s}^{2}}}{100 \frac{\mathrm{kN}}{\mathrm{m}^{2}}}=1.35 \times 10^{-4}
$$

The body force is much less than the adhesion force in shear. The slumping of the frost layer is unlikely to occur when adhesion is much larger than the body force.

4.2.2 Scale analysis during accumulation

During accumulation, water film on hydrophilic surfaces is subjected to gravity, surface tension at the solid/water interface and shear at the water/permeation interface. A ratio is defined as,

$$
\mathrm{FR}_{2}=\frac{\mathrm{G}_{\mathrm{f} 0}}{\mathrm{~F}_{\mathrm{s}-\mathrm{w}}}=\frac{\rho_{\mathrm{f}} \mathrm{gA}_{\mathrm{s}} \delta_{\mathrm{f} 0}}{\gamma \cdot 2(\mathrm{~L}+\mathrm{W}) \cdot \cos \theta}
$$

On hydrophobic surfaces, the force ratio is,

$$
\mathrm{FR}_{2}=\frac{\rho_{\mathrm{f}} \mathrm{g} \mathrm{A}_{\mathrm{s}} \delta_{\mathrm{f} 0}}{\gamma \cdot 2(\mathrm{~L}+\mathrm{W}) \cdot\left(\cos \theta_{\text {rec }}-\cos \theta_{\mathrm{adv}}\right)}
$$


Surface tension is defined as the force per unit length. The surface tension of water is 73 $\mathrm{mN} / \mathrm{m}$. Substituting $\varepsilon=0.7, \rho_{\mathrm{i}}=\frac{900 \mathrm{~kg}}{\mathrm{~m}^{3}}, \delta_{\mathrm{f}}=3 \mathrm{~mm}, \mathrm{~L}=\mathrm{W}=30 \mathrm{~mm}, \mathrm{FR}_{2}$ is,

$$
\mathrm{FR}_{2}=\frac{(1-0.7) \times 900 \frac{\mathrm{kg}}{\mathrm{m}^{3}} \times\left(30^{2} \times 10^{-6} \times 3 \times 10^{-3}\right) \mathrm{m}^{3} \times 9.81 \frac{\mathrm{m}}{\mathrm{s}^{2}}}{73 \frac{\mathrm{mN}}{\mathrm{m}} \times\left(4 \times 30 \times 10^{-3}\right) \mathrm{m} \times \cos \theta}=\frac{0.8}{\cos \theta}
$$

The force ratio for hydrophobic surfaces is,

$$
\mathrm{FR}_{2}=\frac{0.8}{\cos \theta_{\mathrm{rec}}-\cos \theta_{\mathrm{adv}}}
$$

Frost slumping is more likely to occur during the accumulation stage. Surface tension decreases with the surface temperature, and the force ratio increases with time. When the force ratio is greater than 1, the gravity outweighs the surface tension, and slumping is likely to occur where a thin water film accumulates on hydrophilic surfaces or where water droplets stick on hydrophobic surfaces.

\subsubsection{Scale analysis during drainage}

A part of the meltwater drains at this stage, and the force ratio on the surfaces is time dependent. On hydrophilic surfaces, the force ratio becomes,

$$
\mathrm{FR}_{3}=\frac{\rho_{\mathrm{f}} \mathrm{gA}_{\mathrm{s}} \delta_{\mathrm{f} 0}-\rho_{\mathrm{w}} \mathrm{gu}_{\mathrm{w}} \mathrm{W} \delta_{\mathrm{w}} \Delta \mathrm{t}}{\gamma \cdot 2(\mathrm{~L}+\mathrm{W}) \cdot \cos \theta}
$$

The force ratio on hydrophobic surfaces is,

$$
\mathrm{FR}_{3}=\frac{\rho_{\mathrm{f}} \mathrm{gA}_{\mathrm{s}} \delta_{\mathrm{fo}}-\rho_{\mathrm{w}} \mathrm{gu}_{\mathrm{w}} \mathrm{W} \delta_{\mathrm{w}} \Delta \mathrm{t}}{\gamma \cdot 2(\mathrm{~L}+\mathrm{W}) \cdot\left(\cos \theta_{\mathrm{rec}}-\cos \theta_{\mathrm{adv}}\right)}
$$

The slumping condition in the drainage stage depends on the force competition between the gravity and the surface tension. The bulk mass gets smaller due to the meltwater drainage, while the surface tension decreases with the increase of the surface temperature. 
The force ratio might be greater than 1 when the decrease due to surface tension is faster than that due to gravity.

A general scaling analysis is applied to define the criterion for the occurrence of slumping during the accumulation stage. As surface tension decreases with increasing temperature, a linear relation is assumed,

$$
\gamma=-\frac{\gamma_{0}}{\mathrm{~T}_{\mathrm{kp}}} \mathrm{T}+\gamma_{0}
$$

where $\gamma_{0}$ is the surface tension of water at $0{ }^{\circ} \mathrm{C}$. The force ratio on hydrophilic surfaces becomes,

$$
\mathrm{FR}=\frac{\mathrm{g} \rho_{\mathrm{i}}(1-\varepsilon) \mathrm{A}_{\mathrm{s}} \delta_{\mathrm{f} 0}}{\left(-\frac{\gamma_{0}}{\mathrm{~T}_{\mathrm{kp}}} \mathrm{T}+\gamma_{0}\right) \cdot 2(\mathrm{~L}+\mathrm{W}) \cdot \cos \theta}
$$

The force ratio on hydrophobic surfaces becomes,

$$
\mathrm{FR}=\frac{\mathrm{g} \rho_{\mathrm{i}}(1-\varepsilon) \mathrm{A}_{\mathrm{s}} \delta_{\mathrm{f} 0}}{\left(-\frac{\gamma_{0}}{\mathrm{~T}_{\mathrm{kp}}} \mathrm{T}+\gamma_{0}\right) \cdot 2(\mathrm{~L}+\mathrm{W}) \cdot\left(\cos \theta_{\mathrm{rec}}-\cos \theta_{\mathrm{adv}}\right)}
$$

When the aspect ratio is defined as the ratio of plate width to length, $r=W / L$, the force ratio on hydrophilic surfaces becomes,

$$
\mathrm{FR}=\frac{\mathrm{g} \rho_{\mathrm{i}}(1-\varepsilon) \mathrm{W} \delta_{\mathrm{f} 0}}{\left(-\frac{\gamma_{0}}{\mathrm{~T}_{\mathrm{kp}}} \mathrm{T}+\gamma_{0}\right) \cdot 2(1+\mathrm{r}) \cdot \cos \theta}
$$

and the force ratio on hydrophobic surfaces becomes,

$$
\mathrm{FR}=\frac{\mathrm{g} \rho_{\mathrm{i}}(1-\varepsilon) \mathrm{W} \delta_{\mathrm{fo}}}{\left(-\frac{\gamma_{0}}{\mathrm{~T}_{\mathrm{kp}}} \mathrm{T}+\gamma_{0}\right) \cdot 2(1+\mathrm{r}) \cdot\left(\cos \theta_{\mathrm{rec}}-\cos \theta_{\mathrm{adv}}\right)}
$$




\section{Experimental Design}

\subsection{Experimental objectives and apparatus}

The objective of the experiments is to build frost column and investigate defrost mechanisms on the surfaces with different contact angles. The main goals include building a frost column with certain thickness and density, melting the frost column, prepare surfaces with different contact angles, comparing defrost time and efficiency with respect to the heating powers and the surface wettability, and finding the slumping conditions on different surfaces.

Experimental set-up is shown in Fig. 5.1. The test equipment consists of a plastic chamber, cooling and heating system for the test plates, cooling and humidifying system for the chamber. The test chamber provides an enclosed space for frost growth and for ambient control. The chamber is made of transparent acrylic glass for observation. The top of the chamber is open with a heat sink sitting on it. An opening at the side is to place the test plate. The test plate is aluminum and is placed vertically inside the chamber. A thermoelectric module is used to cool the test surface down up to $-20{ }^{\circ} \mathrm{C}$ during the frost growth period. The hot side of the thermoelectric module is cooled by a cooling water block through which chilled water passes. The thermoelectric module is powered by BK DC power supply. A film heater is placed between the test plate and the thermoelectric module to heat up the test surface during the defrost process.

The chamber temperature is controlled by the four thermoelectric modules connected in parallel. A heat sink attached to the thermoelectric module is used to absorb heat from the chamber air. Two cooling fans circulate the air inside the chamber. Two types of fans are applied with the specified volumetric flow rate of $311 \mathrm{~L} / \mathrm{min}$ (11 CFM) and $934 \mathrm{~L} / \mathrm{min}$ ( $33 \mathrm{CFM})$. An air pump is used to extract air from the chamber and pipe the air back into the chamber after humidifying. A water flask works as a saturator filled with distilled water. Humidity inside the chamber is controlled by a flowmeter connected downstream of the air pump. Data sets are collected by Agilent data acquisition unit with multiplexer of 22 channels. Two high resolution cameras are set up at the front and side of the test chamber separately to capture the pictures during the frost growth period and 

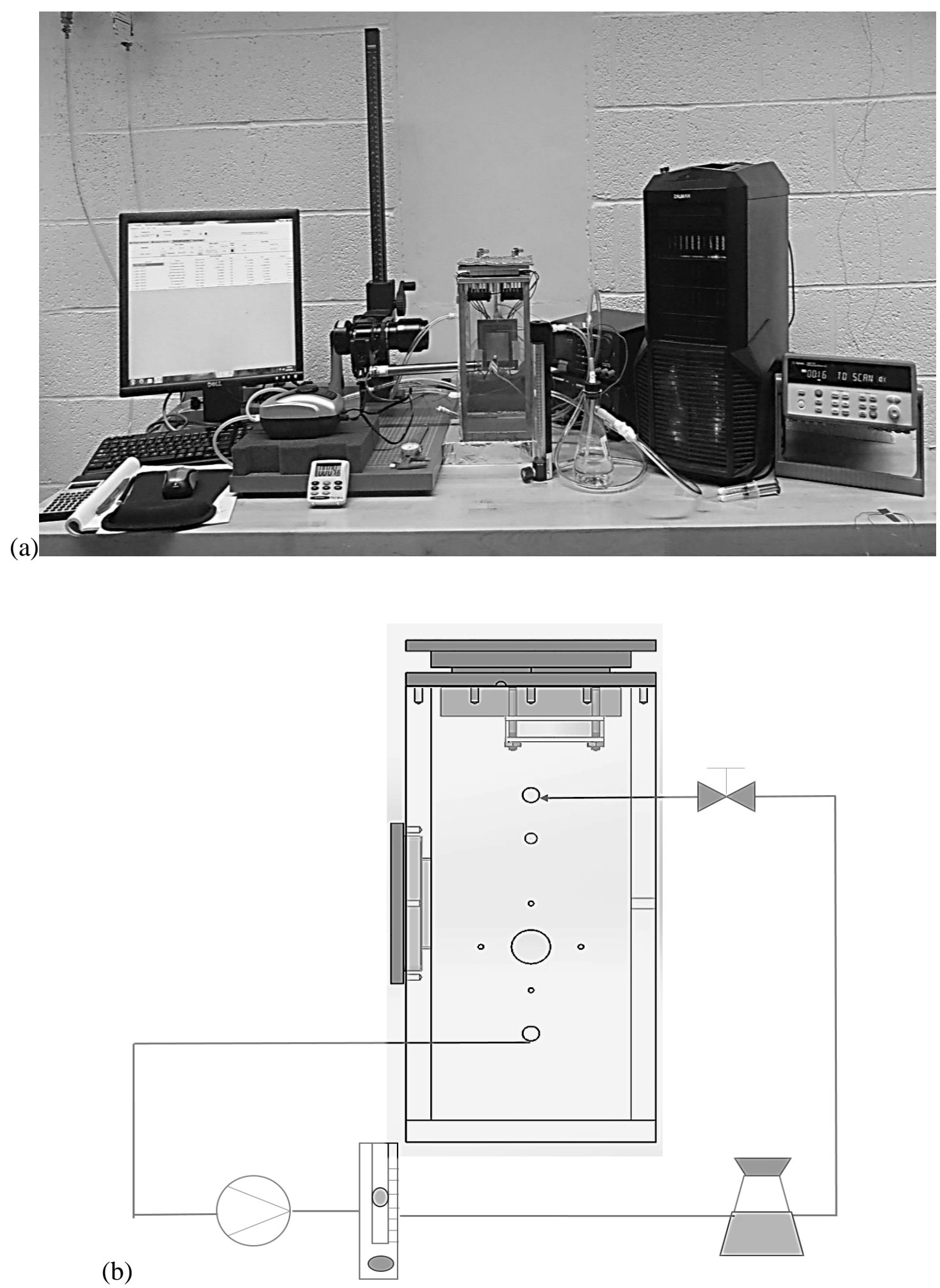

Figure 5.1. Experimental set-up.

(a) Apparatus layout; (b) Test chamber and humidity generator. 
the defrost process. The experimental apparatus is listed in Appendix A, and design drawings can be found in Appendix B.

\subsection{Design analysis}

The experiments are designed for frost and defrost cycles. The test plate temperature can decrease from the melting temperature up to $-20{ }^{\circ} \mathrm{C}$. Chamber temperature can vary from the ambient temperature to $-10{ }^{\circ} \mathrm{C}$, and chamber humidity can be controlled through a wide range. The temperature variation across the test surface is limited to $\sim 1{ }^{\circ} \mathrm{C}$. During the frost growth period, the surface temperature and the heat flux across the test plate reach to a steady state. During the defrost process, the surface temperature increases with time, and the heat flux across the test plate is variant with time.

Thick frost layers grow with low plate temperature, high ambient temperature, and high humidity. A relation of frost properties with the test condition is shown in Table 5.1. From the table, a dense frost layer is obtained with high plate temperature, high ambient temperature, high air velocity and low humidity. In the experiments, the chamber temperature is set to the ambient temperature, and the chamber humidity is set $\sim 50 \%$. The plate temperature is set to $\sim-20^{\circ} \mathrm{C}$.

\subsubsection{Test plate dimensions}

The dimensions of the test plate are designed to promote the slumping conditions. When the melting starts, the motion of the frost column is determined by the forces acting on it. Gravity and surface tension are functions of the surface dimensions of the test plate. A static force analysis is described in Chapters 3 and 4 . The ratio of the gravity to the surface tension is,

$$
\mathrm{FR}=\frac{\mathrm{g} \rho_{\mathrm{i}}(1-\varepsilon) \mathrm{W} \delta_{\mathrm{f} 0}}{\left(-\frac{\gamma_{0}}{\mathrm{~T}_{\mathrm{kp}}} \mathrm{T}+\gamma_{0}\right) \cdot 2(1+\mathrm{r}) \cdot \cos \theta}
$$

Substituting with $\cos \theta=1, \gamma_{0}=76 \frac{\mathrm{mN}}{\mathrm{m}}, \varepsilon=0.6, \delta_{\mathrm{f}}=1 \mathrm{~mm}, \mathrm{r}=1, \mathrm{FR}=1$, the width of the test plate is $40 \mathrm{~mm}$ to achieve the slumping condition. 
Table 5.1. Relation of frost properties with the test conditions.

\begin{tabular}{|l|c|c|c|c|c|c|}
\hline & Time & Humidity & $\begin{array}{c}\text { Plate } \\
\text { surface } \\
\text { temp. }\end{array}$ & $\begin{array}{c}\text { Ambient } \\
\text { temp. }\end{array}$ & $\begin{array}{c}\text { Air } \\
\text { velocity } \\
\text { (Re) }\end{array}$ & $\begin{array}{c}\text { Wettability } \\
\text { (CA) }\end{array}$ \\
\hline Frost density & + & - & + & + & + & - \\
\hline $\begin{array}{l}\text { Frost growth } \\
\text { rate }\end{array}$ & - & + & - & + & + & \\
\hline $\begin{array}{l}\text { Frost } \\
\text { thickness }\end{array}$ & + & + & - & + & + & \\
\hline Frost mass & + & + & - & + & + & \\
\hline
\end{tabular}

"+" means dependent variables increase with the increase of the independent variables; "-" means dependent variables decrease with the increase of the independent variables.

\subsubsection{Film heater}

A film heater is located between the thermoelectric module and the test plate to heat up the test plate during the defrost process. The film heater is the same size as the test plate. The voltage of the heater is $28 \mathrm{~V}$, and the watt density is $10 \mathrm{~W} / \mathrm{in}^{2}$.

\subsubsection{Chamber energy balance}

The chamber is a space with controllable temperature and humidity. The temperature can be cooled down by the thermal electric modules on the top of the chamber. During the defrost process, heat transfer from the test plate into the chamber causes the temperature inside to change. The dimensions of the chamber are designed to maintain a steady temperature condition. Heat transfer into the chamber depends on the heat transfer coefficient on the test plate, the temperature difference between the frost surface and the ambient air inside the chamber,

$$
\mathrm{Q}_{\mathrm{ch}}=\mathrm{h}_{\mathrm{a}} \mathrm{A}_{\mathrm{s}} \Delta \mathrm{t}\left(\mathrm{T}_{\mathrm{fs}}-\mathrm{T}_{\mathrm{ch}}\right) .
$$

The temperature change inside the chamber is,

$$
\Delta \mathrm{T}_{\mathrm{ch}}=\frac{\mathrm{Q}_{\mathrm{ch}}}{\left(\rho \mathrm{c}_{\mathrm{p}}\right)_{\mathrm{a}} \mathrm{V}_{\mathrm{ch}}} .
$$

Heat transfer into the frost layer includes sensible heat and latent heat, 


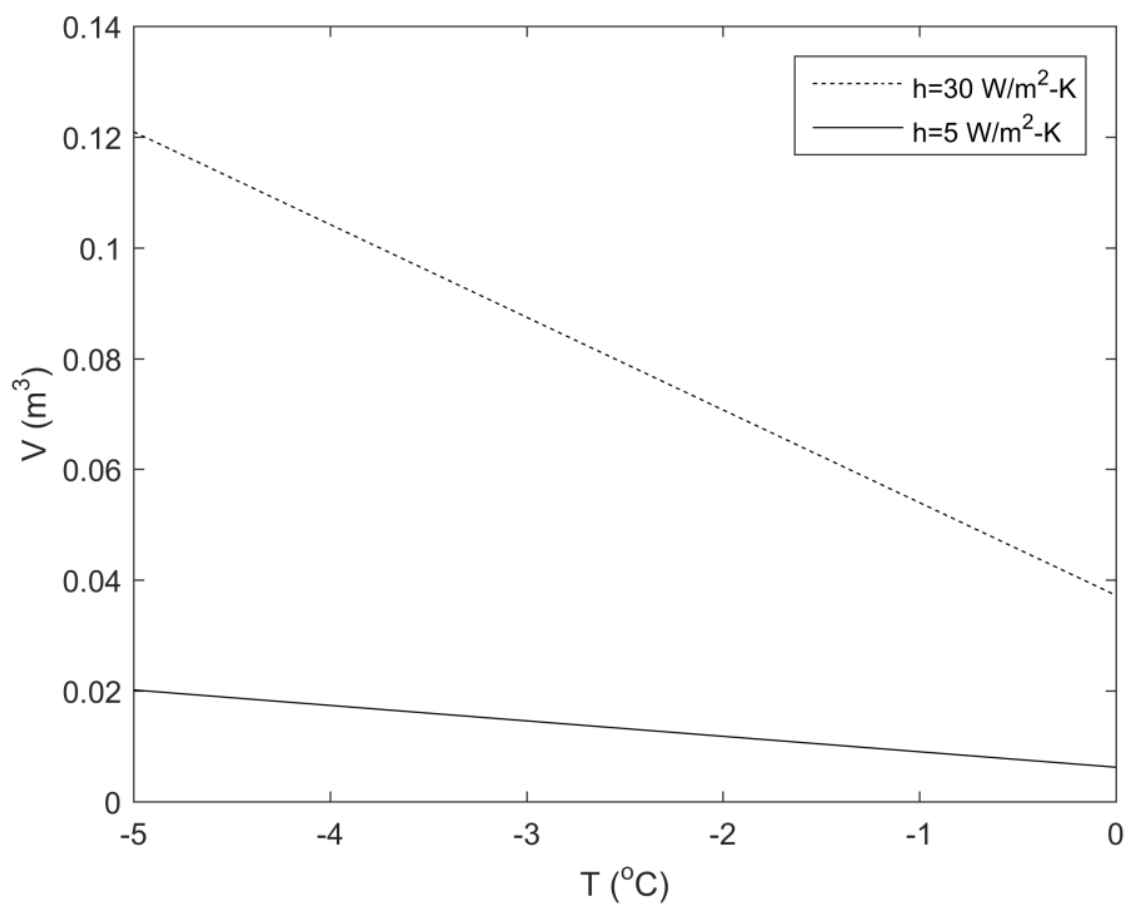

Figure 5.2. Chamber volume versus chamber temperature for a change of $1 \mathrm{~K}$ in the chamber.

$$
\begin{aligned}
& \mathrm{Q}_{\text {sen }}=\mathrm{q}_{\mathrm{s}}^{\prime \prime} \mathrm{A}_{\mathrm{s}} \Delta \mathrm{t}_{\text {sen }}=\left(\mathrm{mc}_{\mathrm{p}}\right)_{\mathrm{f}} \Delta \mathrm{T}_{\mathrm{f}}, \\
& \mathrm{Q}_{\text {lat }}=\mathrm{q}_{\mathrm{s}}^{\prime \prime} \mathrm{A}_{\mathrm{s}} \Delta \mathrm{t}_{\text {lat }}=\mathrm{m}_{\mathrm{f}} \mathrm{L}_{\mathrm{f}} .
\end{aligned}
$$

The temperature change inside the chamber becomes,

$$
\Delta \mathrm{T}_{\mathrm{ch}}=\frac{\mathrm{h}_{\mathrm{a}} \mathrm{A}_{\mathrm{s}} \Delta \mathrm{t}_{\mathrm{sen}}\left(\mathrm{T}_{\mathrm{fs}}-\mathrm{T}_{\mathrm{ch}}\right)+\mathrm{hA}_{\mathrm{s}} \Delta \mathrm{t}_{\text {lat }}\left(\mathrm{T}_{\mathrm{m}}-\mathrm{T}_{\mathrm{ch}}\right)}{\left(\rho \mathrm{c}_{\mathrm{p}}\right)_{\mathrm{a}} \mathrm{V}_{\mathrm{ch}}} .
$$

To maintain a constant temperature, chamber volume increases with the heat transfer coefficient, the test surface area, frost thickness, chamber temperature, and decreases with the applied heat flux and the porosity. Substituting values with $\mathrm{A}_{\mathrm{s}}=50^{2}$ $\mathrm{mm}^{2}, \mathrm{~T}_{\mathrm{fs}}=-20^{\circ} \mathrm{C}, \mathrm{h}=5 \mathrm{~W} / \mathrm{m}^{2}-\mathrm{K}, \varepsilon=0.04, \mathrm{q}_{\mathrm{s}} "=3000 \mathrm{~W} / \mathrm{m}^{2}, \delta_{\mathrm{f}}=5 \mathrm{~mm}$, and $\mathrm{m}_{\mathrm{f}}=6.9 \mathrm{~g}$, the volume of chamber is a function of the chamber temperature as shown in Fig. 5.2. 
During the defrost process, the circulation fan stops, and the heat transfer coefficient becomes small. The internal chamber volume is about $0.003 \mathrm{~m}^{3}$.

\subsubsection{Heat transfer coefficient}

Heat transfer coefficients differ for the frost growth and defrost processes. When frost grows, the cooling fan inside the chamber is on to circulate the air. The heat transfer coefficient is calculated with an empirical correlation under the forced convection condition. During the defrost process, the cooling fan is off, and the free convection determines the heat transfer coefficient. When forced convection over the vertical plate dominates, the velocity of circulating air is,

$$
\mathrm{u}_{\mathrm{a}}=\frac{\text { Volumetric flow rate }}{\text { Area }}=\frac{66 \text { CFM }}{5^{\prime \prime} * 4^{\prime \prime}}=2.4 \frac{\mathrm{m}}{\mathrm{s}} .
$$

Reynolds number is,

$$
\operatorname{Re}=\frac{\rho u_{\mathrm{a}} \mathrm{L}}{\mu_{\mathrm{a}}}=9000 \text { (Laminar flow) } .
$$

The film temperature is,

$$
\mathrm{T}_{\mathrm{f}}=\frac{\mathrm{T}_{\mathrm{fs}}+\mathrm{T}_{\mathrm{ch}}}{2},
$$

and the average Nusselt number with constant temperature at the test surface is [107],

$$
\overline{\mathrm{Nu}}=\frac{\overline{\mathrm{h}} \mathrm{L}}{\mathrm{k}}=0.664 \operatorname{Re}^{1 / 2} \operatorname{Pr}^{1 / 3}=53.2
$$

The average heat transfer coefficient is,

$$
\overline{\mathrm{h}}=\frac{\overline{\mathrm{Nuk}}}{\mathrm{L}}=25.5 .
$$


With constant heat flux at the test surface, local Nusselt number is,

$$
\mathrm{Nu}_{\mathrm{x}}=\frac{\mathrm{h}_{\mathrm{x}} \mathrm{x}}{\mathrm{k}}=0.453 \operatorname{Re}_{\mathrm{x}}{ }^{1 / 2} \operatorname{Pr}^{1 / 3}
$$

Local heat transfer coefficient is,

$$
h_{x}=\frac{N u_{x} k}{x}=\frac{0.453\left(\frac{\rho u_{a} x}{\mu_{a}}\right)^{1 / 2} \operatorname{Pr}^{1 / 3}}{x}
$$

The relation of local Nusselt number and local heat transfer coefficient on the test plate are shown in Figs. 5.3 and 5.4.

When circulation fans are off, the heat transfer coefficient for free convection is,

$$
\overline{\mathrm{Nu}}=\frac{\overline{\mathrm{h}} \mathrm{L}}{\mathrm{k}}=\left(\frac{4}{3}\right)\left(\frac{\mathrm{Gr}_{\mathrm{L}}}{4}\right)^{\frac{1}{4}} \mathrm{~m}(\mathrm{Pr})
$$

where

$$
\mathrm{m}(\operatorname{Pr})=\left(0.75 \operatorname{Pr}^{1 / 2}\right)\left(0.609+1.221 \mathrm{Pr}^{1 / 2}+1.238 \mathrm{Pr}\right)^{-1 / 4}
$$

and

$$
\mathrm{Gr}=\frac{\mathrm{g} \beta\left(\mathrm{T}_{\mathrm{fs}}-\mathrm{T}_{\mathrm{ch}}\right) \mathrm{L}^{3}}{\mathrm{v}^{2}}
$$

The heat transfer coefficient is a function of the temperature difference between the frost surface and the chamber as shown in Fig. 5.5.

\subsubsection{Heat flux at the test surface}

During the defrost process, heat flux at the test surface depends on the electric power into the test plate, the melting rate of the frost layer and the heat transfer into the 


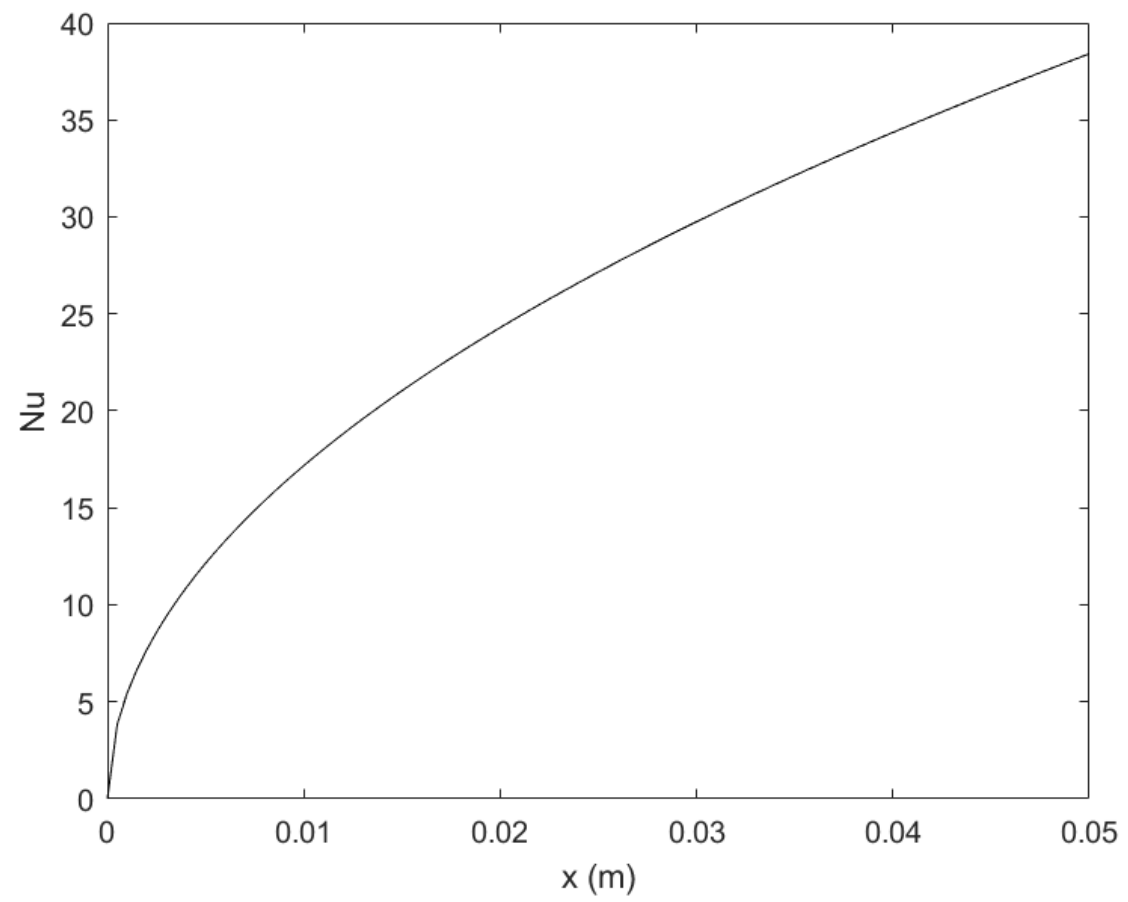

Figure 5.3. Local Nusselt number at constant heat flux where chamber air velocity is $2.4 \mathrm{~m} / \mathrm{s}$.

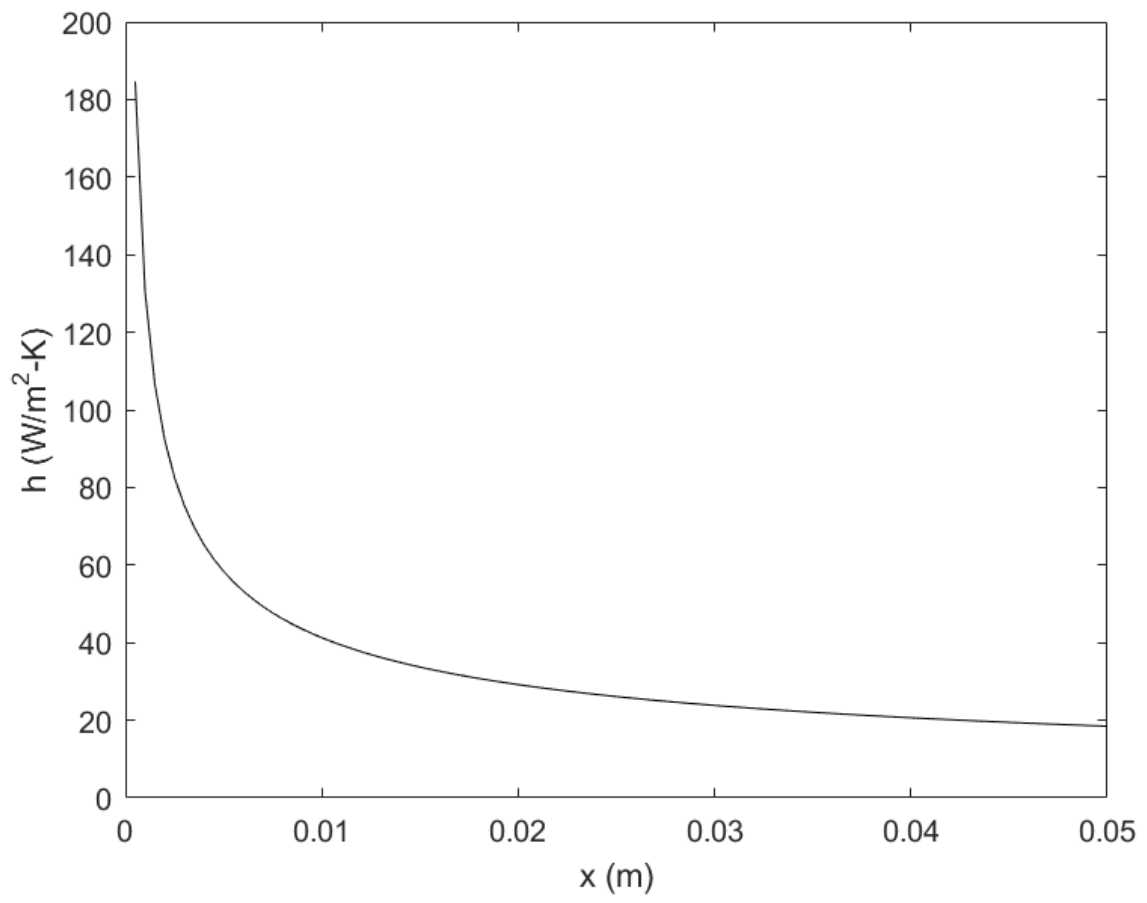

Figure 5.4. Local heat transfer coefficient at constant heat flux where chamber air velocity is $2.4 \mathrm{~m} / \mathrm{s}$. 


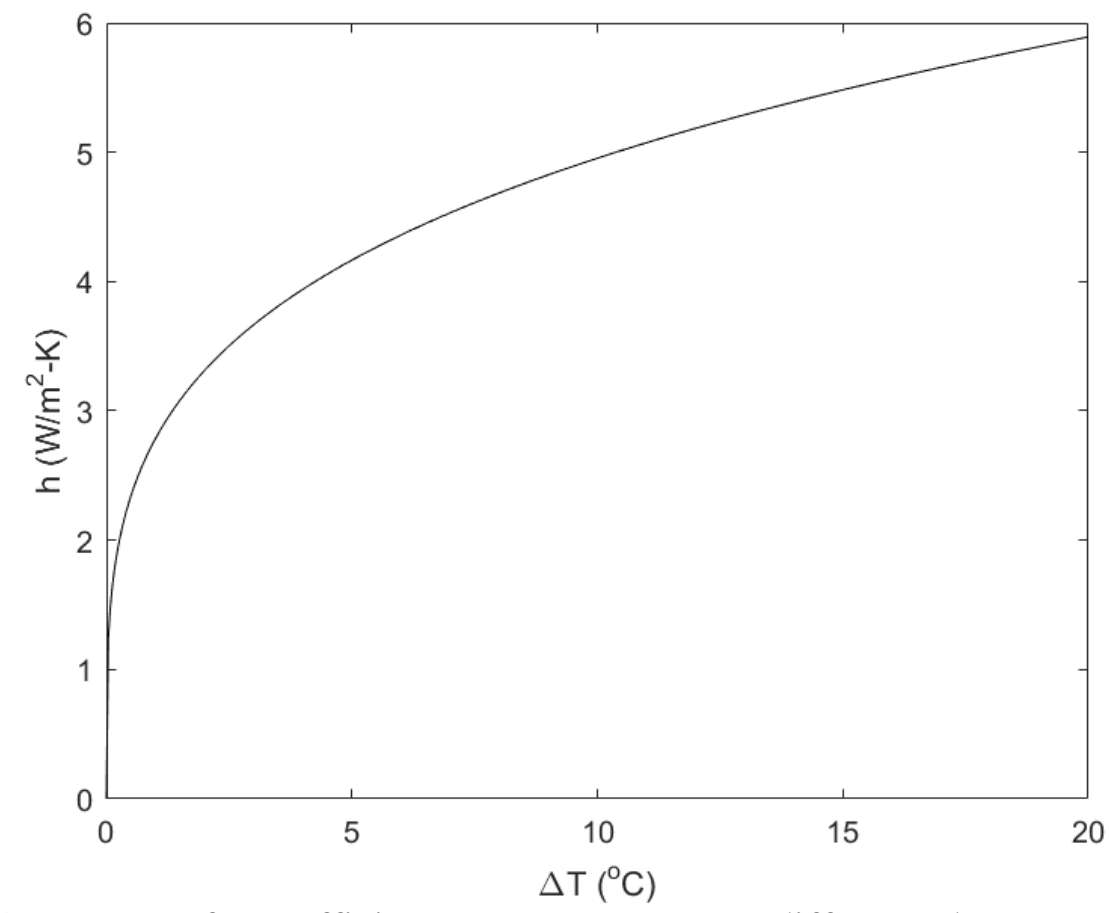

Figure 5.5. Heat transfer coefficient versus temperature difference between the test plate and surrounding under free convection where $\operatorname{Pr}=0.7, \mathrm{~L}=5.5 \mathrm{~cm}$.

chamber. When assuming a uniform temperature across the test plate, the energy equation before melting can be described as,

$$
\left(\rho c_{p}\right)_{\mathrm{Al}} \mathrm{V} \frac{\mathrm{dT}_{\mathrm{tp}}}{\mathrm{dt}}+\left(\rho \mathrm{c}_{\mathrm{p}}\right)_{\mathrm{f}} \delta_{\mathrm{f}} \mathrm{A}_{\mathrm{s}} \frac{\mathrm{dT}_{\mathrm{f}}}{\mathrm{dt}}=\mathrm{A}_{\mathrm{s}}\left[\mathrm{q}_{\mathrm{s}}^{\prime \prime}-\mathrm{h}_{\mathrm{a}}\left(\mathrm{T}_{\mathrm{fs}}-\mathrm{T}_{\mathrm{ch}}\right)\right]
$$

When melting starts, air in the frost layer is replaced by meltwater, which forms a permeation layer, and the energy equation becomes,

$$
\left(\rho c_{p}\right)_{\mathrm{Al}} \mathrm{V} \frac{\mathrm{dT}_{\mathrm{tp}}}{\mathrm{dt}}+\rho_{\mathrm{p}} \mathrm{L}_{\mathrm{f}} \mathrm{A}_{\mathrm{s}} \frac{\mathrm{d} \delta_{\mathrm{p}}}{\mathrm{dt}}=\mathrm{A}_{\mathrm{s}}\left[\mathrm{q}_{\mathrm{s}}^{\prime \prime}-\mathrm{h}_{\mathrm{a}}\left(\mathrm{T}_{\mathrm{fs}}-\mathrm{T}_{\mathrm{ch}}\right)\right] .
$$

To investigate the temperature response at the test surface, a simplified equation based on the lumped analysis is applied when Biot number, 


$$
\mathrm{Bi}=\frac{\mathrm{h}_{\mathrm{a}} \delta}{\mathrm{k}}=\frac{50 \frac{\mathrm{W}}{\mathrm{m}^{2} \mathrm{~K}} 5 \mathrm{~mm}}{200 \frac{\mathrm{W}}{\mathrm{mK}}}<0.1
$$

The energy equation for the test plate is,

$$
\begin{gathered}
\left(\rho c_{\mathrm{p}}\right)_{\mathrm{Al}} \mathrm{V} \frac{\mathrm{dT} \mathrm{T}_{\mathrm{tp}}}{\mathrm{dt}}=\mathrm{A}_{\mathrm{s}}\left[\mathrm{q}_{\mathrm{s}}^{\prime \prime}-\mathrm{h}_{\mathrm{a}}\left(\mathrm{T}_{\mathrm{s}}-\mathrm{T}_{\mathrm{ch}}\right)\right] . \\
\left(\rho \mathrm{c}_{\mathrm{p}}\right)_{\mathrm{Al}} \delta \frac{\mathrm{d}\left(\mathrm{T}_{\mathrm{tp}-} \mathrm{T}_{\mathrm{ch}}\right)}{\mathrm{dt}}=\mathrm{q}_{\mathrm{s}}^{\prime \prime}-\mathrm{h}_{\mathrm{a}}\left(\mathrm{T}_{\mathrm{s}}-\mathrm{T}_{\mathrm{ch}}\right) .
\end{gathered}
$$

The initial temperature at the test surface is,

$$
\mathrm{t}=0, \quad \mathrm{~T}_{\mathrm{s}}=\mathrm{T}_{\mathrm{ch}}
$$

Heat flux at the test surface is,

$$
\mathrm{h}_{\mathrm{a}}\left(\mathrm{T}_{\mathrm{tp}}-\mathrm{T}_{\mathrm{ch}}\right)=\mathrm{q}_{\mathrm{s}}^{\prime \prime}-\left[\mathrm{q}_{\mathrm{s}}^{\prime \prime}-\mathrm{h}_{\mathrm{a}}\left(\mathrm{T}_{\mathrm{s}}-\mathrm{T}_{\mathrm{ch}}\right)\right] \mathrm{e}^{-\frac{\mathrm{h}_{\mathrm{a}}}{\left(\rho \mathrm{c}_{\mathrm{p}}\right)_{\mathrm{Al}} \delta} \mathrm{t}} .
$$

A relation of heat flux with time is shown for free convection and forced convection in Fig. 5.6.

During the defrost process, heat flux at the surface changes with time and is expected to reach a steady value with a large enough heat transfer coefficient.

\subsubsection{Heat sink}

The chamber is cooled by thermoelectric modules, and the heat is removed by a heat sink on top of the chamber. The heat load from the chamber is,

$$
\mathrm{Q}=\left(\rho \mathrm{c}_{\mathrm{p}}\right)_{\mathrm{a}} \mathrm{V}_{\mathrm{ch}} \Delta \mathrm{T}_{\mathrm{ch}}
$$

Thermal resistance includes the fin resistance and the base resistance. 


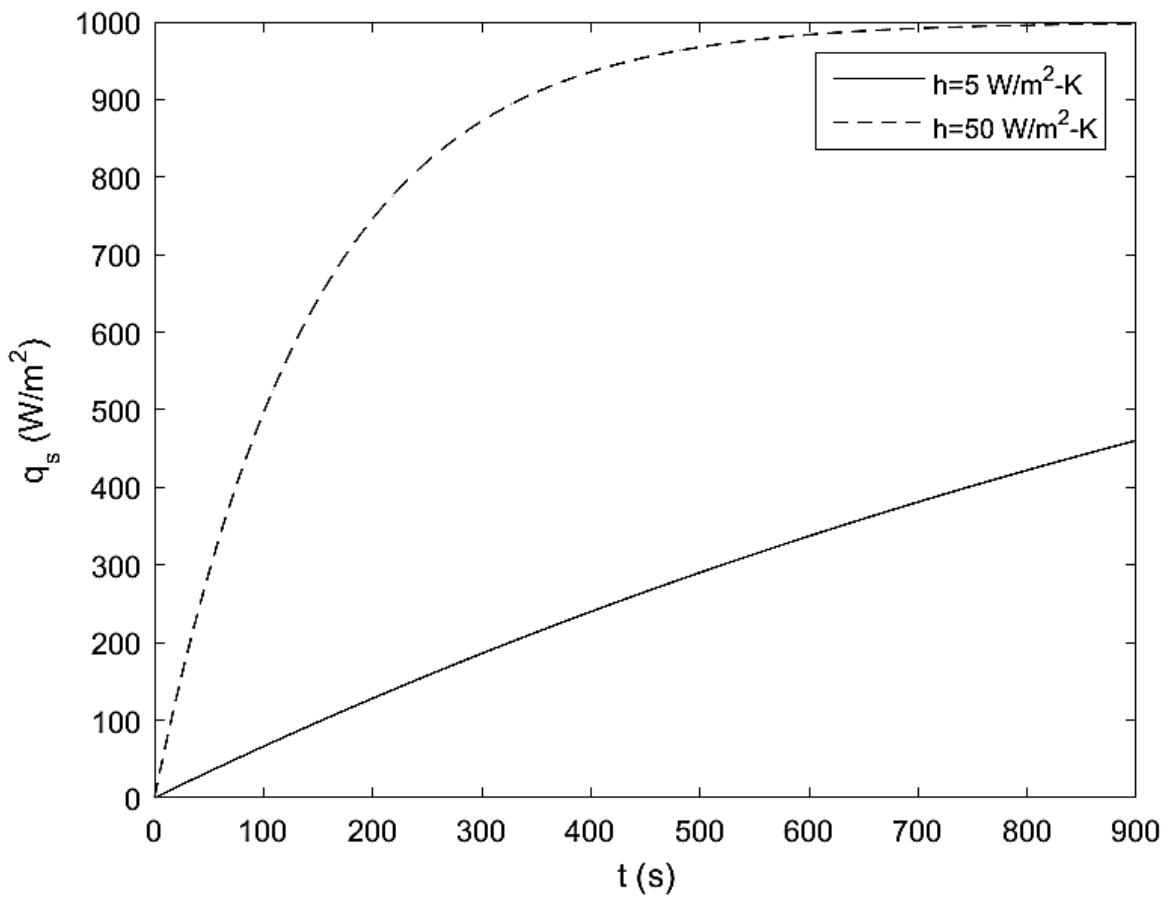

Figure 5.6. Heat flux at test surface.

$$
\begin{gathered}
\mathrm{R}_{\text {th,tot }}=\mathrm{R}_{\text {th,conv }}+\mathrm{R}_{\text {th,cond }}, \\
\mathrm{R}_{\mathrm{th}, \mathrm{conv}}=\frac{1}{\mathrm{~h}\left[\left(\mathrm{~N}_{\mathrm{fin}}-1\right)(\mathrm{bl}) \mathrm{L}+\mathrm{N}_{\mathrm{fin}} \eta_{\mathrm{fin}} 2 \mathrm{H}_{\mathrm{fin}} \mathrm{L}\right]}, \\
\mathrm{R}_{\mathrm{th}, \text { cond }}=\frac{\mathrm{H}_{\mathrm{tot}}-\mathrm{H}_{\mathrm{fin}}}{\mathrm{k}_{\mathrm{Al}} \mathrm{WL}} .
\end{gathered}
$$

where $\mathrm{N}_{\text {fin }}$ is the number of fins, $\eta_{\text {fin }}$ is the fin efficiency, $b l$ is the gap between fins, $L$ is the base length, $\mathrm{W}$ is the base width, $\mathrm{H}_{\text {tot }}$ is the total height of the heat sink, and $\mathrm{H}_{\text {fin }}$ is the height of the fin. The gap between fins, bl, is given by,

$$
\mathrm{bl}=\frac{\mathrm{W}-\mathrm{N}_{\mathrm{fin}} \delta_{\mathrm{fin}}}{\mathrm{N}_{\mathrm{fin}}-1}
$$

where $\delta_{\text {fin }}$ is the thickness of fins.

The fin efficiency is given by, 


$$
\eta_{\text {fin }}=\frac{\tanh \left(\mathrm{mH}_{\mathrm{fin}}\right)}{\mathrm{mH}_{\mathrm{fin}}}
$$

where $\mathrm{m}=\frac{2 \mathrm{~h}}{\mathrm{k}_{\mathrm{Al}} \delta_{\mathrm{fin}}}$.

\subsubsection{Thermoelectric module}

To achieve the temperature of $-20^{\circ} \mathrm{C}$, the test plate is cooled using a thermoelectric module during the frost growth period. The capacity of the thermoelectric module is verified by using heat balance method. During the frost process, steady state is achieved when the heat flux from the cold side of the thermoelectric module equals the convection heat transfer to the chamber.

$$
\mathrm{q}_{\mathrm{c}}^{\prime \prime}=\mathrm{h}_{\mathrm{c}}\left(\mathrm{T}_{\mathrm{ch}}-\mathrm{T}_{\mathrm{s}}\right)
$$

The heat transfer coefficient in the chamber is approximated to be $25.5 \mathrm{~W} / \mathrm{m}^{2} / \mathrm{K}$. The chamber temperature ranges from $-10{ }^{\circ} \mathrm{C}$ to $25^{\circ} \mathrm{C}$, and test surface temperature is from $-20^{\circ} \mathrm{C}$ to $0{ }^{\circ} \mathrm{C}$. In order to achieve a large load, the maximum temperature difference and a scale factor of 2 are applied.

$$
\mathrm{q}_{\mathrm{c}}^{\prime \prime}=2 \times 25.5 \frac{\mathrm{W}}{\mathrm{m}^{2} \mathrm{~K}}(25-(-20)) \mathrm{K}=2295 \frac{\mathrm{W}}{\mathrm{m}^{2}} .
$$

The cold side temperature of the thermoelectric module is,

$$
\mathrm{T}_{\mathrm{c}}=-\frac{\mathrm{q}_{\mathrm{c}} \mathrm{t}}{\mathrm{k}_{\mathrm{Al}}}+\mathrm{T}_{\mathrm{s}} .
$$

As the thermal resistance is relatively small, the cold side temperature of the thermoelectric module is approximated to be the test surface temperature. when assuming the hot side temperature of the thermoelectric module to be $35^{\circ} \mathrm{C}$, the maximum temperature difference becomes $55^{\circ} \mathrm{C}$. Heat transfer on cold side is, 


$$
\mathrm{q}_{\mathrm{c}}=\mathrm{q}_{\mathrm{c}}^{\prime \prime} \mathrm{A}=2295 \frac{\mathrm{W}}{\mathrm{m}^{2}} \times 0.038^{2} \mathrm{~m}^{2}=3.3 \mathrm{~W}
$$

Referring to the thermoelectric module performance, current is approximated to be $5 \mathrm{~A}$, and voltage is $10 \mathrm{~V}$. The thermoelectric module, the input power is,

$$
\mathrm{Pwr}_{\text {in }}=\mathrm{I} \cdot \mathrm{U}=5 \mathrm{~A} \times 10 \mathrm{~V}=50 \mathrm{~W} .
$$

Heat transfer on hot side is,

$$
\mathrm{q}_{\mathrm{h}}=\mathrm{Pwr}_{\mathrm{in}}+\mathrm{q}_{\mathrm{c}}=53.3 \mathrm{~W} \text {. }
$$

The hot side temperature of the thermoelectric module is,

$$
\mathrm{T}_{\mathrm{h}}=\mathrm{T}_{\mathrm{a}}+\mathrm{R}_{\mathrm{th}, \mathrm{fin}} \mathrm{q}_{\mathrm{h}} .
$$

The thermal resistance of the heat sink is approximated with $0.1{ }^{\circ} \mathrm{C} / \mathrm{W}$. The hot side temperature is,

$$
\mathrm{T}_{\mathrm{h}}=25^{\circ} \mathrm{C}+0.1 \frac{{ }^{\circ} \mathrm{C}}{\mathrm{W}} \times 53.3 \mathrm{~W}=30^{\circ} \mathrm{C} \text {. }
$$

As the calculated hot side temperature is smaller than the assumed hot side temperature of $35^{\circ} \mathrm{C}$, the thermoelectric module is verified to be able to cool the test surface down to $-20^{\circ} \mathrm{C}$.

\subsubsection{Insulation}

The test chamber is wrapped with one-inch-thick lightweight polystyrene foam insulation. The heat flow rate $\left(\mathrm{k}\right.$-factor) ${ }^{18}$ of the insulation is 0.26 at $75^{\circ} \mathrm{F}$.

\footnotetext{
${ }^{18} \mathrm{k}$-factor is the time rate of steady heat flow through a unit area of homogeneous material induced by a unit temperature gradient in a direction perpendicular to that unit area.
} 


\subsection{Data acquisition and uncertainty analysis}

During the frost and defrost cycle, the frost properties include frost thickness, frost mass and frost density. The defrost properties include defrost time and efficiency.

\subsubsection{Data acquisition set}

Two important variables in the experiments are defrost time and defrost efficiency. A set of experiments carry out on different test surfaces with varying wettability. In Chapter 3, a theoretical efficiency is defined as the ratio of the energy required to melt the frost to the total heat applied at the surface.

$$
\eta_{\mathrm{df}}=\frac{(1-\varepsilon) \rho_{\mathrm{i}} \delta_{\mathrm{f}}\left[\mathrm{L}_{\mathrm{f}}+\left(\mathrm{c}_{\mathrm{p}}\right)_{\mathrm{i}} \Delta \mathrm{T}_{\mathrm{f}}\right]}{\mathrm{q}_{\mathrm{s}}^{\prime \prime} \mathrm{t}_{\mathrm{df}}} .
$$

In the experiments, a practical definition of defrost efficiency is,

$$
\begin{gathered}
\eta_{\mathrm{df}}=\frac{\text { energy required to melt the frost layer }}{\text { total actual energy consumption }} . \\
\eta_{\mathrm{df}}=\frac{\mathrm{m}_{\mathrm{f}}\left(\mathrm{L}_{\mathrm{f}}+\mathrm{c}_{\mathrm{p}, \mathrm{f}} \Delta \mathrm{T}_{\mathrm{f}}\right)}{\text { Pwr } * \mathrm{t}_{\mathrm{df}}} .
\end{gathered}
$$

Total energy required includes the sensible heat and latent heat to melt the frost layer. The energy consumption is the actual power output multiplied by the total defrost time. Defrost time includes the time for surface preheating, frost melting and the retention water drying-out.

The experimental data sets include a number of measurement variables and dependent variables. During the frost formation period, measurement variables are the temperature and humidity of the chamber, saturated air flow, temperature of the test surface, heat flux across the test plate, frost growing hours and actual power output. For the frost properties, when measuring frost thickness and mass directly, frost density is a dependent variable. During the defrost process, measurement variables are the temperature and humidity of the chamber, temperature at the test surface, heat flux across the test plate, defrost time and actual power output. Defrost efficiency is a dependent 
variable. Two sets of experimental data are acquired for the large test surface $(50 \times 50$ $\mathrm{mm})$ and small test surface $(38 \times 38 \mathrm{~mm})$. Frost grows for different period on the prepared surfaces. Defrost process runs with high heating power and low heating power.

\subsubsection{Measurement methods}

Measurements include the air temperature and humidity inside the chamber, the temperature at the test surface, heat flux across the test surface, air flow, defrost time, frost thickness and frost mass.

The temperature inside the chamber is measured by a shielded type $T$ thermocouples installed at the chamber wall and a thin-film $100 \Omega$ platinum RTD included in the relative humidity temperature transmitter. The humidity transmitter with a current output 4 to $20 \mathrm{~mA}$ is used to monitor the relative humidity inside the chamber. Saturated air flow is adjusted by a glass tube flowmeter to control the chamber humidity.

The temperature of the test surface is measured with five type $\mathrm{T}$ thermocouples. Four of them are placed into the holes at the four corners of the test plate, and one is in the groove at the center. Thermocouples are sealed with high thermal conductive epoxy. Heat flux across the test surface is measured by a heat flux sensor that functions as a selfgenerating thermopile transducer. The readout is obtained by connecting to a DC microvoltmeter. A built-in Type-K thermocouple is used to measure the heat flux sensor temperature. When the test plate is dry, heat transfer coefficient is calculated by measuring the heat flux across the test surface, the temperature at the test surface, and the air temperature inside the chamber at steady state.

Frost thickness is measured via imaging technique. A camera is seated at the side of the test chamber to capture images of the frost thickness. The images are processed in ImageJ. The thickness measured by imaging might be larger than the actual thickness of the frost layer due to the edge effect. A correlation derived by Janssen [10] is used in the frost thickness measurement.

$$
\delta_{\mathrm{f}}=0.0045 \Theta^{(\Theta-4.721)} \mathrm{t}^{\Theta}
$$

where the dimensionless temperature is, 
Table 5.2. Instrument accuracies.

\begin{tabular}{ccc}
\hline Measurement & Instrument & Accuracy \\
\hline Temperature & Type-T thermocouple & $\pm 0.5{ }^{\circ} \mathrm{C}$ \\
Humidity/Temperature & Omega HX94C & $\pm 2 \% / \pm 0.6^{\circ} \mathrm{C}$ \\
Heat flux & Omega HFS-4 & $\pm 0.5 \%$ \\
Flow & Omega FL2012 & $\pm 5 \%$ \\
Time & Agilent BenchLink Data Logger 3 & $0.01 \mathrm{~s}$ \\
Mass & Electrical scale & $\pm 3 \mathrm{mg}$ \\
\hline
\end{tabular}

$$
\Theta=\frac{\mathrm{T}_{\mathrm{a}}-\mathrm{T}_{\mathrm{dp}}}{\mathrm{T}_{\mathrm{a}}-\mathrm{T}_{\mathrm{w}}} .
$$

Total mass of the frost column is calculated by weighing the saturator before and after the frost growth. The mass of the meltwater is also measured. Frost mass can be determined by obtaining the weight reduction of the water in the saturator and the change of vapor pressure in the chamber, or by weighing the meltwater.

$$
\begin{gathered}
\Delta \mathrm{m}_{\mathrm{f}}=\Delta \mathrm{m}_{\mathrm{sat}}-\Delta \mathrm{m}_{\mathrm{v}}, \\
\Delta \mathrm{m}_{\mathrm{v}}=\frac{\Delta \mathrm{P}_{\mathrm{v}} \mathrm{VM}_{\mathrm{v}}}{\overline{\mathrm{R}} \mathrm{T}_{\mathrm{ch}}} \\
\Delta \mathrm{P}_{\mathrm{v}}=\Delta \Phi \mathrm{P}_{\mathrm{g}},
\end{gathered}
$$

where $\Phi$ is the relative humidity of air inside the chamber, and $\mathrm{P}_{\mathrm{g}}$ is the saturated pressure at the chamber temperature.

A tabulated list of measurements and instruments is in Appendix C.

\subsubsection{Experimental uncertainty}

The uncertainty of the direct measurement variables refers to the manufacturer's specification as listed in Table 5.2. 
Table 5.3. Uncertainty of dependent variables.

\begin{tabular}{cc}
\hline Measurement & Accuracy \\
\hline Frost thickness & $\pm 0.01 \mathrm{~mm}$ \\
Frost mass & $\pm 5 \%$ \\
Defrost efficiency & $\pm 10 \%$ \\
\hline
\end{tabular}

The uncertainty of dependent variables is determined by the root sum of squares method. Uncertainty of frost thickness depends on the pixel calibration by using the visual imaging technique. An uncertainty of $\pm 0.01 \mathrm{~mm}$ can be obtained with good calibration.

The uncertainty of frost mass can be calculated by,

$$
\mathrm{U}_{\mathrm{m}_{\mathrm{f}}}=\sqrt{\left(\frac{\partial \mathrm{m}_{\mathrm{f}}}{\partial \mathrm{m}_{\mathrm{sat}}} \mathrm{U}_{\mathrm{m}_{\mathrm{sat}}}\right)^{2}+\left(\frac{\partial \mathrm{m}_{\mathrm{f}}}{\partial \mathrm{m}_{\mathrm{vap}}} \mathrm{U}_{\mathrm{m}_{\mathrm{vap}}}\right)^{2}}=\sqrt{\left(\mathrm{U}_{\mathrm{m}_{\mathrm{sat}}}\right)^{2}+\left(\mathrm{U}_{\left.\mathrm{m}_{\mathrm{vap}}\right)^{2}}\right.} .
$$

The uncertainty of vapor mass can be given by,

$$
\begin{gathered}
\mathrm{U}_{\mathrm{m}_{\text {vap }}}=\sqrt{\left(\frac{\partial \mathrm{m}_{\mathrm{vap}}}{\partial \Phi} \mathrm{U}_{\Phi}\right)^{2}+\left(\frac{\partial \mathrm{m}_{\mathrm{vap}}}{\partial \mathrm{T}_{\mathrm{ch}}} \mathrm{U}_{\mathrm{T}_{\mathrm{ch}}}\right)^{2}}, \\
\mathrm{U}_{\mathrm{m}_{\mathrm{vap}}}=\sqrt{\left(\frac{\mathrm{P}_{\mathrm{g}} \mathrm{VM}_{\mathrm{vap}}}{\overline{\mathrm{R}} \mathrm{T}_{\mathrm{ch}}} \mathrm{U}_{\Phi}\right)^{2}+\left(\frac{\Delta \Phi \mathrm{P}_{\mathrm{g}} \mathrm{VM}_{\mathrm{vap}}}{\overline{\mathrm{R}} \mathrm{T}_{\mathrm{ch}}{ }^{2}} \mathrm{U}_{\mathrm{T}_{\mathrm{ch}}}\right)^{2}} .
\end{gathered}
$$

Defrost efficiency is given by,

$$
\mathrm{U}_{\eta_{\mathrm{df}}}=\sqrt{\left(\frac{\partial \eta_{\mathrm{df}}}{\partial \mathrm{m}_{\mathrm{f}}} \mathrm{U}_{\mathrm{m}_{\mathrm{f}}}\right)^{2}+\left(\frac{\partial \eta_{\mathrm{df}}}{\partial \mathrm{T}_{\mathrm{f}}} \mathrm{U}_{\mathrm{T}_{\mathrm{f}}}\right)^{2}+\left(\frac{\partial \eta_{\mathrm{df}}}{\partial \mathrm{q}_{\mathrm{s}}} \mathrm{U}_{\mathrm{q}_{\mathrm{s}}}\right)^{2}+\left(\frac{\partial \eta_{\mathrm{df}}}{\partial \mathrm{t}_{\mathrm{df}}} \mathrm{U}_{\mathrm{t}_{\mathrm{df}}}\right)^{2}}
$$

The uncertainty of the dependent variables is listed in Table 5.3. 
Table 5.4. Characterization of the sample surfaces.

\begin{tabular}{|c|c|c|c|c|c|}
\hline $\begin{array}{c}\text { Surface } \\
\text { structure }\end{array}$ & Sample 1 & Sample 2 & Sample 3 & Sample 4 & Sample 5 \\
\hline Surface material & $\mathrm{Al} 6061$ & $\mathrm{Al} 6061$ & $\mathrm{Al} 6061$ & $\mathrm{Al} 6061$ & $\mathrm{Al} 6061$ \\
\hline $\begin{array}{l}\text { Surface } \\
\text { machining }\end{array}$ & $\begin{array}{l}32 \mu \mathrm{in} . \text { or } \\
0.8 \mu \mathrm{m}\end{array}$ & $\begin{array}{l}32 \mu \mathrm{in} . \text { or } \\
0.8 \mu \mathrm{m}\end{array}$ & $\begin{array}{l}32 \mu \mathrm{in} . \text { or } \\
0.8 \mu \mathrm{m}\end{array}$ & $\begin{array}{l}32 \mu \mathrm{in} . \text { or } \\
0.8 \mu \mathrm{m}\end{array}$ & $\begin{array}{l}32 \mu \mathrm{in} . \text { or } \\
0.8 \mu \mathrm{m}\end{array}$ \\
\hline $\begin{array}{c}\text { Surface finish } \\
\text { with } 320 \text { grit } \\
\text { sandpaper }\end{array}$ & $\begin{array}{l}8 \mu \mathrm{in} . \text { or } \\
0.2 \mu \mathrm{m}\end{array}$ & $\begin{array}{l}8 \mu \text { in. or } \\
0.2 \mu \mathrm{m}\end{array}$ & $\begin{array}{l}8 \mu \mathrm{in} . \text { or } \\
0.2 \mu \mathrm{m}\end{array}$ & $\begin{array}{l}8 \mu \mathrm{in} . \text { or } \\
0.2 \mu \mathrm{m}\end{array}$ & $\begin{array}{l}8 \mu \mathrm{in} . \text { or } \\
0.2 \mu \mathrm{m}\end{array}$ \\
\hline Surface coating & $\begin{array}{l}\text { Hydrochloric } \\
\text { acid }\end{array}$ & $\begin{array}{l}\text { Commercial } \\
\text { hydrophilic } \\
\text { coating }\end{array}$ & Plain & $\begin{array}{l}\text { Solution of } \\
\text { stearic acid } \\
\text { and acetone }\end{array}$ & $\begin{array}{l}\text { Commercial } \\
\text { hydrophobic } \\
\text { coating }\end{array}$ \\
\hline $\begin{array}{l}\text { Static contact } \\
\text { angle }\left({ }^{\circ}\right)\end{array}$ & $<5$ & 51 & 71 & 119 & 146 \\
\hline
\end{tabular}

\subsection{Surface preparation}

The test surfaces are treated for five different contact angles. Surface wettability can be modified in two ways. One way is to change the micro structure of the surface, and another way is to alter the surface energy with chemical treatment. The treatment methods are characterized in Table 5.4. The superhydrophilic surface is obtained by soaking the test plate in $17 \%$ hydrochloric acid solution for about $10 \mathrm{~min}$ and rinsing with distilled water. A hydrophilic coating applies to the test plate for the hydrophilic surface with contact angle of $51^{\circ}$. The hydrophobic surface is obtained by soaking the test plate in the solution of stearic acid and acetone $(0.284 \mathrm{~g} / 100 \mathrm{ml})$. A commercial hydrophobic coating, NeverWet superhydrophobic coating, applies on the plate to get a superhydrophobic surface with contact angle of about $146^{\circ}$.

The static contact angles are measured using the sessile drop method. A $1 \mathrm{ml}$ needle pump is used to apply droplet on the test surface with one droplet volume is about $3 \mu \mathrm{l}$. The geometries of the droplets are taken with Bigcatch DCM510C and Navitar zoom 7000 as shown in Fig. 5.7. The contact angles are measured using the open program ImageJ. The advancing and receding contact angles are measured on a tilted plate with adjustable sliding angles. The pictures are taken where the droplet grows large enough to roll down the tilted plate as shown in Fig. 5.8. 

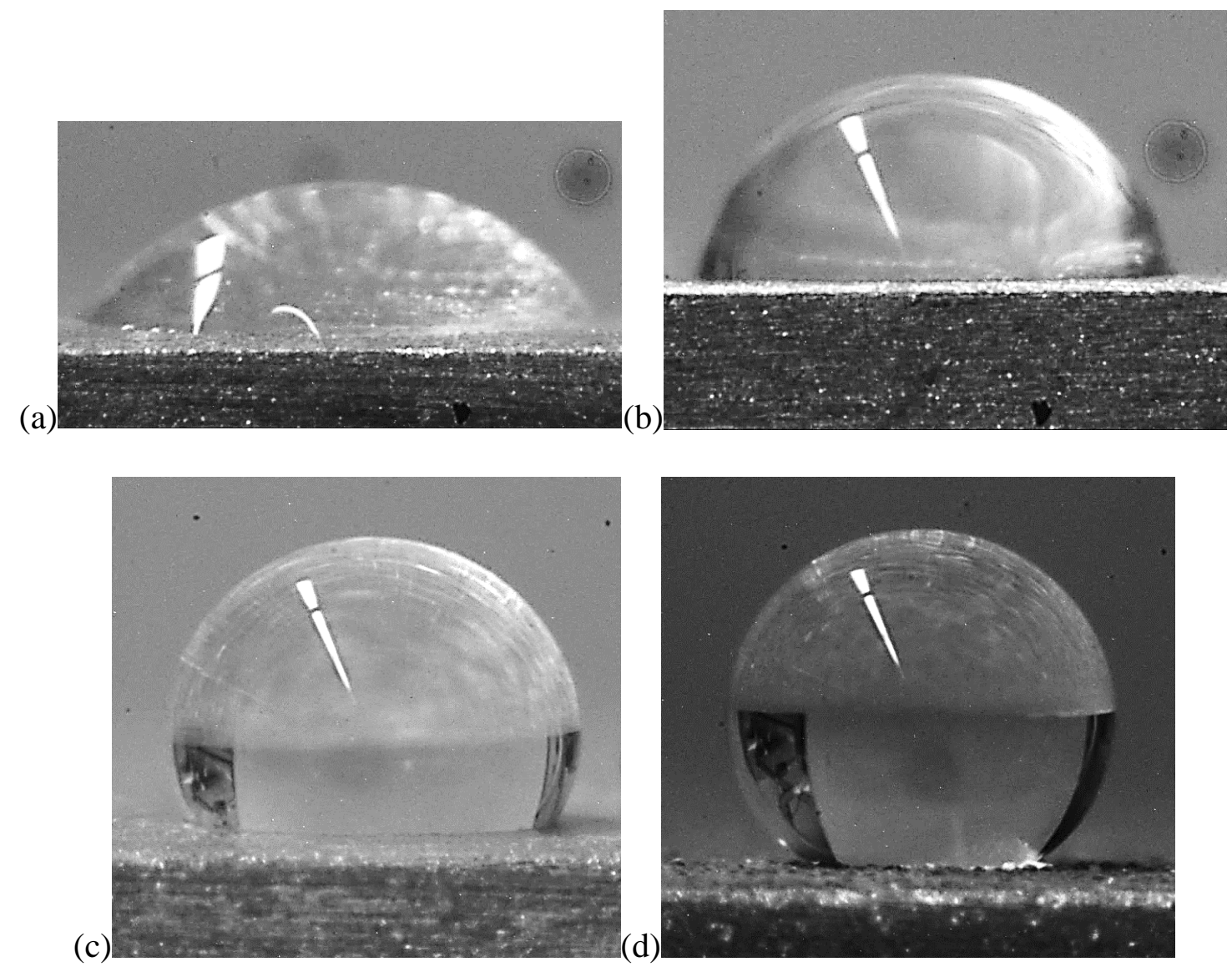

Figure 5.7. Static contact angles.

(a) $\mathrm{CA}=51^{\circ}$; (b) $\mathrm{CA}=71^{\circ}$; (c) $\mathrm{CA}=119^{\circ}$; (d) $\mathrm{CA}=146^{\circ}$.

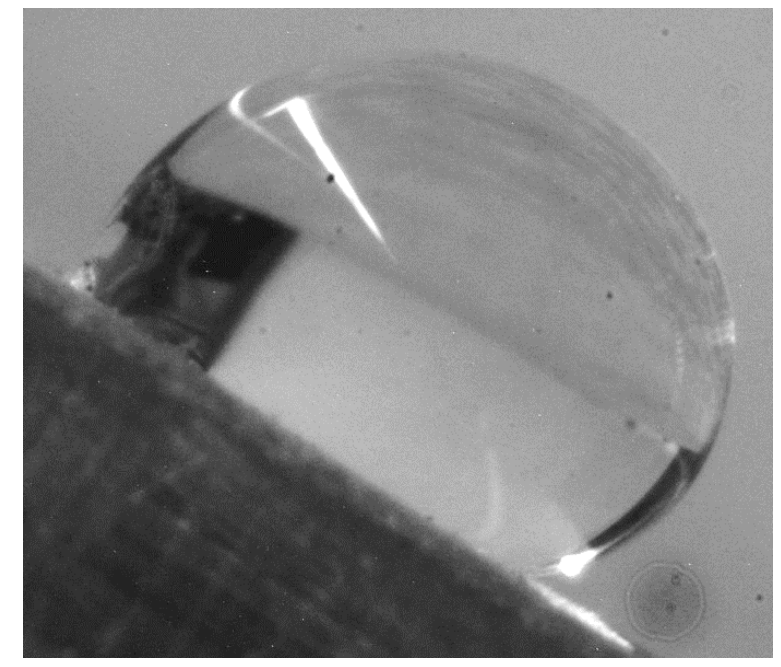

Figure 5.8. Dynamic contact angles. $\theta \mathrm{rec}=107^{\circ}, \operatorname{\theta adv}=149^{\circ}$ ( sliding angle $\sim 28^{\circ}$ ). 


\section{Results}

\subsection{Analytical and numerical results}

In the absorption stage, the frost layer at the test surface melts, and the melting rate depends on the heat flux applied at the test surface, latent heat of fusion, and the density of the permeation layer at the test surface. The relation of the rate of melting with the heat flux and the porosity of the frost layer is described in Eqn. (3.3) and shown in Figs. 6.1. and 6.2.

The rate of melting increases with the porosity smoothly. When the frost layer is less dense, the melting process goes faster. The rate of melting increases from $0.01 \mathrm{~mm} / \mathrm{s}$ to $0.1 \mathrm{~mm} / \mathrm{s}$ when the porosity increases from 0.1 to 0.9 . When the porosity is 0.4 , the rate of melting is $0.016 \mathrm{~mm} / \mathrm{s}$. For a frost layer with $3 \mathrm{~mm}$, the melting time is $187 \mathrm{~s}$.

The dependence of the rate of melting on the heat flux is linear. The rate of melting is directly proportional to the heat flux applied and increases from $5.5 \times 10^{-4} \mathrm{~mm} / \mathrm{s}$ to $0.03 \mathrm{~mm} / \mathrm{s}$ when the heat flux increases from $300 \mathrm{~W} / \mathrm{m}^{2}$ to $6000 \mathrm{~W} / \mathrm{m}^{2}$ where the porosity is 0.4 .

In the absorption stage, water saturation $\mathrm{S}$ is a function of time and location as described in Eqns. (3.10), (4.4). The distribution of water saturation depends on the permeability of the porous medium and capillary pressure, which are assumed to be functions of the water saturation. The relation of the water saturation with time and location are show in Figs. 6.3. and 6.4. The permeability power index and the capillary pressure are not available for the frost column in the current literatures. The values used herein are for snow in the references [76-78]. It is shown that water saturation increases with time and decreases with location due to the meltwater transportation. At the location that is close to the surface, the water saturation increases rapidly in a second as the boundary condition at the surface is assumed to be one. The energy balance in frost layer are described in Eqns. (3.12), (4.12). Dimensionless temperature distribution and evolution are shown in Figs. 6.5. and 6.6. Dimensionless temperature decreases with time and location. Dimensionless temperature at the frost/air interfaces is close to 0.14 at 10 s. The dimensionless temperature profile becomes flat at about the half of the thickness. 


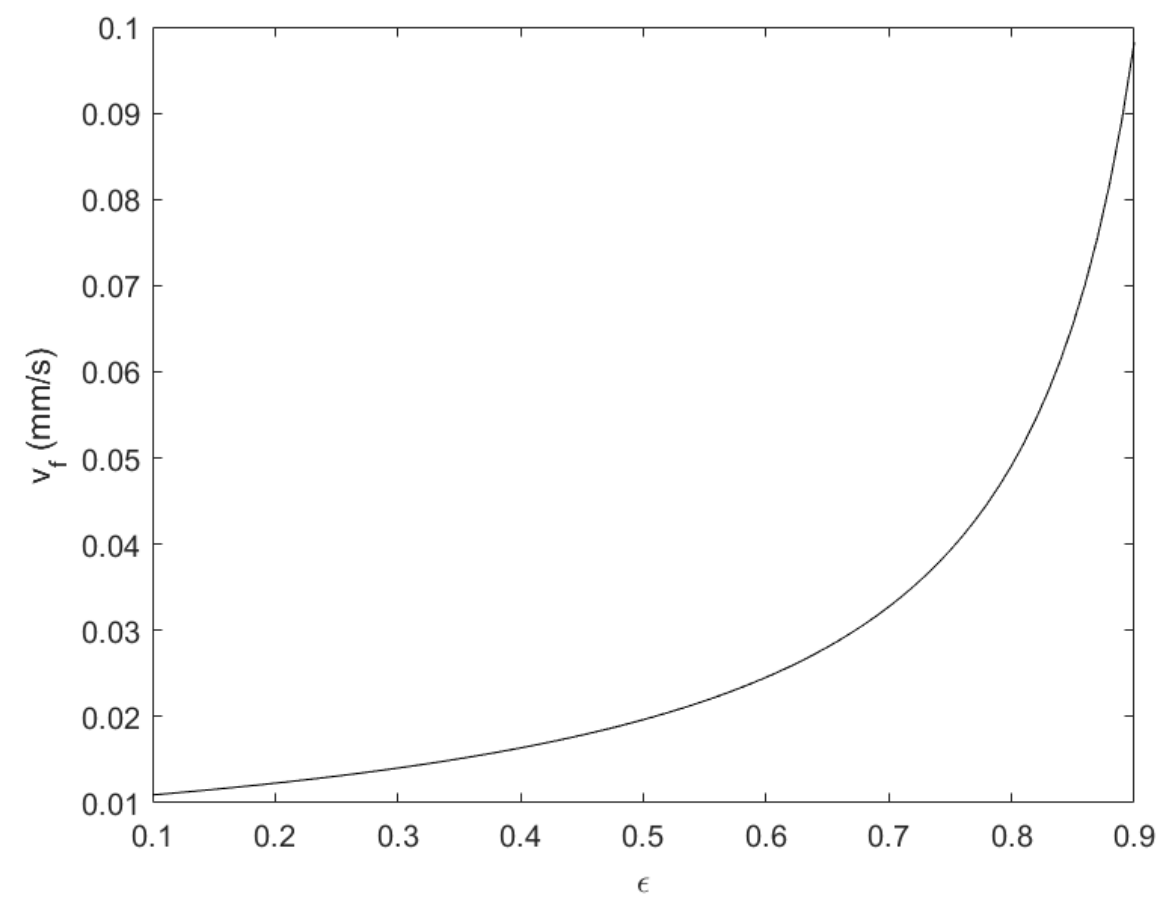

Figure 6.1. The rate of melting versus porosity. qs" $=3000 \mathrm{~W} / \mathrm{m}^{2}$.

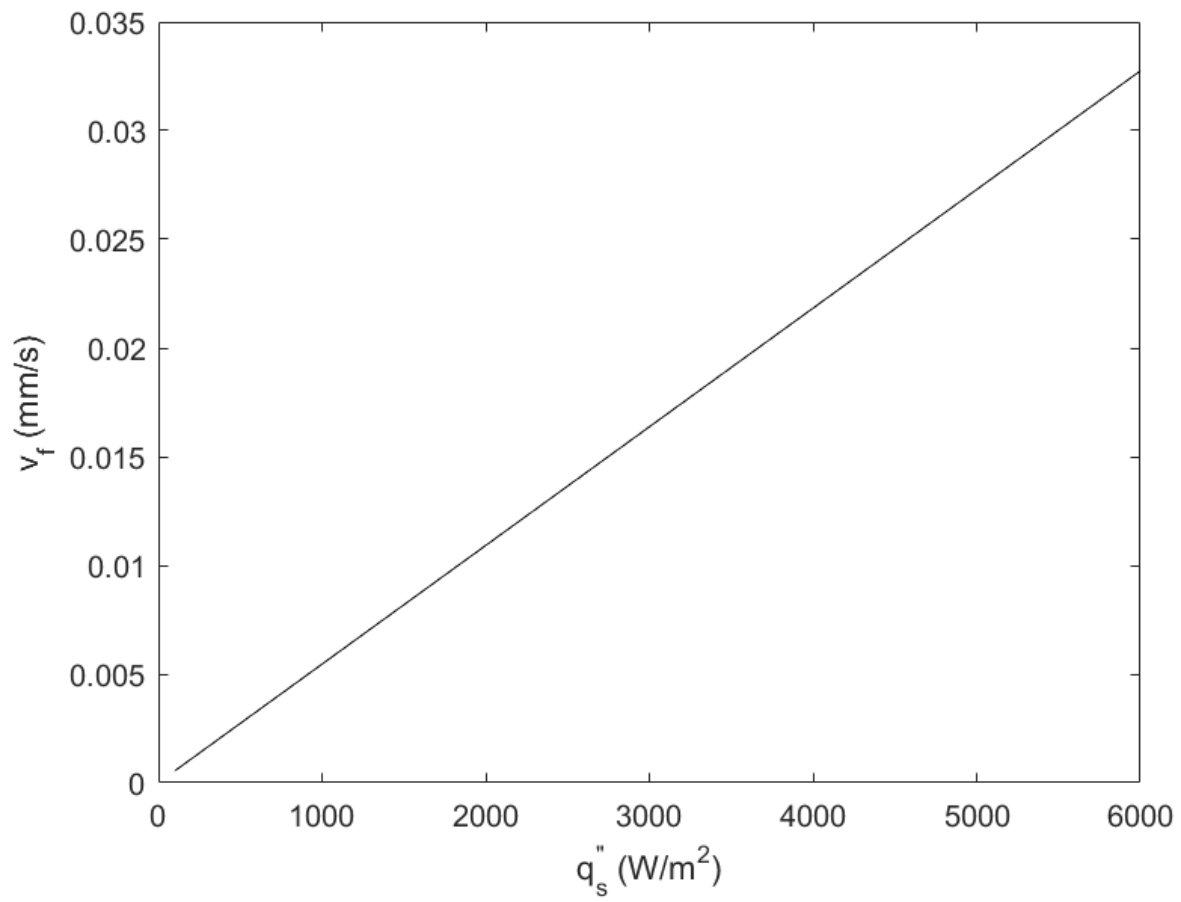

Figure 6.2. The rate of melting versus heat flux applied at the test surface. $\varepsilon=0.4$. 


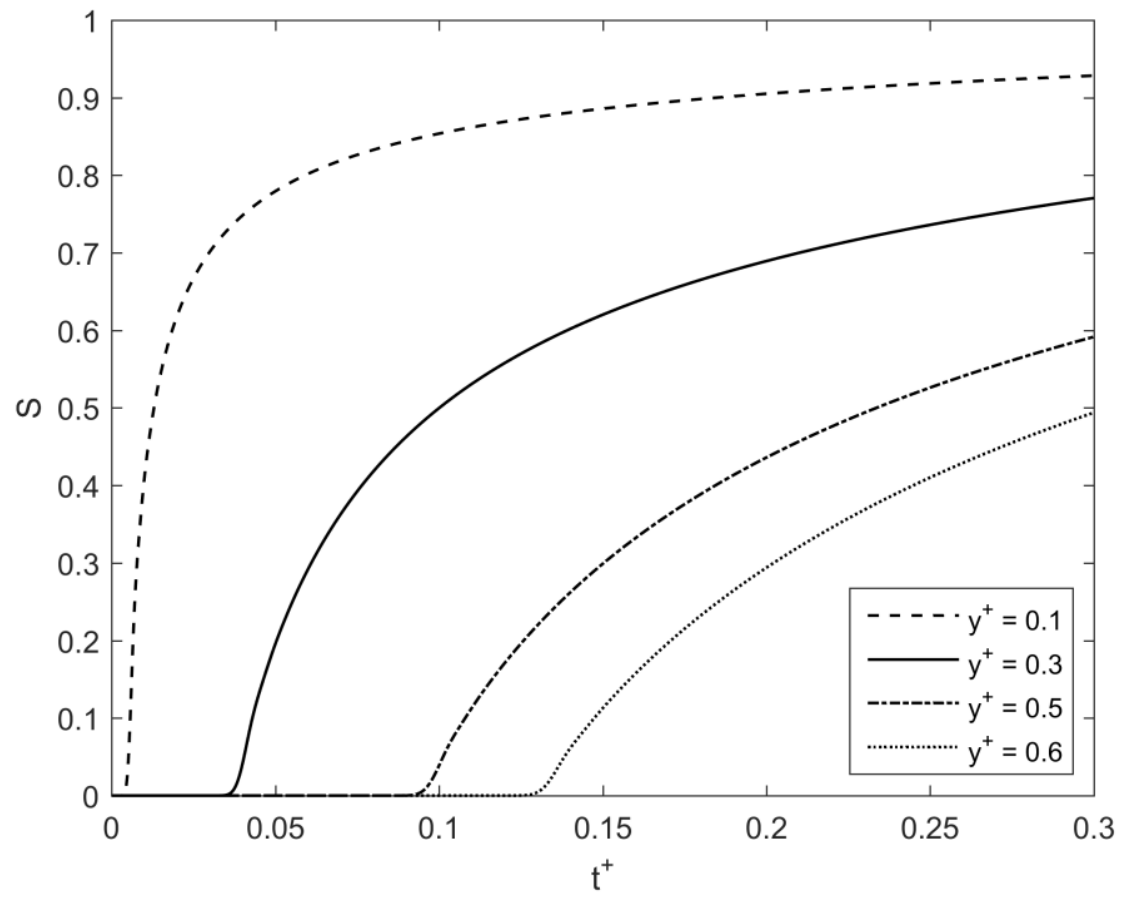

Figure 6.3. Water saturation versus time.

$\mathrm{q}_{\mathrm{s}} "=3000 \mathrm{~W} / \mathrm{m}^{2}, \varepsilon=0.6, \delta_{\mathrm{f}}=5 \mathrm{~mm}, \mathrm{p}=3, \mathrm{q}=1, \mathrm{~K}=3 \times 10^{-12} \mathrm{~m}^{2}, \mathrm{C}=43 \mathrm{~Pa}$.

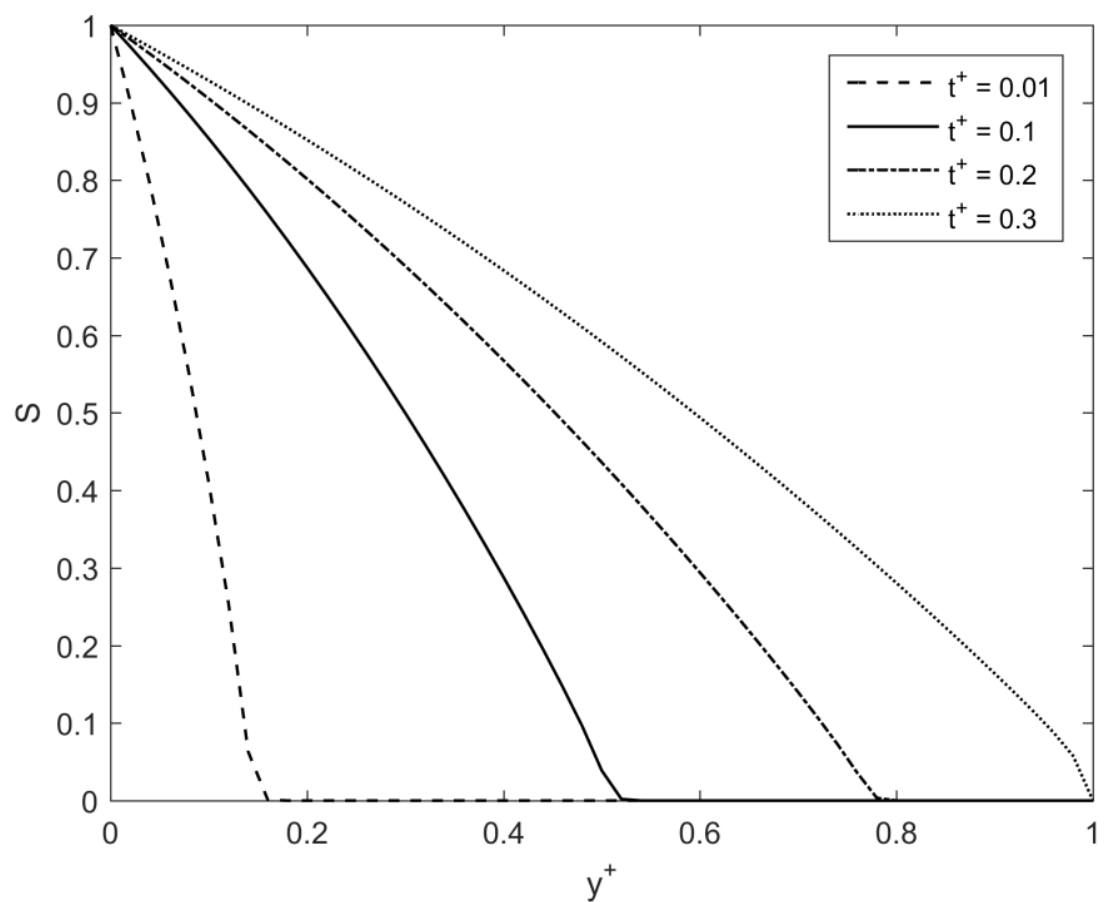

Figure 6.4. Water saturation versus location.

$\mathrm{q}_{\mathrm{s}} "=3000 \mathrm{~W} / \mathrm{m}^{2}, \varepsilon=0.6, \delta_{\mathrm{f}}=5 \mathrm{~mm}, \mathrm{p}=3, \mathrm{q}=1, \mathrm{~K}=3 \times 10^{-12} \mathrm{~m}^{2}, \mathrm{C}=43 \mathrm{~Pa}$. 


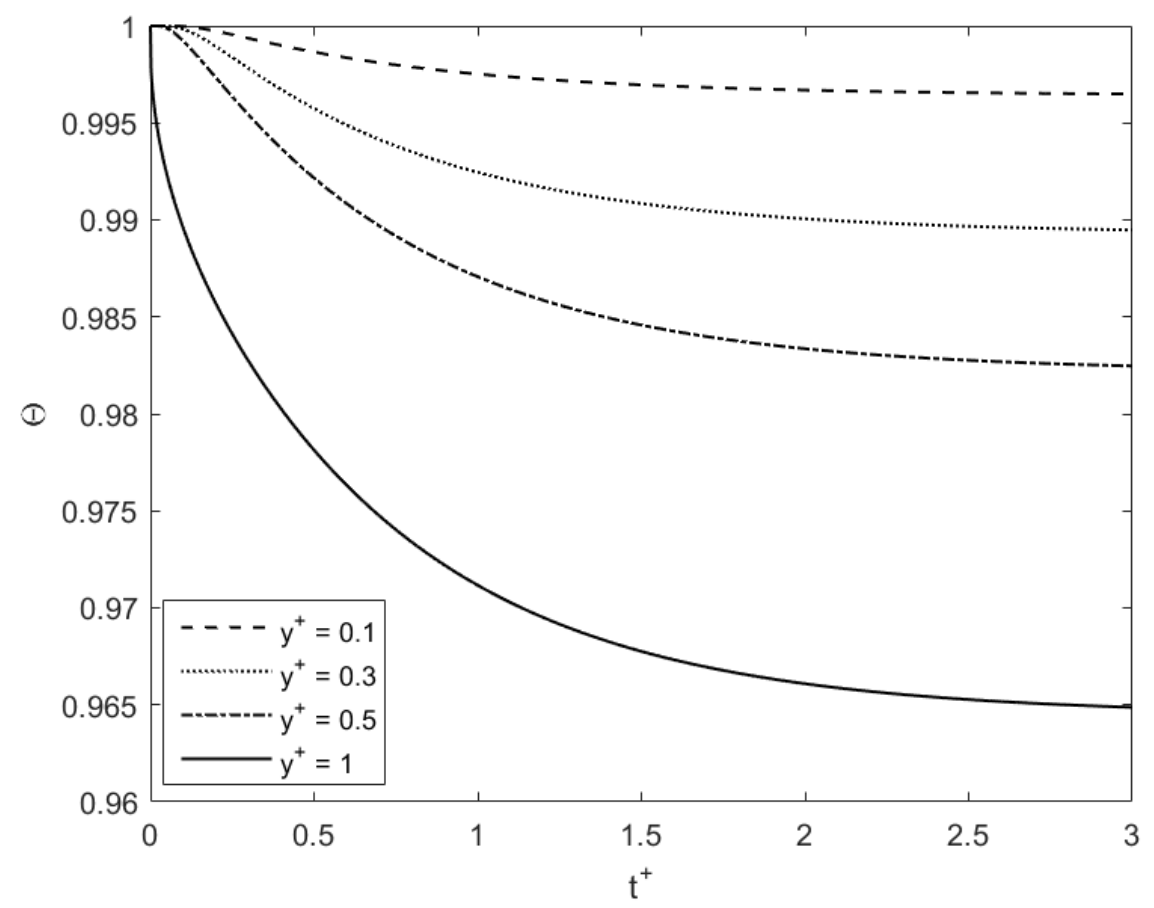

Figure 6.5. Dimensionless temperature of frost layer versus time. $\mathrm{q}_{\mathrm{s}} "=3000 \mathrm{~W} / \mathrm{m}^{2}, \varepsilon=0.7, \delta_{\mathrm{f}}=5 \mathrm{~mm}, \mathrm{~h}_{\mathrm{a}}=5 \mathrm{~W} / \mathrm{m}^{2}-\mathrm{K}$.

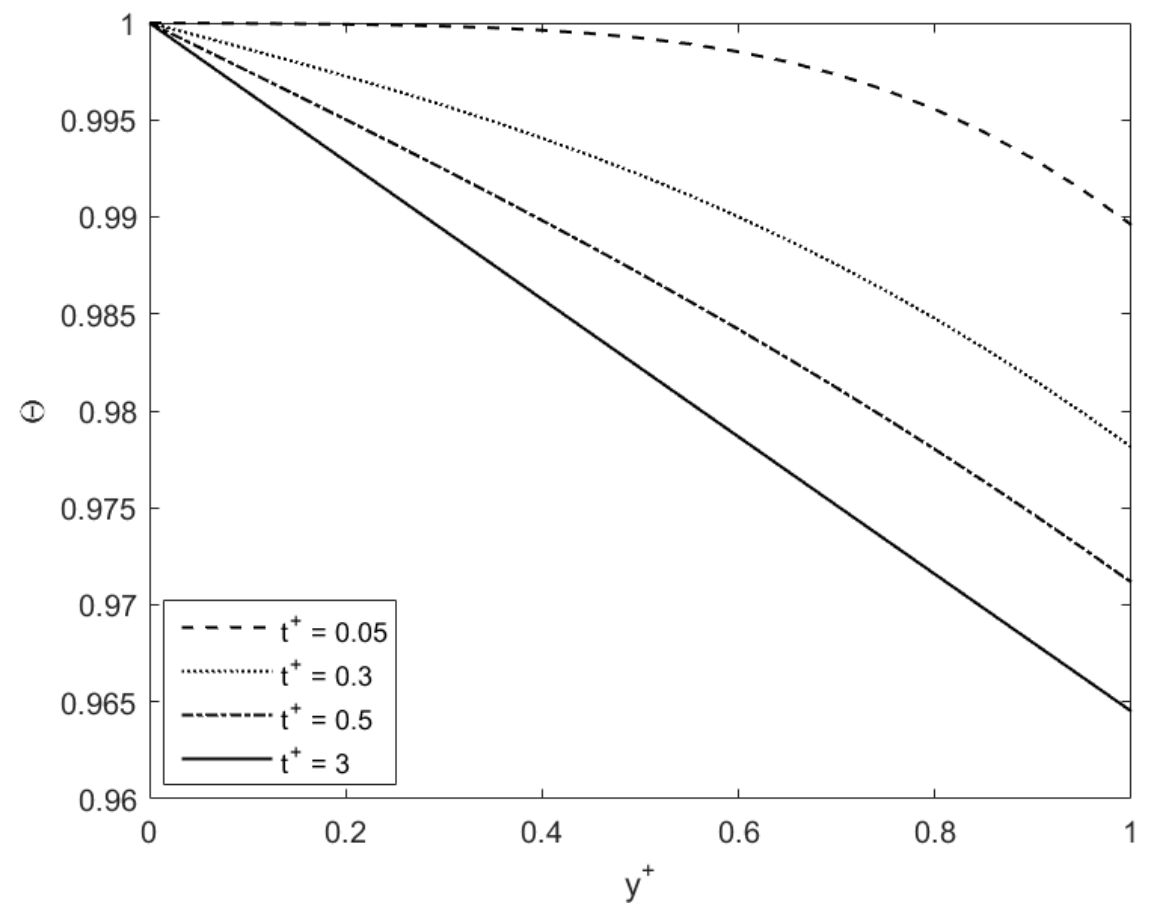

Figure 6.6. Dimensionless temperature distribution in frost layer. $\mathrm{q}_{\mathrm{s}} "=3000 \mathrm{~W} / \mathrm{m}^{2}, \varepsilon=0.7, \delta_{\mathrm{f}}=5 \mathrm{~mm}, \mathrm{~h}_{\mathrm{a}}=5 \mathrm{~W} / \mathrm{m}^{2}-\mathrm{K}$. 


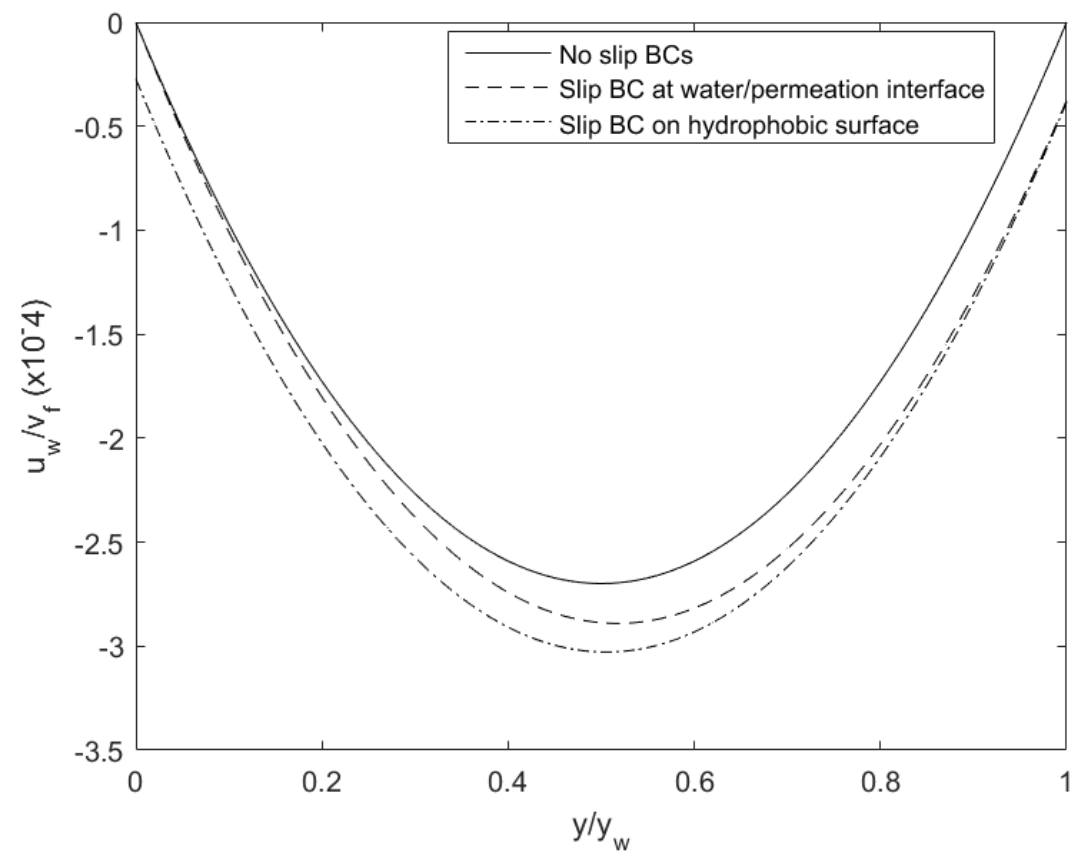

Figure 6.7. Comparison of draining velocities with different boundary conditions. $\alpha=1.2, \mathrm{~K}=10^{-9} \mathrm{~m}^{2}, \mathrm{~b}=20 \mu \mathrm{m}$.

Draining velocities are described in Eqns. (4.37), (4.38). The velocity profiles are determined by the boundary conditions at the solid/water interface and at the water/permeation interface. The curves in Fig. 6.7 are the dimensionless drainage velocities with respect to the variant boundary conditions. Three boundary conditions are presented, and they are no slip boundary conditions at the solid/water interface and at the water/permeation interface, no slip boundary condition at the solid/water interface, and slip boundary condition at the water/permeation interface, slip condition for hydrophobic surface at the solid/water interface and slip condition at the water/permeation interface. The maximum draining velocity occurs when slip conditions are applied to the boundaries at the two interfaces. To better show the improvement of drainage process on the hydrophobic surface, the maximum and the average drainage velocity and the average drainage rate are quantified and listed in Table 6.1.

The drainage velocity depends on fluid properties, the slip length at the solid/water interface, the water film thickness, the slip coefficient at the water/permeation interface, and the permeability of the porous medium. Slip condition results from an 
Table 6.1. Comparison of drainage velocity and average drainage rate.

\begin{tabular}{|l|c|c|c|c|}
\hline & $\begin{array}{c}\text { Maximum } \\
\text { velocity } \\
(\mathbf{m} / \mathbf{s})\end{array}$ & $\begin{array}{c}\text { Average } \\
\text { velocity } \\
(\mathbf{m} / \mathbf{s})\end{array}$ & $\begin{array}{c}\text { Average drainage } \\
\text { rate } \\
\left(\mathbf{m}^{\mathbf{3} / \mathbf{s})}\right.\end{array}$ & $\begin{array}{c}\text { Improvement } \\
\text { of draining } \\
\text { rate }(\%)\end{array}$ \\
\hline $\begin{array}{l}\text { No slip condition at the } \\
\text { solid/water interface and at } \\
\text { the water/permeation } \\
\text { interface }\end{array}$ & 0.437 & 0.288 & $8.9 \times 10^{-6}$ & \\
\hline $\begin{array}{l}\text { No slip condition at the } \\
\text { solid/water interface and } \\
\text { slip condition at the } \\
\text { water/permeation interface }\end{array}$ & 0.468 & 0.318 & $9.83 \times 10^{-6}$ & 10 \\
\hline $\begin{array}{l}\text { Slip condition at the } \\
\text { solid/water interface and at } \\
\text { the water/permeation } \\
\text { interface }\end{array}$ & 0.49 & 0.341 & $1.05 \times 10^{-5}$ & 7.1 \\
\hline
\end{tabular}

*Note: Melting rate is $0.016 \mathrm{~mm} / \mathrm{s}$ where the heat flux applied is $3000 \mathrm{~W} / \mathrm{m}^{2}$ and the porosity is 0.4 . The thickness of water film is $0.8 \mathrm{~mm}$ and the width of the plate is $38 \mathrm{~mm}$.

interplay of many physical and chemical parameters. The influencing factors include the surface wettability, surface roughness, and impurities and shear rate. On a macroscopic level, a large scale of the slip length can be explained as a formation of gas film or phase separated lubricant with lower viscosity between the fluid and the solid wall. An engineered nanostructured superhydrophobic surface can minimize the liquid-solid contact area so that the liquid flows over a layer of air. The surface demonstrates dramatic slip effects with a slip length of $\sim 20 \mu \mathrm{m}$ in water flow. The effect of slip length on the drainage velocity is shown in Fig. 6.8.

The slip coefficient is experimentally determined and depends on the structure of the material at the surface. The experiments show that the slip coefficient of a metal material depends directly on the "average pore diameter" at the interface. The study on the slip coefficient applies to the experimental condition where the gap between the permeable wall and the impermeable wall is much larger than the pore size of the porous material. Taylor and Richardson [91,92] propose a mathematical model and compare the results between the theory and the experiments. The study demonstrates that the slip coefficient is not independent of the external means that producing the external tangential stress. Sahraoui and Kaviany [93] investigate the two-dimensional flow field near the porous medium made of cylinders. The simulation shows that the slip coefficient depends on structure, porosity, flow direction, Reynolds number, the extent of the plain medium 


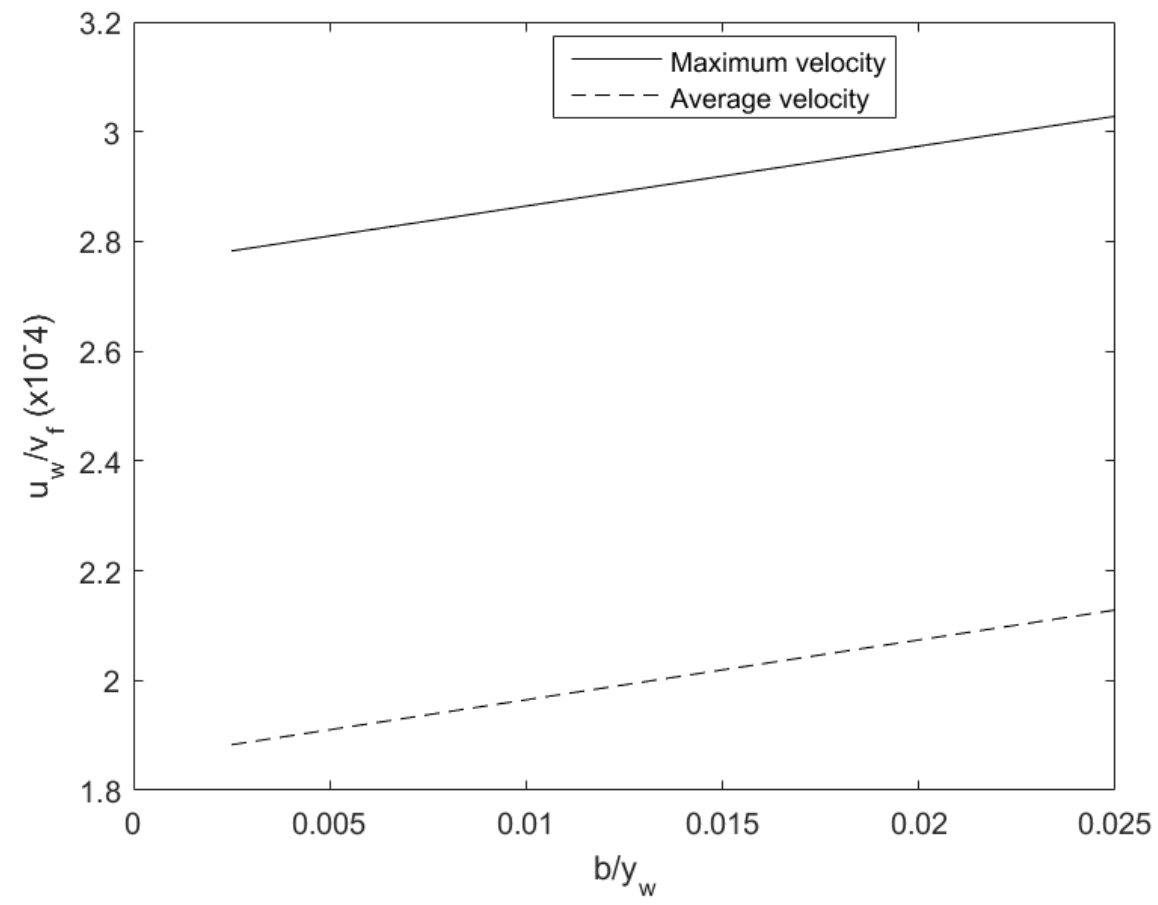

Figure 6.8. The effect of slip length on the draining velocity.

and the non-uniformities in the arrangement of surface particles.

During the drainage stage, defrost time and efficiency are given in Eqns. (3.31), (3.32). Defrost time and efficiency are determined by the heat flux applied at the test surface, the thickness of the water film, the porosity and thickness of the frost layer. Defrost time consists of melting time and draining time. Porosity and applied heat flux are the two factors that can influence the melting time significantly. The relation of melting time with frost thickness and ambient temperature are shown in Figs. 6.9. and 6.10 .

Draining time depends on the porosity, the frost thickness, the height of the plate and the water film thickness, as shown in Figs. 6.11.- 6.14. It is shown that the water film thickness significantly influences the drainage time. Draining time decreases with increase of the porosity and increases with the frost thickness. Draining time decreases from $137 \mathrm{~s}$ to $0.14 \mathrm{~s}$ when the water film thickness increases from $0.1 \mathrm{~mm}$ to $1 \mathrm{~mm}$, and it decreases sharply with the water film thickness from $0.1 \mathrm{~mm}$ to $0.2 \mathrm{~mm}$ and goes flat around $0.4 \mathrm{~mm}$. 


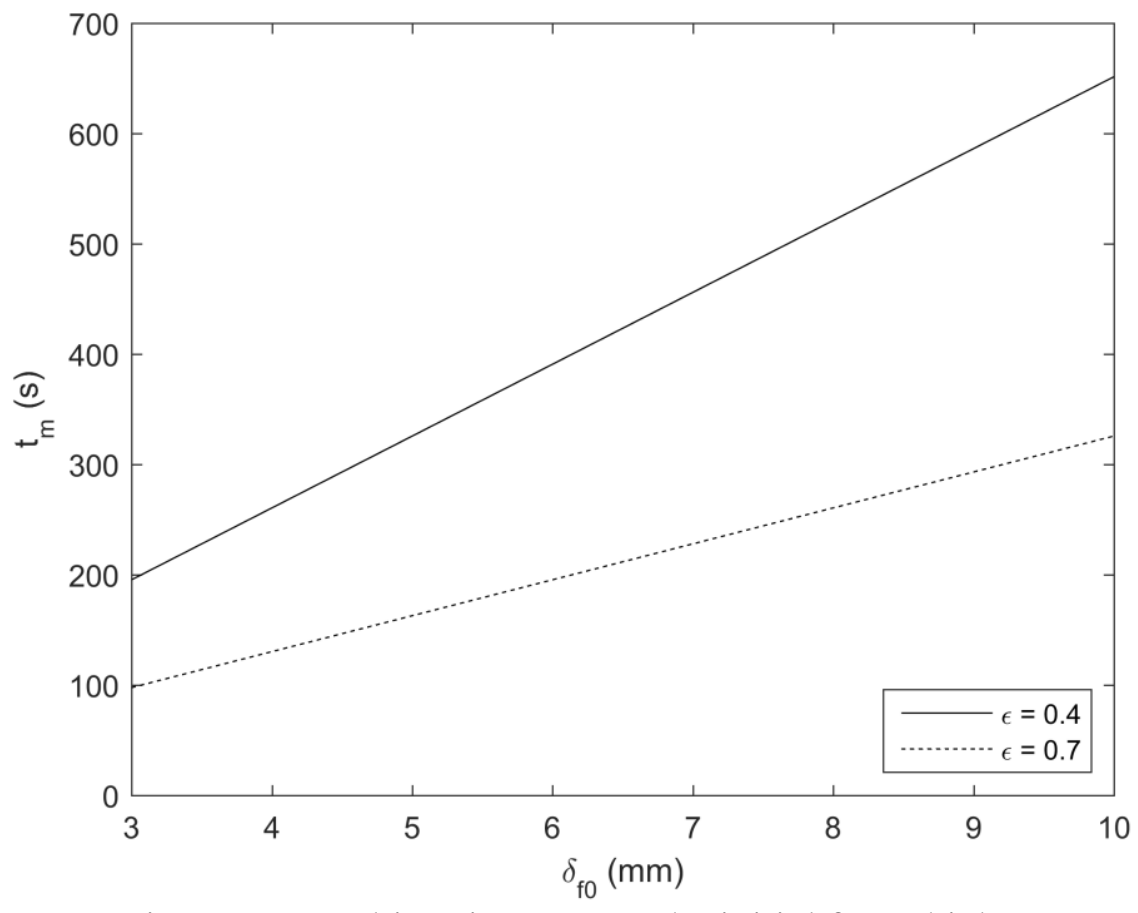

Figure 6.9. Melting time versus the initial frost thickness. $\mathrm{q}_{\mathrm{s}}=3000 \mathrm{~W} / \mathrm{m}^{2}, \mathrm{~T}_{\mathrm{a}}=-5^{\circ} \mathrm{C}$.

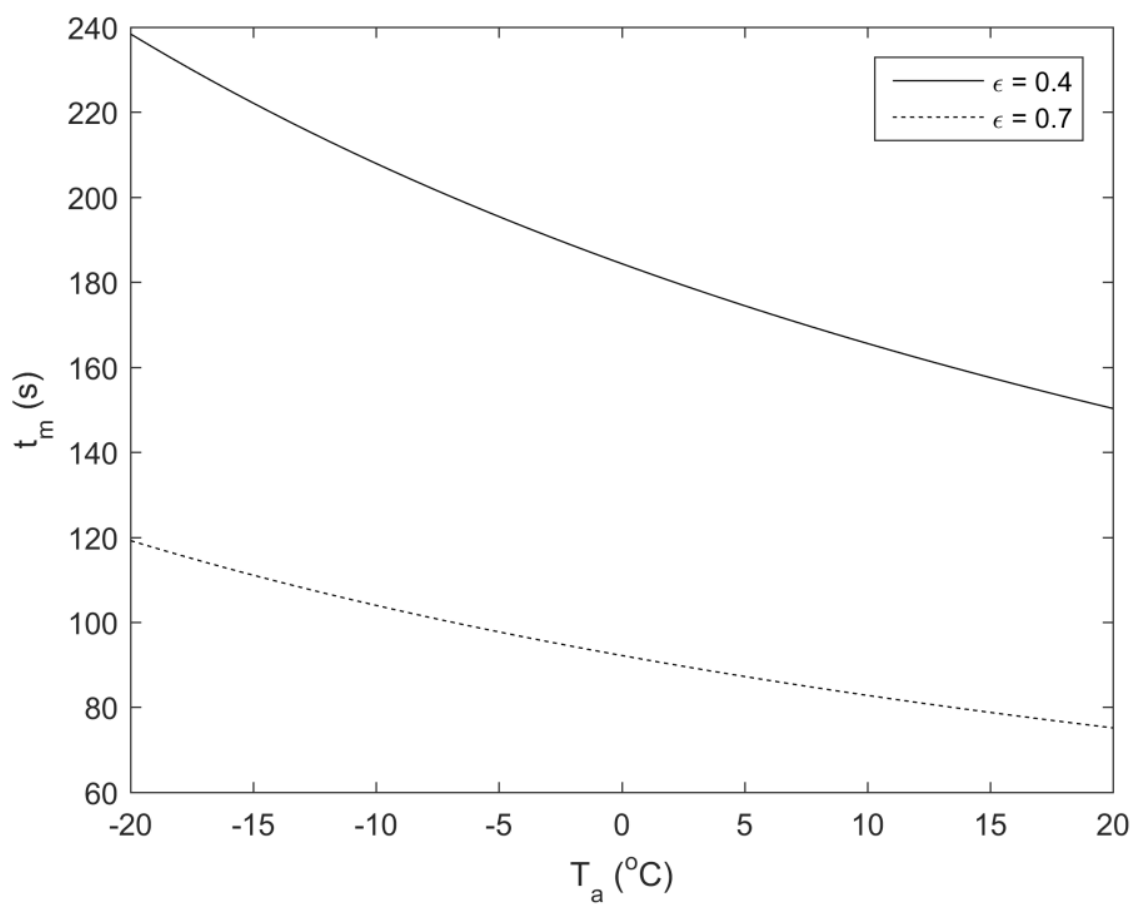

Figure 6.10. Melting time versus ambient temperature. $\mathrm{q}_{\mathrm{s}} "=3000 \mathrm{~W} / \mathrm{m}^{2}, \delta_{\mathrm{f} 0}=3 \mathrm{~mm}$. 


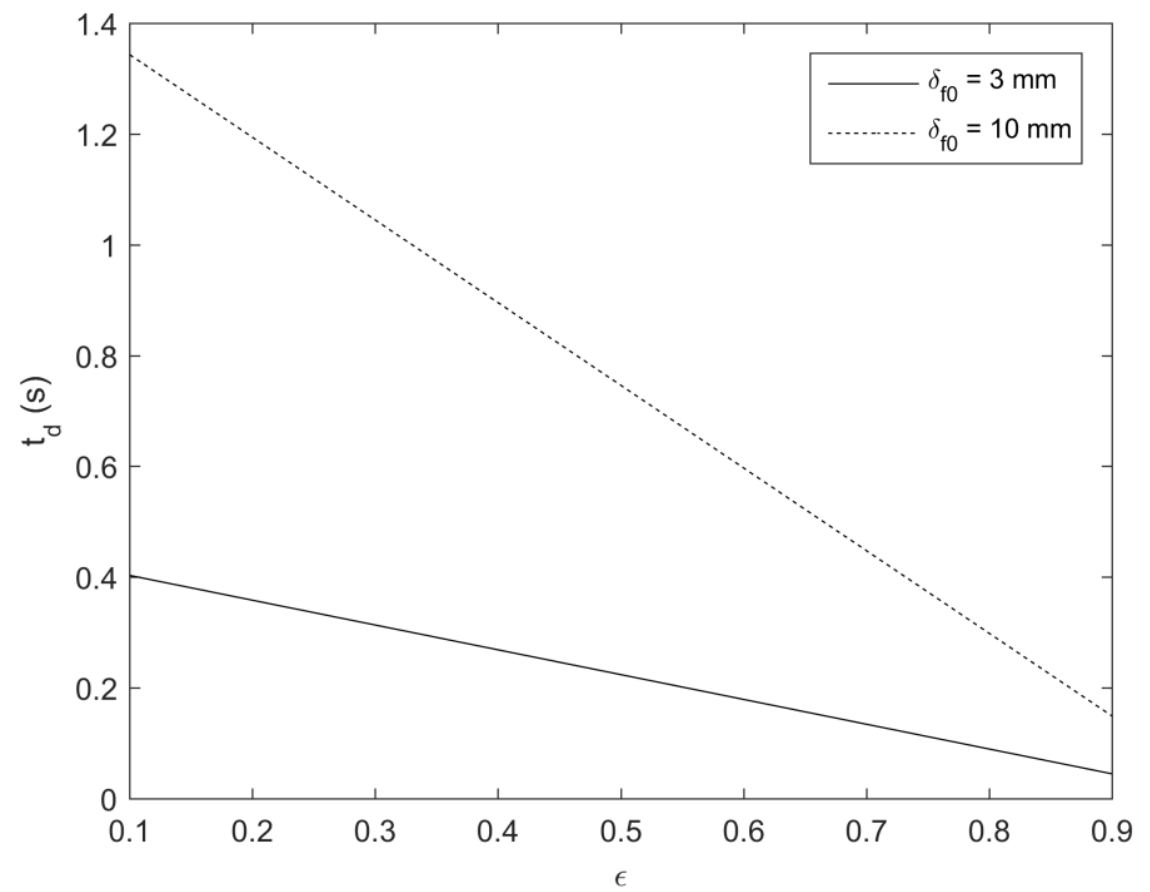

Figure 6.11. The relation of draining time with porosity. $\mathrm{H}=38 \mathrm{~mm}$.

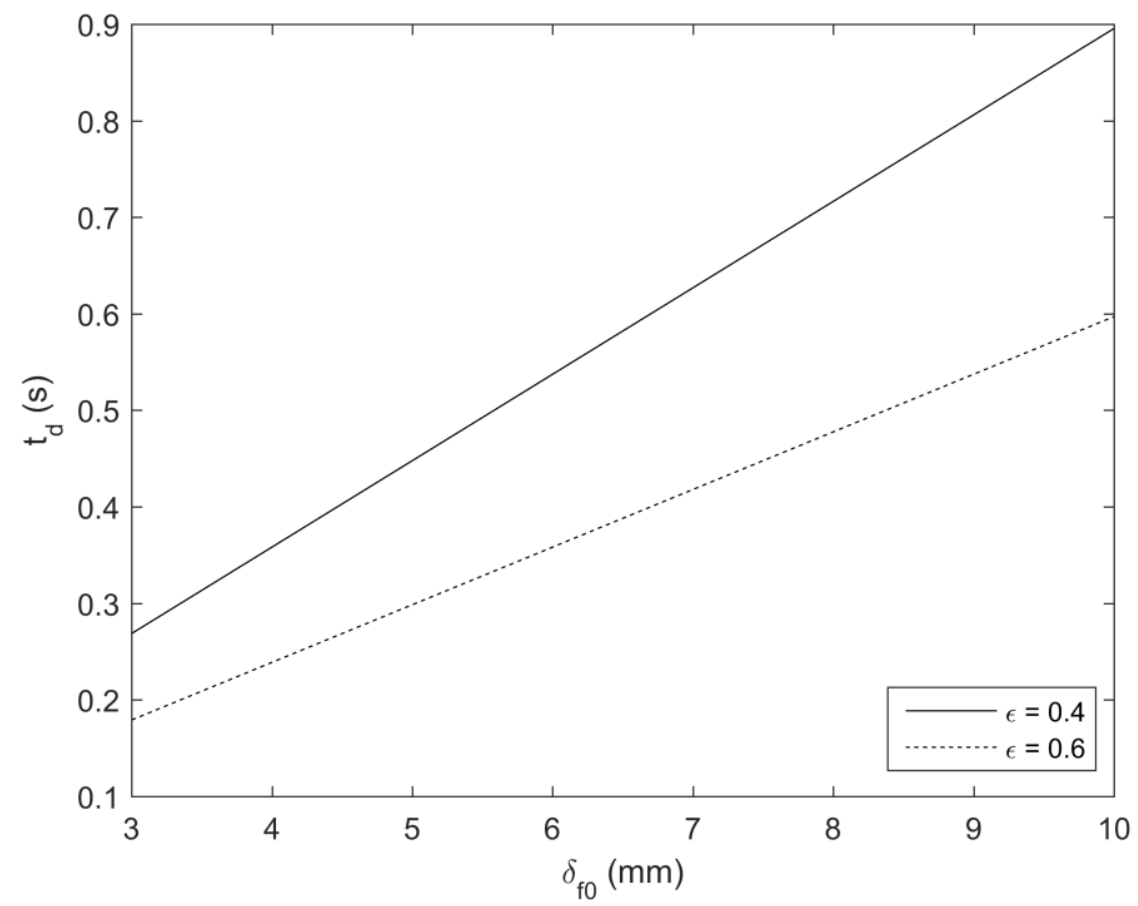

Figure 6.12. The relation of draining time with the initial frost thickness. $\mathrm{H}=38 \mathrm{~mm}$. 


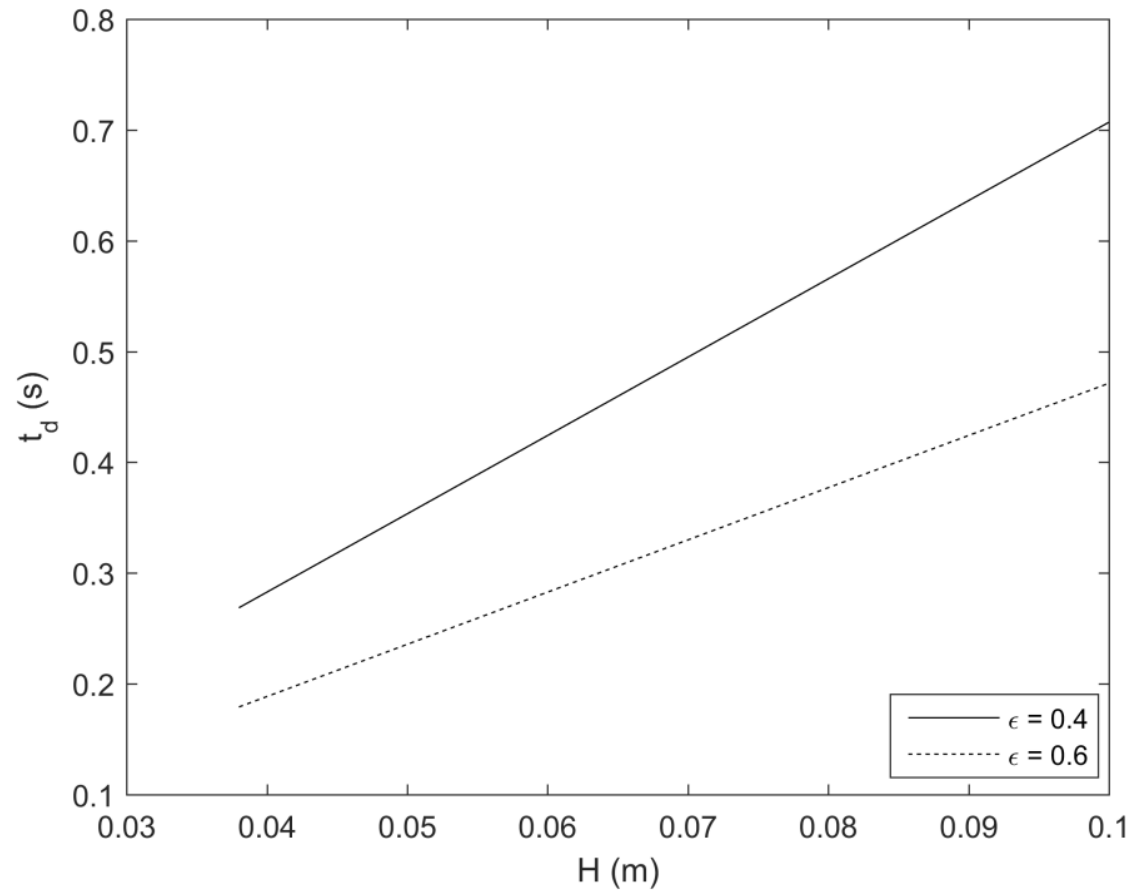

Figure 6.13. The relation of draining time with the height of test plate. $\delta_{\mathrm{f} 0}=3 \mathrm{~mm}$.

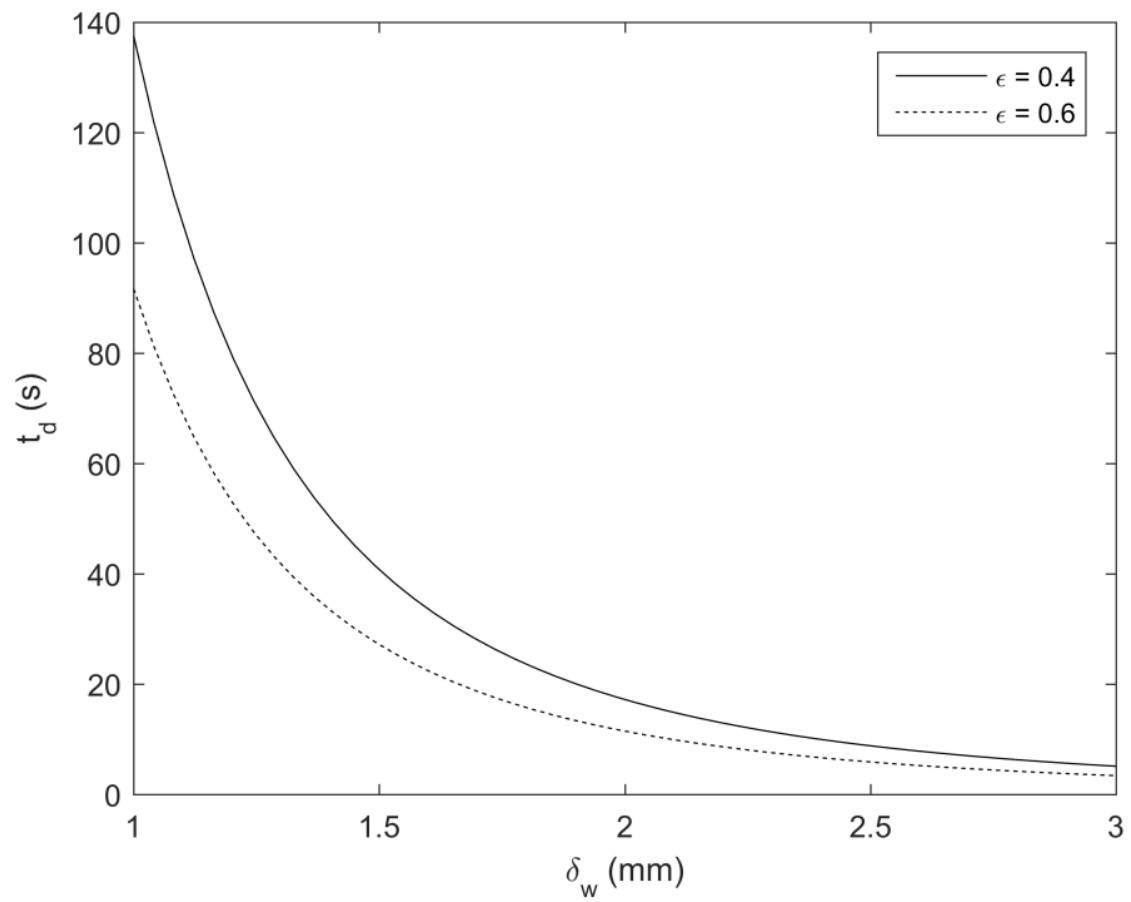

Figure 6.14. The relation of draining time with the water film thickness. $\mathrm{H}=38 \mathrm{~mm}$. 
For relatively large thicknesses of the water film, the draining time is small compared to the melting time. The relation of defrost time with the porosity, the water film thickness, the heat flux and the height of the test plate are shown in Figs. 6.15.- 6.18. Defrost time is sensitive to the water film thickness and the height of the test plate. The influence of water film thickness on the defrost time is illustrated in Figs. 6.15. and 6.16. The variation between the melting time and the draining time is relatively small where the water film thickness equals $0.3 \mathrm{~mm}$. Defrost time is thus determined by the melting time and the draining time. When the water film thickness equals $0.6 \mathrm{~mm}$, defrost time is mainly determined by the melting time, and the draining time is relatively small. The influence of the height of test plate on defrost time is shown in Fig. 6.17. When the height of test plate equals $38 \mathrm{~mm}$, draining time is relatively small, and the defrost time is mainly determined by the melting time. Defrost time increases with the decrease of the heat flux as shown in Fig. 6.18.

The relation of drainage time and defrost time to surface wettability are shown in Figs. 6.19. and 6.20. When the height of the test plate is relatively small and the water film thickness is relatively large, the melting time is much larger than the draining time. Defrost time is mainly determined by the melting time. In this scenario, the effect of surface wettability on the defrost time is insignificant. The smallest drainage time occurs when slip boundary conditions apply at both the solid/water interface and the water/permeation interface. When the water film gets thinner, the effect of the slip boundary conditions gets larger on the average velocity and the draining time. Defrost time is smallest with slip conditions at both interfaces. The effect of the slip conditions is less significant on defrost time compared to that on the draining time.

Defrost efficiency depends on applied heat flux at the solid surface, the water film thickness, the height of the test plate, heat transfer coefficient at the permeation/air interface, the ambient temperature and the slip conditions at the solid/water interface and at the water/permeation interface. For the given conditions, defrost efficiency with slip condition is improved about 5.5\% compared to that with no slip boundary condition at the solid/water interface. 


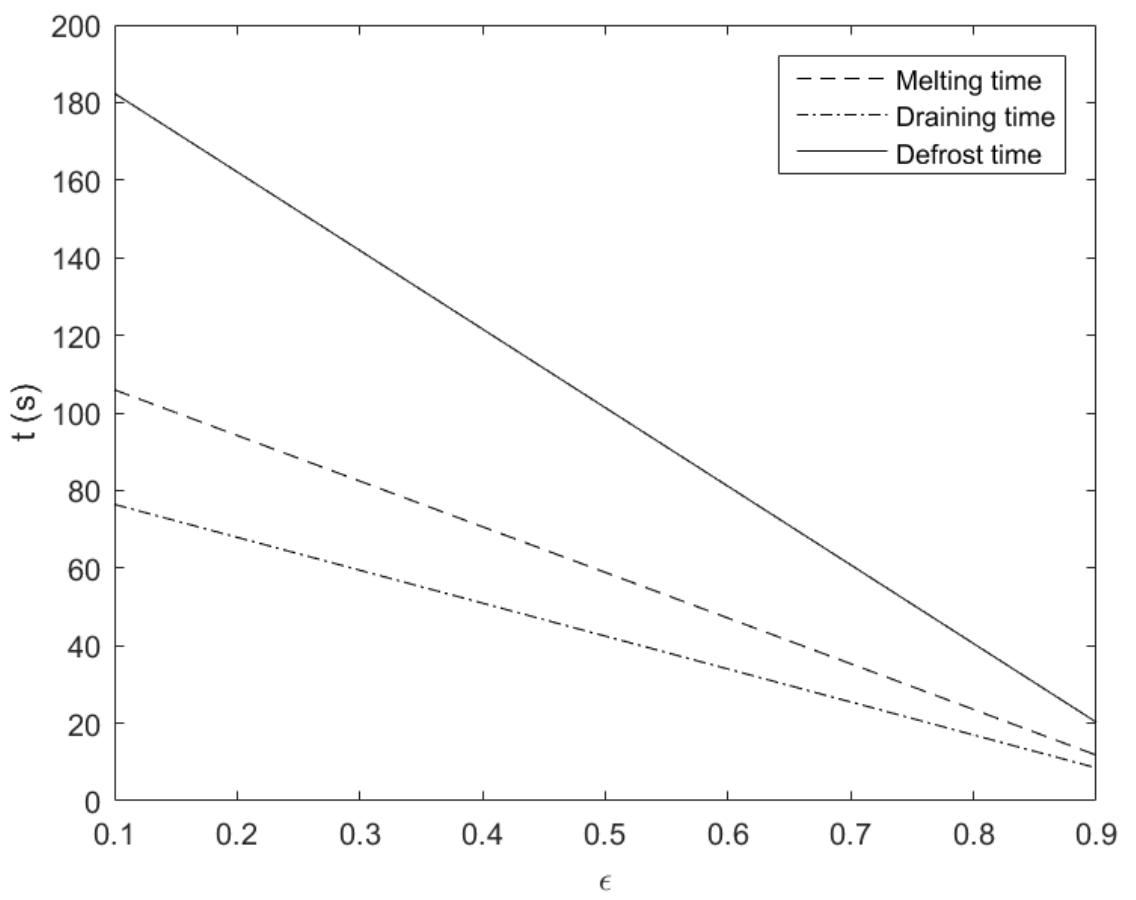

Figure 6.15. The relation of defrost time with the porosity. $\mathrm{q}_{\mathrm{s}} "=8000 \mathrm{~W} / \mathrm{m}^{2} . \mathrm{H}=380 \mathrm{~mm} . \delta_{\mathrm{w}}=0.3 \mathrm{~mm}$.

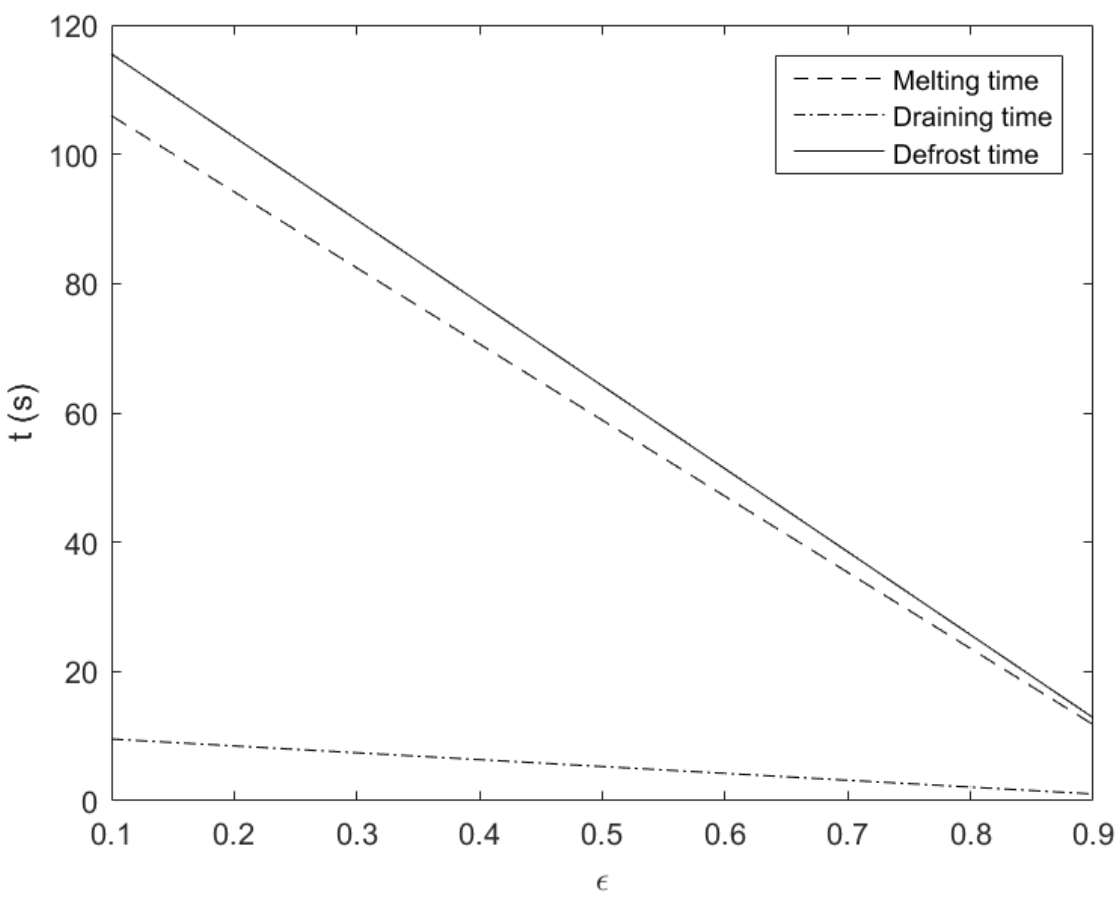

Figure 6.16. The relation of defrost time with the porosity. $\mathrm{q}_{\mathrm{s}}=8000 \mathrm{~W} / \mathrm{m}^{2} . \mathrm{H}=380 \mathrm{~mm} . \delta_{\mathrm{w}}=0.6 \mathrm{~mm}$. 


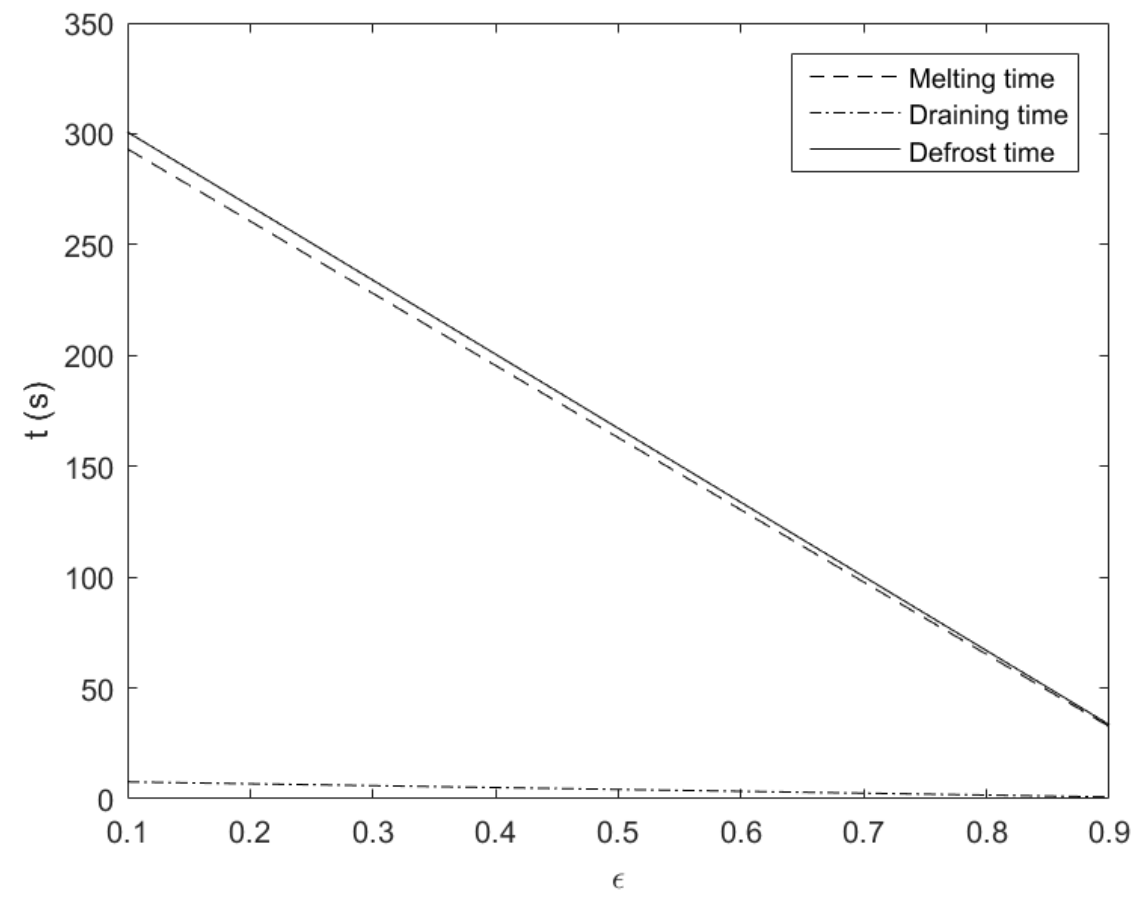

Figure 6.17. The relation of defrost time with the porosity. $\mathrm{qs}^{\prime \prime}=3000 \mathrm{~W} / \mathrm{m}^{2} . \mathrm{H}=38 \mathrm{~mm} . \delta_{\mathrm{w}}=0.3 \mathrm{~mm}$.

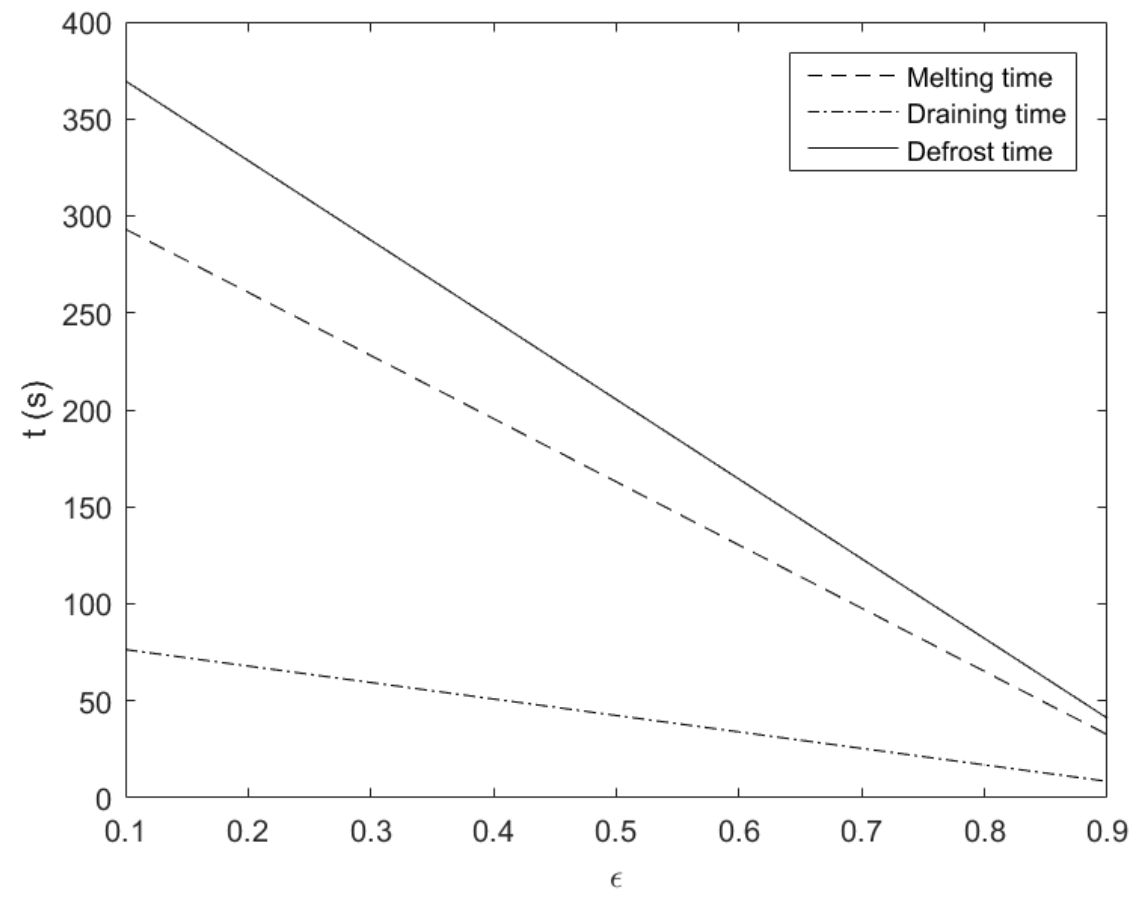

Figure 6.18. The relation of defrost time with the porosity. $\mathrm{q}_{\mathrm{s}}=3000 \mathrm{~W} / \mathrm{m}^{2} . \mathrm{H}=380 \mathrm{~mm} . \delta_{\mathrm{w}}=0.3 \mathrm{~mm}$. 


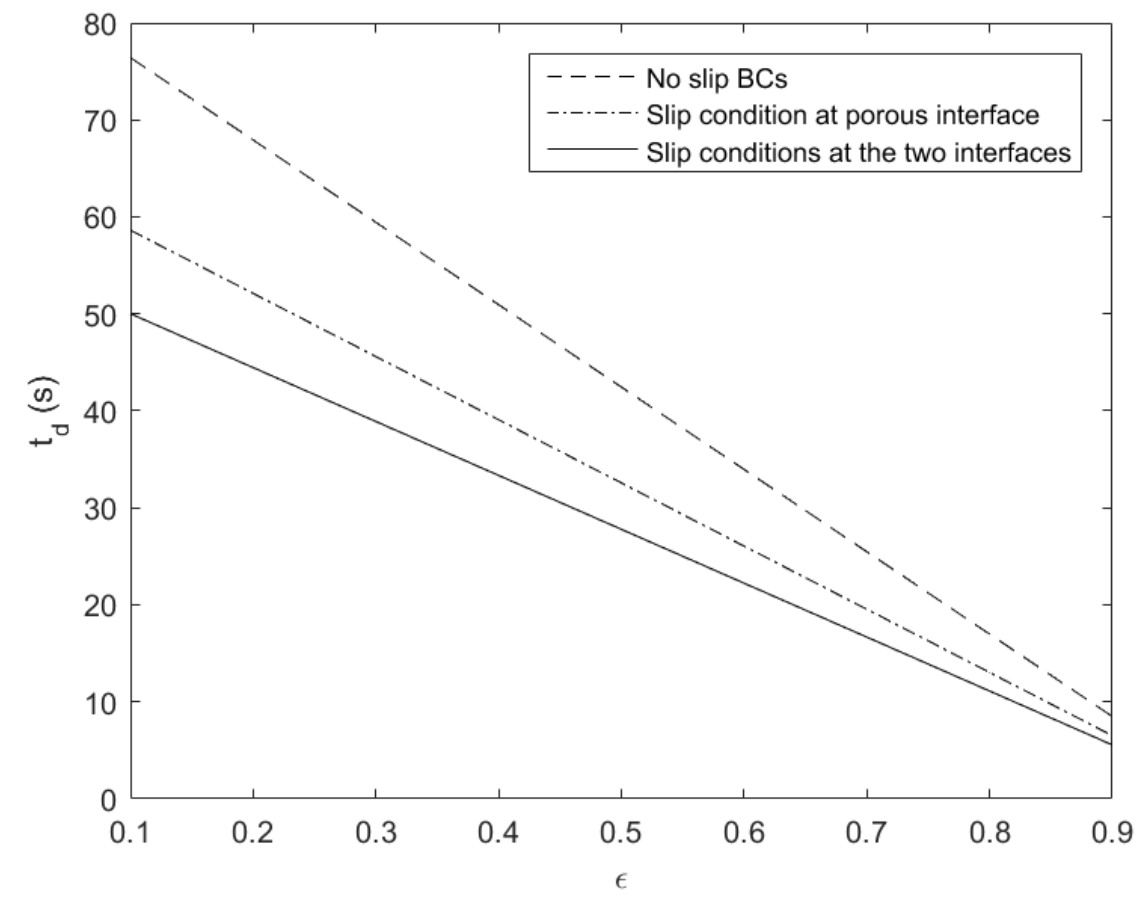

Figure 6.19. Comparison of the draining time with different boundary conditions. $\mathrm{H}=380 \mathrm{~mm} . \delta_{\mathrm{w}}=0.3 \mathrm{~mm}$.

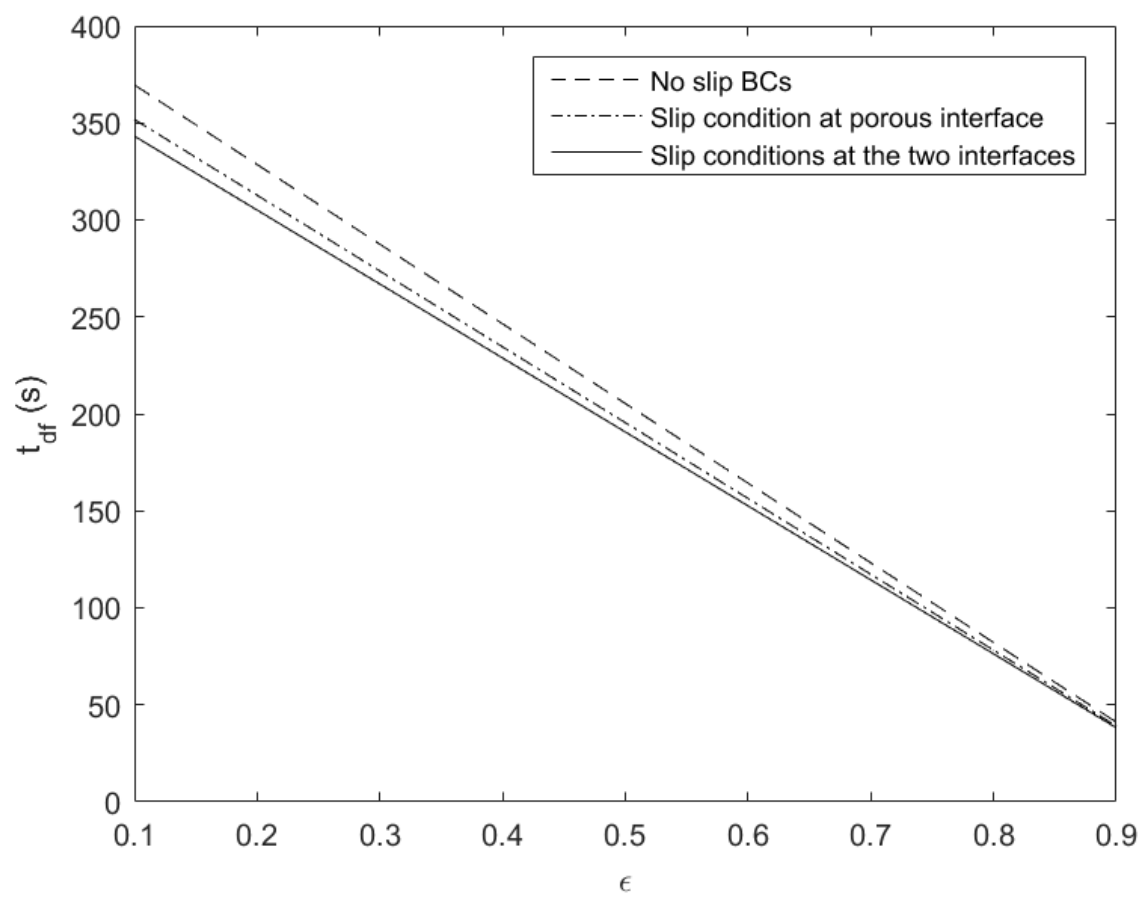

Figure 6.20. Comparison of defrost time with different boundary conditions. $\mathrm{q}_{\mathrm{s}}=3000 \mathrm{~W} / \mathrm{m}^{2} . \mathrm{H}=380 \mathrm{~mm} . \delta_{\mathrm{w}}=0.3 \mathrm{~mm}$. 


\subsection{Slumping criterion}

Slumping conditions have been discussed in each stage of the melting process. A general formula is defined based on the static force analysis as described in Eqns. (4.50), (4.51). The ratio of gravity to the retaining force is defined as a measure of the slumping possibilities. Retaining forces vary with the different stages in the melting process. In the absorption stage, the retaining force is the adhesion due to shear force. In the accumulation and the drainage stages, the retaining forces are surface tension around the perimeters of the frost column. The ratio of gravity to surface tension is bigger in the accumulation stage. The possibility of frost slumping is thus higher during the accumulation stage. The force ratio is related to the porosity and thickness of the frost layer, the geometry of the test plate, the temperature at the test surface and the surface characteristics of the test surfaces.

The force ratio with respect to the porosity is shown in Fig. 6.21. The slumping ratio decreases from 2.5 to 0.36 when the porosity ranges from 0.3 to 0.9 . When the porosity is larger than 0.7 , the frost layer is very loose, and the slumping is unlikely to occur, based on estimates using the given parameters. Dense frost falls off falls off more easily compared to the loose frost layer. The force ratio with respect to the aspect ratio is shown in Fig. 6.22. At the given width of the test plate, the slumping force ratio decreases from 2.6 to 0.7 when the aspect ratio increases from 0.1 to 3 . When the aspect ratio is greater than 1.8, the slumping force ratio is less than 1 . A larger force ratio favors slumping at a given width of the test plate. Temperature has influence on the surface tension. The higher the temperature, the smaller the surface tension is. The force ratio thus is related to temperature as shown in Fig. 6.23. The force ratio increases from 0.97 to 1.07 when the temperature increases from $-5{ }^{\circ} \mathrm{C}$ to $30{ }^{\circ} \mathrm{C}$. In the absorption stage, the temperature at the test plate surface maintains the melting temperature as the mixture of the ice crystals and the meltwater is attached to the test plate.

The effect of surface wettability on the force ratio depends on the physical models of the slumping condition. A thin water film is assumed to form on hydrophilic surfaces during the melting process, and the surface tension depends on the contact angle of water. For hydrophobic surfaces, water droplets are assumed to distribute on the test plate, and the surface tension depends on the receding and advancing contact angles. 


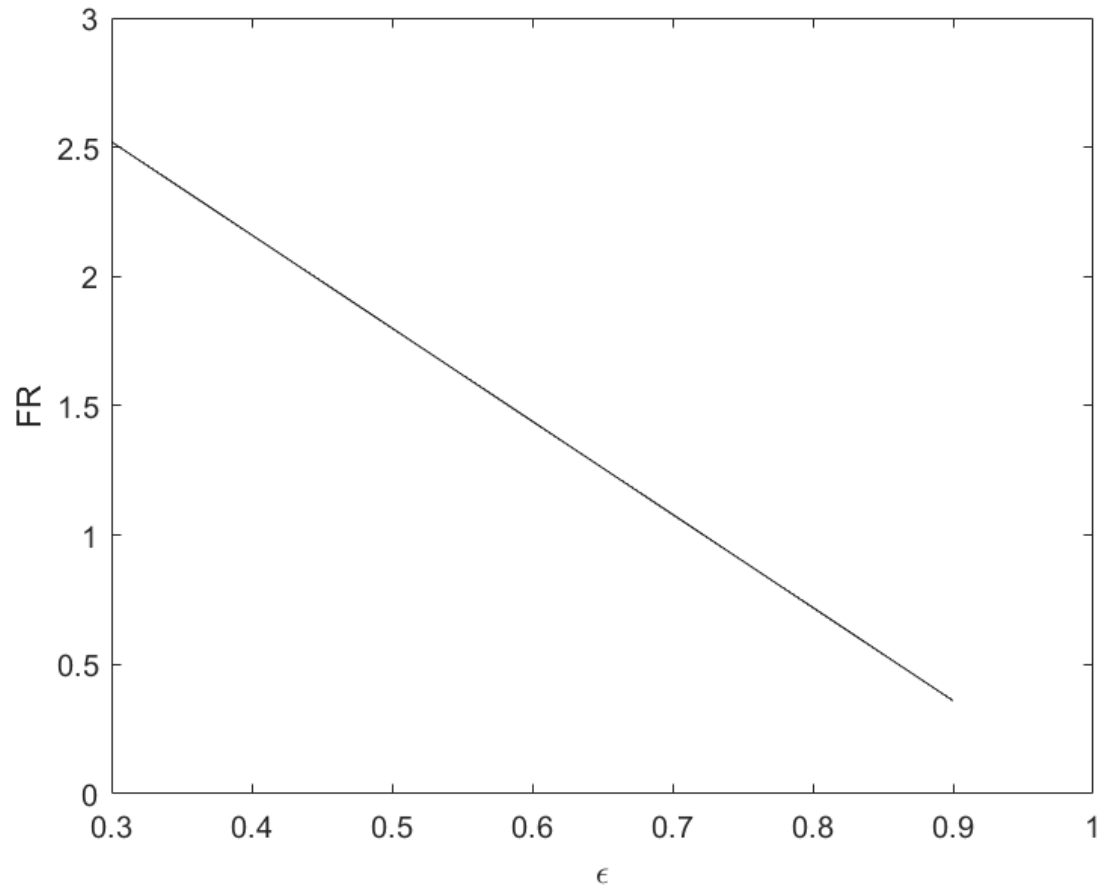

Figure 6.21. Force ratio versus porosity. $\mathrm{W}=38 \mathrm{~mm} . \delta_{\mathrm{f} 0}=3 \mathrm{~mm} . \mathrm{r}=1 . \mathrm{CA}=20^{\circ}$.

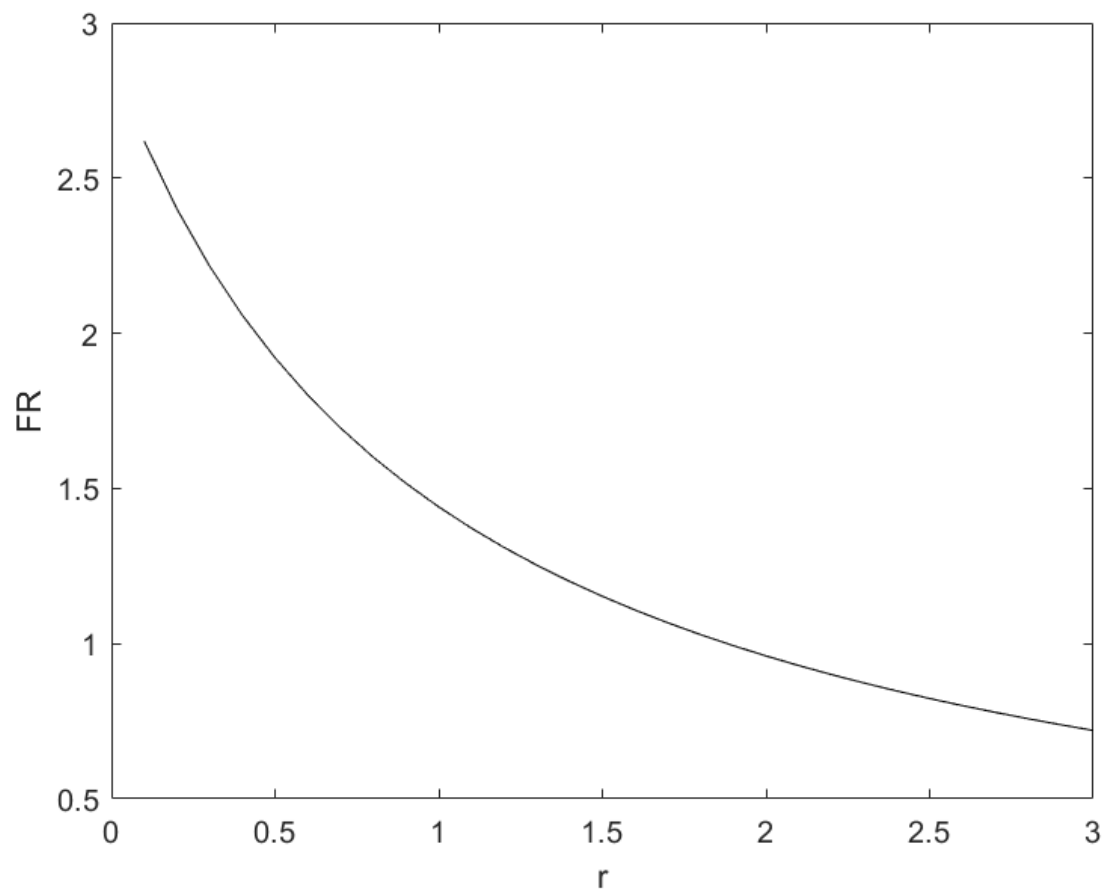

Figure 6.22. Force ratio versus aspect ratio of the test plate. $\mathrm{W}=38 \mathrm{~mm} . \delta_{\mathrm{f} 0}=3 \mathrm{~mm} . \varepsilon=0.6 . \mathrm{CA}=20^{\circ}$. 


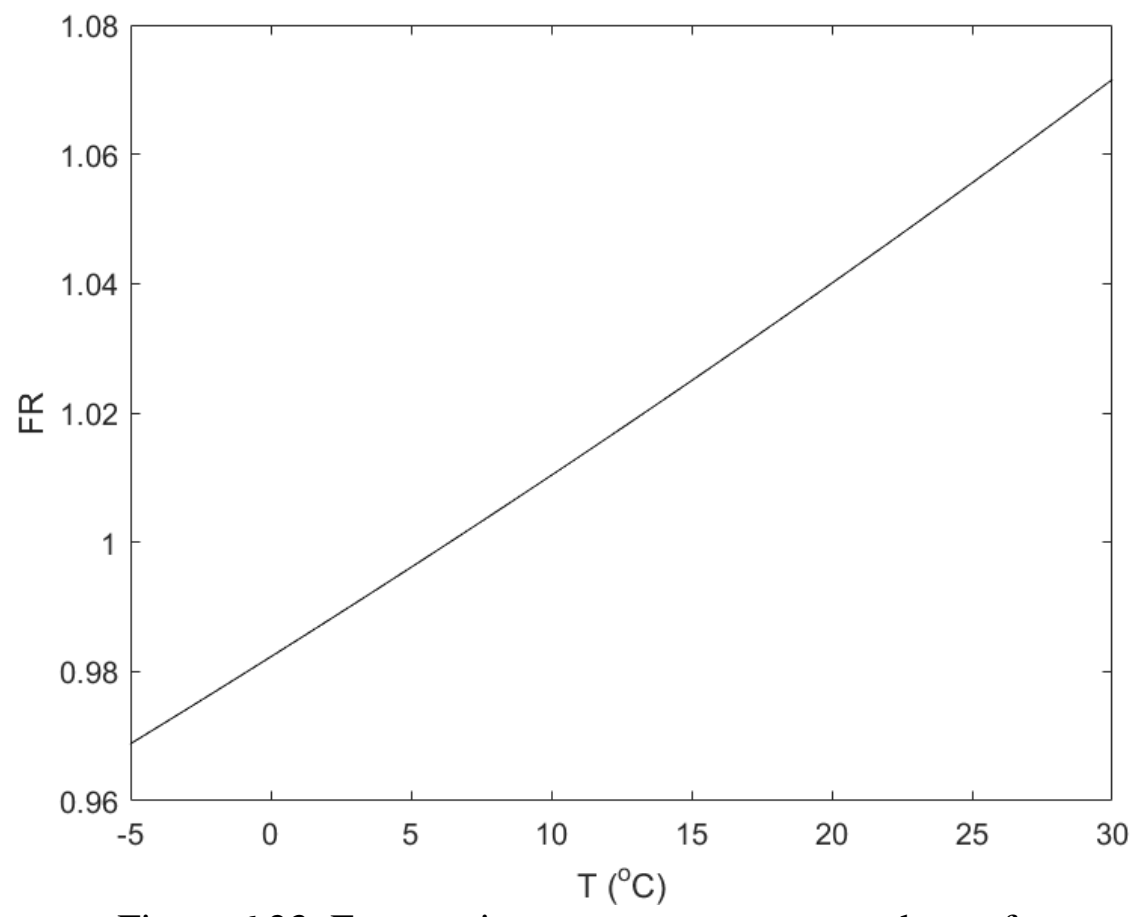

Figure 6.23. Force ratio versus temperature at the surface. $\mathrm{W}=38 \mathrm{~mm} . \delta_{\mathrm{f} 0}=3 \mathrm{~mm} . \mathrm{r}=1.2, \varepsilon=0.6 . \mathrm{CA}=20^{\circ}$.

The force ratio with respect to the contact angle on hydrophilic surfaces is shown in Fig. 6.24. When the contact angle is less than $50^{\circ}$, the force ratio increases smoothly with the contact angle. The force ratio with respect to the receding contact angle and the contact angle hysteresis for hydrophobic surfaces is shown in Fig. 6.25. Three contact angle hysteresis values are applied, and they are $5^{\circ}, 15^{\circ}$ and $30^{\circ}$. The force ratio increases with the receding contact angle and decreases with the contact angle hysteresis. When the contact angle hysteresis is $5^{\circ}$, the force ratio is about five times of that when the contact angle hysteresis is $30^{\circ}$. The slumping condition is favorable with a large force ratio where the surface energy is low and the contact angle hysteresis is small.

Based on the assumptions on the physical mechanism of slumping condition, the force ratio is the smallest where the surface is fully wetted. The force ratio is much greater than unity on hydrophobic surfaces where the contact angle hysteresis is $5^{\circ}$. With the increase of the contact angle hysteresis, the difference of the force ratio on hydrophobic and hydrophilic surfaces decreases. The slumping would be likely to occur on hydrophobic surfaces with small contact angle hysteresis. 


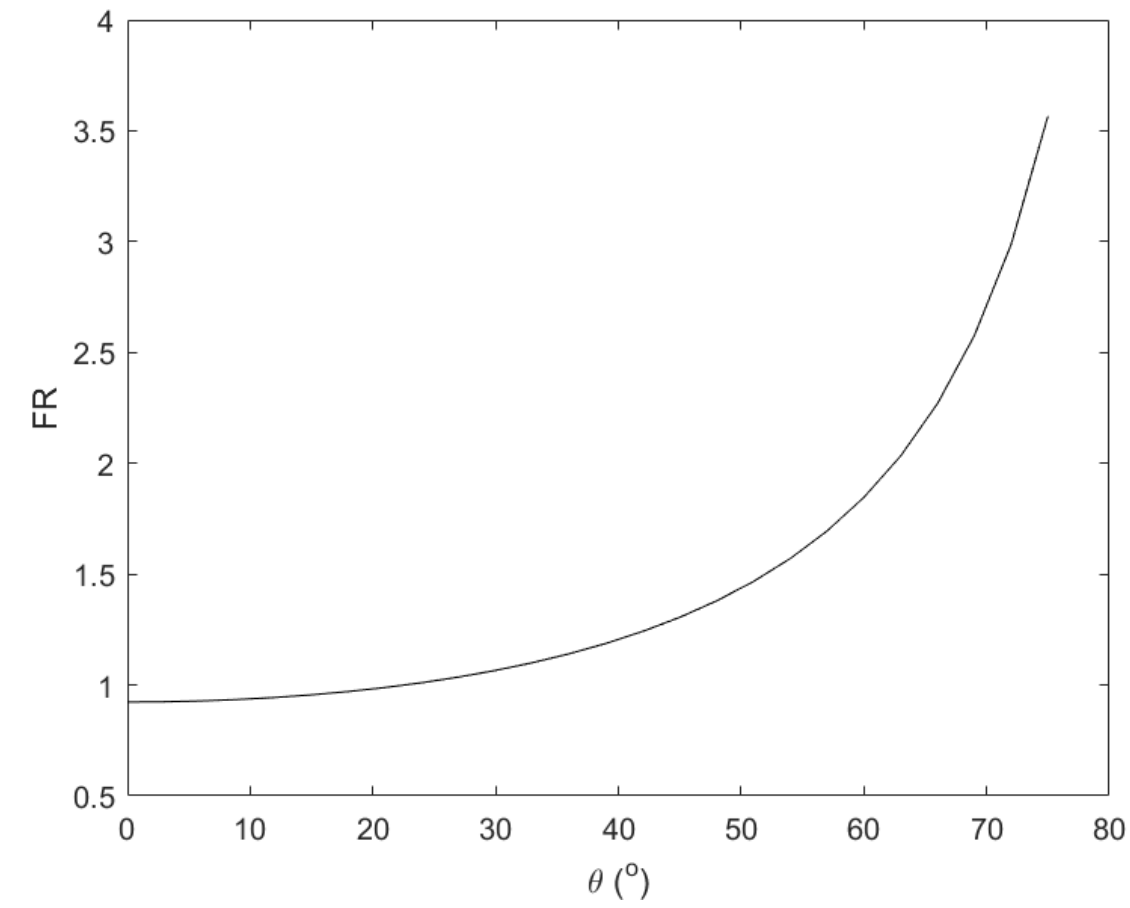

Figure 6.24. Force ratio versus contact angle on hydrophilic surfaces. $\mathrm{W}=38 \mathrm{~mm} . \delta_{\mathrm{f} 0}=3 \mathrm{~mm} . \mathrm{r}=1.2, \varepsilon=0.7$.

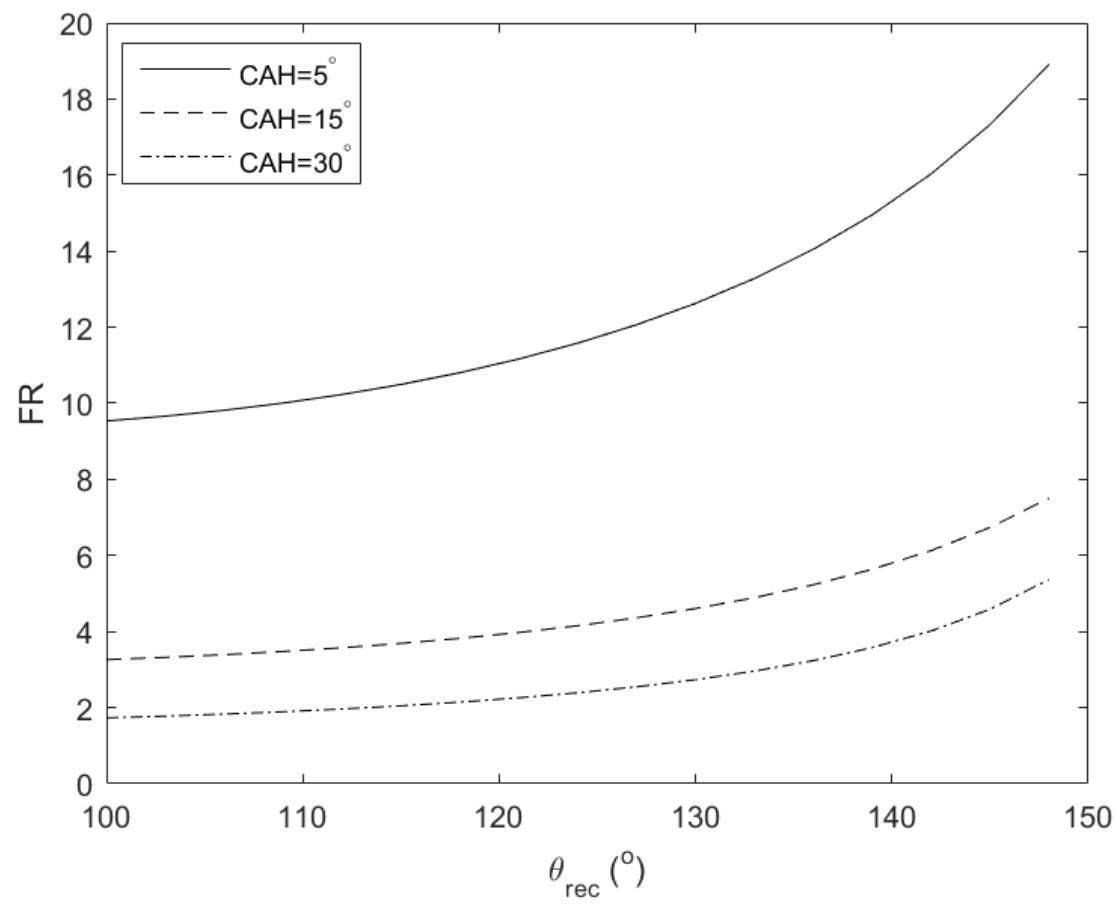

Figure 6.25. Force ratio versus receding contact angle on hydrophobic surfaces. $\mathrm{W}=38 \mathrm{~mm}$. $\delta_{\mathrm{f} 0}=3 \mathrm{~mm} . \mathrm{r}=1.5, \varepsilon=0.7$. 


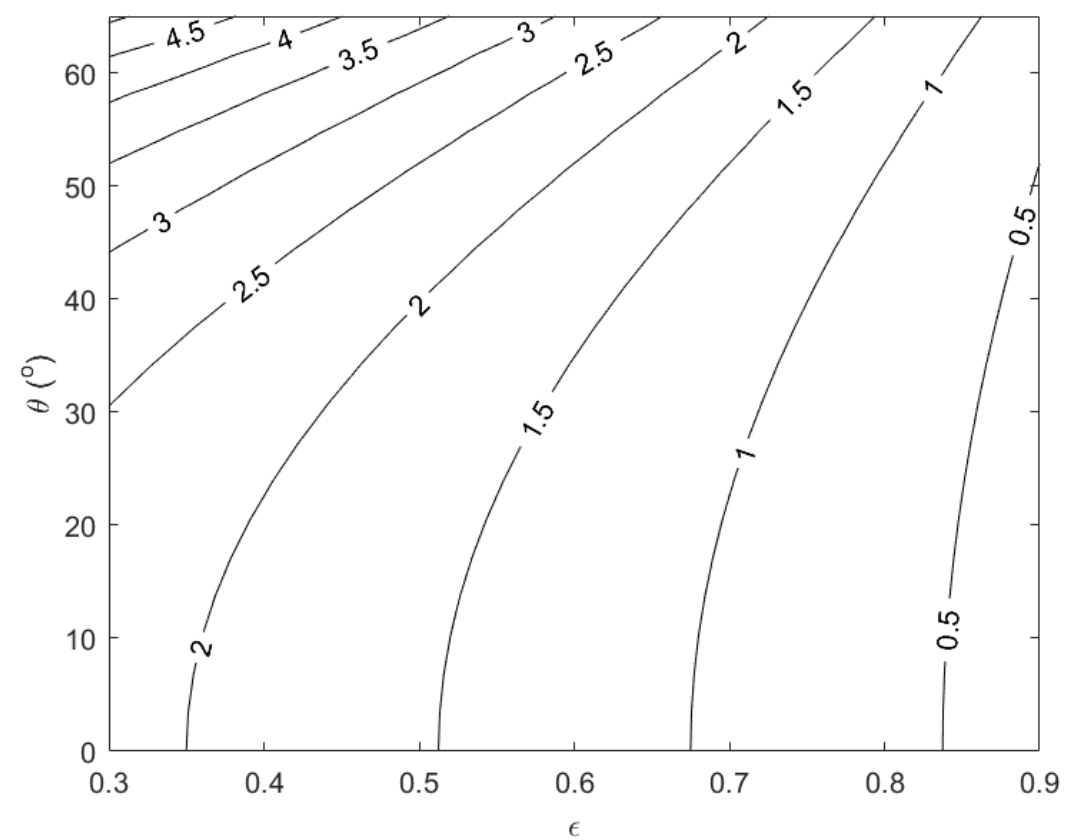

Figure 6.26. Force ratio versus porosity and contact angle. $\mathrm{W}=38 \mathrm{~mm} . \delta_{\mathrm{f} 0}=3 \mathrm{~mm} . \mathrm{r}=1.2$.

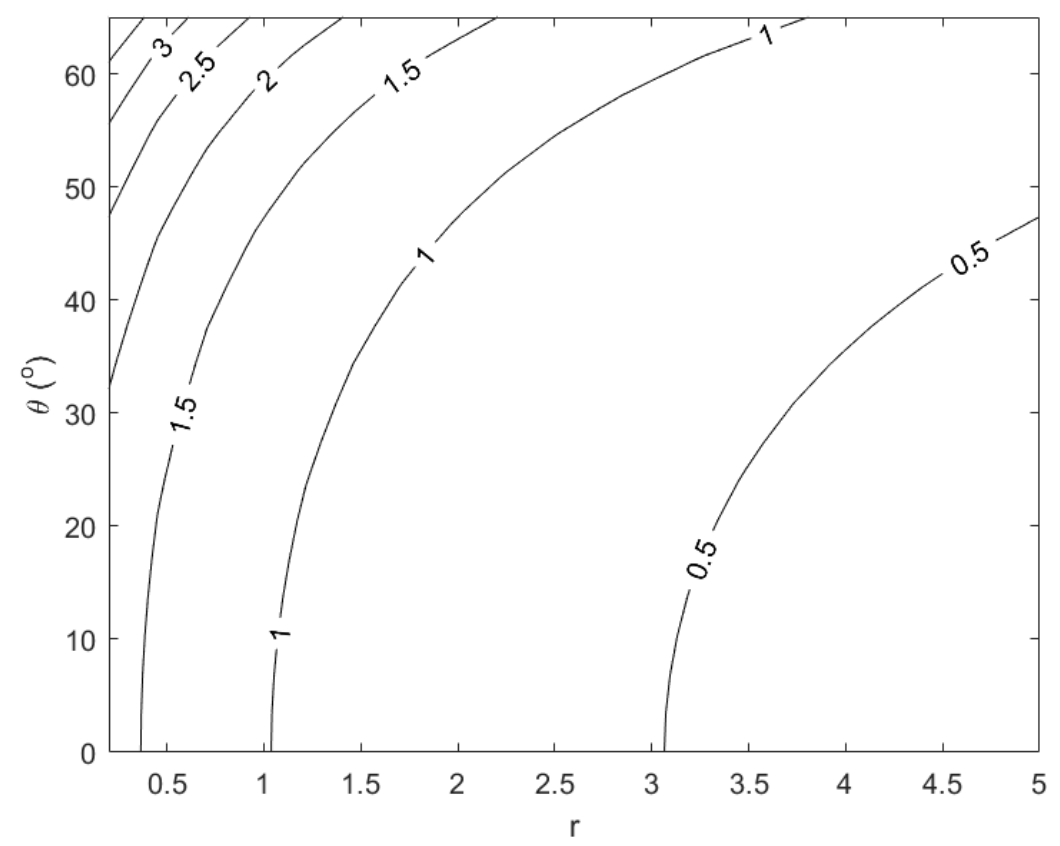

Figure 6.27. Force ratio versus aspect ratio and contact angle. $\mathrm{W}=38 \mathrm{~mm} . \delta_{\mathrm{f} 0}=3 \mathrm{~mm}$., $\varepsilon=0.7$.

With the specified surface temperature, the relation of slumping ratio with respect to porosity, aspect ratio and surface contact angle are shown in Figs. 6.26. and 6.27. 


\subsection{Experimental results}

Experiments are tested on two sizes of test surfaces: $50 \mathrm{~mm}$ x $50 \mathrm{~mm}$ surface and $38 \mathrm{~mm}$ x $38 \mathrm{~mm}$ surface. A large surface area is tested to reduce the effect at the edges. Two sets of apparatus are sized for the test surfaces. Six test samples are tested and numbered, as shown in Table 6.2. The test conditions for frost growth are shown in Table 6.3. The test surface is cooled down up to $-19{ }^{\circ} \mathrm{C}$ by the thermal electric module. Chamber temperature is the ambient temperature that is maintained at $19{ }^{\circ} \mathrm{C}$ to achieve high supercooling. The relative humidity is as high as $51 \%$ to increase the supersaturation for frost growth.

The front and side views of the frost formation process for the superhydrophilc, plain and superhydrophobic surfaces are shown in Figs. 6.28. - 6.33. Superhydrophilic and surperhydrophobic surfaces are relatively rough compared to the plain surface. At the first $10 \mathrm{~min}$, the photos record the vapor nucleation process and the frost formation process. Condensation is observed over $5 \mathrm{~min}$ on all the different surfaces. Observations show that the superhydrophobic surface does not significantly retard nucleation and frost formation. It can be seen that condensation spreads over the test surface in $5 \mathrm{~min}$ from Fig. 6.32(b). The reason might be that high supercooling degree and high relative humidity speed up the vapor nucleation process in the experiments. Crystal growth starts at $\sim 10 \mathrm{~min}$, followed by the frost growth at all the different surfaces. Frost gets denser where part of the vapor diffuses into it and gets thicker with the deposition of the vapor on the frost surface. The densification and thickening process are recorded in the photos taken in the middle and at the end of the frost growth process where $\mathrm{t}=1 \mathrm{~h}, 3 \mathrm{~h}$ and $6 \mathrm{~h}$.

Frost properties on the six surfaces are listed in Table 6.4. The frost mass increase with time, as shown in Fig. 6.34. The density increases with time, but the variation of the density on the different surfaces is not significant. The reason could be that the temperature at the test surface and the temperature and humidity inside the chamber change slightly, which would influence the thickness accordingly. The uncertainties of the thermocouples and the humidity transmitters also change the dew point temperature and, thus, the thickness to some extent. Also, due to edge effects, the frost on the edges are thicker and denser compared to frost on the center of the surface. 
Table 6.2. Test samples numbering.

\begin{tabular}{ccc}
\hline Test plate identifier & Test plate dimensions $(\mathbf{m m})$ & Test surface CA $\left(^{\circ}\right)$ \\
\hline TestID-1 & $38 \times 38 \times 3.8$ & $<5$ \\
TestID-2 & $38 \times 38 \times 3.8$ & $\sim 71$ \\
TestID-3 & $38 \times 38 \times 3.8$ & $\sim 146$ \\
TestID-4 & $50 \times 50 \times 5$ & $<5$ \\
TestID-5 & $50 \times 50 \times 5$ & $\sim 71$ \\
TestID-6 & $50 \times 50 \times 5$ & $\sim 146$ \\
\hline
\end{tabular}

(a)

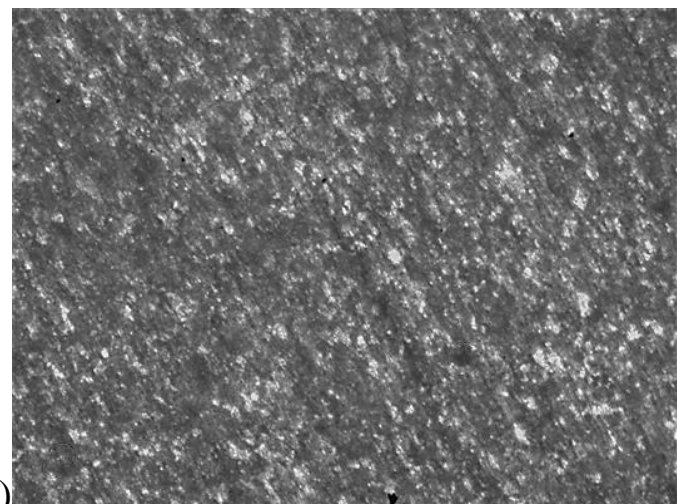

(c)

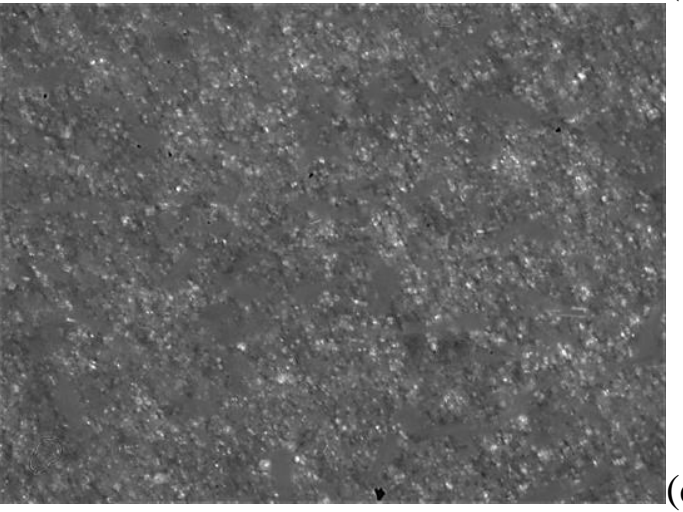

(b)

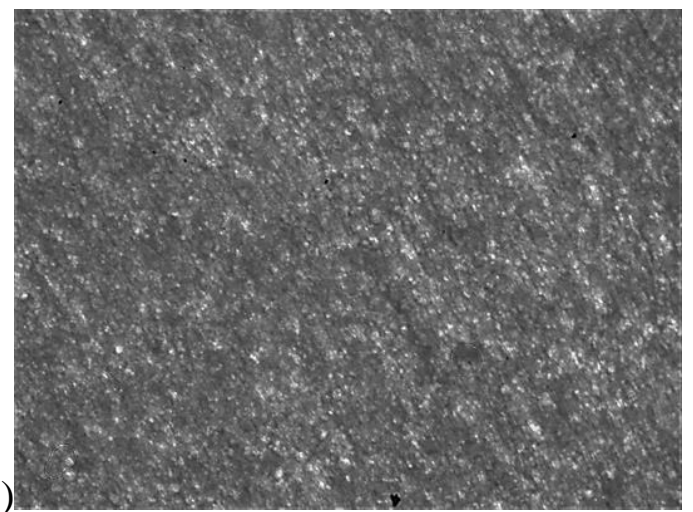

d)
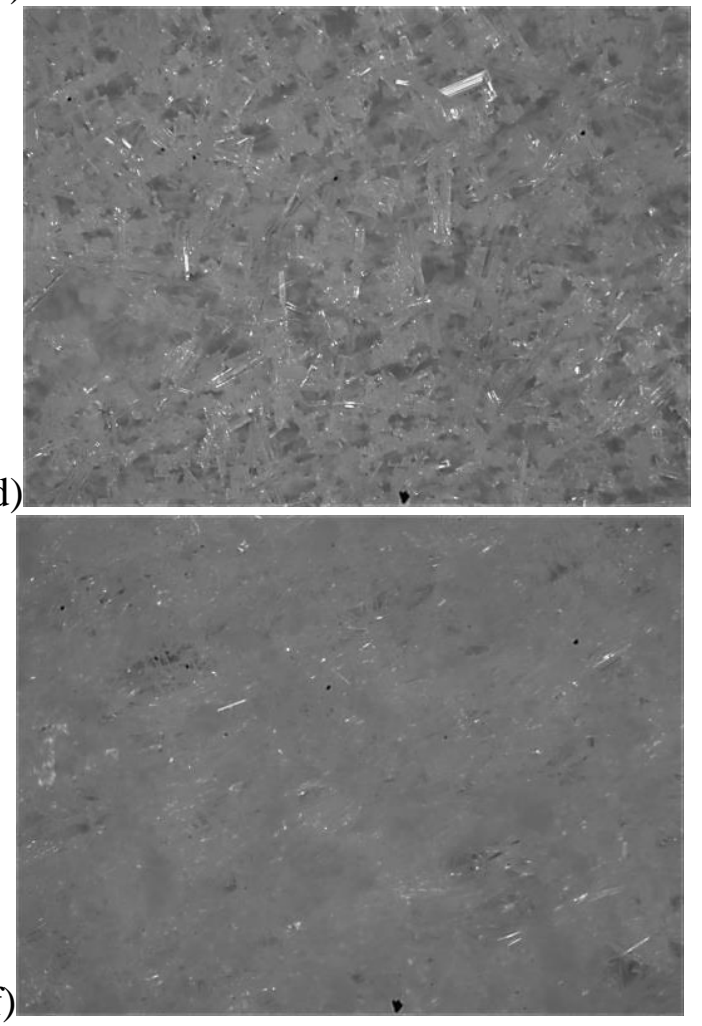

(e)

Figure 6.28. Front view of the frost formation at test surface (TestID-1). (a) $\mathrm{t}=0$; (b) $\mathrm{t}=5 \mathrm{~min}$; (c) $\mathrm{t}=10 \min$; (d) $\mathrm{t}=1 \mathrm{~h}$; (e) $\mathrm{t}=3 \mathrm{~h}$; (f) $\mathrm{t}=6 \mathrm{~h}$. 


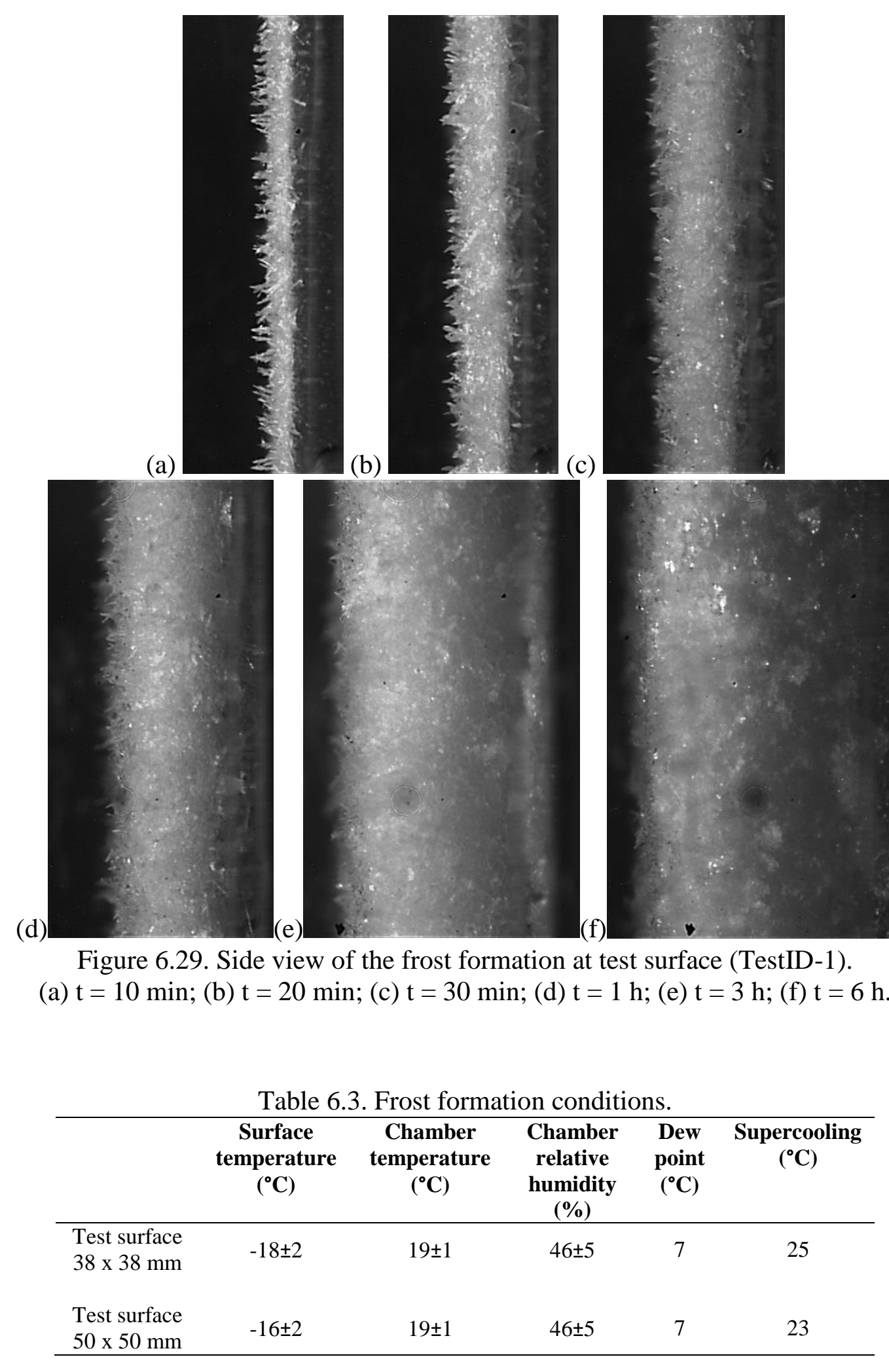


(a)
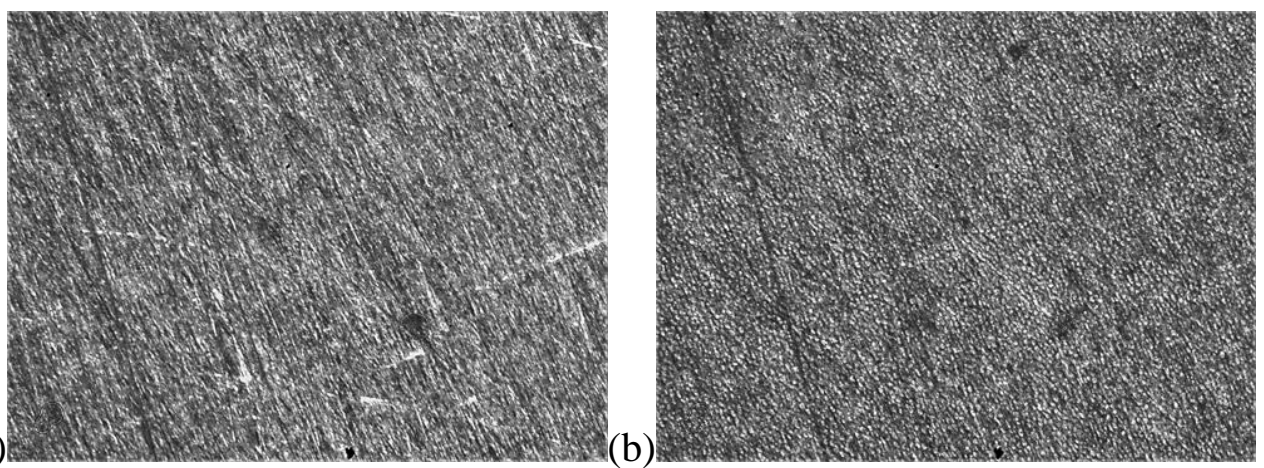

(c)
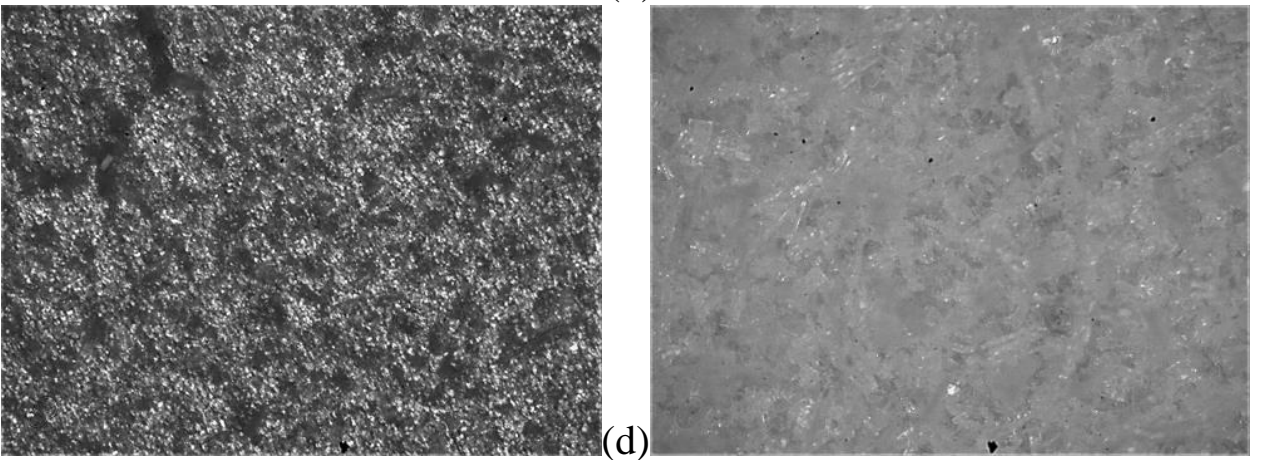

(e)
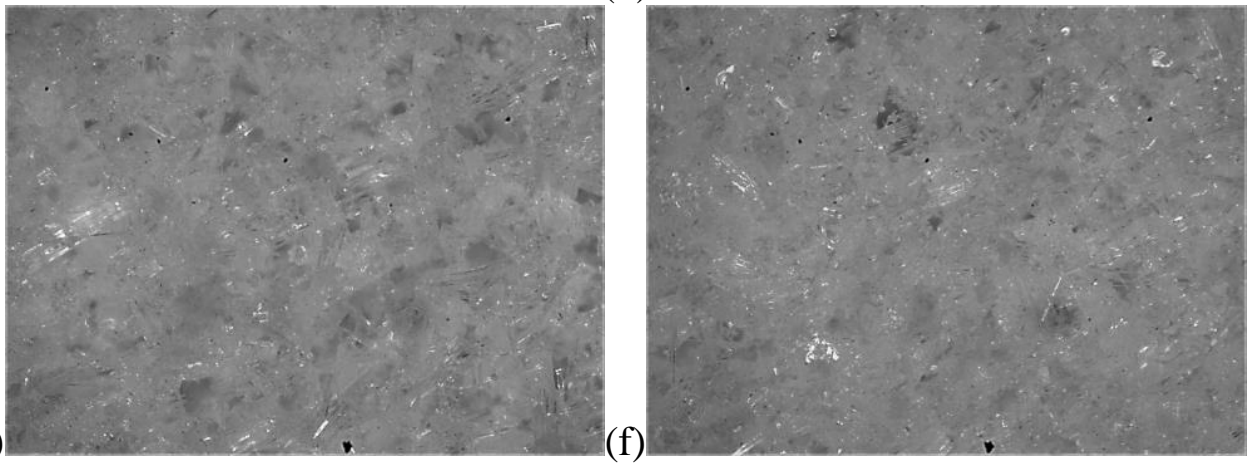

Figure 6.30. Front view of the frost formation at test surface (TestID-2). (a) $\mathrm{t}=0$; (b) $\mathrm{t}=5 \min$; (c) $\mathrm{t}=10 \min$; (d) $\mathrm{t}=1 \mathrm{~h}$; (e) $\mathrm{t}=3 \mathrm{~h}$; (f) $\mathrm{t}=6 \mathrm{~h}$. 


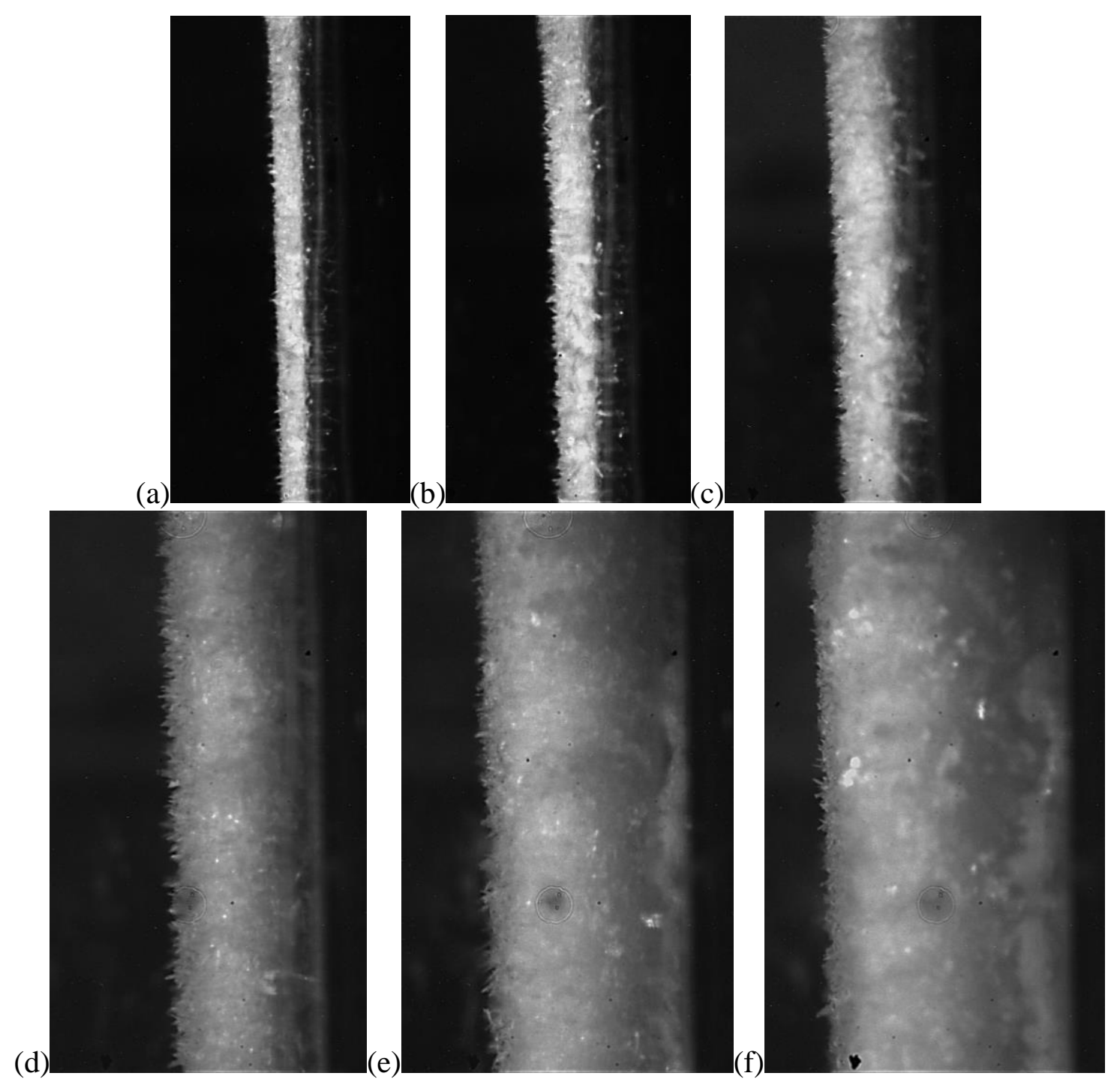

Figure 6.31. Side view of the frost formation at test surface (TestID-2).

(a) $\mathrm{t}=10 \mathrm{~min}$; (b) $\mathrm{t}=20 \mathrm{~min}$; (c) $\mathrm{t}=30 \mathrm{~min}$; (d) $\mathrm{t}=1 \mathrm{~h}$; (e) $\mathrm{t}=3 \mathrm{~h}$; (f) $\mathrm{t}=6 \mathrm{~h}$. 

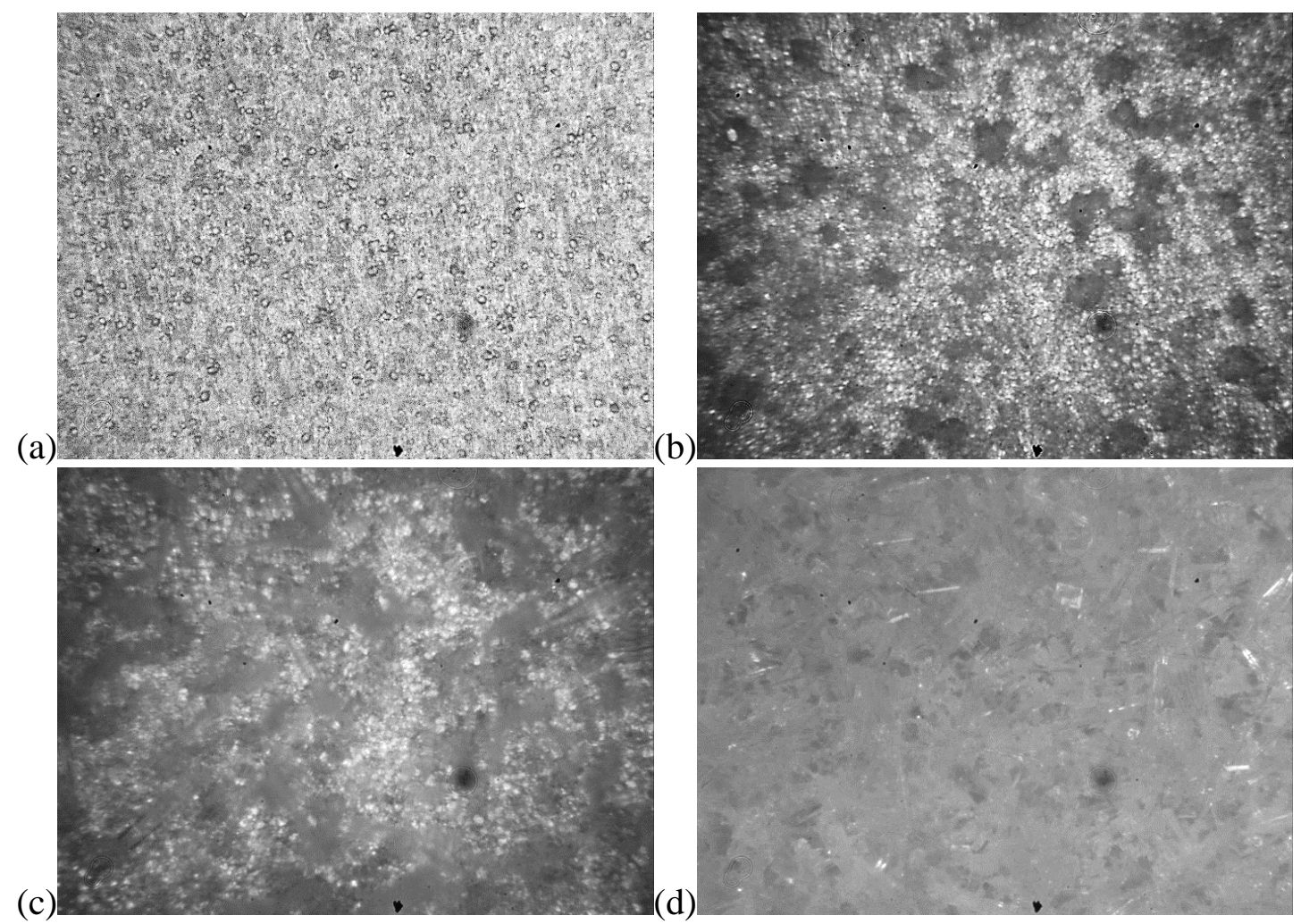

(e)
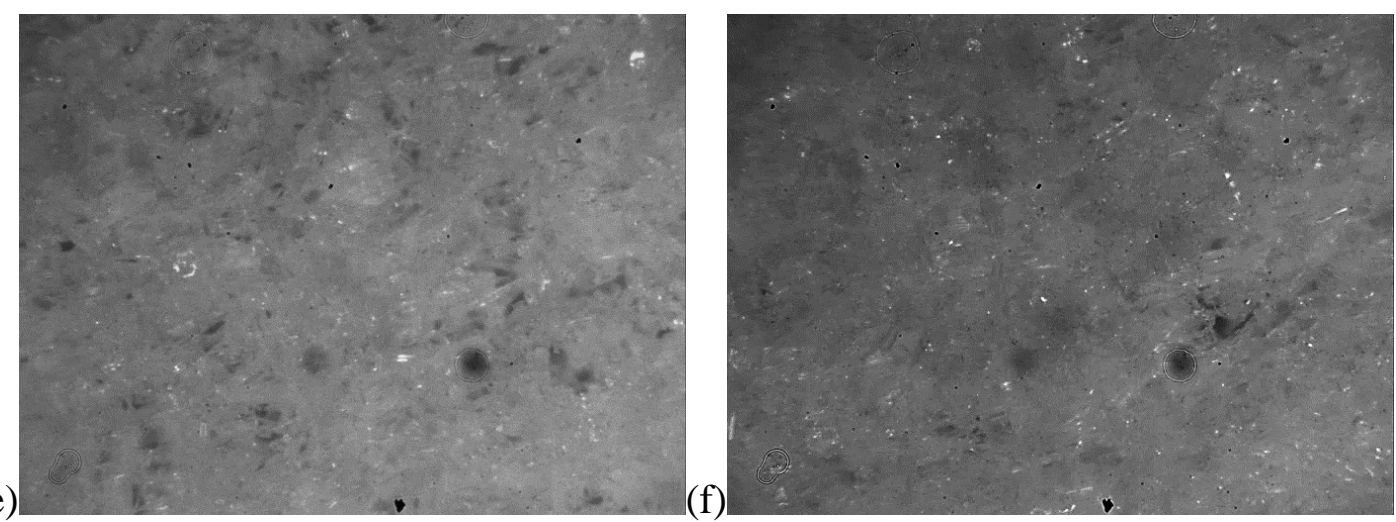

Figure 6.32. Front view of the frost formation at test surface (TestID-3). (a) $\mathrm{t}=0$; (b) $\mathrm{t}=5 \mathrm{~min}$; (c) $\mathrm{t}=10 \mathrm{~min}$; (d) $\mathrm{t}=1 \mathrm{~h}$; (e) $\mathrm{t}=3 \mathrm{~h}$; (f) $\mathrm{t}=6 \mathrm{~h}$. 


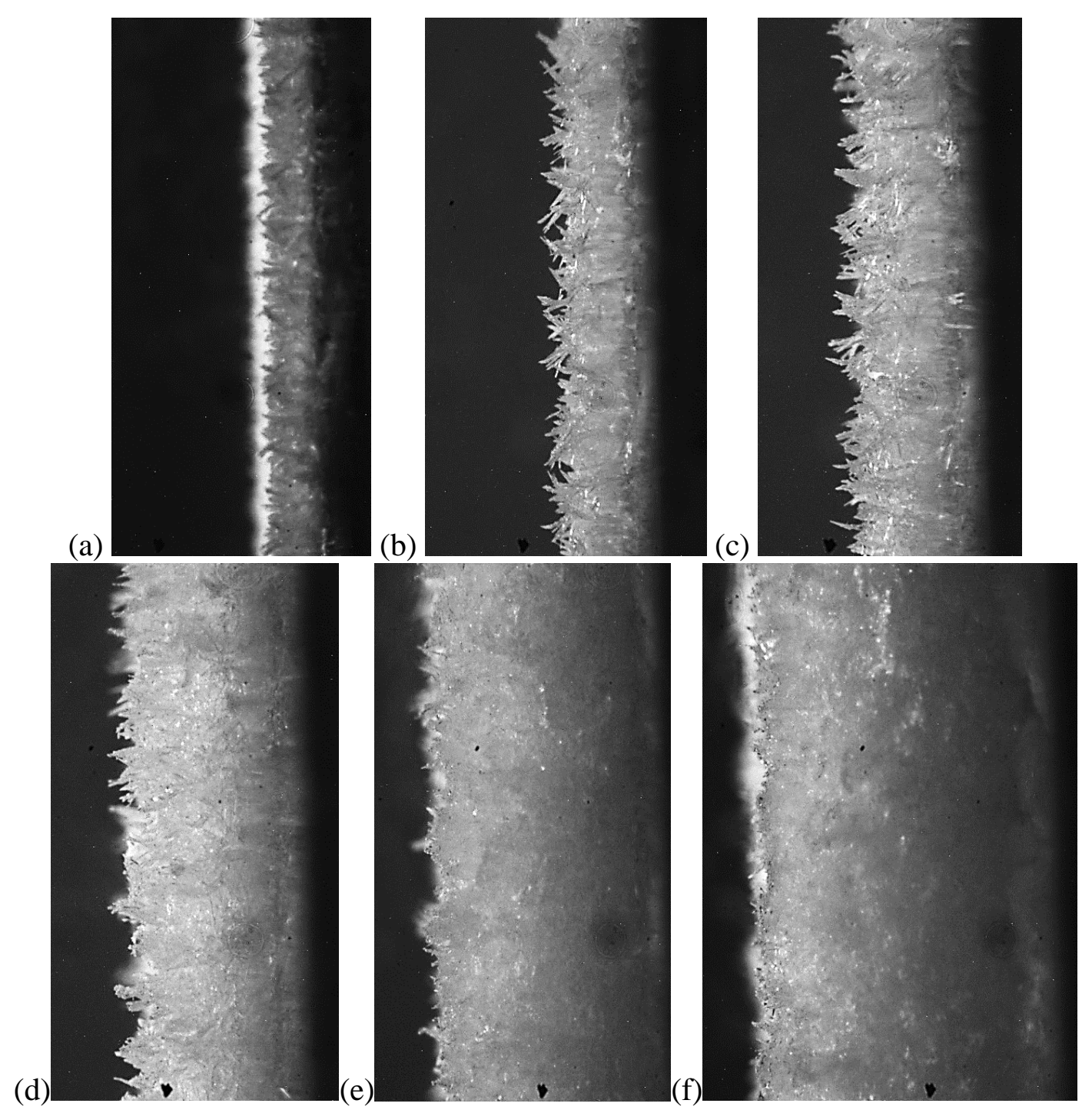

Figure 6.33. Side view of the frost formation at test surface (TestID-3). (a) $\mathrm{t}=10 \mathrm{~min}$; (b) $\mathrm{t}=20 \mathrm{~min}$; (c) $\mathrm{t}=30 \mathrm{~min}$; (d) $\mathrm{t}=1 \mathrm{~h}$; (e) $\mathrm{t}=3 \mathrm{~h}$; (f) $\mathrm{t}=6 \mathrm{~h}$. 
Table 6.4. Frost properties.

\begin{tabular}{lcccc}
\hline & $\begin{array}{c}\text { Frost growth } \\
\text { period } \\
(\mathbf{h})\end{array}$ & $\begin{array}{c}\text { Frost } \\
\text { thickness } \\
(\mathbf{m m})\end{array}$ & $\begin{array}{c}\text { Frost mass } \\
(\mathbf{g})\end{array}$ & $\begin{array}{c}\text { Frost } \\
\text { porosity }\end{array}$ \\
\hline TestID-1 & 4 & 4.34 & 1.608 & 0.72 \\
TestID-1 & 4 & 4.26 & 1.488 & 0.74 \\
TestID-1 & 6 & 5.20 & 2.267 & 0.67 \\
TestID-2 & 4 & 4.3 & 1.473 & 0.74 \\
TestID-2 & 4 & 4.38 & 1.462 & 0.75 \\
TestID-2 & 6 & 5.35 & 2.236 & 0.69 \\
TestID-3 & 4 & 4.88 & 1.772 & 0.73 \\
TestID-3 & 4 & 4.8 & 1.561 & 0.76 \\
TestID-3 & 6 & 5.48 & 2.55 & 0.65 \\
TestID-4 & 4 & 3.4544 & 2.78 & 0.65 \\
TestID-4 & 4 & 3.4798 & 2.744 & 0.66 \\
TestID-4 & 4 & 3.6322 & 2.617 & 0.69 \\
TestID-5 & 4 & 3.71 & 2.979 & 0.65 \\
TestID-5 & 4 & 3.86 & 2.966 & 0.67 \\
TestID-5 & 8 & 5.2324 & 4.52 & 0.62 \\
TestID-6 & 4 & 3.5814 & 2.761 & 0.66 \\
TestID-6 & 4 & 3.5814 & 2.679 & 0.67 \\
TestID-6 & 6 & 4.4196 & 4.08 & 0.6 \\
\hline
\end{tabular}

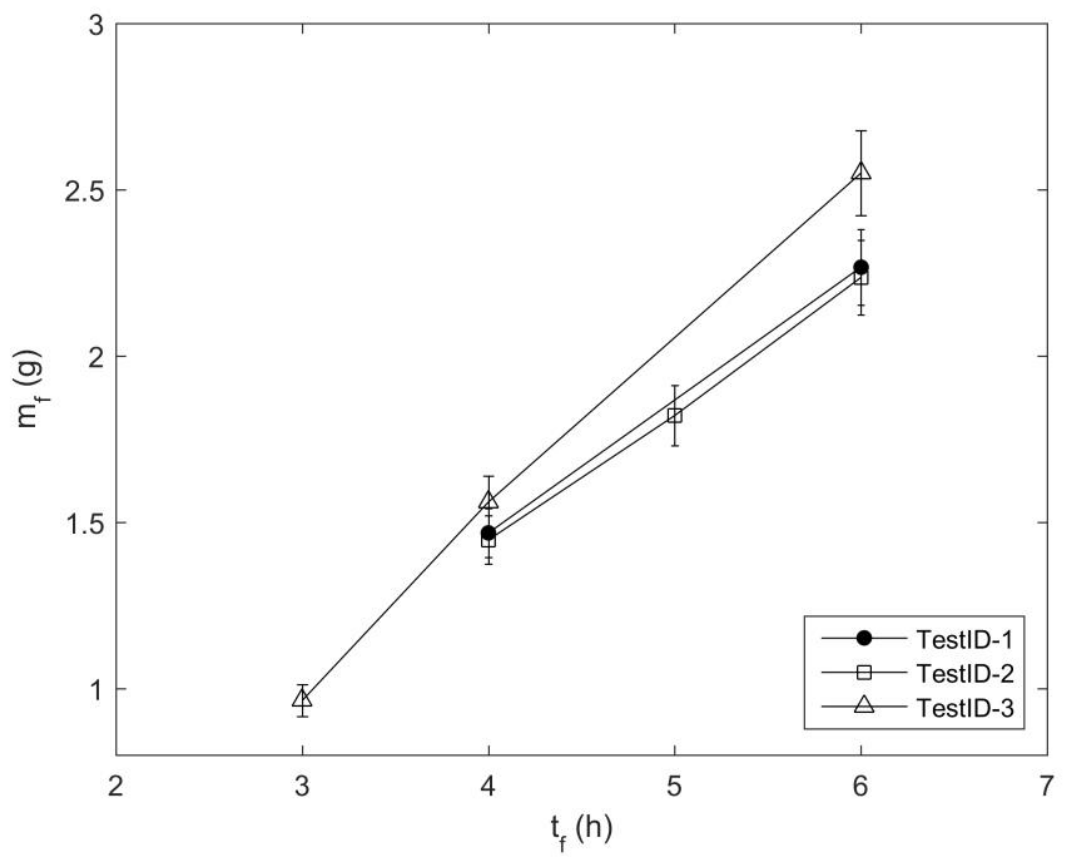

Figure 6.34. Frost mass versus frost growth period. 
The defrost processes were run on the six test surfaces and recorded for superhydrophilic, plain and superhydrophobic surfaces, as shown in Figs. 6.35-6.37. The physical mechanisms of the melting process are very different on the surfaces with different wettability. On the superhydrophilic surface and the plain surfaces, frost melts first at the center where frost is less denser and thicker. A large portion of the meltwater is absorbed into the frost layer at the sides where the frost is denser and thicker. The remaining meltwater takes the form of water film on the superhydrophilic surface and retention droplets on the plain surface. The frost at bottom then melts and drains on superhydrophilic surface. With the water accumulation at the side surfaces, part of the meltwater drains along the sides. The remaining frost falls off with the meltwater. When all the frost on the front surface melts away, a water film band is observed at the bottom part of the superhydrophilic surface, and non-uniform retention droplets are left on the plain surface.

The melting process on the superhydrophobic surface varies greatly from that on the superhydrophilic and plain surfaces. Frost slumping occurs on the test surfaces where frost grows for $3 \mathrm{~h}, 4 \mathrm{~h}$ and $6 \mathrm{~h}$ with high heating power and lower heating power applied separately. When heating applies on the superhydrophobic surface for a period of time, the frost at the center seems to detach from the surface first, and then the frost falls off as a whole piece with the heating continues. In the slumping process, the frost layer looks like a rigid mass, and no water drainage is observed. After the frost slumping, no droplet is left on the test surface. The different melting mechanisms might be explained by the two defrost models by Sanders [56]. The absorption model applies to the superhydrophilic and the plain surfaces. In the melting process, meltwater is absorbed into the frost layer, and the frost layer maintains the contact with the test surface. Different from the absorption model, an air gap model applies to the superhydrophobic surface. During the melting process, meltwater is absorbed into the frost layer leaving an air gap at the solid/frost interface. The air gap increases the thermal resistance and reduces the heat transferred into the frost layer. The frost column drops off at the point where the gravity outweighs the adhesion force. 


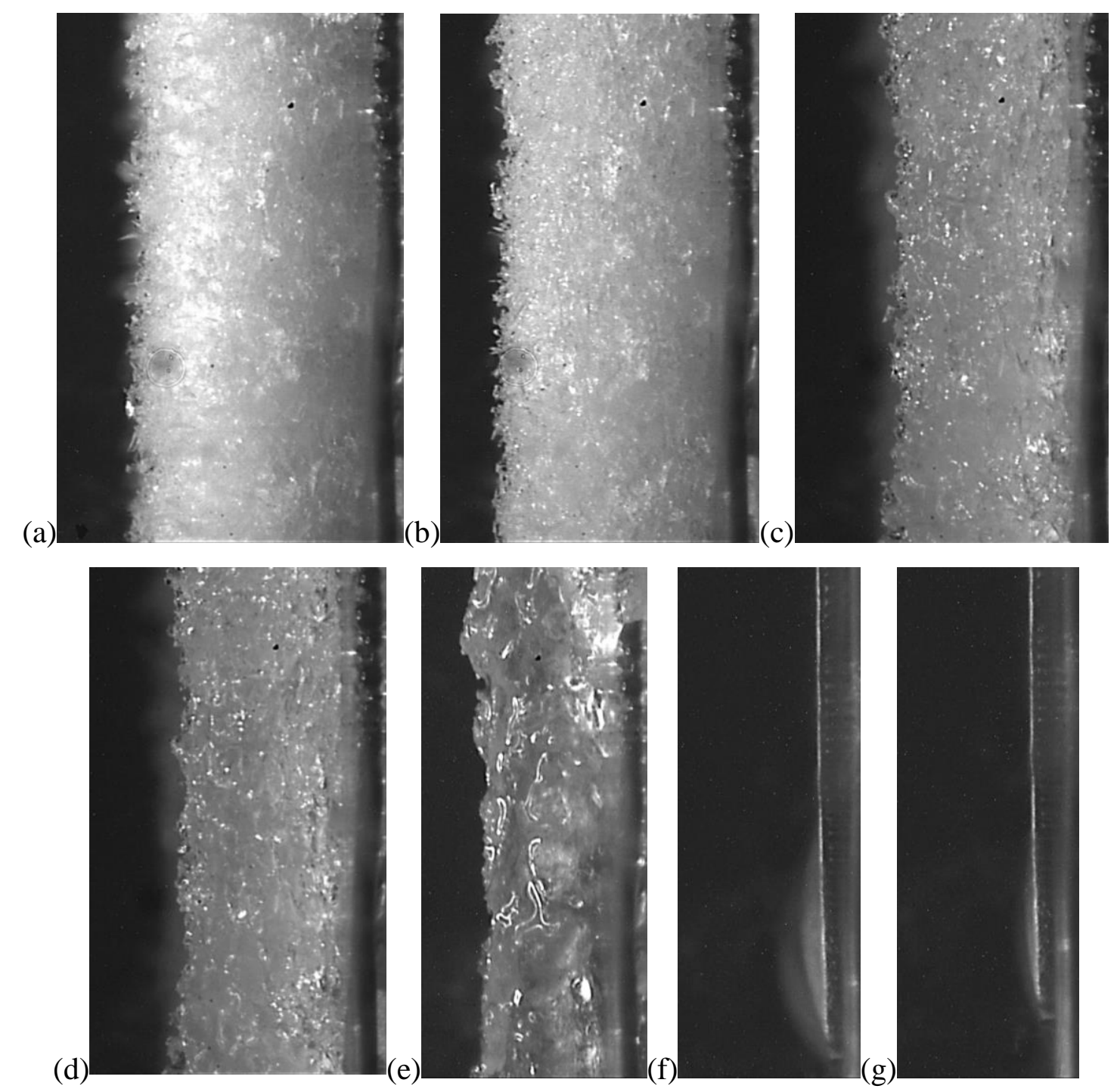

Figure 6.35. Defrost process after frost grows for $4 \mathrm{~h}$ (TestID-1).

(a) $\mathrm{t}=10 \mathrm{~s}$; (b) $\mathrm{t}=30 \mathrm{~s}$; (c) $\mathrm{t}=40 \mathrm{~s}$; (d) $\mathrm{t}=60 \mathrm{~s}$; (e) $\mathrm{t}=80 \mathrm{~s}$; (f) $\mathrm{t}=120 \mathrm{~s}$; (g) $\mathrm{t}=160 \mathrm{~s}$. 


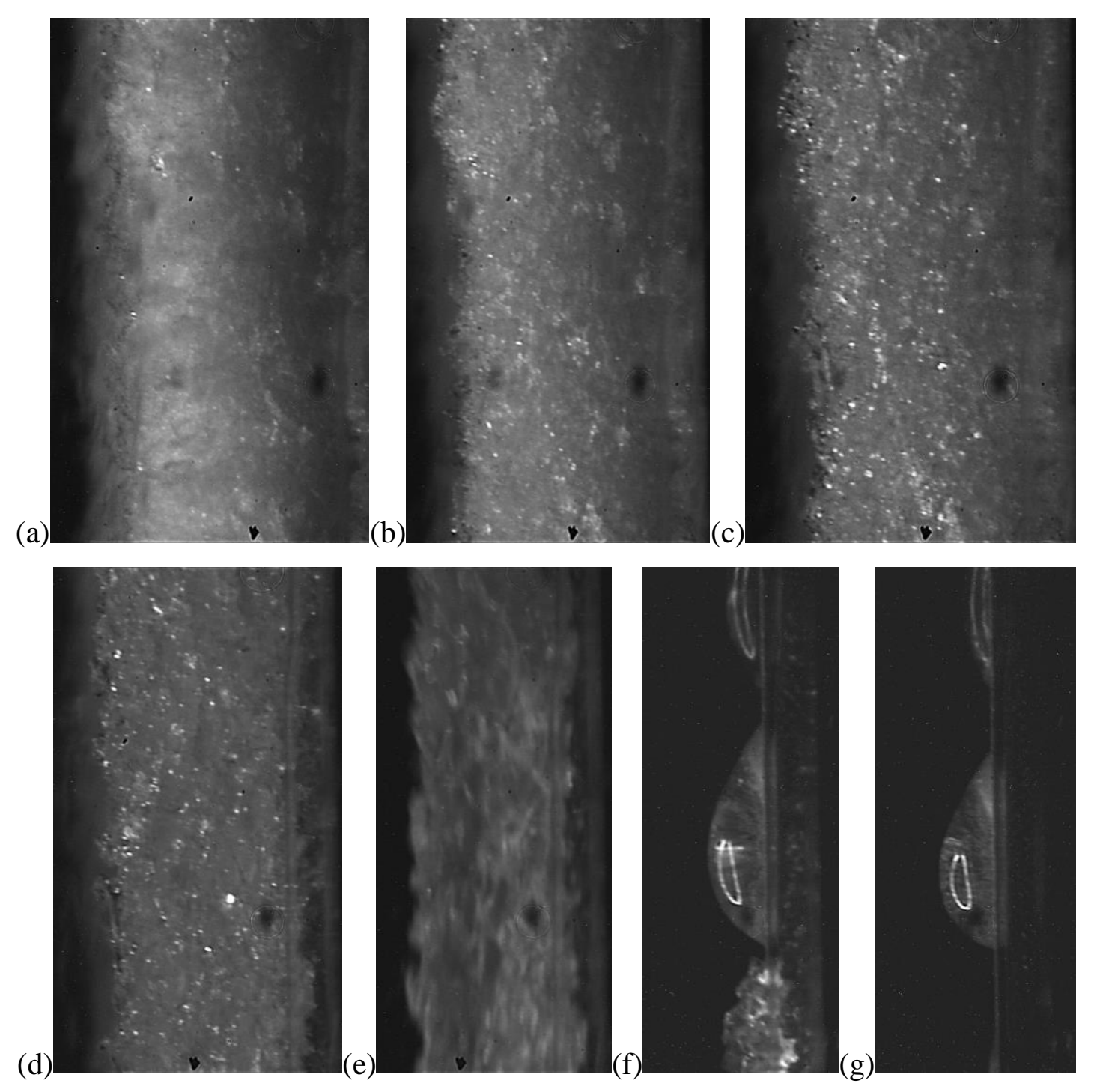

Figure 6.36. Defrost process after frost grows for $4 \mathrm{~h}$ (TestID-2).

(a) $\mathrm{t}=10 \mathrm{~s}$; (b) $\mathrm{t}=20 \mathrm{~s}$; (c) $\mathrm{t}=40 \mathrm{~s}$; (d) $\mathrm{t}=60 \mathrm{~s}$; (e) $\mathrm{t}=90 \mathrm{~s}$; (f) $\mathrm{t}=92 \mathrm{~s}$; (g) $\mathrm{t}=100 \mathrm{~s}$. 


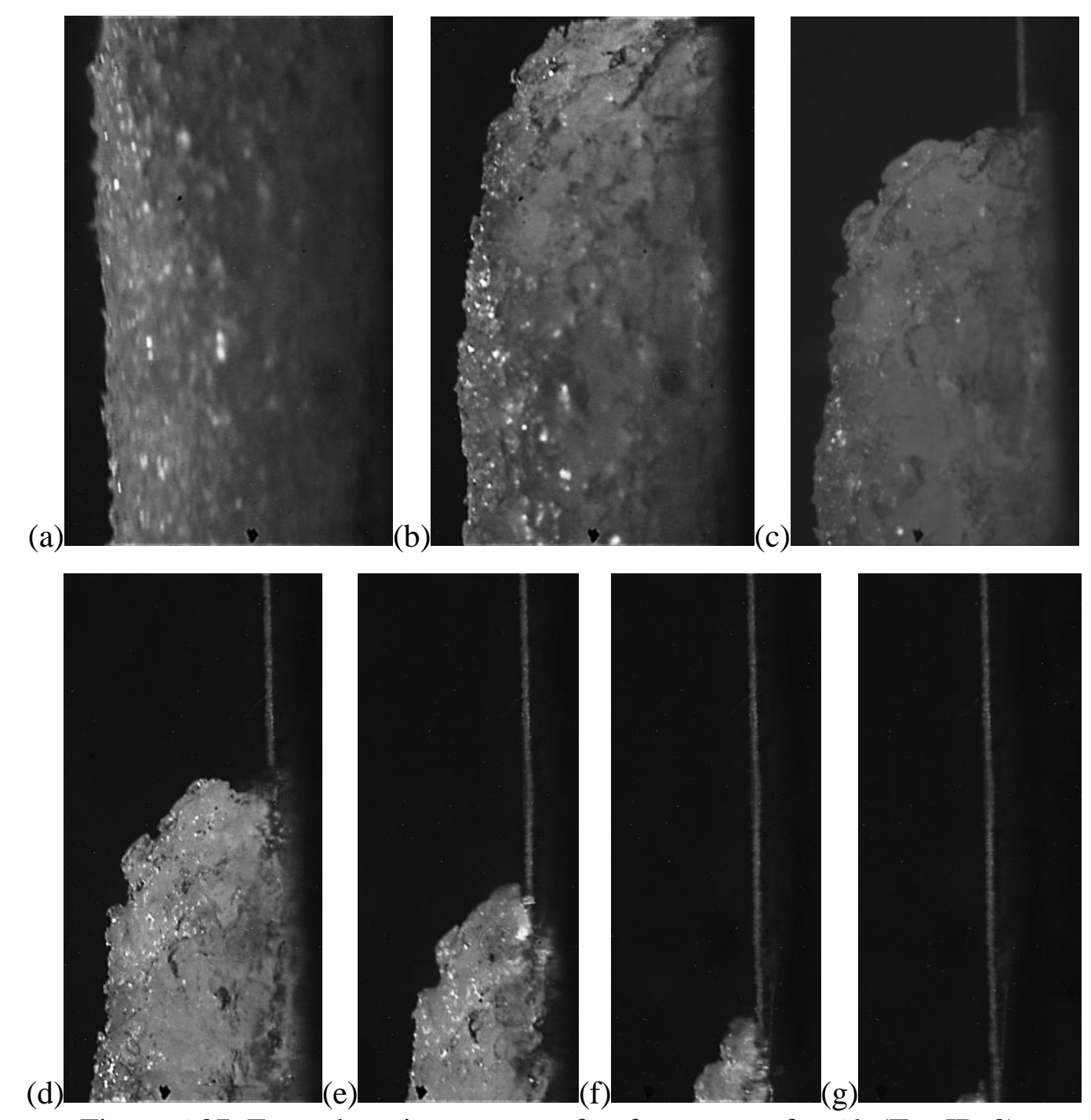

Figure 6.37. Frost slumping process after frost grows for $6 \mathrm{~h}$ (TestID-3).

(a) $\mathrm{t}=10 \mathrm{~s} ;$ (b) $\mathrm{t}=80 \mathrm{~s}$; (c) $\mathrm{t}=100 \mathrm{~s}$;

(d) $\mathrm{t}=110 \mathrm{~s} ;(\mathrm{e}) \mathrm{t}=120 \mathrm{~s} ;$ (f) $\mathrm{t}=126 \mathrm{~s} ;(\mathrm{g}) \mathrm{t}=130 \mathrm{~s}$.

The small test plates $(38 \mathrm{~mm} \times 38 \mathrm{~mm})$ are heated by the thermoelectric module with the DC power settings of $60 \mathrm{~W}, 15 \mathrm{~W}$ and $6 \mathrm{~W}$. The defrost properties are listed in Table 6.5. During the defrost process, the actual output of the DC power varies with time. Heat flux at the test plate varies with time as shown in Fig. 6.38. Heat flux increases rapidly at the first $20 \mathrm{~s}$ because the temperature at the heat flux sensor increases much quicker than that at the test plate. When the temperature difference between the heat flux sensor and the test plate becomes smaller, the heat flux decreases accordingly. The profile of the heat flux is consistent with the profile of the temperature difference between the heat flux sensor and the test plate as shown in Fig. 6.39. The temperature at the test 
Table 6.5. Defrost properties for test surfaces $38 \mathrm{~mm}$ x $38 \mathrm{~mm}$.

\begin{tabular}{lccccccc}
\hline & $\begin{array}{c}\text { Frost } \\
\text { mass } \\
(\mathbf{g})\end{array}$ & $\begin{array}{c}\text { Average } \\
\text { heat flux } \\
\text { applied } \\
\left(\mathbf{W} / \mathbf{m}^{2}\right)\end{array}$ & $\begin{array}{c}\text { Time to } \\
\text { melting } \\
\text { temperature } \\
(\mathbf{s})\end{array}$ & $\begin{array}{c}\text { Defrost } \\
\text { time } \\
(\mathbf{s})\end{array}$ & $\begin{array}{c}\text { Time to } \\
\text { dry out } \\
(\mathbf{s})\end{array}$ & $\begin{array}{c}\text { Defrost } \\
\text { efficiency } \\
\text { (dry } \\
\text { surface) }\end{array}$ & $\begin{array}{c}\text { Defrost } \\
\text { efficiency } \\
\text { (wet } \\
\text { surface) }\end{array}$ \\
\hline TestID-1 & 1.608 & 3525 & 25 & 89 & 171 & 0.07 & 0.13 \\
TestID-1 & 1.488 & 1219 & 42 & 109 & 325 & 0.16 & 0.41 \\
TestID-1 & 1.468 & 3394 & 26 & 85 & 185 & 0.06 & 0.12 \\
TestID-2 & 1.473 & 4120 & 23 & 97 & $>240$ & & 0.11 \\
TestID-2 & 1.422 & 1857 & 39 & 119 & $>320$ & & 0.36 \\
TestID-2 & 1.516 & 1404 & 48 & 135 & $>400$ & & 0.88 \\
TestID-3 & 1.800 & 3853 & 26 & 120 & & 0.11 & \\
TestID-3 & 1.561 & 1642 & 46 & 165 & & 0.30 & \\
TestID-3 & 1.772 & 1226 & 55 & 177 & & 0.82 & \\
\hline
\end{tabular}

"Dry surface" means that test surfaces are dried without water droplets or water film after heating.

"Wet surface" means that test surfaces are still covered by water droplets on plain surface and by water film on superhydrophilic surface.

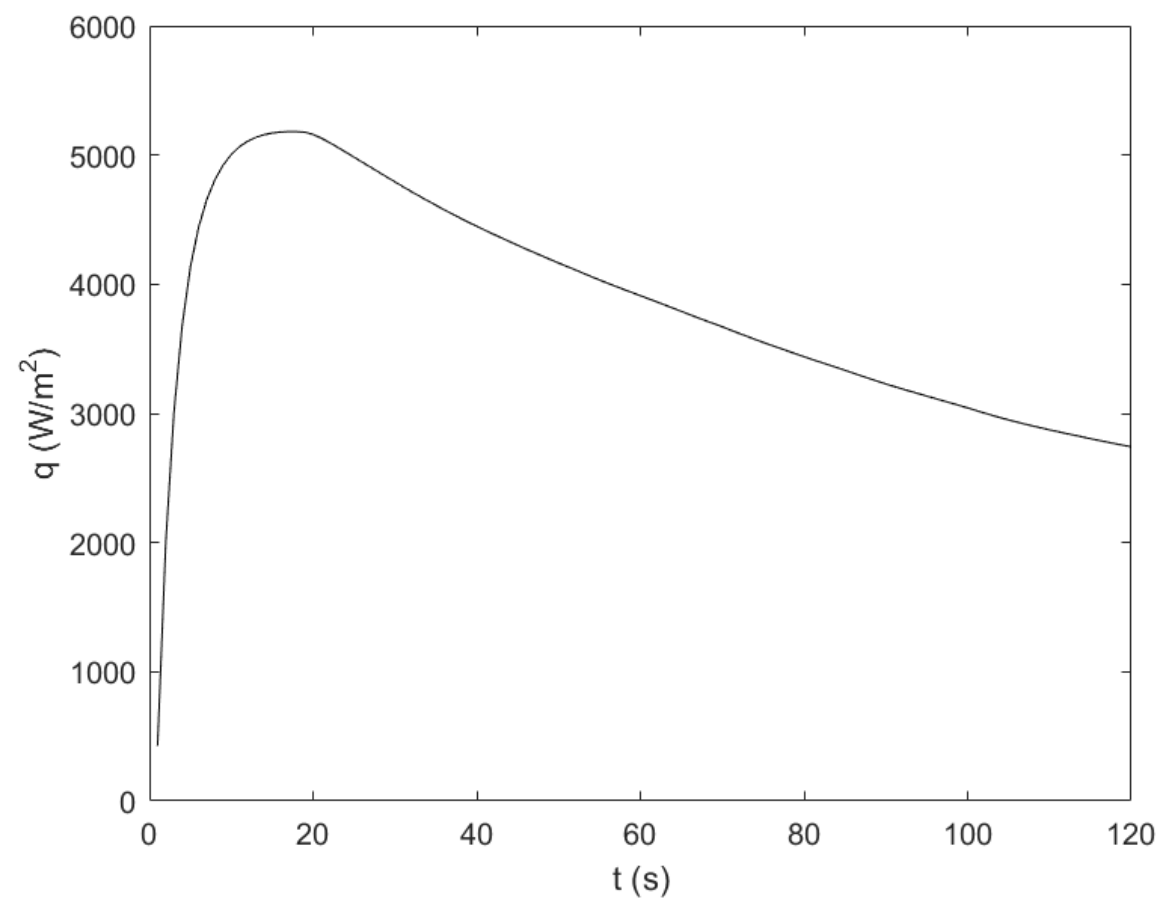

Figure 6.38. Heat flux applied at the test plate (TestID-3) where direct current (DC) sets at $12 \mathrm{~V} / 5 \mathrm{~A}$. 


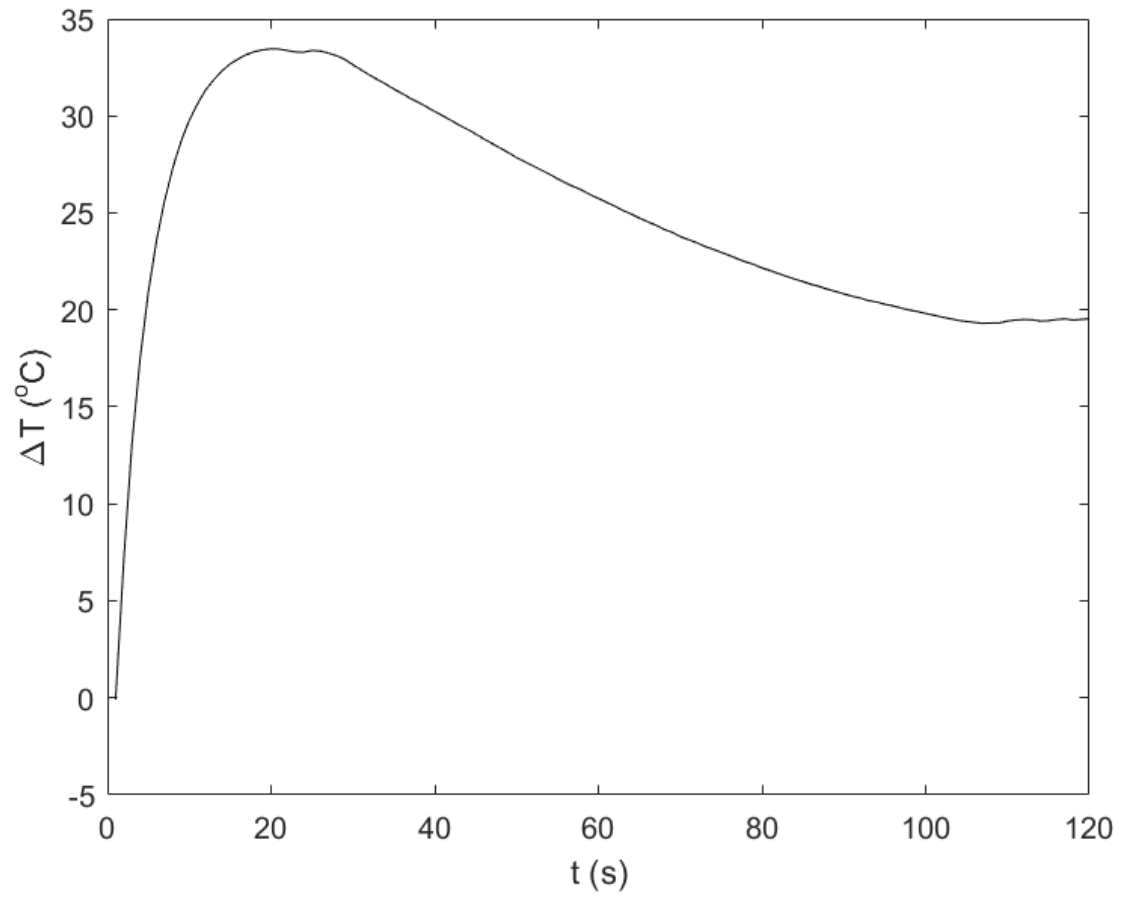

Figure 6.39. Temperature difference between the heat flux sensor and the test plate (TestID-3) where DC sets at 12V/5A.

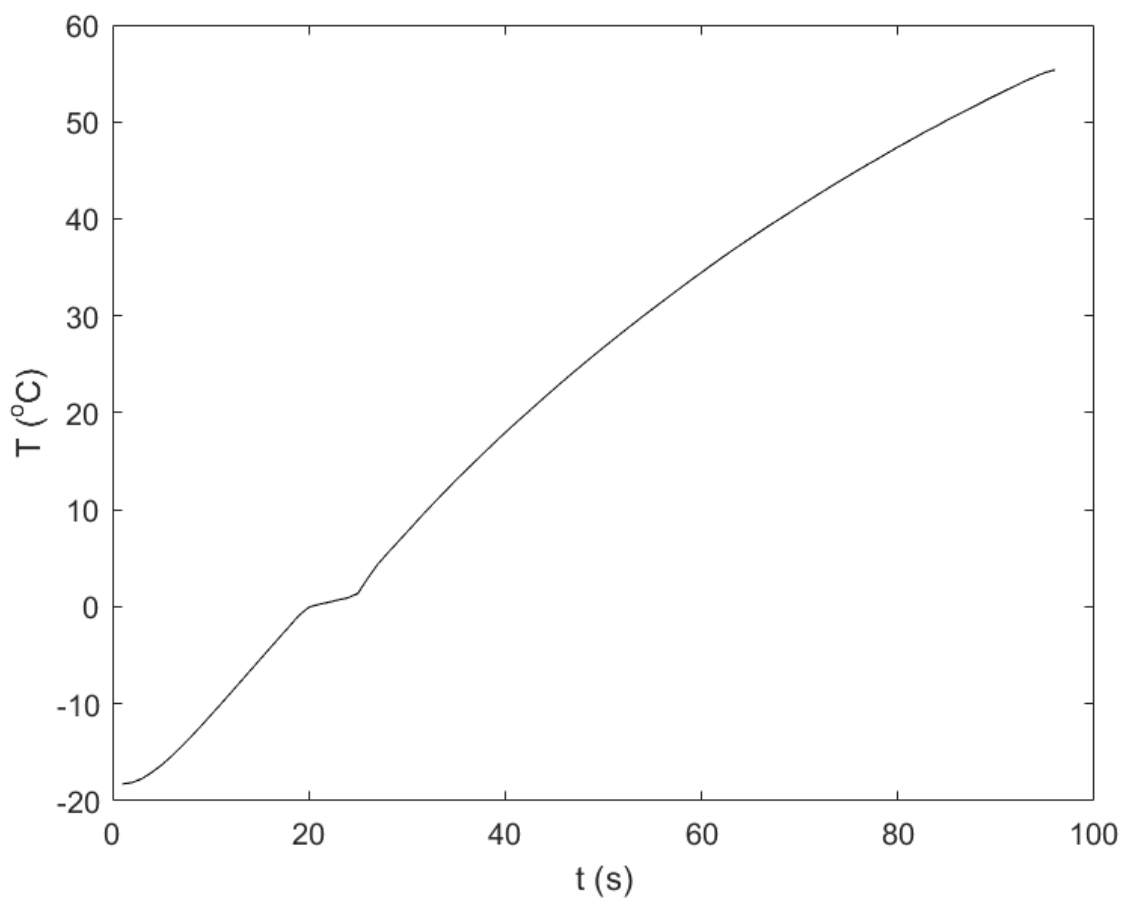

Figure 6.40. Temperature at the test plate (TestID-2) during the defrost period where DC sets at $12 \mathrm{~V} / 5 \mathrm{~A}$. 


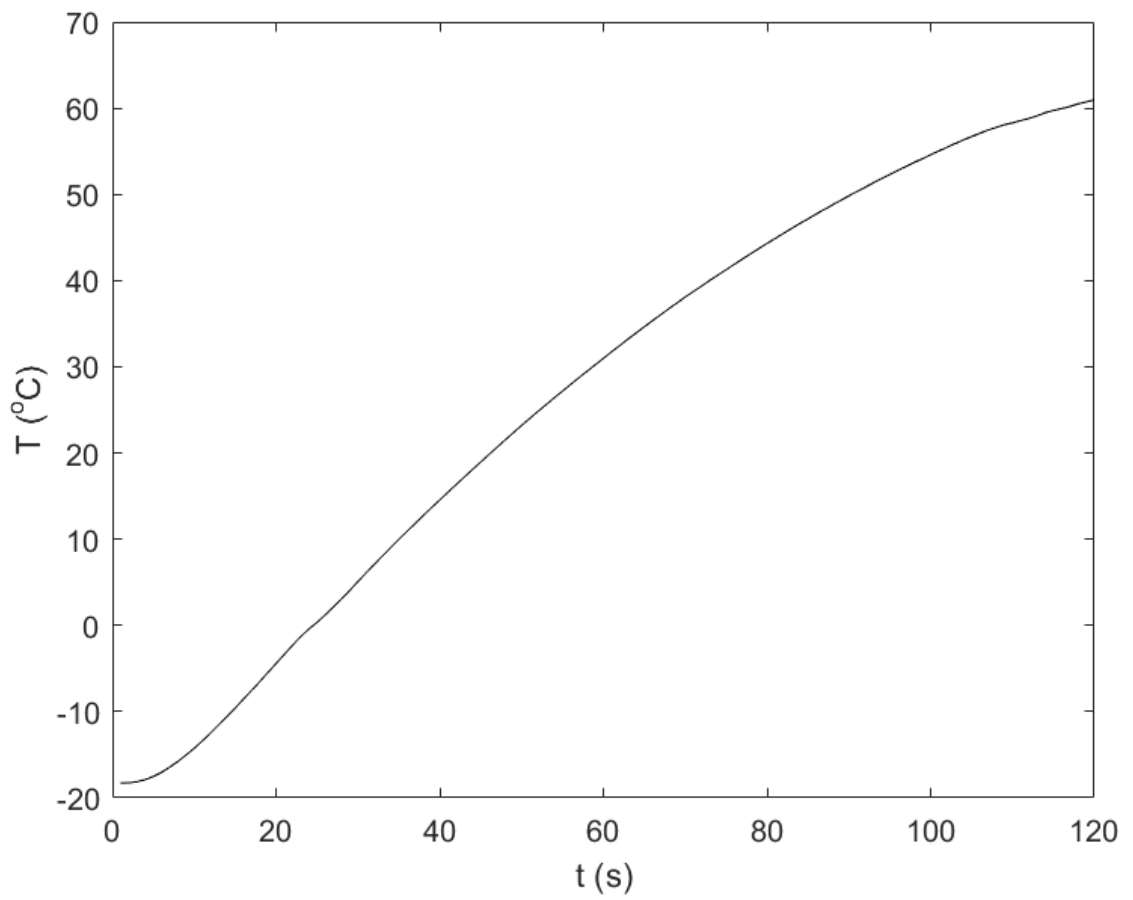

Figure 6.41. Temperature at the test plate (TestID-3) during the defrost period where $\mathrm{DC}$ sets at $12 \mathrm{~V} / 5 \mathrm{~A}$.

surface increases with time as shown in Figs. 6.40. and 6.41. The temperature on the plain surface maintains at the melting temperature for a few minutes which is different than the strict rising on the superhydrophobc surface. The explanation might be that the frost layer attaches to the test surface on a plain surface but detaches from the test surface on a superhydrophobic surface during melting. The temperature variation inside the chamber is not significant. The temperature remains around $19.6^{\circ} \mathrm{C}$ at the upper and $18.4^{\circ} \mathrm{C}$ at the lower of the chamber for a test run, as shown in Fig. 6.42.

Defrost time and efficiency depend on frost mass, porosity, heating power and surface wettability. Defrost process shortens on the higher heating power. Table 6.5. shows that the defrost time decreases from $109 \mathrm{~s}$ to $85 \mathrm{~s}$ on TestID-1, from $119 \mathrm{~s}$ to $97 \mathrm{~s}$ on TestID-2, and from $165 \mathrm{~s}$ to $120 \mathrm{~s}$ on TestID-3 with the heating power setting increases from $15 \mathrm{~W}$ to $60 \mathrm{~W}$. However, the defrost efficiency is larger on the lower heating power. Defrost efficiency on a wet surface increases from $12 \%$ to $41 \%$ on TestID-1 and $11 \%$ to $36 \%$ on TestID- 2 with the heating power setting decreases from $60 \mathrm{~W}$ to $15 \mathrm{~W}$. The 


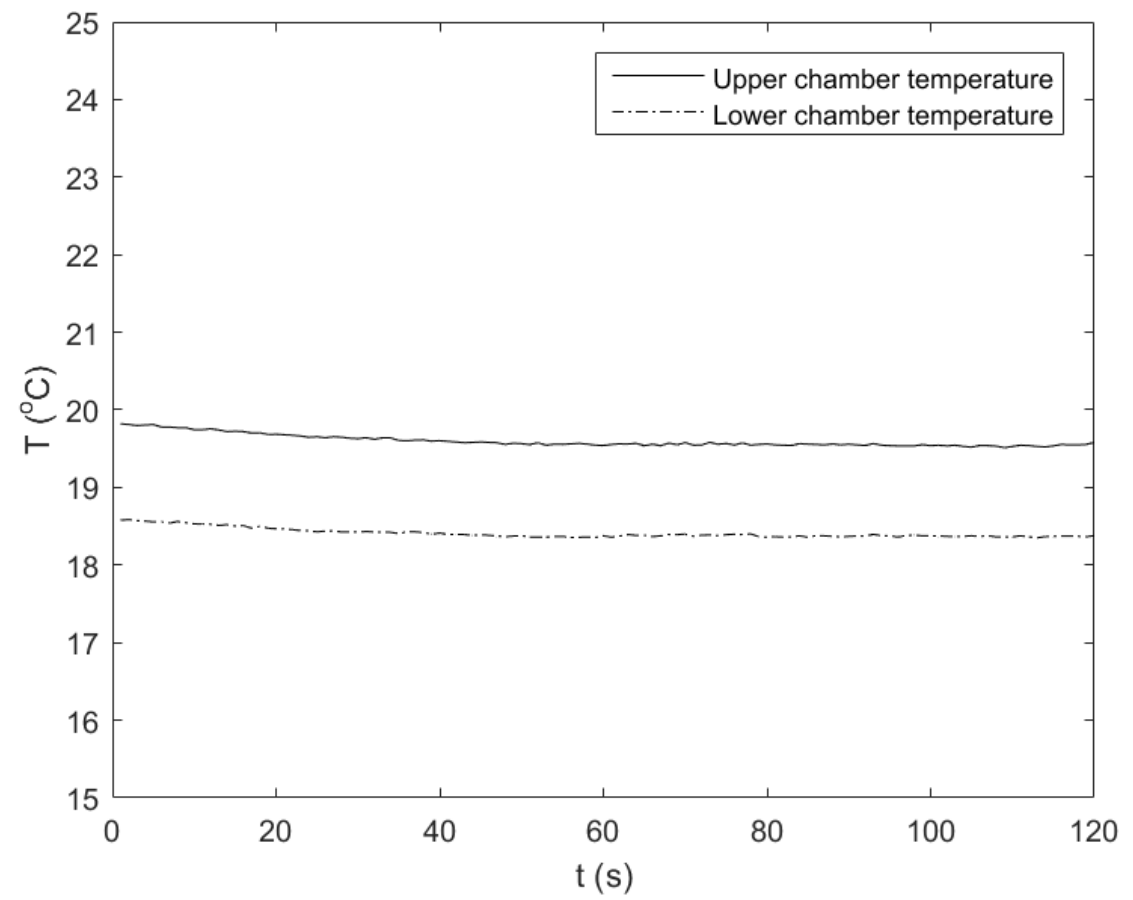

Figure 6.42. Temperature inside the chamber during the defrost period where DC sets at $12 \mathrm{~V} / 5 \mathrm{~A}$.

defrost efficiency on dry surface increases from $11 \%$ to $82 \%$ on TestID-3 with the heating power setting decreased from $60 \mathrm{~W}$ to $6 \mathrm{~W}$. The dependences of defrost time and defrost efficiency on heat flux are shown in Figs. 6.43. and 6.44. The defrost process was run on the superhydrophobic surface after frost grows for $4 \mathrm{~h}$. The frost mass is $1.772 \mathrm{~g}, 1.561$ $\mathrm{g}$ and $1.8 \mathrm{~g}$, corresponding to the average heat flux of $1,226 \mathrm{~W} / \mathrm{m}^{2}, 1,642 \mathrm{~W} / \mathrm{m}^{2}$ and 3,853 $\mathrm{W} / \mathrm{m}^{2}$. Among the three runs, the defrost time is the shortest with the highest average heat flux, and the defrost efficiency is the highest with the lowest average heat flux.

The effect of surface wettability on defrost time is shown in Figs. 6.45. and 6.46. for wet surface and dry surface. During the defrost period, a thin film is retained on the superhydrophilic surface, and some non-uniform droplets stick on the plain surface. The test surface is wet when the frost melts away but the water film or retention droplets are still on it. The defrost time is shorter on the superhydrophilic surface than that on the plain surface. The explanation is that the water film on the superhydrophilic surface improves the partial slumping of the frost and the drainage of the meltwater. The evaporation time is shorter on the superhydrophlic surface than on the plain surface. The 


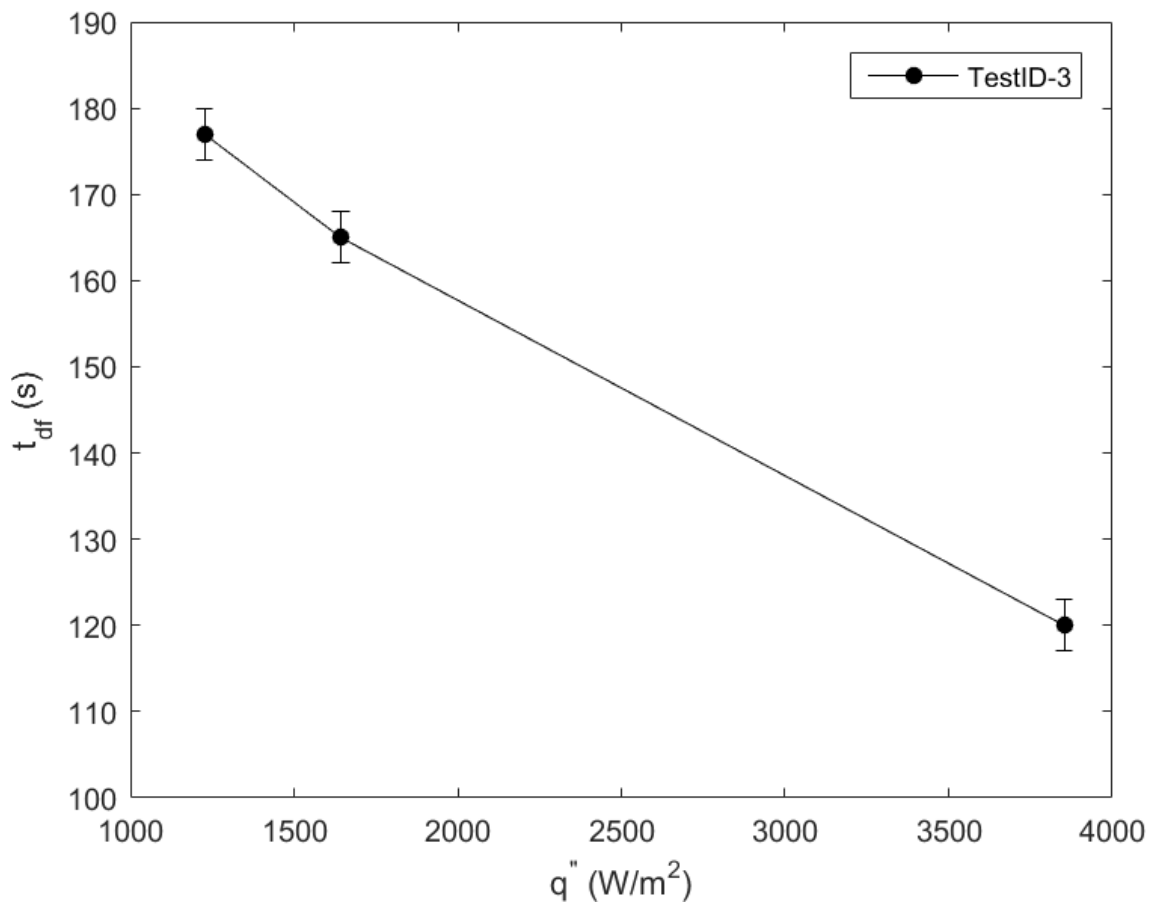

Figure 6.43. Defrost time versus average heat flux at TestID-3 where frost grows for $4 \mathrm{~h}$.

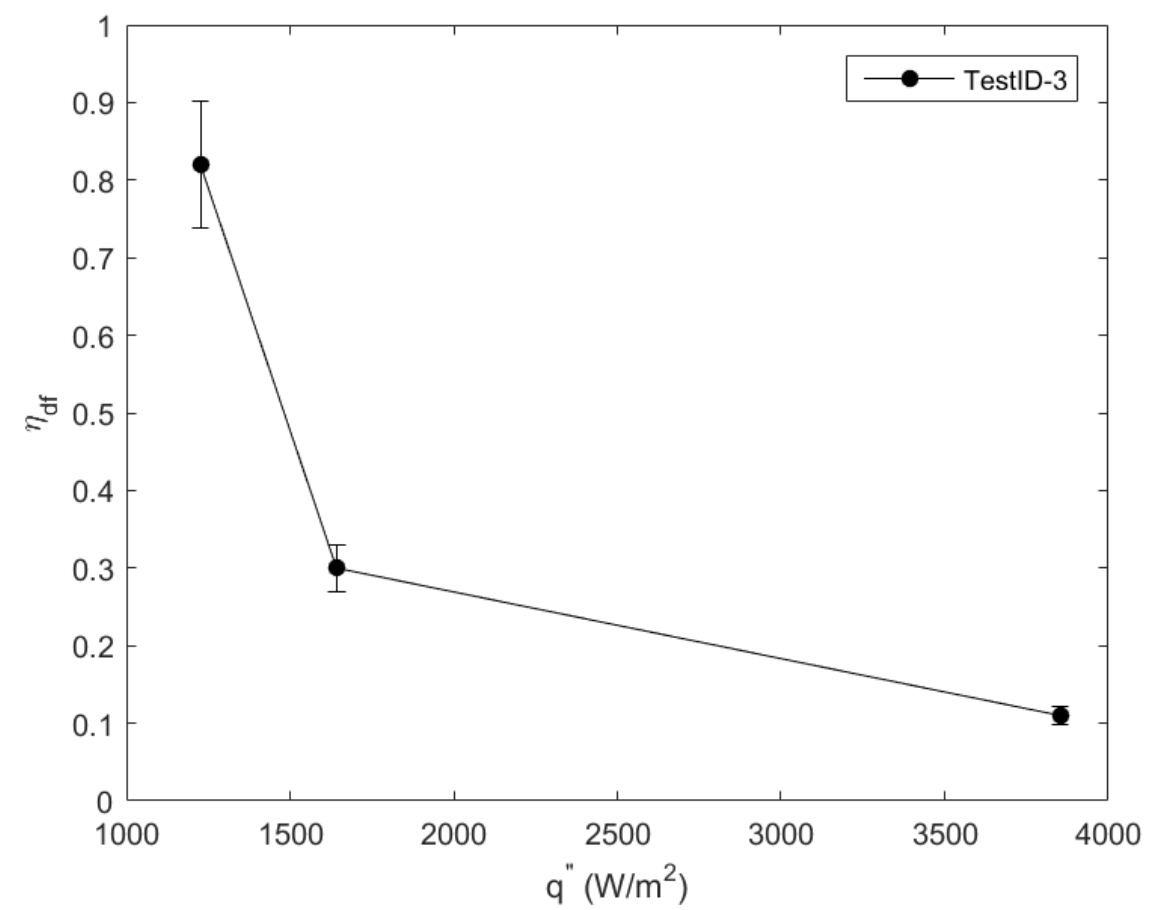

Figure 6.44. Defrost efficiency versus average heat flux at TestID-3 where frost grows for $4 \mathrm{~h}$. 


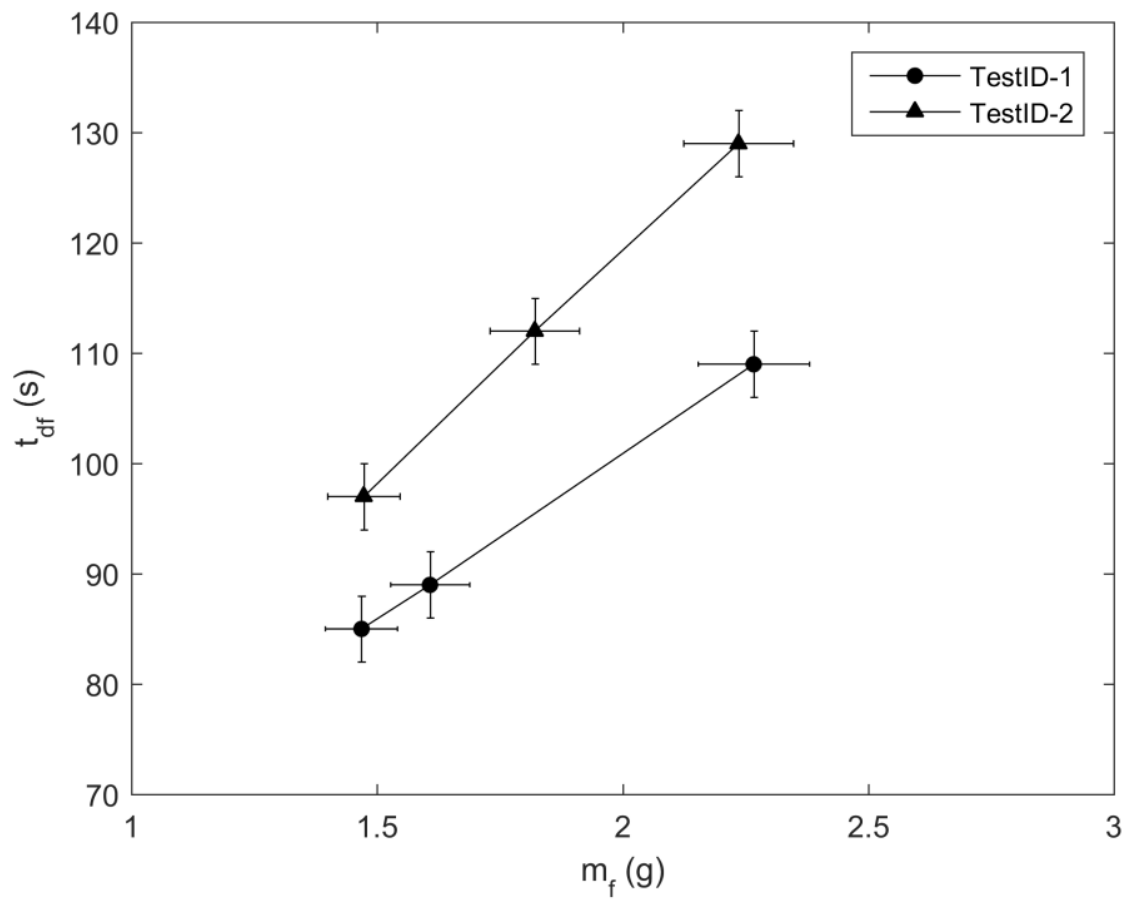

Figure 6.45. Defrost time versus mass on wet surface where heating power sets at $60 \mathrm{~W}$.

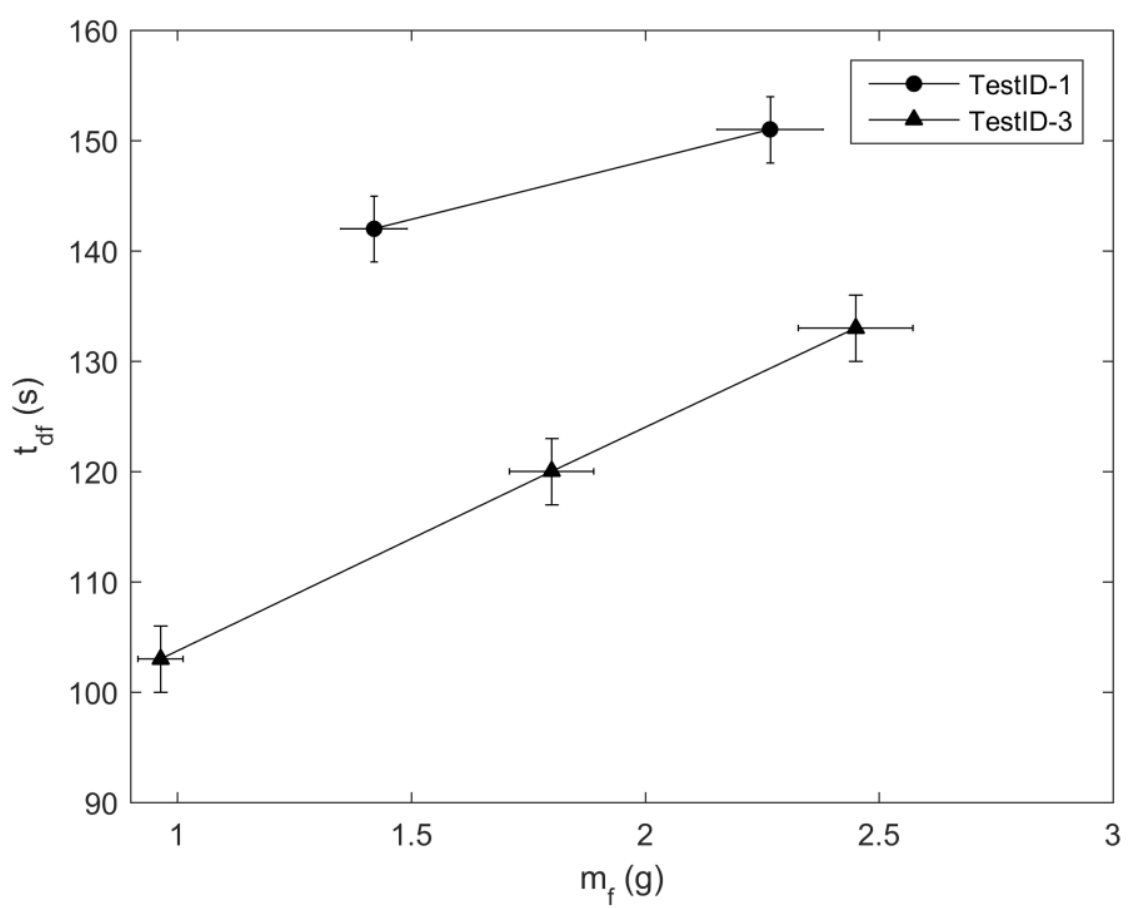

Figure 6.46. Defrost time versus mass on dry surface where heating power sets at $60 \mathrm{~W}$. 
reason is that thin water film spreads over the surface and increases the contact area between the test surface and the water film. Heat transfer is thus larger on the superhydrophilic surface. The evaporation time is much longer on the plain surface as the contact area of water droplets to the test surface is much smaller. It is observed from the experiments that thin water film over the surface dries away quickly, but a thicker water film accumulates at the bottom of the test surface and takes quite some time to dry away. The evaporation time is much longer with lower heating power, compared to that with high heating power. The surface is dry when no water droplets or water film are on it. The defrost time is shorter on the superhydrophobic surface than on the superhydrophilic surface. When frost melts on the superhydrophobic surface, the frost layer detaches from the test surface and falls off without retention of droplets. No evaporation time is required, thus the defrost time is reduced significantly.

The influences of surface wettability on defrost efficiency are shown in Figs. 6.47. and 6.48. When the test plates are wet, the defrost efficiency is larger on the superhydrophilic surface than that on the plain surface due to the shorter defrost time. When the test plates are dry, the defrost efficiency is larger on the superhydrophobic surface compared to that on the superhydrophilic surface. The reason is that the defrost time is shorter on the superhydrophobic surface. The improvement of defrost efficiency is noticeable with lower heating power. Defrost efficiency increases from $11 \%$ to $30 \%$ on the superhydrophobic surface compared to the increase from $7 \%$ to $16 \%$ on the superhdyrophilic surface when the heating power setting decreases from $60 \mathrm{~W}$ to $15 \mathrm{~W}$. It can be explained by the increase of the evaporation time on the superhydrophilic surface with lower heating power. 


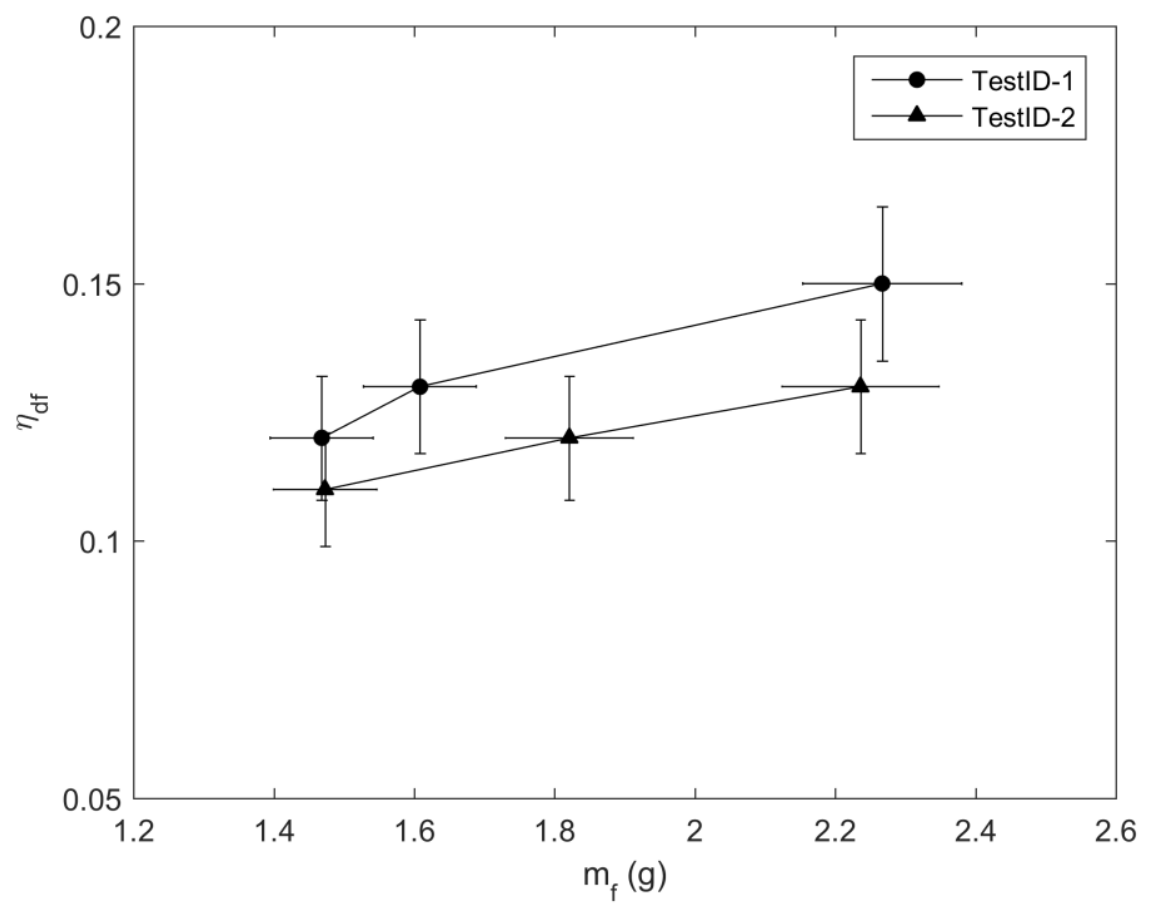

Figure 6.47. Defrost efficiency versus mass on wet surface where heating power sets at $60 \mathrm{~W}$.

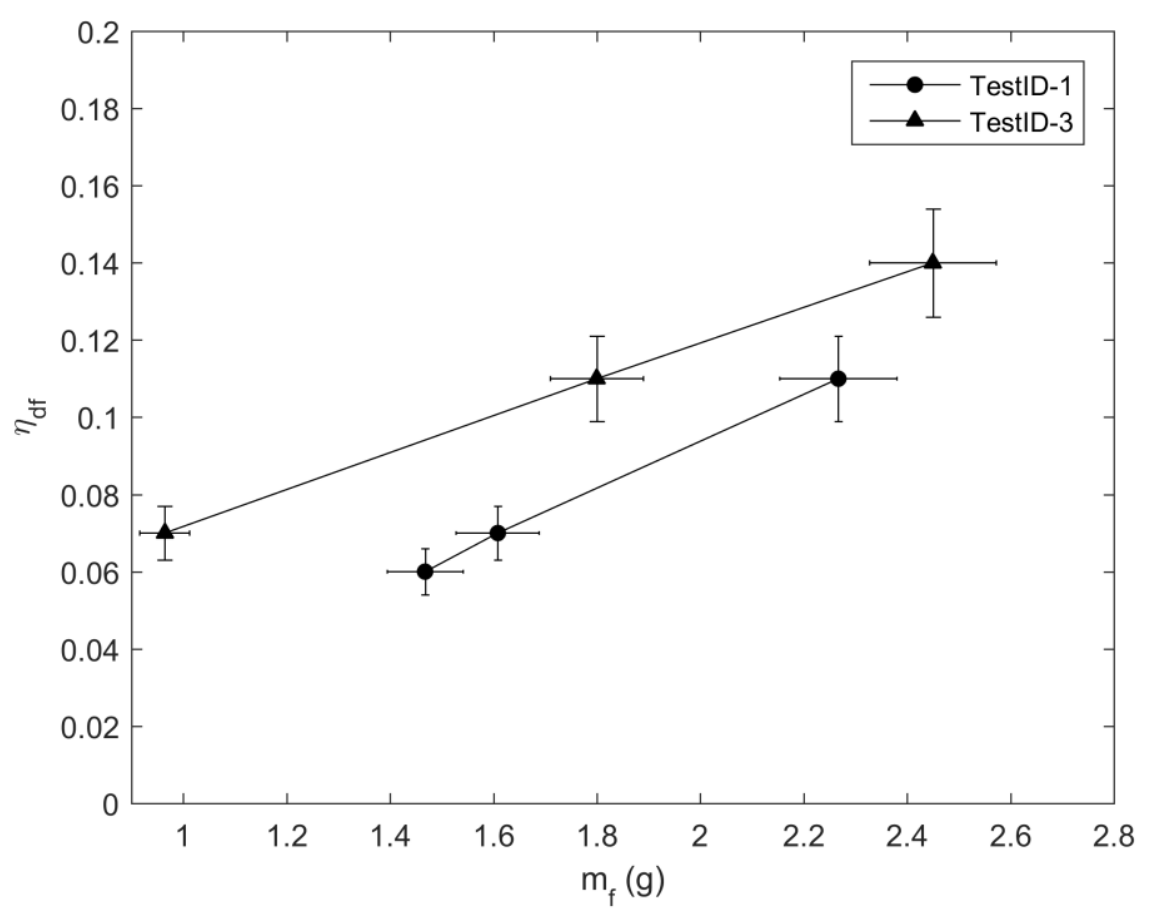

Figure 6.48. Defrost efficiency versus mass on dry surface where heating power sets at $60 \mathrm{~W}$. 
Table 6.6. Defrost properties for test surfaces $50 \mathrm{~mm}$ x $50 \mathrm{~mm}$.

\begin{tabular}{lccccccc}
\hline & $\begin{array}{c}\text { Frost } \\
\text { mass } \\
(\mathbf{g})\end{array}$ & $\begin{array}{c}\text { Average } \\
\text { heat flux } \\
\text { applied } \\
\left(\mathbf{W} / \mathbf{m}^{2}\right)\end{array}$ & $\begin{array}{c}\text { Time to } \\
\text { melting } \\
\text { temperature } \\
(\mathbf{s})\end{array}$ & $\begin{array}{c}\text { Defrost } \\
\text { time } \\
(\mathbf{s})\end{array}$ & $\begin{array}{c}\text { Time to } \\
\text { dry out } \\
(\mathbf{s})\end{array}$ & $\begin{array}{c}\text { Defrost } \\
\text { efficiency } \\
\text { (dry } \\
\text { surface) }\end{array}$ & $\begin{array}{c}\text { Defrost } \\
\text { efficiency } \\
\text { (wet } \\
\text { surface) }\end{array}$ \\
\hline TestID-4 & 2.78 & 417 & 62 & 165 & $>600$ & $<0.22$ & 0.8 \\
TestID-4 & 2.744 & 339 & 62 & 158 & $>600$ & $<0.22$ & 0.83 \\
TestID-4 & 2.86 & 301 & 61 & 153 & $>600$ & $<0.23$ & 0.9 \\
TestID-5 & 2.577 & 407 & 64 & 167 & $>600$ & & 0.73 \\
TestID-5 & 2.828 & 355 & 69 & 205 & $>600$ & & 0.66 \\
TestID-5 & 2.966 & 336 & 65 & 178 & $>600$ & & 0.8 \\
TestID-6 & 2.679 & 247 & 68 & 177 & & 0.71 & \\
TestID-6 & 2.711 & 230 & 74 & 161 & & 0.79 & \\
TestID-6 & 2.992 & 190 & 72 & 184 & & 0.76 & \\
\hline
\end{tabular}

A thin film heater is used to heat the large test plates $(50 \mathrm{~mm} \times 50 \mathrm{~mm})$ with the actual power output of $7.7 \mathrm{~W}$. The defrost properties are listed in Table 6.6. Compared to the heating by thermoelectric module, the average heat flux at the test plate is much smaller. The evaporation time is much longer due to the low heat flux, and the defrost efficiency is higher than that with the high heating power. The dependence of defrost time and efficiency on surface wettability is shown in Figs. 6.49.-6.52. When the test plates are wet, defrost time is shorter on the superhydrophilic surface compared to that on the plain surface. Defrost efficiency improves as well on the wet superhydrophilic surface. When the test plates are dry, defrost time is much shorter on the superhydrophobic surface than that on the superhydrophilic surface. It is observed that the evaporation time lasts over $600 \mathrm{~s}$ on the superhydrophilic surface and the plane surface. Defrost efficiency improves greatly on the superhydrophobic surface as there is no evaporation time for the defrost process. Frost and defrost experimental procedures are in Appendix D. 


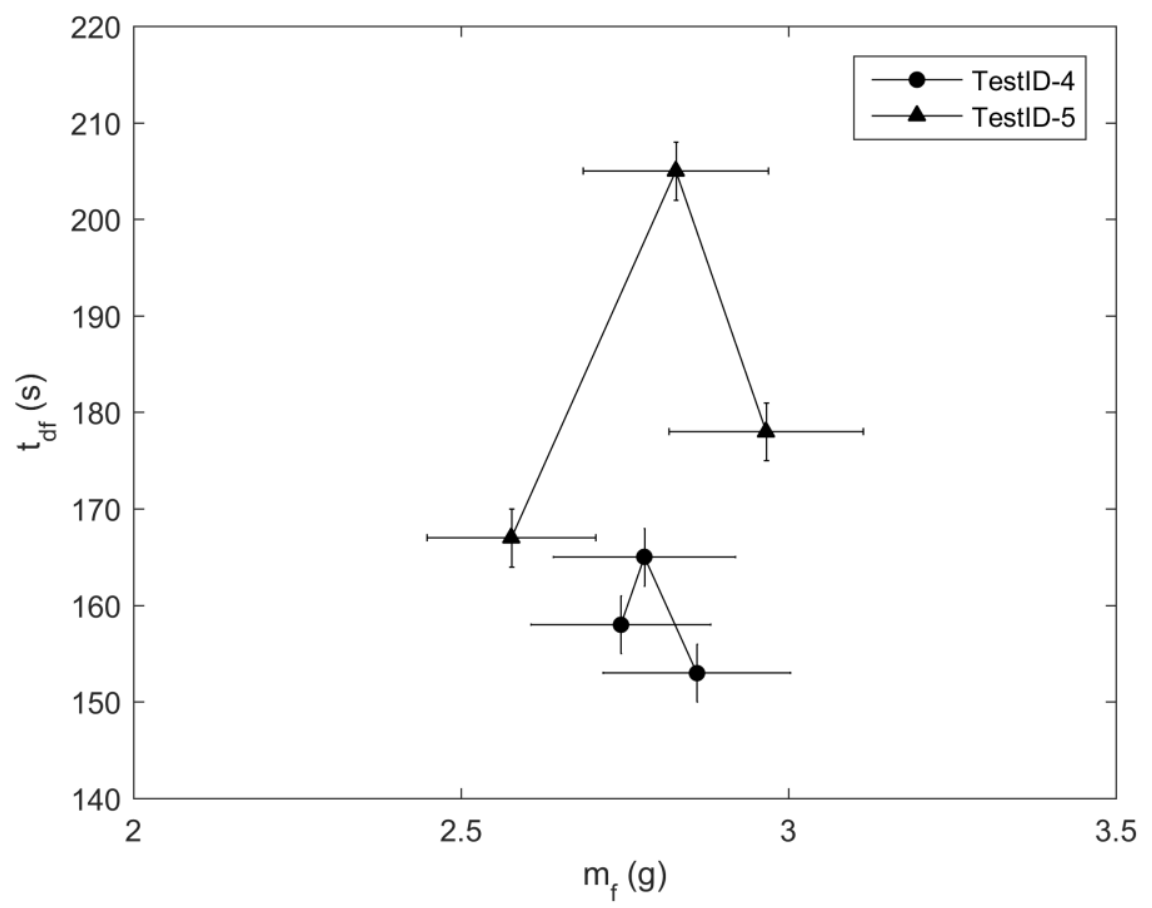

Figure 6.49. Defrost time versus mass on wet surface where actual heating power is $7.7 \mathrm{~W}$.

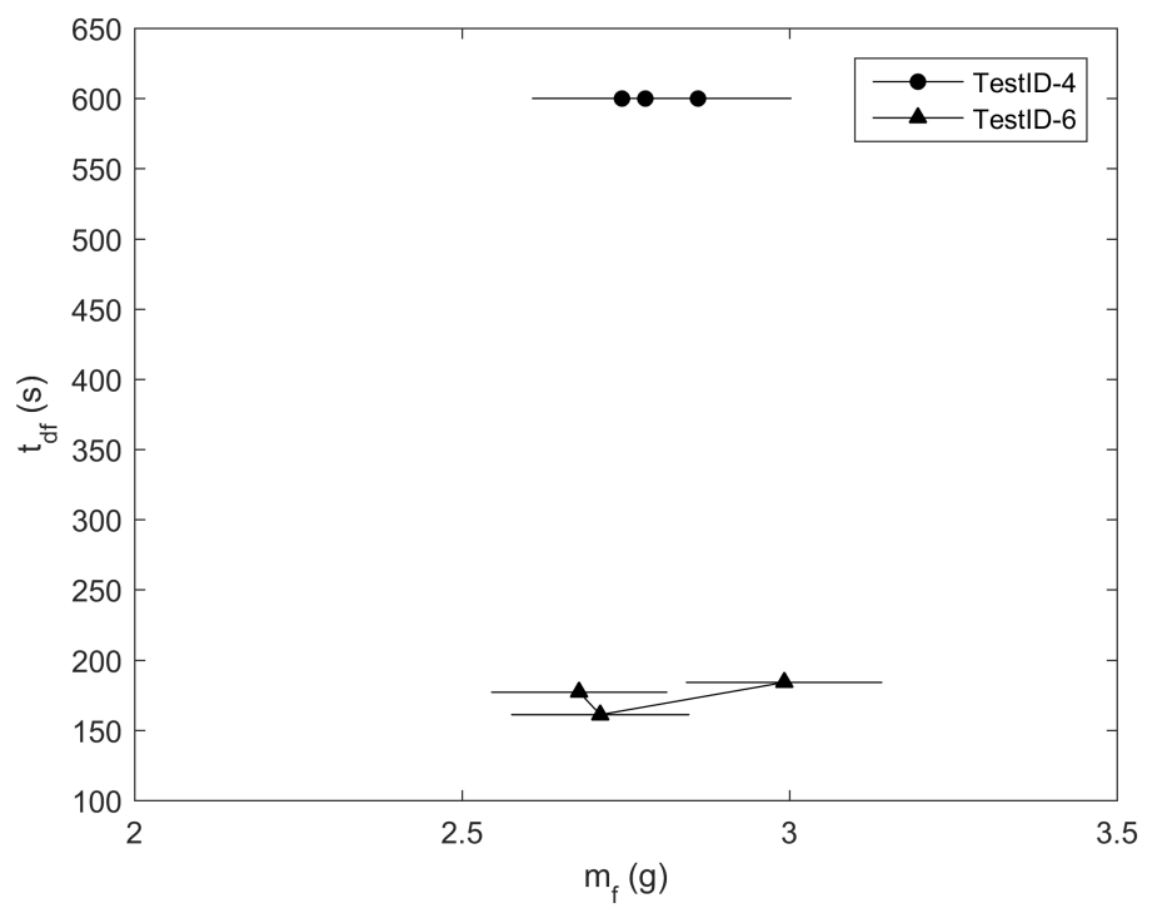

Figure 6.50. Defrost time versus mass on dry surface where actual heating power is $7.7 \mathrm{~W}$. 


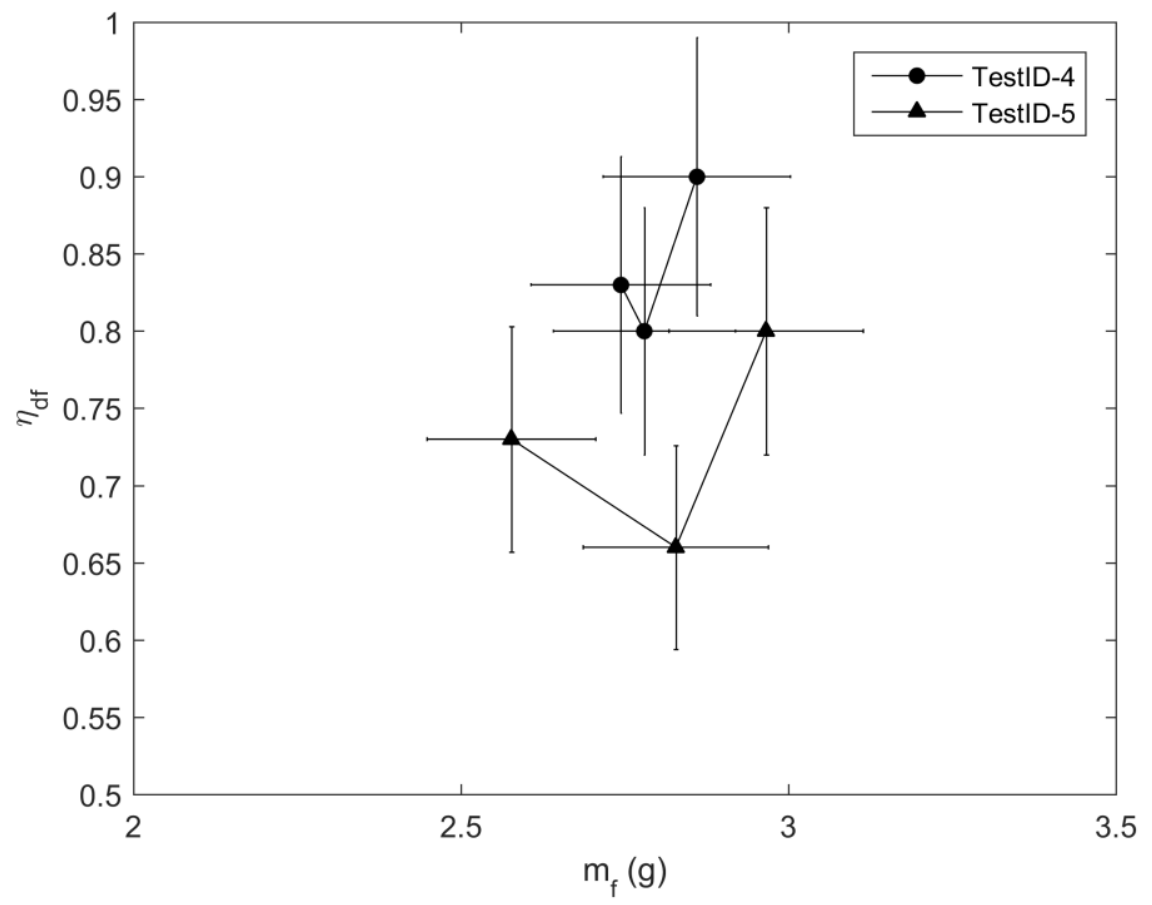

Figure 6.51. Defrost efficiency versus mass on wet surface where actual heating power is $7.7 \mathrm{~W}$.

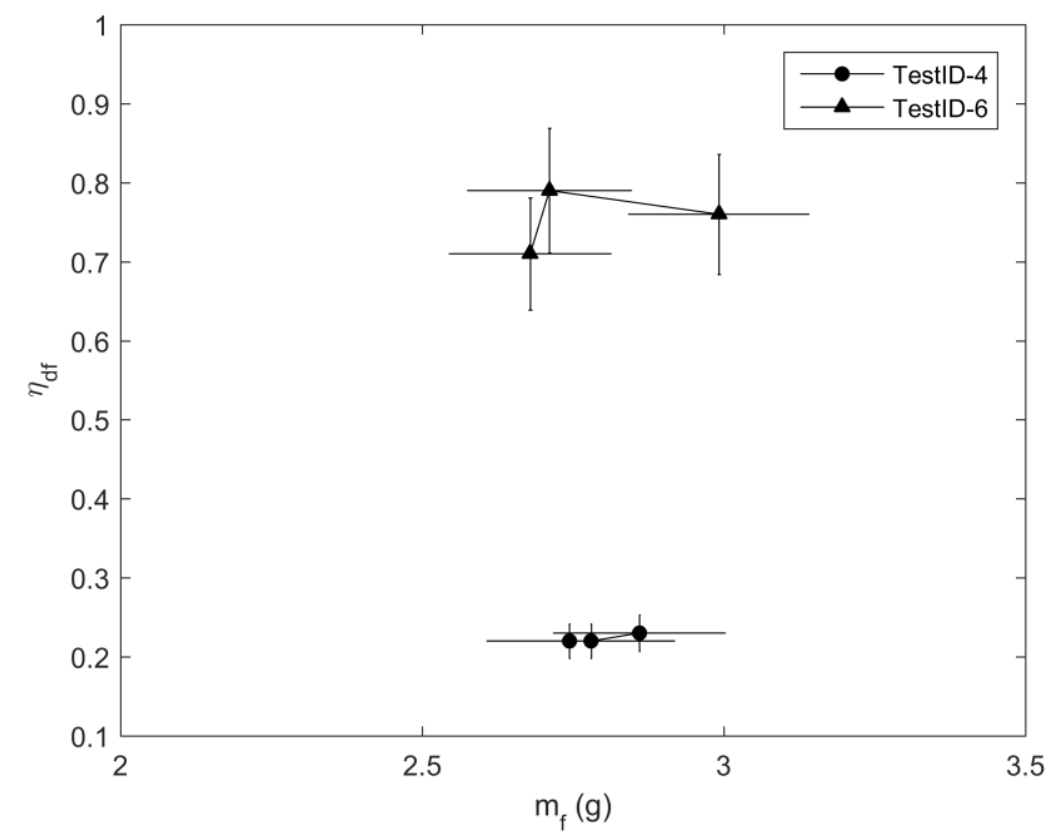

Figure 6.52. Defrost efficiency versus mass on dry surface where actual heating power is $7.7 \mathrm{~W}$. 


\subsection{Comparison between physical model and experiments}

Defrost processes are complicated because many factors affect the defrost mechanisms. Defrost time and efficiency are two key variables when controlling defrost processes in applications. The relationship between defrost time and efficiency and defrost mechanisms are discussed in the model and validated by the experiments. Surface wetting properties could influence frost properties as well as defrost processes.

A defrost process is divided into three stages based on motions of meltwater. The magnitude of volume flux of water, melting velocity and draining velocity determines the motions of meltwater as well as defrost mechanisms. When the volume flux water is greater than melting velocity, the meltwater is absorbed into the frost layer. The absorption was validated at the early period during the defrost process. With water saturation increasing, volume flux of water decreases, and meltwater starts to drain. When the volumetric draining rate is less than the volumetric rate of melting water, part of the meltwater accumulates between the surface and saturated frost layer. Frost could fall off with the draining water. The drainage was observed in the middle of the defrost process, and the remaining frost finally fell off.

The effects of surface wettability are discussed in the model and the slumping criterion. Surface wetting properties could influence the volume flux of water and melting velocity by affecting the frost properties. The average volumetric draining rate is predicted to increase by $7.1 \%$ on hydrophobic surfaces due to the slip velocity at the surface. The draining velocity is not measured in the experiments. However, the prediction agrees with the literature [41] in which the draining velocity is shown to be larger on hydrophobic surfaces than that on hydrophilic surfaces. The slumping force ratio is greater on hydrophobic surfaces as predicted in the model. In experiments, frost slumping occurred on superhydrophobic surfaces during the defrost processes.

Defrost time and efficiency depend on the defrost mechanisms. The defrost model predicts the defrost time larger compared to the values measured in the experiments. The reason is that frost slumping reduced the defrost time. The model could better predict defrost time when coupling with the frost slumping criterion. In applications, the geometry and other related factors have to be taken into consideration when formulating frost slumping criteria. 


\section{Conclusions and Future Work}

\subsection{Conclusions}

This research is motivated by the current problem in refrigeration system that how would surface wettability influences the defrost process. Defrost process is analytically formulated based on the physical mechanisms of the defrost process. In the literature, meltwater is either assumed to be absorbed into the frost layer or drained in the current defrost models. However, the factors affecting the meltwater behavior are not studied. In this work, water permeation rate is inspected in absorption, and drainage rate is investigated with respect to the different surface wettability. The slumping criterion is studied as a potential method of frost removal. Slumping conditions vary on surfaces with different surface wettability. Superhydrophilic and superhydrophobic surfaces are prepared and examined in the experiments, and the results show that frost falls off as rigid

pieces on the superhydrophobic surface while it melts with partial slumping on the superhydrophilic surface.

A general defrost process consists of surface preheating, frost melting and retention water evaporation. This work is focused on frost melting and meltwater behaviors. Three variables determine the melting scheme. They are melting rate, water permeation rate and draining rate. Melting rate depends on the heat flux applied at the surface and the porosity of the frost layer. Water permeation rate is a function of water saturation and frost layer permeability. Draining rate is related to the velocity boundary conditions at the interfaces. The competition among the three variables determines whether meltwater is absorbed into the frost layer or drains along the test surface. Based on these studies, the melting process is divided into three stages: absorption, accumulation and drainage. In the absorption stage, meltwater is absorbed into the frost layer by capillary force. Water saturation is formulated with mass continuity and is shown as a function of time and location. A thin water film could form over the test surface due to surface tension around the perimeters of the frost column in accumulation. In the drainage stage, meltwater drains by gravity. The draining rate varies with the velocity at the solid/water interface and at the water/permeation interface. 
Frost slumping is a phenomenon in which frost columns fall off from the surface as rigid pieces or as parts of the bulk mass. In comparison with the traditional defrost methods, frost removal by slumping could reduce defrost time and energy consumption. In this work, a slumping criterion is formulated based on the static force analysis. A slumping force ratio is defined as the ratio of gravity to adhesive force at the surface. Both gravity and adhesive force change with defrost time. In the absorption/accumulation stage, ice adhesion/surface tension attaches the frost mass to the surface, and the strength of ice adhesion/surface tension decreases with increases of the surface temperature. In the drainage stage, both the gravity and surface tension decrease, and the force ratio depends on the drainage rate of the meltwater and the surface temperature.

Surface wettability influences the defrost process and the slumping criterion. In the absorption stage, water permeation rate is related to the structure of the frost layer, which varies with surface wettability. The water flux increases with the permeability of the frost layer, which increases with the frost porosity. The draining rate is a function of the velocity at the solid/water interface. A no slip boundary condition is assumed on the hydrophilic surface, and a slip boundary condition is applied to the hydrophobic surface. The model shows that the draining rate increases about $7 \%$ on hydrophobic surfaces compared to that on hydrophilic surfaces. Slumping criterion is formulated for hydrophilic surface and hydrophobic surface separately in the accumulation and drainage stages. The expressions of surface tension are different for hydrophilic surfaces and for hydrophobic surfaces. A thin water film is assumed on hydrophilic surfaces, and the surface tension is a function of the contact angle. Water droplets are assumed on hydrophobic surfaces, and the surface tension is a function of advancing contact angle and receding contact angle.

Experiments have been conducted on the superhydrophilic surface, plain surface and superhydrophobic surface. The defrost process is observed to be different on the three types of surface. On the superhydrophilic and plain surfaces, frost melts at the center of the surface very quickly when the surface temperature reaches the melting temperature. The meltwater divides into two parts. One part is absorbed into the thicker frost layer at the edges, and the other part retains on the surface in the form of water droplets on the plain surface and water film on the superhydrophilic surface. On the edges 
of the test plate, the frost at the bottom melts and drains first. The frost at the top falls with draining water after a period of time. On the superhydrophobic surface, the center area of the frost column seems to detach from the surface when the surface temperature reaches the melting temperature. The frost column still adheres to the surface when the frost at the edges attaches to the surface and finally falls off as a rigid whole piece. After the defrost process, no water retention is observed on the superhydrophobic surface, while water droplets are retained on the plain surface and water film is retained on the superhydrophilic surface. When the evaporation time of water droplets or water film is not considered, defrost time and efficiency do not vary significantly on the three types of surfaces. However, defrost time and efficiency are improved considerably when the water droplets or water film are evaporated. Heating powers could influence the defrost time and efficiency during the defrost process. With higher heating power, the defrost time is shorter, but the defrost efficiency is lower. With lower heating power, the defrost time is longer, but the defrost efficiency is longer. Defrost time and efficiency also depend on the ambient temperature, the system design and the defrost methods.

\subsection{Future work}

Current work includes formulating the mathematical model of the melting process, analyzing the influence of the surface wettability on the melting process quantitatively and theoretically, and investigating the slumping criterion during the defrost process. The research could be explored and extended in many aspects.

The formulation of the mass continuity in the permeation layer is one dimensional based on the assumptions that the frost layer is uniform. A multi-dimensional formulation could better describe the frost layer with non-uniform properties. The frost layer melts with a moving boundary. The thickness of the frost layer decreases with time. The analytical solution might be possible in the future study. The boundary conditions are assumed to be fixed at the solid/permeation interface and at the permeation/frost interface. In the application, the practical boundary conditions should be included, and surface wettability might influence the frost structures and thus the permeation rate.

The formula of the permeation flux can be modified to accommodate the frost column. In the formula, the intrinsic permeability, the entry capillary pressure and the power law constants are not available in the current literatures. The values in the 
references are used in this work. In the application, the values should be determined by experiments. Visualization scheme might be applied to track the saturation ratio and the permeation front with time.

Calibration of the convection heat transfer coefficient can be improved. The heat transfer coefficient at the test surface/air interface is calculated by measuring the temperature at the test surface and the temperature of air that is very close to the test surface. A heat flux sensor is attached to the test surface to obtain the heat flux across the surface. The calculated value is small compared to that from the correlations. The error might result from the inaccuracy of the air temperature measurement.

The thermal boundary condition at the test surface is expected to be controllable. In current design, a thermal electric module is applied for cooling cycle, and a film heater is used for heating cycle. During the defrost cycle, the test plate experiences a transient state when heat is applied at the plate. Heat flux across the test surface would not be constant. In refrigeration industries, hot gas purge might be applied in the tube for the defrost process, so the constant temperature boundary condition can be considered when setting up the model. The temperature boundary condition can be realized by remodeling the current design with a constant temperature controller and a bath. The coolant absorbs the heat from the test plate quickly, and the temperature of the coolant increases significantly in the current system.

The test plate is placed inside the chamber without fastening to avoid the interference with the frost and defrost process. Thermal resistance between the test plate and the cooling/heating apparatus thus increases. A mechanical fixture could help reduce the thermal resistance if the design does not affect the frost and defrost process. The measurement of frost properties could be improved. The frost growth period is accompanied by the thickening of the frost density and the growing of the frost thickness. Frost porosity varies with time and location. In current measurement, a uniform density is assumed. Also, the frost layer is denser and thicker at the edges. In the future, a round geometry of the test plate might be used to avoid the edge effects.

The range of the parameters is restricted by the cooling method of the chamber. The chamber is cooled by thermal electric modules, and heat is removed by the heat sink extended inside the chamber. The sink temperature becomes very low in order to achieve 
low temperature inside the chamber. Frost might form on the heat sink when the relative humidity in the chamber is high. In the future, the air could be cooled down from a different system, and cooling air could be circulated through the test chamber.

The physical mechanism of slumping is more complicated with the involvement of the physics of interfacial forces. Herein the slumping condition is based on the force balance analysis. Further research can formulate the slumping criterion with respect to the physical mechanism of fracture or crack of the frost column. In that case, the cohesive forces of the frost and the adhesive forces at the interfaces should be considered.

The slumping criterion is expected to be verified on surfaces with different contact angles and contact angle hysteresis. In the current experiments, surface treatment is limited to a superhydrophilic surface and a superhydrophobic surface. The contact angle hysteresis is not controllable for the hydrophobic surface. The slumping criterion on hydrophobic surface depends on the advancing/receding contact angles. The rolling of the droplet occurs with small contact angle hysteresis and proper droplet volume and sliding angle. In the experiments, surface treatment methods also lead to different defrost mechanisms. Frost might fall off as a rigid body or break up into fractures on the different superhydrophobic surfaces. More samples with different surface properties are expected in the experiments.

Tests on reliability and repeatability of the surface effects are expected. In the current experiments, the surface shows good superhydrophobicity, and the results are relatively consistent. Frost slumping occurs after different frost formation periods and with different defrost heating methods. In rare cases, it is observed that few small droplets stick to the superhydrophobic surface after the defrost process. The droplets do not roll off after the frost and defrost cycle.

The experiments are expected to test with large scale equipment. In the application, coils have different geometries. In the current study, frost and defrost cycles are on a flat aluminum plate placed vertically. A complicated multi-dimensional model can be formulated with consideration of fin arrays and interaction between fins. 


\section{References}

[1] Na B, Webb RL (2003) A fundamental understanding of factors affecting frost nucleation. Int J Heat Mass Tran 46: 3797-3808

[2] Piucco RO, Hermes CJL, Melo C, Barbosa Jr. JR (2008) A study of frost nucleation on flat surfaces. Exp Therm Fluid Sci 32:1710-1715

[3] Thibaut Brian PL, Reid RC, Shah YT (1970) Frost deposition on cold surfaces. Ind Eng Chem Fund 9 (3):375-380

[4] Kennedy LA, Goodman J (1974) Free convection heat and mass transfer under conditions of frost deposition. Int J Heat Mass Trans 17:477-484

[5] Hayashi Y, Aoki A, Adachi S, K. Hori K (1977) Study of frost properties correlating with frost formation types. Trans ASME J Heat Trans 99:239-245

[6] Cremers CJ, Mehra VK (1982) Frost formation on vertical cylinders in free convection. Trans ASME J Heat Trans 104:3-7

[7] Fossa M, Tanda G (2002) Study of free convection frost formation on a vertical plate. Exp Therm Fluid Sci 26:661-668

[8] Liu FZ, Chen HX, Fu JK (2002) Study on frost characteristics of finned-tube heat exchanger under low temperature conditions. Fluid Machinery 30(11):54-57

[9] Wu X, Dai W, Xu W, Tang L, (2007) Mesoscale investigation of frost formation on a cold surface. Exp Therm Fluid Sci 31:1043-1048

[10] Janssen DD, Mohs WF, Kulacki FA (2016) Frost layer growth based on highresolution image analysis. Transactions of the ASME 8:021018-1-021018-12

[11] Jones BW, Parker JD (1975) Frost formation with varying environmental parameters. Trans ASME J Heat Trans 97(2):255-259

[12] Schneider HW (1978) Equation of the growth rate of frost forming on cooled surfaces. Int J Heat Mass Trans 21:1019-1024

[13] Dietenberger MA (1983) Generalized correlation of the water frost thermal conductivity. Int J Heat Mass Trans 26(4):607-619

[14] Tao Y-X, Besant RW, Rezkallah KS (1993) A mathematical model for predicting the densification and growth of frost on a flat plate. Int J Heat Mass Trans 36(2):353363

[15] Tao Y-X, Besant RW (1993) Prediction of spatial and temporal distributions of frost growth on a flat plate under forced convection. Trans ASME J Heat Trans 115:278281

[16] Lee K-S, Kim W-S, Lee T-H (1997), A one-dimensional model for frost formation on a cold flat surface. Int J Heat Mass Trans 40(18):4359-4365

[17] Le Gall R, Grillot JM (1997) Modelling of frost growth and densification. Int J Heat Mass Trans 40(13):3177-3187 
[18] Cheng C-H, Cheng Y-C (2001) Predictions of frost growth on a cold plate in atmospheric air. Int Comm Heat Mass Trans 28(7):953-962

[19] Lee K-S, Jhee S, Yang D-K (2003) Prediction of the frost formation on a cold flat surface. Int J Heat Mass Trans 46:3789-3796

[20] Na B, Webb RL (2004) Mass transfer on and within a frost layer. Int J Heat Mass Trans 47:899-911

[21] Lee YB, Ro ST (2005) Analysis of the frost growth on a flat plate by simple models of saturation and Supersaturation. Exp Therm Fluid Sci 29:685-696.

[22] Na B, Webb RL (2004) New model for frost growth rate. Int J Heat Mass Trans 47:925-936

[23] Hao YL, Iragorry J, Tao Y-X (2005) Frost-air interface characterization under natural convection. Trans ASME J Heat Trans 127: 1174-1180

[24] Lenic K, Anica Trp, Bernard Frankovic (2006) Unsteady heat and mass transfer during frost formation in a fin-and-tube heat exchanger. Energy and the Environment 35-48

[25] Sahin AZ (1995) An analytical study of frost nucleation and growth during the crystal growth period. Heat Mass Trans 30:321-330

[26] Sahin AZ (2000) Effective thermal conductivity of frost during the crystal growth period. Int J Heat Mass Trans 43:539-553

[27] Shin J, Tikhonov AV, Kim C (2003) Experimental study on frost structure on surfaces with different hydrophilicity: density and thermal conductivity. Trans ASME J Heat Trans 125(1):84-94

[28] Zhong YF, Jacobi AM, Georgiadis JG (2006) Condensation and wetting behavior on surfaces with micro-structures: super-hydrophobic and super-hydrophilic. Proc Int Ref Air Cond, Paper 828

[29] Liu ZL, Wang HY, Zhang XH, Meng S, Ma CF (2006) An experimental study on minimizing frost deposition on a cold surface under natural convection conditions by use of a novel anti-frosting paint, Part I. International Journal of Refrigeration 29:229-236

[30] Liu ZL, Zhang XH, Wang HY, Meng S, Cheng S (2007) Influences of surface hydrophilicity on frost formation on a vertical cold plate under natural convection conditions. Exp Therm Fluid Sci 31(7):789-794

[31] Liu ZL, Gou YJ, Wang JT, Cheng S (2008) Frost formation on a super-hydrophobic surface under natural convection conditions. Int J Heat Transfer 51(25-26):59755982

[32] Chen C-H, Cai Q, Tsai C, Chen C-L, Xiong G, Yu Y, Ren Z (2007) Dropwise condensation on superhydrophobic surfaces with two-tier roughness. Appl Phys Lett 90 Letters 90:173108.

[33] Wang H, Tang LM, Wu XM, Dai WT, Qiu YP (2007) Fabrication and anti-frosting performance of superhydrophobic coating based on modified nano-sized calcium 
carbonate and ordinary polyacrylate. Appl Surf Sci 253(22):8818-8824

[34] Wang FC, Li CR, Lv YZ, Du YF (2009) A facile superhydrophobic surface for mitigating ice accretion. Proceedings of the 9th International Conference on Properties and Applications of Dielectric Materials A-34:150-153

[35] Varanasi KP, Deng T, Smith JD, Hsu M, Nitin Bhate N (2010) Frost formation and ice adhesion on superhydrophobic surfaces. Appl Phys Lett 97(23):234102

[36] He M, Wang JX, Li HL, Jin XL, Wang JJ, Liu BQ, Song YL (2010) Superhydrophobic film retards frost formation. Soft Matter 6:2396-2399

[37] He M, Wang JX, Li HL, Song YL (2011) Super-hydrophobic surfaces to condensed micro-droplets at temperatures below the freezing point retard ice/frost formation. Soft Matter 7:3993-4000

[38] Farhadi S, Farzaneh M, SKulinich SA (2011) Anti-icing performance of superhydrophobic surfaces. Appl Surf Sci 257(14):6264-6269

[39] Bahadur V, Mishchenko L, Hatton B, Taylor JA, Aizenberg J, Krupenkin T (2011) Predictive model for ice formation on superhydrophobic surfaces. Langmuir 27(23):14143-14150

[40] Min J, Webb RL, Bemisderfer CH (2000) Long-term hydraulic performance of dehumidifying heat-exchangers with and without hydrophilic coatings. HVAC\&R Res 6(3):257-272

[41] Jhee S, Lee K-S, Kim W-S (2002) Effect of surface treatments on the frosting/defrosting behavior of a fin-tube heat exchanger. Int J Ref 25:1047-1053

[42] Kim K, Lee KS (2011) Frosting and defrosting characteristics of a fin according to surface contact angle. Int J Heat Mass Trans 54(13-14):2758-2764

[43] Wu XM, Webb RL (2001) Investigation of the possibility of frost release from a cold surface. Exp Therm Fluid Sci 2 (3-4):151-156

[44] Huang LY, Liu ZL, Liu YM, Gou YJ, Wang JT (2009) Experimental study on frost release on fin-and-tube heat exchangers by use of a novel anti-frosting paint. Exp Therm Fluid Sci 33:1049-1054

[45] Antonini C, Innocenti M, Horn T, Marengo M, Amirfazli A (2011) Understanding the effect of superhydrophobic coatings on energy reduction in anti-icing systems. Cold Regions Sci Tech 67:58-67

[46] Jing T, Kim Y, Lee S, Kim D, Kim J, Hwang W (2013) Frosting and defrosting on rigid superhydrophobic surface. Appl Surf Sci 276:37-42

[47] Boreyko JB, Srijanto BR, Nguyen TD, Carlos Vega C, Fuentes-Cabrera M, Collier CP (2013) Dynamic defrosting on nanostructured superhydrophobic surfaces. Langmuir 29:9516-9524

[48] Chen XM, Ma RY, Zhou HB, Zhou XF, Che LF, Yao SH, Wang ZK (2013) Activating the microscale edge effect in a hierarchical surface for frosting suppression and defrosting promotion. Scientific Rep 3:2515. 
[49] Korte C, Jacobi AM (2001) Condensate retention effects on the performance of plain-fin-and-tube heat exchangers: Retention data and modeling. Trans ASME J Heat Trans 123(5):926-936

[50] Min J, Webb RL (2001) Condensate formation and drainage on typical fin materials. Exp Therm Fluid Sci 25:101-111

[51] Zhong Y, Joardar A, Gu Z, Park Y-G, Jacobi AM (2005) Dynamic dip testing as a method to assess the condensate drainage behavior from the air-side surface of compact heat exchangers. Exp Therm Fluid Sci 29:957-970

[52] EI Sherbini AI, Jacobi AM (2006) A model for condensate retention on plain-fin heat exchangers. Trans ASME J Heat Trans 128:427-433

[53] Sommers AD, Jacobi AM (2008) Wetting phenomena on micro-grooved aluminum surfaces and modeling of the critical droplet size. J Colloid Interf Sci 328(2):402411

[54] Liu L, Jacobi AM (2009) Air-side surface wettability effects on the performance of slit-fin-and-tube heat exchangers operating under wet-surface conditions. Trans ASME J Heat Trans 13:051802-(1-9)

[55] Rahman AM, Jacobi AM (2012) Drainage of frost meltwater from vertical brass surfaces with parallel microgrooves. Int J Heat Mass Trans 55:1596-1605

[56] Sanders CT (1974) The influence of frost formation and defrosting on the performance of air coolers. Doctoral dissertation, Delft University of Technology

[57] Krakow KI, Yan L, S. Lin S (1992) A model of hot-gas defrosting of evaporators, Part 1: Heat and mass transfer theory. ASHRAE Trans 98(1):451-461

[58] Krakow KI, Yan L, Lin S (1992) A model of hot-gas defrosting of evaporators-part 2: Experimental analysis. ASHRAE Trans 98(1):462-474

[59] Sherif SA, Hertz MG (1998) A semi-empirical model for electric defrosting of a cylindrical coil cooler. Int J Energy Res 22(1):85-92

[60] Lamberg P, Siren K (2003) Analytical model for melting in a semi-infinite PCM storage with an internal fin. Heat Mass Trans 39:167-176

[61] Liu Z, Tang G, Zhao F (2003) Dynamic simulation of air-source heat pump during hot-gas defrost. Appl Therm Eng 23:675-685

[62] Hoffenbecker N, Klein SA, Reindl DT (2005) Hot gas defrost model development and validation. Int J Refrigeration 28(4)605-615

[63] Dopazo JA, Fernandez-Seara J, Uhia FJ, Diz R (2010) Modelling and experimental validation of the hot-gas defrost process of an air-cooled evaporator. Int $\mathrm{J}$ Refrigeration 33(4):829-839

[64] Minglu Q, Liang X, Shiming D, Yiqiang J (2012) A study of the reverse cycle defrosting performance on a multi-circuit outdoor coil unit in an air source heat pump - Part I: Experiments. Appl Energy 91:122-129 
[65] Qu M, Pan D, Xia L, Deng S, Jiang Y (2012) A study of the reverse cycle defrosting performance on a multi-circuit outdoor coil unit in an air source heat pump - Part II: Modeling analysis. Appl Energy 91:274-280

[66] Mohs WF (2012) Heat and mass transfer during the melting process of a porous frost layer on a vertical surface. Doctoral dissertation, University of Minnesota

[67] Raraty LE, Tabor D (1958) The adhesion and strength properties of ice. Proc R. Soc. Lond. A Mat 245:84-201

[68] Jellinek HHG (1959) Adhesive properties of ice. J Colloid Interf Sci 14:268-280

[69] Ryzhkin IA, Petrenko VF (1997) Physical mechanisms responsible for ice adhesion. J Phys Chem B 101(32):6267-6270

[70] Makkonen L (2012) Ice adhesion - Theory, measurements and countermeasures. J Adhes Sci Technol 26:413-445

[71] Chen J, Liu J, He M, Li K, Cui D, Zhang Q, Zeng X, Zhang Y, Wang J, Song Y (2012) Superhydrophobic surfaces cannot reduce ice adhesion. Appl Phys Lett 101(11):111603-1-3

[72] Meuler AJ, Smith JD, Varanasi KK, Mabry JM, McKinley GH,Cohen RE (2010) Relationships between water wettability and ice adhesion. Appl Mat Interfaces 2(11):3100-3110. doi: 10.1021/am1006035

[73] Majumdar A, Mezic I (1999) Instability of ultra-thin water films and the mechanism of droplet formation on hydrophilic surfaces. Trans ASME J Heat Trans 121:964971

[74] Aoki K, Hattori M, Ujiie T (1988) Snow melting by heating from the bottom surface. JSME Int J 31(2):269-275

[75] Colbeck SC, Davidson G, (1972) Water percolation through homogeneous snow. IASH Publication 107:242-257

[76] Colbeck SC, (1974) The capillary effects on water percolation in homogeneous snow. J Glaciology 13(67):85-97

[77] Colbeck SC (1976) An analysis of water flow in dry snow. Water Res Research 12(3) (1976) 523-527

[78] S.C. Colbeck (1982) The permeability of a melting snow cover. Water Resour Res 18(4):904-908

[79] Bengtsson L (1982) Percolation of meltwater through a snowpack. Cold Reg SciTechnol 6:73-81

[80] Whitaker S (1986) Flow in porous media I: A theoretical derivation of Darcy's law. Transport Porous Med 1:3-25

[81] Shaun Sellers S (2000) Theory of water transport in melting snow with moving surface. Cold Reg Sci Technol 31:47-57. 
[82] Manthey S, Hassanizadeh SM, Helmig R, Hilfer R (2008) Dimensional analysis of two-phase flow including a rate-dependent capillary pressure-saturation relationship. Adv Water Resour 31:1137-1150

[83] Daanen RP, Nieber JL (2009) Model for coupled liquid water flow and heat transport with phase change in a snowpack. J Cold Reg Eng., 23(2): 43-68

[84] Hirashima H, Yamaguchi S, Sato A, Lehning M (2010) Numerical modeling of liquid water movement through layered snow based on new measurements of the water retention curve. Cold Reg Sci Tech 64:94-103

[85] Yamaguchi S, Katsushima T, Sato A, Kumakura T (2010) Water retention curve of snow with different grain sizes. Cold Reg Sci Technol 64:87-93

[86] Szymkiewicz A (2013), Modeling Water Flow in Unsaturated Porous Media. Springer-Verlag Berlin Heidelberg

[87] Katsushima T, Satoru Yamaguchi S, Kumakura T, Atsushi Sato A (2013) Experimental analysis of preferential flow in dry snowpack. Cold Reg Sci Technol 85:206-216

[88] Washburn EW (1921) The dynamics of capillary flow. Phys Rev 18(3):273-283

[89] Tsypkin GG (2010) Effect of the capillary forces on the moisture saturation distribution during the thawing of a frozen soil. Fluid Dyn 45(6):942-951

[90] Beavers GS, Joseph DD, (1967) Boundary conditions at a naturally permeable wall. J Fluid Mech 30(1):197-207

[91] Taylor GI (1971) A model for the boundary condition of a porous material. Part 1 J. Fluid Mech. 49(2):319-326

[92] Richardson S (1971) A model for the boundary condition of a porous material, Part 2. J Fluid Mech 49(2):327-336

[93] Sahraoui M, Kaviany M (1992) Slip and no-slip velocity boundary conditions at interface of porous, plain media. Int J Heat Mass Trans 35(4):927-943

[94] Vinogradova OI (1995) Drainage of a thin liquid film confined between hydrophobic surfaces. Langmuir 11(6):2213-2220

[95] Barrat JL (1999) Large slip effect at a nonwetting fluid-solid interface. Physical Review Letters 82(23):4671-4674

[96] Baidry J, Charlaix E (2001) Experimental evidence for a large slip effect at a nonwetting fluid-solid interface. Langmuir 17(17):5232-5236

[97] de Gennes PG (2002) On fluid/wall slippage. Langmuir 18(9):3413-3414

[98] Andrienko D, Dünweg B (2003) Boundary slip as a result of a prewetting transition. J Chem Phys 119(24):13106-13112

[99] Lauga E, Brenner MP, Stone HA, (2005) Microfluidics: The No-Slip Boundary Condition. Handbook of Experimental Fluid Dynamics, Foss, J., Tropes, C, Yarin, A, Eds, Springer, New-York, Ch. 15 
[100]Choi C-H, Kim C-J (2006) Large slip of aqueous liquid flow over a nanoengineered superhydrophobic surface. Phys Rev Lett 96: 066001

[101]Crank J (1984) Free and moving boundary problems. Oxford University Pres MJs, New York

[102] Alexiades V, Solomon AD (1993). Mathematical modeling of melting and freezing. Hemisphere, Washington

[103] Morton KW, Mayers DF (2005) Numerical solutions of partial differential equations. Cambridge University Press, Cambridge, England

[104]Hamming RW (1973) Numerical methods for scientists and engineers. Dover Publications, Inc., New York

[105] Kahraman R, Zughbi HD, Al-Nassar N (1998) A numerical simulation of melting of ice heated from above. Mathematical \& Computational Applications 3(3):127137

[106]Lee TE, Baines MJ, Langdon S (2015) A finite difference moving mesh method based on conservation for moving boundary problems. Journal of Computational and Applied Mathematics 288:1-17

[107]Holman JP (2002) Heat transfer, $9^{\text {th }}$ ed. McGraw-Hill, New York 


\title{
Appendices
}

\author{
Appendix A Test apparatus
}

Table A.1. Test apparatus for test surface $50 \mathrm{~mm}$ x $50 \mathrm{~mm}$.

\begin{tabular}{|c|c|c|c|}
\hline Apparatus & Model & Specification & Function \\
\hline Test chamber & & $\begin{array}{l}\text { Material: Acrylic glass } \\
\text { Thickness: } 12.7 \mathrm{~mm} \\
\text { Inside dimensions: } \\
254 \text { x } 127 \text { x } 101.6 \mathrm{~mm}\end{array}$ & $\begin{array}{l}\text { Frost growth and } \\
\text { observation }\end{array}$ \\
\hline $\begin{array}{l}\text { Polyisocyanurate } \\
\text { foam }\end{array}$ & & Thickness: $25 \mathrm{~mm}$ & Insulation \\
\hline Test plate & & $\begin{array}{l}\text { Material: Al } 6061 \\
\text { Dimensions: } 50 \text { × } 50 \text { × } 5 \mathrm{~mm}\end{array}$ & \\
\hline $\begin{array}{l}\text { Thermoelectric } \\
\text { module }\end{array}$ & $\begin{array}{l}\text { Tellurex } \\
\text { Corporation: C2- } \\
\text { 50-1514 }\end{array}$ & $\begin{array}{l}\text { THot: } 50^{\circ} \mathrm{C} \\
\text { Qmax }(\mathrm{W}): 148 \\
\text { DT } \max \left({ }^{\circ} \mathrm{C}\right): 76\end{array}$ & $\begin{array}{l}\text { Cooling for test plate } \\
\text { during frost growth. }\end{array}$ \\
\hline $\begin{array}{l}\text { Thermoelectric } \\
\text { module }\end{array}$ & $\begin{array}{l}\text { Tellurex } \\
\text { Corporation: C2- } \\
40-2511\end{array}$ & $\begin{array}{l}\text { THot: } 50^{\circ} \mathrm{C} \\
\text { Qmax }(\mathrm{W}): 191.7 \\
\text { DT } \max \left({ }^{\circ} \mathrm{C}\right): 79\end{array}$ & $\begin{array}{l}\text { Cooling the chamber } \\
\text { air during frost growth. }\end{array}$ \\
\hline Cooling water block & $\begin{array}{l}\text { Machined at } \\
\text { workshop }\end{array}$ & Material: Al 6061 & $\begin{array}{l}\text { Remove the heat } \\
\text { generated on the hot } \\
\text { side of the } \\
\text { thermoelectric module. }\end{array}$ \\
\hline DC power supply & $\begin{array}{l}\text { BK Precision: } \\
1696\end{array}$ & $1-20 \mathrm{~V}, 0-10 \mathrm{~A}$ & $\begin{array}{l}\text { Provide DC power to } \\
\text { thermoelectric module }\end{array}$ \\
\hline Film heater & $\begin{array}{l}\text { Omega: } \\
\text { KHLV-202/10 }\end{array}$ & Total wattage: $10 \mathrm{~W}$ & $\begin{array}{l}\text { Heating the test plate } \\
\text { during the defrost } \\
\text { process. }\end{array}$ \\
\hline Heat sink & $\begin{array}{l}\text { Machined at } \\
\text { workshop }\end{array}$ & Material: Al 6061 & $\begin{array}{l}\text { Absorb heat from the } \\
\text { chamber air. }\end{array}$ \\
\hline Circulation fans & $\begin{array}{l}\text { McMASTER- } \\
\text { CARR: } \\
\text { 1939K113 }\end{array}$ & 934 LPM (33 CFM) & Circulate chamber air \\
\hline Circulation fans & $\begin{array}{l}\text { McMASTER- } \\
\text { CARR: } 1939 \text { K46 }\end{array}$ & 311 LPM (11 CFM) & Circulate chamber air \\
\hline Sealed air pump & $\begin{array}{l}\text { TOP FIN: air } \\
\text { pump Air-4000 }\end{array}$ & $\mathrm{AC} 120 \mathrm{~V} / 60 \mathrm{~Hz}, 3.5 \mathrm{~W}$ & Pumping air \\
\hline Water flask & & $250 \mathrm{ml}$ & $\begin{array}{l}\text { Humidifying the air } \\
\text { passing through it. }\end{array}$ \\
\hline Glass tube flowmeter & $\begin{array}{l}\text { Omega } \\
\text { Engineering Inc.: } \\
\text { FL-5561ST }\end{array}$ & $6600 \mathrm{cc} / \mathrm{min}$ & $\begin{array}{l}\text { Control the chamber } \\
\text { humidity }\end{array}$ \\
\hline Data acquisition unit & $\begin{array}{l}\text { Agilent: 34970A } \\
\text { with 34901A } \\
\text { multiplexer }\end{array}$ & $\begin{array}{l}20 \text { channels, } \\
\text { scan rate } 60 \mathrm{ch} / \mathrm{s}\end{array}$ & Acquiring data set \\
\hline $\begin{array}{l}\text { High resolution } \\
\text { cameras }\end{array}$ & & & $\begin{array}{l}\text { Acquiring real time } \\
\text { images of front and } \\
\text { side profiles of frost } \\
\text { layer. }\end{array}$ \\
\hline
\end{tabular}


Table A.2. Test apparatus for test surface $38 \mathrm{~mm}$ x $38 \mathrm{~mm}$.

\begin{tabular}{|c|c|c|c|}
\hline Apparatus & Model & Specification & Function \\
\hline Test chamber & & $\begin{array}{l}\text { Material: Acrylic glass } \\
\text { Thickness: } 12 \mathrm{~mm} \\
\text { Inside dimensions: } \\
200 \text { x } 100 \text { x } 50 \mathrm{~mm}\end{array}$ & $\begin{array}{l}\text { Frost growth and } \\
\text { observation }\end{array}$ \\
\hline $\begin{array}{l}\text { Polyisocyanurate } \\
\text { foam }\end{array}$ & & Thickness: $25 \mathrm{~mm}$ & Insulation \\
\hline Test plate & & $\begin{array}{l}\text { Material: Al 5052, temper H32 } \\
\text { Dimensions: } 38 \text { x } 38 \text { x } 3.88 \mathrm{~mm}\end{array}$ & \\
\hline $\begin{array}{l}\text { Copper heat spreader } \\
\text { block }\end{array}$ & & $\begin{array}{l}\text { Material: } 99.9 \% \text { copper } \\
\text { Dimensions: } 45 \times 40 \times 9.5 \mathrm{~mm}\end{array}$ & \\
\hline $\begin{array}{l}\text { Thermoelectric } \\
\text { module }\end{array}$ & $\begin{array}{l}\text { Tellurex } \\
\text { Corporation: } \mathrm{C} 1- \\
1.4-127-1.14\end{array}$ & $\begin{array}{l}\text { Thot: } 50^{\circ} \mathrm{C} \\
\text { Qmax }(\mathrm{W}): 80.6 \\
\text { DT } \max \left({ }^{\circ} \mathrm{C}\right): 79\end{array}$ & $\begin{array}{l}\text { Cooling for test plate } \\
\text { and chamber air during } \\
\text { frost growth; } \\
\text { Heating for test plate } \\
\text { during defrost process. }\end{array}$ \\
\hline Heat sink & $\begin{array}{l}\text { Alpha Novatech } \\
\text { Inc. : FS10040PU }\end{array}$ & $\begin{array}{l}\text { Pin fin style with fins of } \\
2 \times 2 \times 40 \mathrm{~mm} ; \\
\mathrm{R}_{\mathrm{th}}: 0.15^{\circ} \mathrm{C} / \mathrm{W}\end{array}$ & $\begin{array}{l}\text { Reject heat generated } \\
\text { on the hot side of the } \\
\text { thermoelectric module. }\end{array}$ \\
\hline Cooling fan & $\begin{array}{l}\text { ORIX DC } \\
\text { Brushless: } \\
\text { MD925A-12S }\end{array}$ & $\mathrm{DC} 12 \mathrm{~V} / 0.24 \mathrm{~A}$ & $\begin{array}{l}\text { Remove heat from the } \\
\text { heat sink. }\end{array}$ \\
\hline DC power supply & $\begin{array}{l}\text { BK Precision: } \\
1696\end{array}$ & $\begin{array}{l}\text { DC output: } \\
1-20 \mathrm{~V}, 0-10 \mathrm{~A}\end{array}$ & $\begin{array}{l}\text { Provide DC power to } \\
\text { thermoelectric module }\end{array}$ \\
\hline Shunt & $\begin{array}{l}\text { Deltec: MKA-20- } \\
50\end{array}$ & $50 \mathrm{mV}, 20 \mathrm{Amp}$ & $\begin{array}{l}\text { Measure the current of } \\
\text { the thermoelectric } \\
\text { module }\end{array}$ \\
\hline Circulation fans & & $\begin{array}{l}\text { Velocity } 0.9 \mathrm{~m} / \mathrm{s} ; \\
20 \text { air exchange/min }\end{array}$ & Circulate chamber air \\
\hline Sealed air pump & $\begin{array}{l}\text { TOP FIN: air } \\
\text { pump Air- } 4000\end{array}$ & $\mathrm{AC} 120 \mathrm{~V} / 60 \mathrm{~Hz}, 3.5 \mathrm{~W}$ & Pumping air \\
\hline Water flask & & $250 \mathrm{ml}$ & $\begin{array}{l}\text { Humidifying the air } \\
\text { passing through it. }\end{array}$ \\
\hline $\begin{array}{l}\text { Variable flow } \\
\text { rotameter }\end{array}$ & $\begin{array}{l}\text { Omega } \\
\text { Engineering: } \\
\text { RMA-26 }\end{array}$ & 0 to $2.5 \mathrm{~L} / \mathrm{min}$ & $\begin{array}{l}\text { Control the chamber } \\
\text { humidity }\end{array}$ \\
\hline Data acquisition unit & $\begin{array}{l}\text { Agilent: } 34970 \mathrm{~A} \\
\text { with 34901A } \\
\text { multiplexer }\end{array}$ & $\begin{array}{l}20 \text { channels, } \\
\text { scan rate } 60 \mathrm{ch} / \mathrm{s}\end{array}$ & Acquiring data set \\
\hline $\begin{array}{l}\text { High resolution } \\
\text { cameras }\end{array}$ & & & $\begin{array}{l}\text { Acquiring real time } \\
\text { images of front and } \\
\text { side profiles of frost } \\
\text { layer. }\end{array}$ \\
\hline
\end{tabular}


Appendix B Design drawings
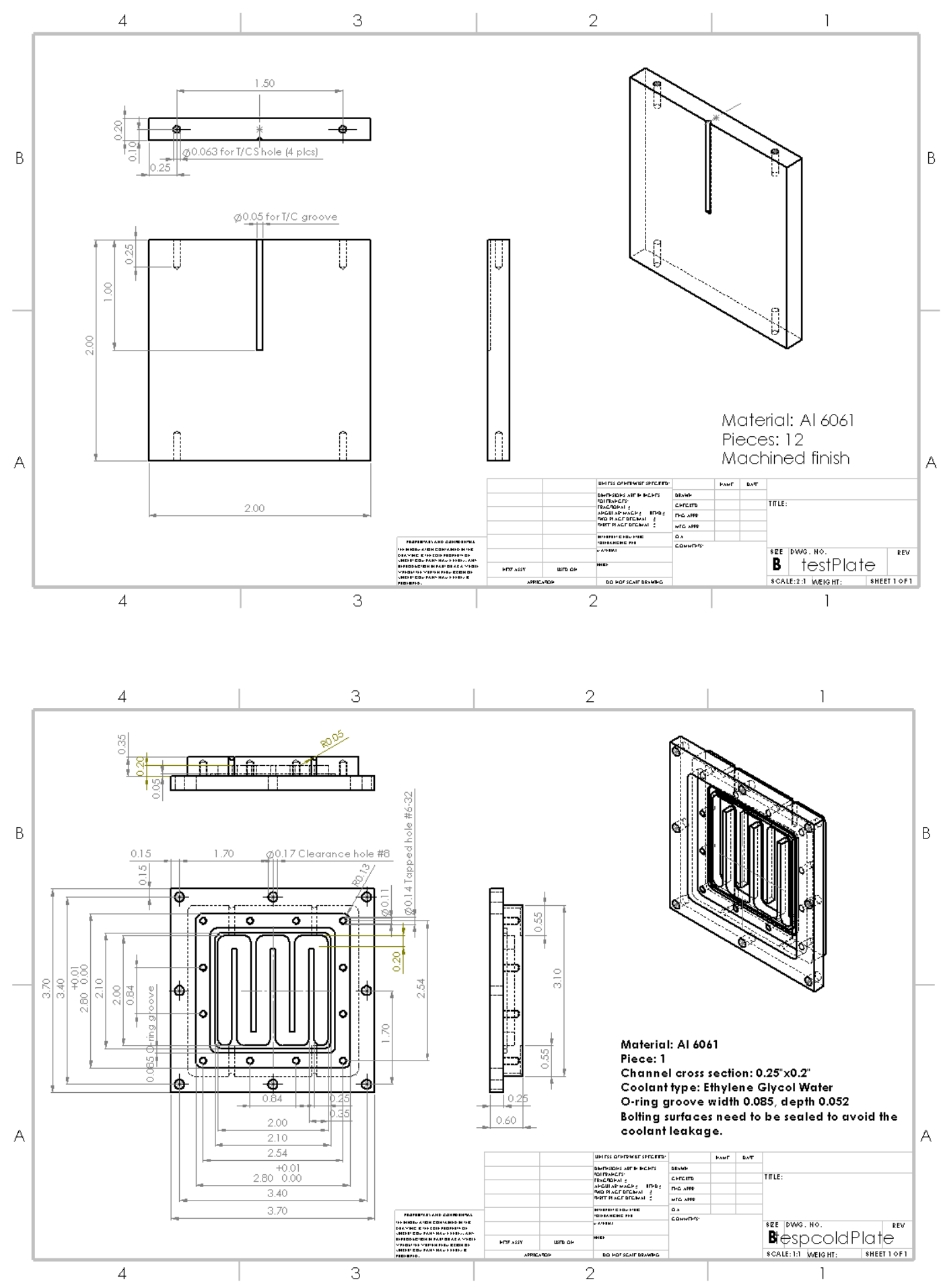

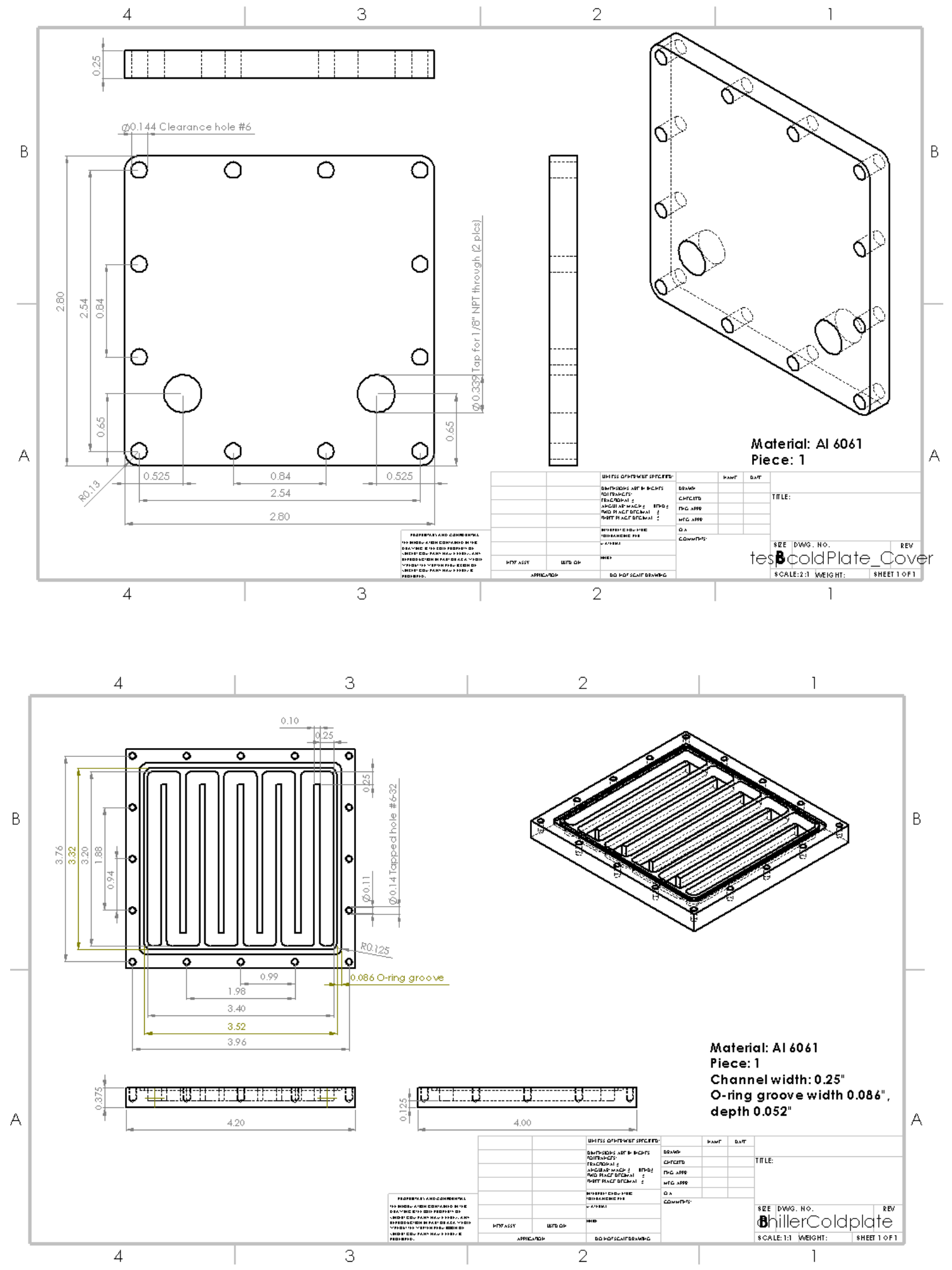

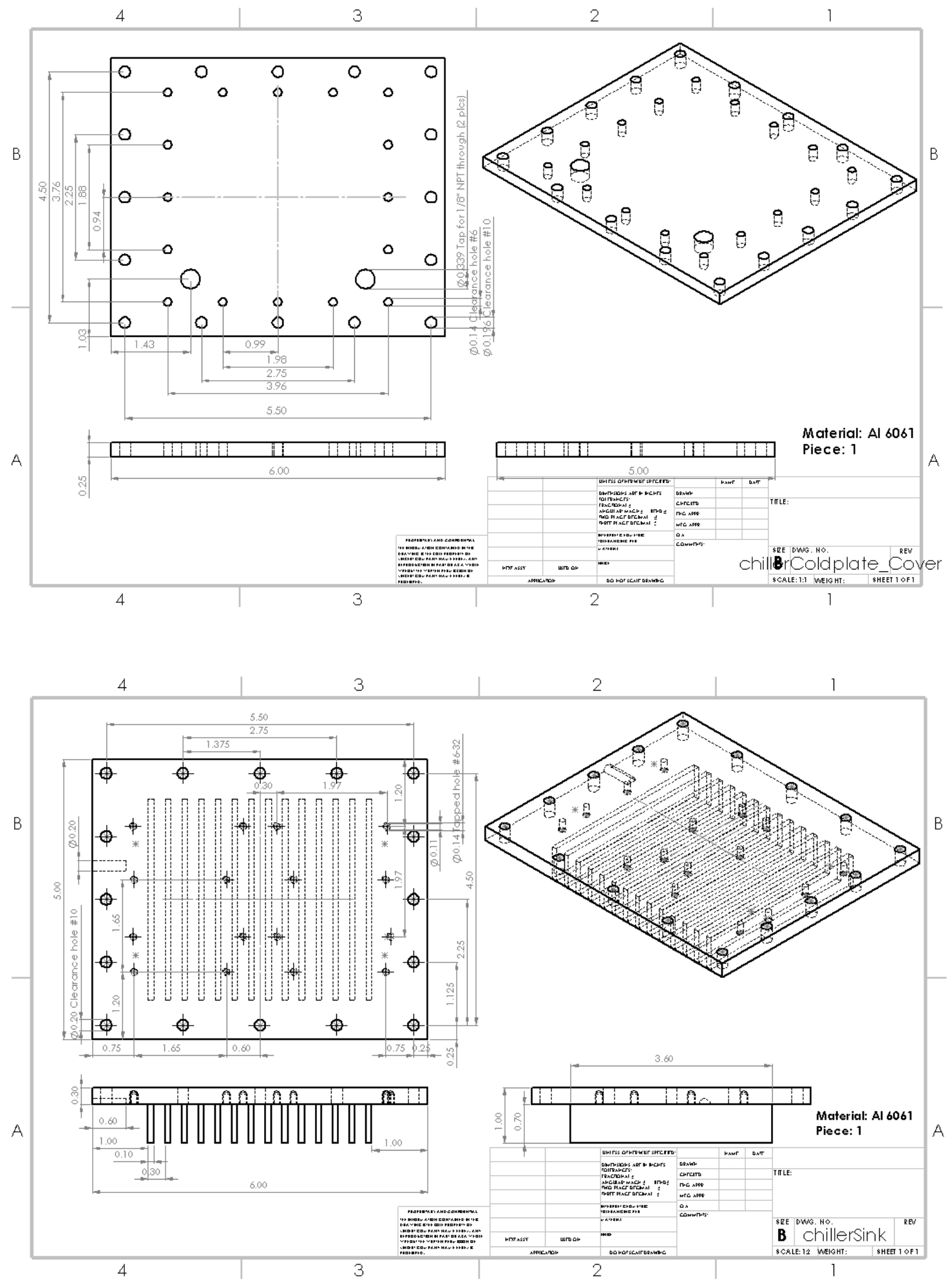

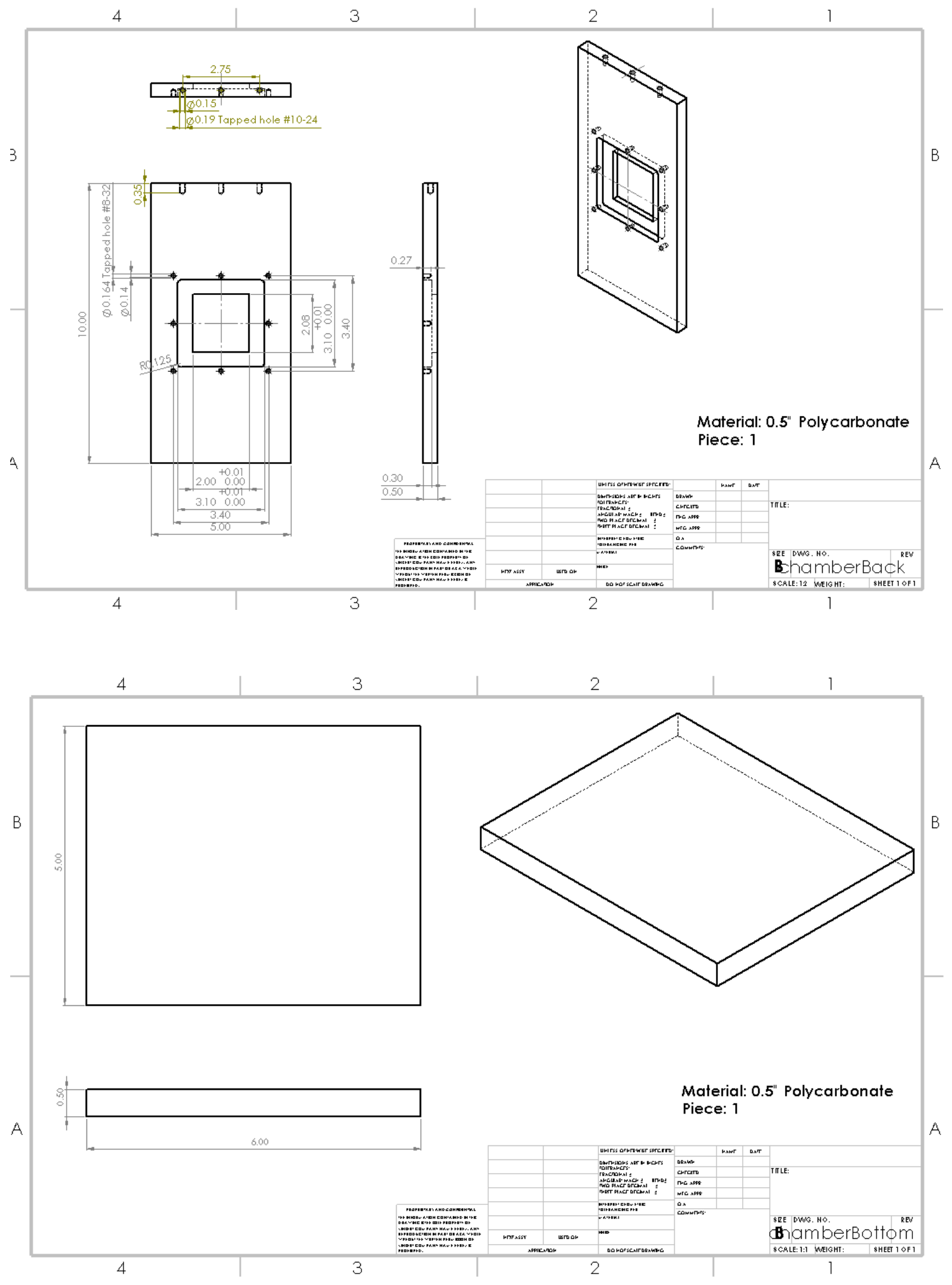


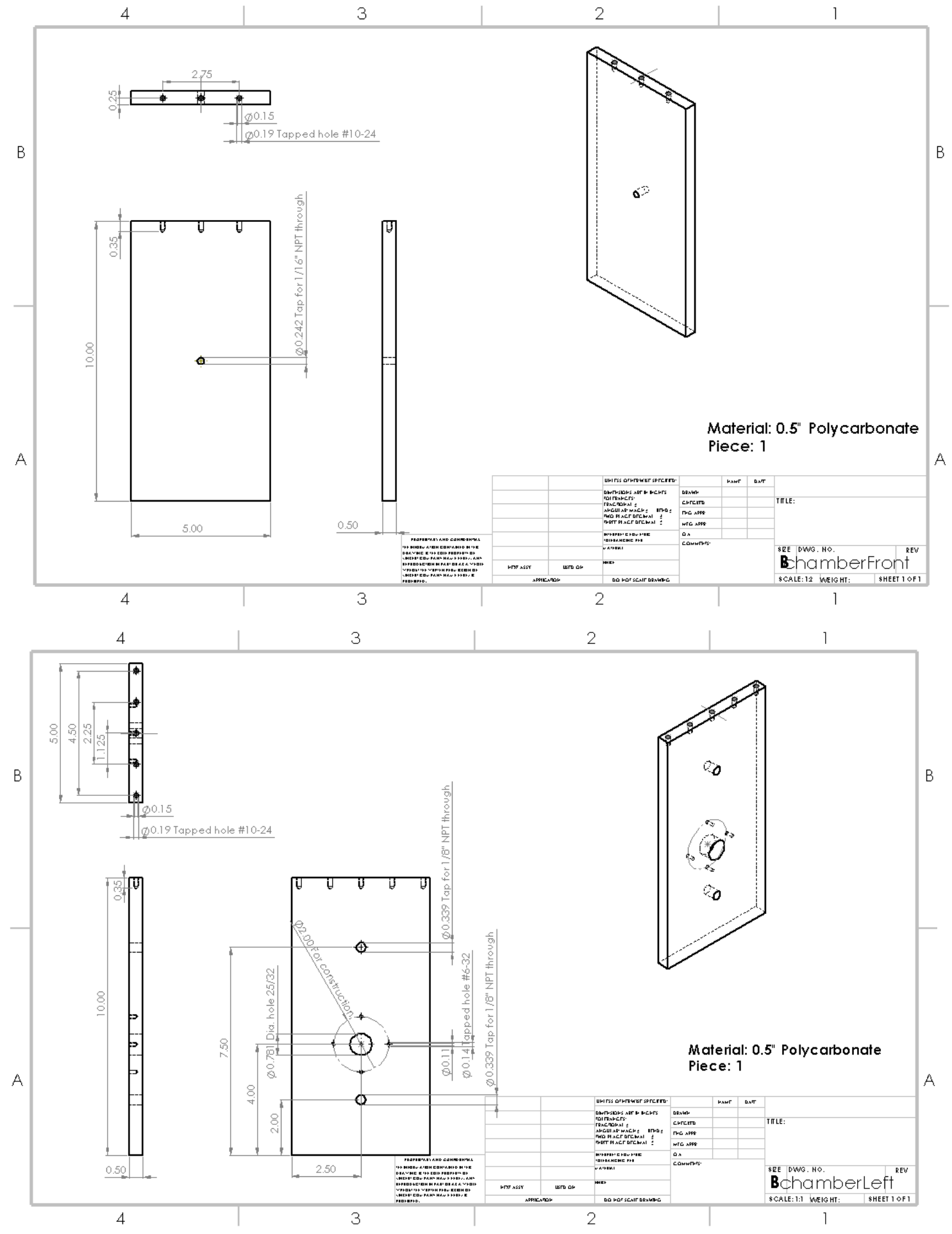



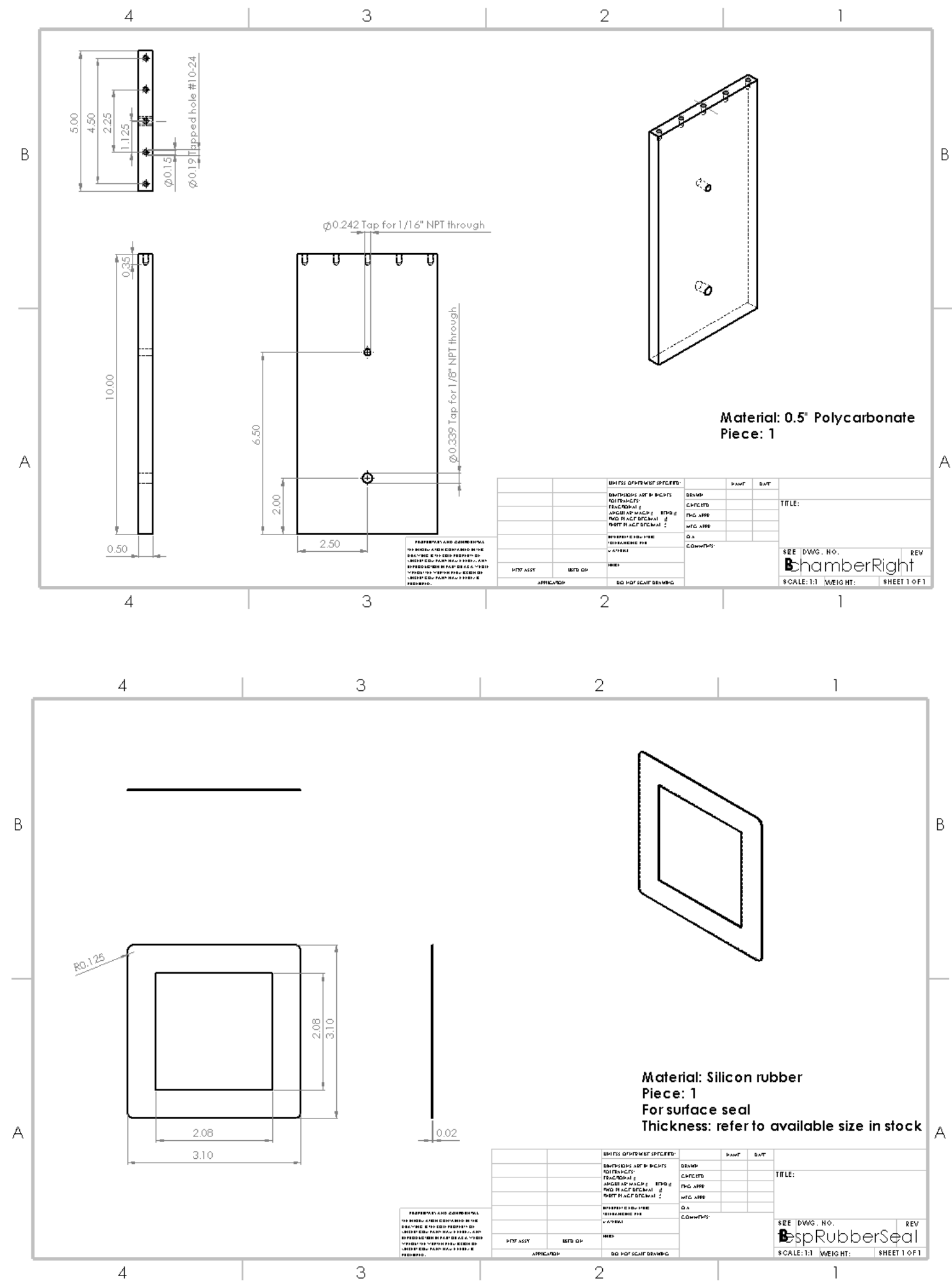


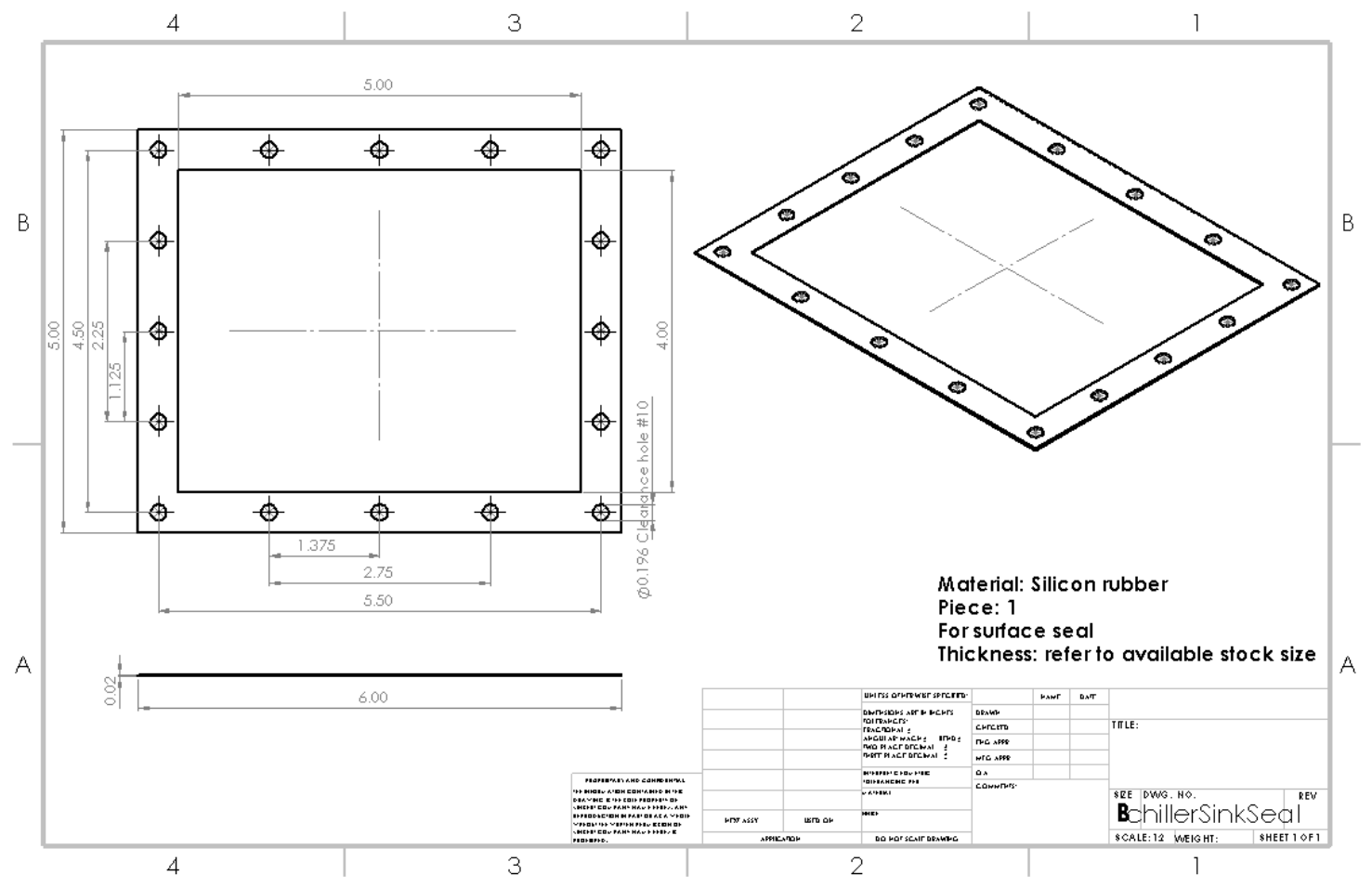




\section{Appendix C Measurement instruments}

Table C.1. Measurement instruments.

\begin{tabular}{|c|c|c|c|c|}
\hline $\begin{array}{c}\text { Measurement } \\
\text { variables }\end{array}$ & Instruments & Model & Range & Accuracy \\
\hline $\begin{array}{l}\text { Chamber } \\
\text { temperature }\end{array}$ & $\begin{array}{l}\text { Relative } \\
\text { humidity/temperature } \\
\text { transmitter }\end{array}$ & $\begin{array}{l}\text { Omega } \\
\text { Engineering: } \\
\text { HX94CW }\end{array}$ & $0-100^{\circ} \mathrm{C}$ & $\pm 0.6^{\circ} \mathrm{C}$ \\
\hline $\begin{array}{l}\text { Chamber } \\
\text { temperature }\end{array}$ & $\begin{array}{l}\text { Quick disconnection } \\
\text { TCs }\end{array}$ & $\begin{array}{l}\text { Omega } \\
\text { Engineering: } \\
\text { SCPSS-062G-6 }\end{array}$ & & \\
\hline Chamber humidity & $\begin{array}{l}\text { Relative } \\
\text { humidity/temperature } \\
\text { transmitter }\end{array}$ & $\begin{array}{l}\text { Omega } \\
\text { Engineering: } \\
\text { HX94CW }\end{array}$ & $3 \%-95 \%$ & $\pm 2 \%$ \\
\hline $\begin{array}{l}\text { Test plate } \\
\text { temperature }\end{array}$ & PFA insulated T/Cs & $\begin{array}{l}\text { Omega } \\
\text { Engineering: 5TC- } \\
\text { TT-T-30-72 }\end{array}$ & $\begin{array}{l}-267 \text { to } 260{ }^{\circ} \mathrm{C} \\
\text { OR } \\
-450 \text { to } 500 \mathrm{~F}\end{array}$ & $\pm 0.5^{\circ} \mathrm{C}$ \\
\hline Heat flux & $\begin{array}{l}\text { Thin-film heat flux } \\
\text { sensor }\end{array}$ & $\begin{array}{l}\text { Omega } \\
\text { Engineering: } \\
\text { HFS-4 }\end{array}$ & $\begin{array}{l}<30,000 \mathrm{Btu} / \mathrm{Ft}^{2}- \\
\mathrm{Hr}\end{array}$ & $\begin{array}{l}\text { Sensitivity of } 6.5 \\
\mu \mathrm{V} / \mathrm{Btu} / \mathrm{Ft}^{2}-\mathrm{Hr} ; \\
\pm 0.5 \%\end{array}$ \\
\hline $\begin{array}{l}\text { Heat flux } \\
\text { temperature }\end{array}$ & $\begin{array}{l}\text { Thin-film heat flux } \\
\text { sensor with built-in } \\
\text { T/C Type K }\end{array}$ & $\begin{array}{l}\text { Omega } \\
\text { Engineering: } \\
\text { HFS-4 }\end{array}$ & $\begin{array}{l}-200 \text { to } 150{ }^{\circ} \mathrm{C} \\
\text { OR } \\
-330 \text { to } 300 \mathrm{~F}\end{array}$ & \\
\hline Mass & Digital scale & $\begin{array}{l}\text { Acculab: ALC- } \\
320.3\end{array}$ & 0 to $320 \mathrm{~g}$ & $\pm 3 \mathrm{mg}$ \\
\hline Frost image & $\begin{array}{l}\text { High-intensity } \\
\text { illuminator }\end{array}$ & $\begin{array}{l}\text { Edmund Fiber- } \\
\text { Lite Optics: MI- } \\
150\end{array}$ & & \\
\hline $\begin{array}{l}\text { Frost front/side } \\
\text { profile }\end{array}$ & $\begin{array}{l}5.1 \text { megapixel CMOS } \\
\text { color camera }\end{array}$ & $\begin{array}{l}\text { BigCatch: } \\
\text { DCMC510 }\end{array}$ & & \\
\hline Frost front profile & Zoom imaging lens & $\begin{array}{l}\text { Edmund Optics: } \\
\text { VZM 450i, 4.5X }\end{array}$ & & \\
\hline Frost side profile & Zoom imaging lens & $\begin{array}{l}\text { Navitar Zoom } \\
7000,6.0 \mathrm{X}, \\
6.4 \mathrm{~mm} ; \\
0.5 \text { " CCD } \\
\text { monochrome } \\
\text { sensor }\end{array}$ & 25 frame $/ \mathrm{s}$ & \\
\hline
\end{tabular}


Appendix D Experimental procedure

D. 1 Large chamber operations (Test surface $50 \times 50 \times 5 \mathrm{~mm}$ )

Frost procedure

- Close the gap between the chamber and the test plate

- Start the cooling water line at least $1 \mathrm{~h}$ before the test run

- Prepare the record log

- Weigh 3 cotton balls and attach at the bottom of the chamber

- Set up the test equipment

- Connect the camera before starting the computer

- Start the computer, start Agilent, set the scanning time

- Record the Vernier caliper readings (dye the Caliper as necessary)

- Weigh the saturator before the frosting

- Calibrate the camera, capture the baseline, record the reference scale

- Reset the DC power as necessary:

- Start the saturator, start TEM cooling

- Record the time, record the air flow, record the power supply

- Capture the front photos at $\mathrm{t}=0(3 \mathrm{x}), 5 \mathrm{~min}(3 \mathrm{x}), 10 \mathrm{~min}(3 \mathrm{x}), 30 \mathrm{~min}, 1 \mathrm{~h}$, t $\_$end

- Capture the side photos at $\mathrm{t}=0,10 \mathrm{mins}, 30 \mathrm{mins}, 1 \mathrm{~h}$, t_middle, $\mathrm{t} \_$end

- Record the frost formation conditions: test surface temperature, heat flux across the heat flux sensor, chamber temperature, chamber humidity

- Re-check the power supply, re-check the air flow

- Frost formation runs for $6 \mathrm{~h}$ OR $4 \mathrm{~h}$, record the frost thickness, frost mass

- Save the frost formation data file

Defrost procedure

- Check the frost properties (test plate temperature, chamber temperature, chamber humidity) before defrosting, get the screw driver ready

- Record the Vernier caliper reading

- Prepare camera to record the retention droplets distribution

- Set the camera capturing period to $2 \mathrm{~s}$

- Re-set the scanning period to $1 \mathrm{~s}$, start Agilent 
- Stop the saturator

- Reset DC power as necessary

- Stop TEM, start the film heating, start the timer recorder

- Auto capturing photos, record the defrost time

- Record the defrosting power

- Stop timer recorder, record the defrost time

- Stop film heating, stop camera capturing, stop Agilent, save defrost data file

- Record the evaporation time of retaining droplets

- Measure the weight of the saturator

- Dry out the chamber

D.2 Small chamber operations (Test surface 38 x 38 x $3.8 \mathrm{~mm}$ )

Frost procedure

- Prepare the record log

- Weigh 3 cotton balls and attach at the bottom of the chamber

- Set up the test equipment

- Connect the camera before starting the computer

- Start the computer, start Agilent, set the scanning time

- Weigh the saturator before the frosting

- Calibrate the camera, capture the baseline, record the reference scale

- Reset the DC power as necessary:

- Start the saturator, start TEM cooling fan, start TEM cooling

- Record the time, record the air flow, record the power supply

- Capture the front photos at $\mathrm{t}=0(3 \mathrm{x}), 5 \mathrm{mins}(3 \mathrm{x}), 10 \mathrm{~min}(3 \mathrm{x}), 30 \mathrm{~min}, 1 \mathrm{~h}, \mathrm{t}$ _end

- Capture the side photos at $\mathrm{t}=0,10 \mathrm{~min}, 30 \mathrm{~min}, 1 \mathrm{~h}, \mathrm{t}$ _middle, $\mathrm{t}$ _end

- Record the frost formation conditions: test surface temperature, heat flux across the heat flux sensor, chamber temperature, chamber humidity

- Re-check the power supply, re-check the air flow

- Frost formation runs for $6 \mathrm{~h}$ OR $4 \mathrm{~h}$, record the frost thickness, frost mass

- Save the frost formation data file 


\section{Defrost procedure}

- Check the frost properties (test plate temperature, chamber temperature, chamber humidity) before defrosting, get the screw driver ready

- Prepare the camera to record the defrost power if necessary

- Re-set the scanning period to $1 \mathrm{~s}$

- $\quad$ Set the camera capturing period to $2 \mathrm{~s}$

- Stop the saturator

- Start Agilent

- Reset DC power as necessary

- Start the heating, start the timer recorder

- Auto capturing photos, record the defrost time

- Record the defrosting power

- Stop timer recorder, record the defrost time

- Stop TEM

- Stop Agilent, save defrost data file

- Stop camera capturing

- Stop cooling fan

- Record the evaporation time of retaining droplets

- Measure the weight of the saturator

- Dry out the chamber 
Appendix E Slumping images

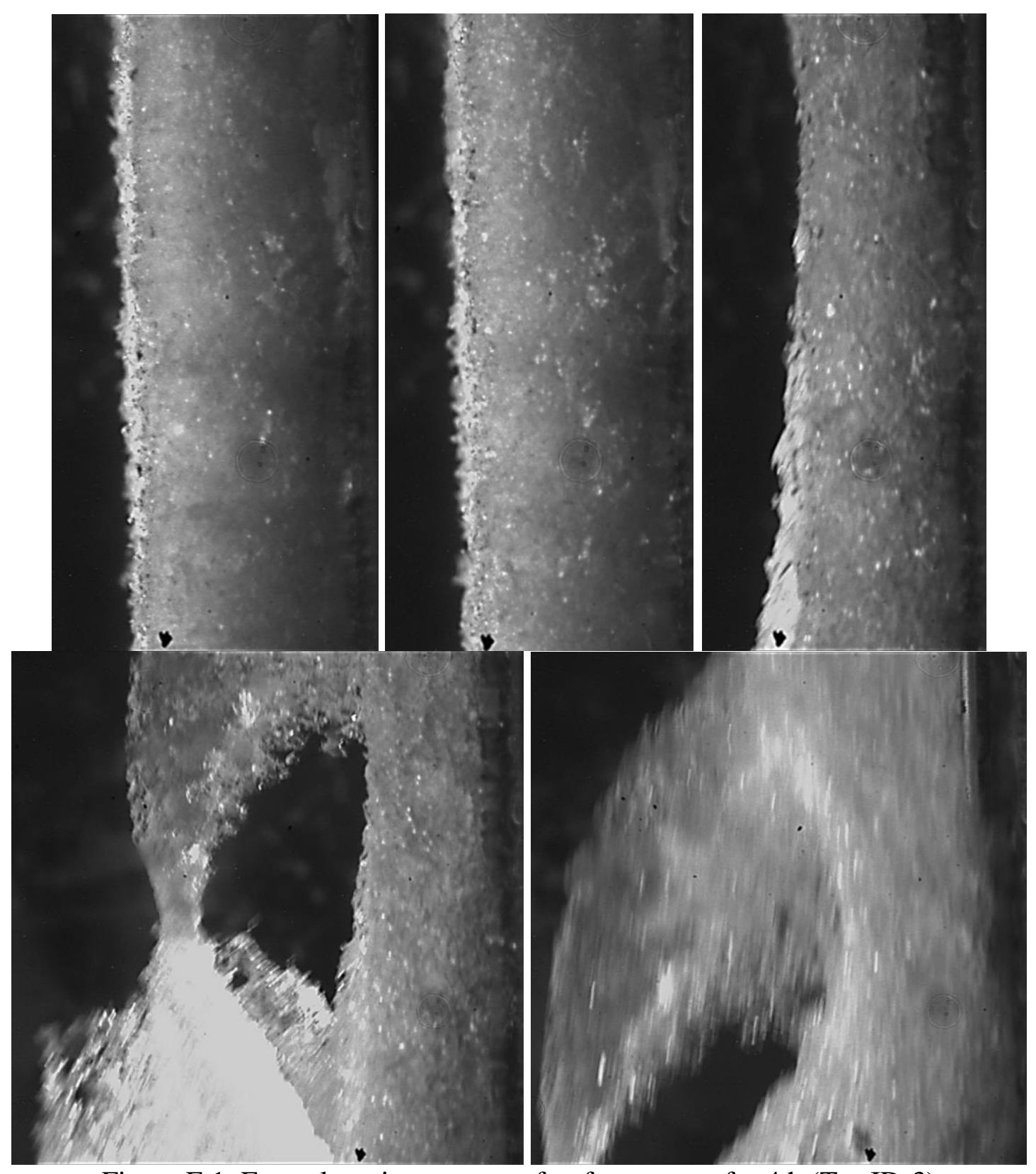

Figure E.1. Frost slumping process after frost grows for $4 \mathrm{~h}$ (TestID-3) 